\title{
Extracellular vesicles as mediators of the response to respiratory exposures
}

Citation for published version (APA):

Benedikter, B. J. (2018). Extracellular vesicles as mediators of the response to respiratory exposures.

[Doctoral Thesis, Maastricht University]. Maastricht University. https://doi.org/10.26481/dis.20180607bb

Document status and date:

Published: 01/01/2018

DOI:

10.26481/dis.20180607bb

Document Version:

Publisher's PDF, also known as Version of record

\section{Please check the document version of this publication:}

- A submitted manuscript is the version of the article upon submission and before peer-review. There can be important differences between the submitted version and the official published version of record.

People interested in the research are advised to contact the author for the final version of the publication, or visit the DOI to the publisher's website.

- The final author version and the galley proof are versions of the publication after peer review.

- The final published version features the final layout of the paper including the volume, issue and page numbers.

Link to publication

\footnotetext{
General rights rights.

- You may freely distribute the URL identifying the publication in the public portal. please follow below link for the End User Agreement:

www.umlib.nl/taverne-license

Take down policy

If you believe that this document breaches copyright please contact us at:

repository@maastrichtuniversity.nl

providing details and we will investigate your claim.
}

Copyright and moral rights for the publications made accessible in the public portal are retained by the authors and/or other copyright owners and it is a condition of accessing publications that users recognise and abide by the legal requirements associated with these

- Users may download and print one copy of any publication from the public portal for the purpose of private study or research.

- You may not further distribute the material or use it for any profit-making activity or commercial gain

If the publication is distributed under the terms of Article $25 \mathrm{fa}$ of the Dutch Copyright Act, indicated by the "Taverne" license above, 
The research presented in this dissertation was conducted within the NUTRIM School of Nutrition and Translational Research in Metabolism of Maastricht University.

This work was financially supported by the Netherlands Organization for Scientific Research (NWO) NUTRIM graduate programme awarded to the $\mathrm{PhD}$ candidate (NWO grant number 022.003.011).

Financial support by the Dutch Heart Foundation for the publication of this thesis is gratefully acknowledged. Additionally, the thesis publication was financially supported by DISTRILAB PARTICLE TECHNOLOGY B.V.

Cover Design: Mayk Lucchesi

Printed by: Gildeprint - Enschede

Copyright (C) Birke Benedikter, Maastricht, 2018

ISBN 978-94-6233-969-9 


\title{
Extracellular vesicles as mediators of the response to respiratory exposures
}

\author{
Dissertation
}

To obtain the degree of Doctor at Maastricht University,

On the authority of the Rector Magnificus Prof. Rianne M. Letschert In accordance with the decision of the Board of Deans

To be defended in public on Thursday, June $7^{\text {th }} 2018,16.00$ hours by

\section{Birke J. Benedikter}




\section{Promotores}

Prof. dr. Paul H.M. Savelkoul

Prof. dr. Emiel F.M. Wouters

\section{Copromotores}

Dr. Frank R.M. Stassen

Prof. dr. Gernot G.U. Rohde (Klinikum der Goethe-Universität Frankfurt)

\section{Beoordelingscommissie}

Prof. dr. Tilman M. Hackeng (voorzitter)

Prof. dr. Aalt Bast

Prof. dr. Ronit Shiri-Sverdlov

Prof. dr. Marca H.M. Wauben (Universiteit Utrecht)

Dr. Rienk Nieuwland (AMC Amsterdam) 


\section{Contents}

Chapter 1: General introduction and outline of the thesis.

Chapter 2: Extracellular vesicles released in the response to respiratory exposures: implications for chronic disease 21

Chapter 3: Bead-based flow cytometry for semi-quantitative analysis of complex membrane vesicle populations released by bacterial and host cells . .61

Chapter 4: Ultrafiltration combined with size exclusion chromatography efficiently isolates extracellular vesicles from cell culture media for compositional and functional studies .81

Chapter 5: Proteomic analysis reveals procoagulant properties of cigarette smokeinduced extracellular vesicles. 115

Chapter 6: Detection of extracellular vesicles in plasma of healthy smokers 151

Chapter 7: Cigarette smoke extract-induced exosome release is mediated by depletion of exofacial thiols and can be inhibited by thiol antioxidants 169

Chapter 8: Exposure to various respiratory toxicants modulates the release of extracellular vesicles by different pulmonary cell

Chapter 9: Redox-dependent thiol modifications: implications for the release of extracellular vesicles 211

Chapter 1o: General discussion and future perspectives 239

Addendum .255

I - Abbreviations. 256

II - Summary .260

III - Samenvatting 264

IV - Valorisation 268

V - Acknowledgements. .273

VI - Curriculum Vitae 276

VII - List of publications .277 

Chapter 1

General introduction and outline of the thesis 


\section{Prevalence of tobacco smoking and the associated public health burden}

Tobacco smoke is the major preventable cause of morbidity and mortality worldwide [1]. It accounts for approximately 6 million deaths every year, corresponding to more than $10 \%$ of all deaths $[1,2]$. This includes more than 600,000 deaths from involuntary smoke exposure [3]. Moreover, in 2012, the economic cost of tobacco smoking due to productivity losses and health expenditures was estimated to amount to US\$ 1436 billion, i.e. $1.2 \%$ of the world's gross domestic product [4]. To lower this immense public health burden, tobacco control policies have been implemented in many countries over the past decades. Such measures include tobacco access restrictions for adolescents [5], health warnings [6], mass media campaigns [7], increased taxes on tobacco products [8], smoking bans in public places [9], advertisement bans [10] and cessation treatment [11, 12]. Between 1990 and 2015, such tobacco control policies resulted in a $28.4 \%$ decrease in worldwide smoking prevalence in men and a $34.4 \%$ decrease in women to $25.0 \%$ and $5.4 \%$, respectively [2]. However, the decline in smoking prevalence has decelerated over the past years and is expected to slow down further, possibly until stagnation $[2,13,14]$. Moreover, while the percentage of smokers is decreasing, population ageing, as well as population growth in developing countries will lead to an increase in the absolute number of smokers [2]. Therefore, tobacco smoking will continue to contribute to the public health burden and is anticipated to cause more than 8 million deaths in 2030 [1]. Additionally, related respiratory exposures, such as smoke from domestic fires, occupational toxicants and air pollution contribute substantially to the worldwide morbidity and mortality and may act through the same biological processes as tobacco smoke [15-18].

The three major contributors to the smoking-associated disease burden are cardiovascular diseases (CVD), cancers and chronic respiratory diseases [2]. Moreover, tobacco smoking contributes to the risk of several other chronic conditions, including type II diabetes mellitus [19], rheumatoid arthritis [20] and age-related macular degeneration [21]. While the molecular mechanisms underlying tobacco smoke-induced disease are incompletely understood, it is well established that oxidative stress and chronic inflammation are involved in all smokingassociated diseases and occur in smokers before the onset of clinical disease [22]. As the results of this dissertation are of particular relevance for smoking-associated CVD and chronic obstructive pulmonary disease (COPD), these two conditions will be discussed in more detail below. 


\section{Composition of tobacco smoke and experimental models for smoke exposure}

Tobacco is most commonly consumed in the form of cigarettes [23]. Therefore, this dissertation focuses on cigarette smoke in particular. Cigarette smoke is a complex mixture containing several thousand chemically distinct compounds that arise from distillation, pyrolysis and combustion of tobacco [24, 25]. This includes gaseous components as well as components associated with microscopic aerosol droplets, referred to as the particulate phase $[24,25]$. Individual smoke constituents may be found in the gas phase, the particulate phase, or both [24]. Cigarette smoke components with high abundance and known cytotoxic effects include nicotine, $\mathrm{N}$ nitrosamines, polycyclic aromatic hydrocarbons, volatile organic compounds such as carbonyls, heavy metals, aromatic amines and polycyclic amines [24]. The exact composition of cigarette smoke depends on both, cigarette design and individual smoking behaviour [24]. For instance, the puff volume and the number of puffs per cigarette are of influence [24]. Most in vitro and animal studies are performed using machine-smoked research reference cigarettes with a well-documented and standardised cigarette design and tobacco composition [24]. For in vitro studies, cigarette smoke is commonly drawn through an aqueous buffer to obtain cigarette smoke extract (CSE), which is then diluted in cell culture media [26].

\section{Structure and function of the respiratory system}

As the respiratory system forms the major site of interaction between tobacco smoke and the human body, its structure and function will be discussed briefly in this section. Environmental air is inhaled either via the nasal or the oral cavity [27]. It then travels through the trachea into the main conducting airways or bronchi [27]. These branch out into secondary and tertiary bronchi and then into progressively smaller airways called bronchioles [27]. The smallest bronchioles terminate in socalled alveoli or air-sacs, where gas-exchange takes place between the oxygen-rich inhaled air and the oxygen-poor capillary blood [27]. The entire surface of the respiratory system is covered with the respiratory epithelium, a layer of cells that are tightly attached to each other via tight junctions and adherens junctions in order to form a barrier for potentially harmful inhaled substances [28, 29]. In the larger or conducting airways, the epithelium, referred to as the bronchial epithelium, is pseudostratified with several specialised cellular subtypes [28, 29]. Among others, these include goblet cells, which secrete mucus that serves to trap foreign particles. They also include ciliated epithelial cells, whose cilia perform a coordinated 
movement in order to transport the mucus-trapped particles out of the respiratory tract. Together, goblet cells and ciliated cells form the mucociliary escalator [29]. Underneath the bronchial epithelium lies the lamina propria, a loose layer of connective tissue. Pulmonary fibroblasts are the major cell type of the lamina propria and their major function is synthesizing extracellular matrix components [30]. Other interstitial cell types include smooth muscle cells which regulate the airway diameter, as well as various innate and adaptive immune cells [27].

In contrast to the bronchial epithelium, the alveolar epithelium is formed by a simple cell layer, which contains two cellular subtypes [31]. Type I alveolar epithelial cells have a highly extended and extremely thin cytoplasm [27]. They share a single fused basement membrane with the underlying pulmonary capillary endothelial cells which are likewise highly extended [27, 32]. The thinness of this epithelial-endothelial barrier allows efficient gas exchange between the air in the alveoli and the blood in the pulmonary capillaries [31]. Occasionally, pulmonary fibroblasts are found in the alveolar septa, interspersed between type I alveolar epithelial cells and pulmonary capillary endothelial cells [27]. Type II alveolar epithelial cells account for $60 \%$ of all alveolar epithelial cells but cover only $5 \%$ of the alveolar surface $[27,33]$. They are specialised in the production of surfactant, which reduces surface tension and thus prevents alveolar collapse during expiration [31, 33]. Moreover, they are involved in innate immunity, among others by secreting immune-regulatory cytokines [31,33]. Alveolar macrophages are present in the alveolar lumen, where they phagocytose inhaled particles and pathogens. Thereby, they prevent epithelial damage and potentially harmful pro-inflammatory activation of epithelial cells [34].

\section{Interaction of inhaled cigarette smoke with the human body}

When air is inhaled through the nose, a large fraction of the air-borne particulate matter is trapped in the mucus of the nasal cavity [27]. However, cigarette smoke, which contains a much larger fraction of particulates than environmental air, is typically inhaled through the oral cavity. Therefore, it does not undergo any pre-clearing before entering the conducting airways. Part of the cigarette smoke particulates are removed by the mucociliary escalator of the conducting airways before reaching the alveoli [35]. Similarly, gaseous smoke constituents partly dissolve in epithelial lining fluid, followed by mucociliary clearance [35]. However, cigarette smoke disturbs the function of the mucociliary escalator by inducing mucus hypersecretion and impairing cilia function [35]. 
Consequently, a significant fraction of gaseous and particulate cigarette smoke constituents reach the alveolar compartment [35]. Thus, both bronchial and alveolar epithelial cells are important target cells for the direct biological effects of cigarette smoke components from both phases. Another cell type that comes in direct contact with inhaled smoke is alveolar macrophages. Importantly, the number of macrophages in the lung lumen is elevated in active smokers, likely due to recruitment of monocytes from the blood circulation followed by monocyte-tomacrophage differentiation $[36,37]$.

Several constituents of cigarette smoke are likely to diffuse across the respiratory epithelium into the underlying tissue. Moreover, chronic exposure to cigarette smoke results in epithelial damage and impaired barrier function [38, 39]. Consequently, the epithelium of smokers becomes more permeable than that of non-smokers and cells that are located deeper inside the tissue can also become exposed to cigarette smoke constituents of the particulate phase. Thus, pulmonary fibroblasts and other interstitial cells are potentially exposed to cigarettes smoke and affected in their activity, be it to a lesser extent than epithelial cells and luminal macrophages. Finally, the extreme thinness of the epithelial-endothelial barrier in the alveoli allows absorption of certain cigarette smoke constituents into the blood vessels [40] where they may affect the behaviour of endothelial cells and circulating blood cells $[23,41,42]$.

Taken together, both gas phase and particulate phase constituents of cigarette smoke interact with various cell types, most importantly bronchial and alveolar epithelial cells, but also macrophages, pulmonary fibroblasts, pulmonary capillary endothelial cells and circulating blood cells, among others. Therefore, studying the effects of cigarette smoke on cultured cells is a relevant model for the mechanisms that underlie smoking-induced chronic diseases.

\section{Cigarette smoking and cardiovascular disease}

Cigarette smoking is a major cause of cardiovascular morbidity and mortality. Ezzati et al. estimated that cigarette smoking caused more than $10 \%$ of cardiovascular deaths worldwide in the year 2000 (1,670,0oo deaths) [43]. Numbers were highest in industrialised countries, amounting to approximately $13 \%$ of cardiovascular deaths in Western Europe (200,00o deaths) and 22\% in North America (220,00o deaths) [43]. Importantly, even moderate smokers who smoke less than 5 cigarettes per day and individuals who are passively exposed to cigarette smoke have an elevated cardiovascular risk compared to unexposed individuals [24, 44]. 
Concerning the biological mechanisms underlying the elevated cardiovascular risk, cigarette smoking is known to influence several cardiovascular risk factors, including glucose intolerance and the blood lipid profile [45]. Thus, smoking particularly contributes to the initiation and progression of atherosclerotic lesions. Congruently, the atherosclerotic complications ischemic heart disease and cerebrovascular disease are the most common causes of smoking-associated cardiovascular mortality worldwide, accounting for $25 \%$ and $54 \%$ of smoking associated cardiovascular deaths, respectively [43]. Importantly, smokers with myocardial infarction are younger than non-smokers at the time of infarction [46]. They also have less cardiovascular risk factors and less severe underlying atherosclerotic disease [46]. Therefore, thrombosis may have a stronger contribution to myocardial infarction in smokers than in non-smokers.

\section{Cigarette smoking and chronic obstructive pulmonary disease}

COPD is a chronic lung disease characterised by incompletely reversible and progressive airflow obstruction. According to estimates for the year 2010, 384 million people worldwide suffer from COPD and COPD is the third leading cause of mortality after ischemic heart disease and cerebrovascular disease [47, 48]. Globally, COPD accounts for nearly 3 million annual deaths, corresponding to $6 \%$ of all deaths [49]. While only about $10 \%$ of all cardiovascular deaths are attributed to cigarette smoking [43], the contribution of cigarette smoking to the morbidity and mortality of COPD is much more pronounced. Up to 50\% of all long-term smokers may eventually develop COPD [50]. Moreover, an estimated $73 \%$ of COPD mortality in high income countries and $40 \%$ in low to middle income countries are caused by cigarette smoking [48]. Related exposures, such as occupational respirable exposures, smoke from indoor cooking and outdoor pollution are thought to account for a large fraction of the none-smoking related COPD incidence and mortality $[15,51]$. As a considerable fraction of long-term smokers never develop COPD, genetic susceptibility likely plays a role as well.

The pathology underlying COPD is heterogeneous and characterised by different degrees of small airway inflammation (chronic bronchitis) and degradation of the lung tissue (emphysema) [52, 53]. Both bronchial and alveolar epithelial cells of smokers are directly exposed to high doses of gas phase and particulate phase cigarette smoke constituents. Several of these constituents are known cause cytotoxicity and to promote inflammation [24, 54]. Upon repetitive exposure, this leads to a vicious cycle of oxidative stress, tissue damage, inflammation, remodelling 
and repair [54]. These processes contribute to the small airway inflammation, emphysema formation and fibrosis that hallmark COPD [54].

\section{Extracellular vesicles}

Extracellular vesicles (EVs) are small membrane vesicles that are thought to be released by all cell types and that are present in various biological fluids, including bronchoalveolar lavage fluid (BALF) [55] and blood [56]. They consist of a lipid bilayer surrounding an aqueous lumen, and act as carriers for molecules derived from their cell of origin, including membrane proteins, cytoplasmic proteins and RNA. Via their complex cargo, EVs exert versatile functions in the vicinity of or distant from their cell of origin. For instance, EV-borne proteins can bind to receptors on the surface of target cells and trigger intracellular signal transduction [57]. Additionally, EVs can fuse with the membrane of their target cell and thereby deliver functional RNA and proteins to modulate the target cell's activity [57]. Finally, EV-bound proteins exert functions in the extracellular space, such as scavenging of pathogens [58] or remodelling of the extracellular matrix [59]. EV release, composition and, consequently, function are modulated by various cellular stressors, including pro-inflammatory mediators, oxidants and cigarette smoke [6o62]. Of note, chronic inflammation and oxidative stress are both common hallmarks of CS-induced diseases, including CVD and COPD [54, 63-65]. Moreover, EVs have been implicated in the pathogeneses of CVD and chronic lung disease $[66,67]$. It is therefore conceivable that EVs mechanistically contribute to the link between exposure to CS and the elevated risk for developing chronic disease.

EVs are not a single homogeneous population, but form a continuum of subpopulations with overlapping biochemical and biophysical properties [68]. Although it is difficult to study EV subpopulations separately, it is well accepted that there are three major subtypes with distinct biogenetic pathways (summarised in Figure 1) [68]. The first subtype, exosomes, is formed by inward budding of the endosomal membrane to form intraluminal vesicles, resulting in so-called multivesicular endosomes or multivesicular bodies (MVBs). When MVBs fuse with the plasma membrane, the intraluminal vesicles are released to the extracellular space as exosomes. The second EV subtype, commonly referred to as microvesicles or microparticles, arises by direct outward budding of the plasma membrane. The third EV subtype is apoptotic bodies, large membrane vesicles formed by apoptotic membrane blebbing. Apoptotic bodies contain DNA fragments and cellular organelles. This dissertation focuses primarily on exosomes, but in some chapters, microvesicles are also discussed. 
A

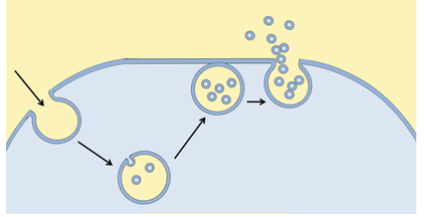

B

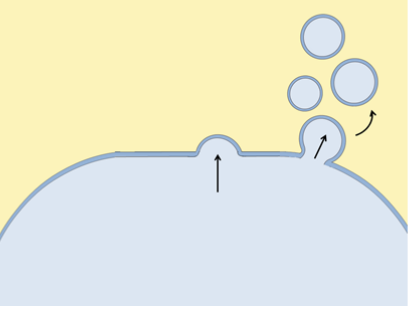

C

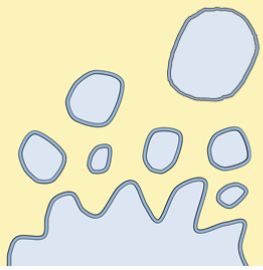

Figure 1 - Schematic representation of the formation of the three major EV subtypes. (A) Exosome biogenesis starts when endosomes are formed by inward budding of the plasma membrane. Upon formation of intraluminal vesicles, late endosomes are referred to as MVBs. When MVBs fuse with the plasma membrane, the intraluminal vesicles are released as exosomes. (B) Microvesicles form by outward budding of the plasma membrane. (C) Apoptotic bodies are formed during apoptotic membrane blebbing.

Due to their endosomal origin, exosomes $(50-150 \mathrm{~nm})$ are smaller than microvesicles (100-1000 nm). Moreover, they are enriched in proteins of the endosomal sorting complexes required for transport (ESCRT, e.g. Alix, TSG1o1) and in tetraspanins (e.g. $\mathrm{CD} 9, \mathrm{CD6} 3$, and CD81) [68]. As exosomes are smaller than the resolution limit of conventional optical techniques (light microscopy, flow cytometry scatter) [69], highly dedicated technology is required for their detection, for instance electron microscopy, nanoparticle tracking analysis [7o], tuneable resistive pulse sensing [71], or high resolution flow cytometry with fluorescence triggering [72]. Alternatively, they can be characterised by bulk analysis techniques such as Western blotting or bead-coupled flow cytometry, a technique in which EVs are linked to large beads and subsequently stained for exosome marker proteins [73, 74]. In contrast, microvesicles that are larger than $300 \mathrm{~nm}$ are commonly studied by conventional flow cytometry which allows characterizing individual vesicles [69].

\section{Aims and outline of the thesis}

Tobacco smoking is highly prevalent and acts as a major risk factor for various chronic inflammatory diseases, including CVD and COPD. Despite all efforts to decrease smoking prevalence, the current expectation is that smoking will continue to contribute substantially to morbidity and mortality in the coming decades. Moreover, related respiratory exposures such as air pollution are associated with similar pathologies and may act via the same biological processes. A better 
understanding of the mechanisms that underlie respiratory exposure-induced pathologies is likely to improve disease prevention and management. It is conceivable that EVs contribute to the mechanistic link between environmental exposures and elevated disease risk because they have been implicated in the pathogeneses of CVD and COPD and because their production is modulated by environmental triggers at the cellular level. This thesis explores how EVs are influenced by exposure to cigarette smoke and related respiratory exposures, and whether they may contribute to the pathogenesis of smoking-associated diseases.

To start with, an overview is given of the literature that is available on how respiratory exposures affect the release, composition and biological functions of EVs (chapter 2). EVs released in the response to respiratory toxicants have been proposed to modulate various biological processes that are of relevance for the development of chronic disease. However, as EV research is a relatively new field and techniques for EV isolation, quantification and characterisation are rapidly evolving, many of the available studies have been performed with outdated methodology that does not allow unambiguously attributing biological functions to EVs rather than to co-isolated contaminants. Therefore, one important aspect of the work presented in this dissertation was to establish protocols for specific and reliable EV detection, isolation and characterisation before studying the biological functions of respiratory exposure-induced EVs. In chapter 3, we provide a protocol for bead-based flow cytometry for semi-quantitative detection of bacterial as well as human cell derived EVs. In chapter 4, we then compare two protocols for EV isolation from cell culture media; the classical ultracentrifugation and the more recently described combination of ultrafiltration with size exclusion chromatography. In chapter $\mathbf{5}$, we characterise the proteomic composition of EVs secreted by CSE-exposed bronchial epithelial cells and unexposed control cells. Based on the proteomic composition, we predict biological functions of the CSE-induced EVs and we validate these functions in biological assays. In chapter $\mathbf{6}$ we perform a pilot study to translate the findings of chapter 5 to the human situation. In chapter 7 , we investigate the biochemical mechanism through which CSE modulates EV release by bronchial epithelial cells and whether the effects of CSE can be counteracted by antioxidants. In chapter 8, we then investigate whether modulation of EV release is a common effect of respiratory exposures in different pulmonary cell types and for different types of respiratory toxicants. In chapter 9, we review modification of redox sensitive protein thiols as a regulatory mechanism of EV release. The thesis concludes with chapter 1o, in which we summarise and discuss our findings and make suggestions for future research. 


\section{References}

1.

2.

3.

4.

5.

6.

8.

9.

10.

11.

12.

13.

14.

15.

16.

17.

18.

19.

20.

21.

22.

24.

23. Bridges, A.B., A. Hill, and J.J. Belch, Cigarette smoking increases white blood cell aggregation in

Organization, W.H., WHO report on the global tobacco epidemic 2011. 2011, Geneva: World Health Organization.

GBD 2015 Tobacco Collaborators. Smoking prevalence and attributable disease burden in 195 countries and territories, 1990-2015: a systematic analysis from the Global Burden of Disease Study 2015. Lancet, 2017. 389(10082): p. 1885-1906.

Oberg, M., et al., Worldwide burden of disease from exposure to second-hand smoke: a retrospective analysis of data from 192 countries. Lancet, 2011. 377(976o): p. 139-46.

Goodchild, M., N. Nargis, and E. Tursan d'Espaignet, Global economic cost of smokingattributable diseases. Tob Control, 2017.

Lipperman-Kreda, S., K.B. Friend, and J.W. Grube, Rating the effectiveness of local tobacco policies for reducing youth smoking. J Prim Prev, 2014. 35(2): p. 85-91.

Hammond, D., et al., Effectiveness of cigarette warning labels in informing smokers about the risks of smoking: findings from the International Tobacco Control (ITC) Four Country Survey. Tob Control, 2006. 15 Suppl 3: p. iiing-25.

Wakefield, M.A., et al., Impact of tobacco control policies and mass media campaigns on monthly adult smoking prevalence. Am J Public Health, 2008. 98(8): p. 1443-50.

Chaloupka, F.J., A. Yurekli, and G.T. Fong, Tobacco taxes as a tobacco control strategy. Tob Control, 2012. 21(2): p. 172-8o.

Hopkins, D.P., et al., Smokefree policies to reduce tobacco use. A systematic review. Am J Prev Med, 2010. 38(2 Suppl): p. S275-89.

Henriksen, L., Comprehensive tobacco marketing restrictions: promotion, packaging, price and place. Tob Control, 2012. 21(2): p. 147-53.

Goldberg, D.N., et al., Outcomes for a Public Hospital Tobacco Cessation Program: The Cook County Health and Hospitals System Experience. J Community Health, 2016. 41(6): p. 1130-1139.

Celik, I., et al., Nationwide Smoking Cessation Treatment Support Program--Turkey project. Health Policy, 2015. 119(1): p. 50-6.

$\mathrm{Ng}, \mathrm{M}$., et al., Smoking prevalence and cigarette consumption in 187 countries, 1980-2012. JAMA, 2014. 311(2): p. 183-92.

Carreras, G., et al., Predicting the future prevalence of cigarette smoking in Italy over the next three decades. Eur J Public Health, 2012. 22(5): p. 699-704.

Salvi, S.S. and P.J. Barnes, Chronic obstructive pulmonary disease in non-smokers. Lancet, 2009. 374(9691): p. 733-43.

Laumbach, R.J. and H.M. Kipen, Respiratory health effects of air pollution: update on biomass smoke and traffic pollution. J Allergy Clin Immunol, 2012. 129(1): p. 3-11; quiz 12-3.

Hoek, G., et al., Long-term air pollution exposure and cardio-respiratory mortality: a review. Environ Health, 2013. 12(1): p. 43.

Cosselman, K.E., A. Navas-Acien, and J.D. Kaufman, Environmental factors in cardiovascular disease. Nat Rev Cardiol, 2015. 12(11): p. 627-42.

Willi, C., et al., Active smoking and the risk of type 2 diabetes: a systematic review and metaanalysis. JAMA, 2007. 298(22): p. 2654-64.

Di Giuseppe, D., et al., Cigarette smoking and risk of rheumatoid arthritis: a dose-response metaanalysis. Arthritis Res Ther, 2014. 16(2): p. R61.

Chakravarthy, U., et al., Clinical risk factors for age-related macular degeneration: a systematic review and meta-analysis. BMC Ophthalmol, 2010. 10: p. 31.

Health., N.C.f.C.D.P.a.H.P.U.O.o.S.a., 11, General Morbidity and All-Cause Mortality, in The Health Consequences of Smoking-5o Years of Progress: A Report of the Surgeon General. Atlanta (GA): Centers for Disease Control and Prevention (US). 2014. whole blood. J R Soc Med, 1993. 86(3): p. 139-40.

Bjartveit, K. and A. Tverdal, Health consequences of smoking 1-4 cigarettes per day. Tob Control, 2005. 14(5): p. 315-20. 
25. Wooten, J.B., S. Chouchane, and T.E. McGrath, Tobacco Smoke Constituents Affecting Oxidative Stress, in Cigarette Smoke and Oxidative Stress, B.B. Halliwell and H.E. Poulsen, Editors. 20o6, Springer Berlin Heidelberg: Berlin, Heidelberg. p. 5-46.

26. Park, J.M., et al., Differential Effects between Cigarette Total Particulate Matter and Cigarette Smoke Extract on Blood and Blood Vessel. Toxicol Res, 2016. 32(4): p. 353-358.

27. Young, B., et al., 12 Respiratory System, in Wheater's functional histology - a text and color atlas. 2006, Elsevier.

28. Hiemstra, P.S., P.B. McCray, Jr., and R. Bals, The innate immune function of airway epithelial cells in inflammatory lung disease. Eur Respir J, 2015. 45(4): p. 1150-62.

29. Whitsett, J.A. and T. Alenghat, Respiratory epithelial cells orchestrate pulmonary innate immunity. Nat Immunol, 2015. 16(1): p. 27-35.

30. White, E.S., Lung extracellular matrix and fibroblast function. Ann Am Thorac Soc, 2015.12 Suppl 1: p. S30-3.

31. Guillot, L., et al., Alveolar epithelial cells: master regulators of lung homeostasis. Int J Biochem Cell Biol, 2013. 45(11): p. 2568-73.

32. Vaccaro, C.A. and J.S. Brody, Structural features of alveolar wall basement membrane in the adult rat lung. J Cell Biol, 1981. 91(2 Pt 1): p. 427-37.

33. Mason, R.J., Biology of alveolar type II cells. Respirology, 2006. 11 Suppl: p. S12-5.

34. Byrne, A.J., et al., Pulmonary macrophages: key players in the innate defence of the airways. Thorax, 2015. 70(12): p. 1189-96.

35. Johnstone, R.M., et al., Vesicle formation during reticulocyte maturation. Association of plasma membrane activities with released vesicles (exosomes). J Biol Chem, 1987. 262(19): p. 9412-20.

36. Wallace, W.A., M. Gillooly, and D. Lamb, Intra-alveolar macrophage numbers in current smokers and non-smokers: a morphometric study of tissue sections. Thorax, 1992. 47(6): p. 43740.

37. Perez-Rial, S., et al., Role of recently migrated monocytes in cigarette smoke-induced lung inflammation in different strain of mice. PLoS One, 2013. 8(9): p. e72975.

38. Olivera, D.S., et al., Cellular mechanisms of mainstream cigarette smoke-induced lung epithelial tight junction permeability changes in vitro. Inhal Toxicol, 2007. 19(1): p. 13-22.

39. Nishida, K., et al., Cigarette smoke disrupts monolayer integrity by altering epithelial cell-cell adhesion and cortical tension. Am J Physiol Lung Cell Mol Physiol, 2017: p. ajplung 0oo74 2017.

40. Ashley, D.L., et al., Measurement of volatile organic compounds in human blood. Environ Health Perspect, 1996. 104 Suppl 5: p. 871-7.

41. Michael Pittilo, R., Cigarette smoking, endothelial injury and cardiovascular disease. Int J Exp Pathol, 200o. 81(4): p. 219-30.

42. Messner, B. and D. Bernhard, Smoking and cardiovascular disease: mechanisms of endothelial dysfunction and early atherogenesis. Arterioscler Thromb Vasc Biol, 2014. 34(3): p. 509-15.

43. Ezzati, M., et al., Role of smoking in global and regional cardiovascular mortality. Circulation, 2005. $112(4)$ : p. 489-97.

44. Whincup, P.H., et al., Passive smoking and risk of coronary heart disease and stroke: prospective study with cotinine measurement. BMJ, 2004. 329(7459): p. 200-5.

45. (US)., C.f.D.C.a.P.U.N.C.f.C.D.P.a.H.P.U.O.o.S.a.H., How Tobacco Smoke Causes Disease: The Biology and Behavioral Basis for Smoking-Attributable Disease: A Report of the Surgeon General, in How Tobacco Smoke Causes Disease: The Biology and Behavioral Basis for SmokingAttributable Disease: A Report of the Surgeon General. 2010: Atlanta (GA).

46. Metz, L. and D.D. Waters, Implications of cigarette smoking for the management of patients with acute coronary syndromes. Prog Cardiovasc Dis, 2003. 46(1): p. 1-9.

47. Lozano, R., et al., Global and regional mortality from 235 causes of death for 20 age groups in 1990 and 2010: a systematic analysis for the Global Burden of Disease Study 2010. Lancet, 2012. 380(9859): p. 2095-128.

48. Adeloye, D., et al., Global and regional estimates of COPD prevalence: Systematic review and meta-analysis. J Glob Health, 2015. 5(2): p. 020415. 
49. Burney, P.G., et al., Global and regional trends in COPD mortality, 1990-2010. Eur Respir J, 2015. 45(5): p. 1239-47.

50. Lundback, B., et al., Not 15 but 50\% of smokers develop COPD?--Report from the Obstructive Lung Disease in Northern Sweden Studies. Respir Med, 2003. 97(2): p. 115-22.

51. Lamprecht, B., et al., COPD in never smokers: results from the population-based burden of obstructive lung disease study. Chest, 2011. 139(4): p. 752-763.

52. Demedts, I.K., et al., Role of apoptosis in the pathogenesis of COPD and pulmonary emphysema. Respir Res, 2006. 7: p. 53.

53. Ferlay, J., et al., Cancer incidence and mortality worldwide: sources, methods and major patterns in GLOBOCAN 2012. Int J Cancer, 2015. 136(5): p. E359-86.

54. Crotty Alexander, L.E., S. Shin, and J.H. Hwang, Inflammatory Diseases of the Lung Induced by Conventional Cigarette Smoke: A Review. Chest, 2015. 148(5): p. 1307-22.

55. Admyre, C., et al., Exosomes with major histocompatibility complex class II and co-stimulatory molecules are present in human BAL fluid. Eur Respir J, 2003. 22(4): p. 578-83.

56. Wolf, P., The nature and significance of platelet products in human plasma. Br J Haematol, 1967. 13(3): p. $269-88$.

57. Camussi, G., et al., Exosome/microvesicle-mediated epigenetic reprogramming of cells. Am J Cancer Res, 2011. 1(1): p. 98-110.

58. Kesimer, M., et al., Characterization of exosome-like vesicles released from human tracheobronchial ciliated epithelium: a possible role in innate defense. FASEB J, 2009. 23(6): p. 1858-68.

59. Lacroix, R. and F. Dignat-George, Microparticles: new protagonists in pericellular and intravascular proteolysis. Semin Thromb Hemost, 2013. 39(1): p. 33-9.

6o. Ayers, L., et al., Dynamic microvesicle release and clearance within the cardiovascular system: triggers and mechanisms. Clin Sci (Lond), 2015. 129(11): p. 915-31.

61. Li, C.J., et al., Novel proteolytic microvesicles released from human macrophages after exposure to tobacco smoke. Am J Pathol, 2013. 182(5): p. 1552-62.

62. Fujita, Y., et al., Suppression of autophagy by extracellular vesicles promotes myofibroblast differentiation in COPD pathogenesis. J Extracell Vesicles, 2015. 4: p. 28388.

63. Barnes, P.J., Cellular and molecular mechanisms of chronic obstructive pulmonary disease. Clin Chest Med, 2014. 35(1): p. 71-86.

64. Siti, H.N., Y. Kamisah, and J. Kamsiah, The role of oxidative stress, antioxidants and vascular inflammation in cardiovascular disease (a review). Vascul Pharmacol, 2015. 71: p. 40-56.

65. Austin, V., et al., COPD and stroke: are systemic inflammation and oxidative stress the missing links? Clin Sci (Lond), 2016. 130(13): p. 1039-50.

66. Loyer, X., et al., Microvesicles as cell-cell messengers in cardiovascular diseases. Circ Res, 2014. 114(2): p. 345-53.

67. Fujita, Y., et al., Extracellular vesicles in lung microenvironment and pathogenesis. Trends Mol Med, 2015. 21(9): p. 533-42.

68. Yanez-Mo, M., et al., Biological properties of extracellular vesicles and their physiological functions. J Extracell Vesicles, 2015. 4: p. 27066.

69. van der Pol, E., et al., Optical and non-optical methods for detection and characterization of microparticles and exosomes. J Thromb Haemost, 2010. 8(12): p. 2596-607.

70. Sokolova, V., et al., Characterisation of exosomes derived from human cells by nanoparticle tracking analysis and scanning electron microscopy. Colloids Surf B Biointerfaces, 2011. 87(1): p. 146-50.

71. Maas, S.L., J. De Vrij, and M.L. Broekman, Quantification and size-profiling of extracellular vesicles using tunable resistive pulse sensing. J Vis Exp, 2014(92): p. e51623.

72. Nolte-'t Hoen, E.N., et al., Quantitative and qualitative flow cytometric analysis of nanosized cell-derived membrane vesicles. Nanomedicine, 2012. 8(5): p. 712-20.

73. Volgers, C., et al., Bead-based flow-cytometry for semi-quantitative analysis of complex membrane vesicle populations released by bacteria and host cells. Microbiol Res, 2017. 200: p. 2532. 
General introduction and outline of the thesis $\mid 19$

74. Suarez, H., et al., A bead-assisted flow cytometry method for the semi-quantitative analysis of Extracellular Vesicles. Sci Rep, 2017. 7(1): p. 11271. 

Chapter 2

\section{Extracellular vesicles released in the response to respiratory exposures: Implications for chronic disease}

Birke J. Benedikter, Emiel F.M. Wouters, Paul H.M.

Savelkoul, Gernot G.U. Rohde, Frank R.M. Stassen

Journal of Toxicology and Environmental Health Part B - Critical Reviews. 2018 May 1. doi: 10.1080/10937404.2018.1466380. [Epub Ahead of Print] 


\section{Abstract}

Extracellular vesicles (EV) are secreted signaling entities that enhance various pathological processes when released in response to cellular stresses. Respiratory exposures such as cigarette smoke and air pollution exert cellular stresses and are associated with an increased risk for several chronic diseases. The aim of this review was to examine the evidence that modifications in EV contribute to respiratory exposure-associated diseases. Publications were searched using PubMed and Google Scholar with the search terms (cigarette smoke OR tobacco smoke OR air pollution OR particulate matter) AND (extracellular vesicles OR exosomes OR microvesicles OR microparticles OR ectosomes). All original research articles were included and reviewed. Fifty articles were identified, most of which investigated the effect of respiratory exposures on EV release in vitro (25) and/or on circulating EV in human plasma (24). The majority of studies based their main observations on the relatively insensitive scatter-based flow cytometry of EV (29). EV induced by respiratory exposures were found to modulate inflammation (19), thrombosis (13), endothelial dysfunction (11), tissue remodeling (6) and angiogenesis (3). By influencing these processes, EV may play a role in development of cardiovascular diseases and chronic obstructive pulmonary disease (COPD) and possibly lung cancer and allergic asthma. The current findings warrant additional research with improved methodologies to evaluate the contribution of respiratory exposure-induced EV to disease etiology, as well as their potential as biomarkers of exposure or risk and as novel targets for preventive or therapeutic strategies. 


\section{Health hazards of respiratory exposures}

The adult human lungs inhale between 10,000 and 20,000 L of air daily, which interact with the vast $70 \mathrm{~m}^{2}$ surface of the lungs (Brochu et al. 2006, Frohlich et al. 2016). While this makes lungs efficient for enabling gas exchange, it also makes pulmonary tissue highly vulnerable to airborne toxicants. Airborne toxicants may originate from personal exposures such as tobacco smoking (Lee et al. 2017), from occupational exposures including nanoparticles, asbestos, and volatile organic chemicals (Kermanizadeh et al. 2016, Paciencia et al. 2016, Umbright et al. 2017), and from environmental exposures such as particulate matter (PM) from outdoor air pollution (Chen and Yang 2018). Chronic exposure to respiratory toxicants substantially increases the risk of developing lung disease, cardiovascular disease (CVD) and cancer (Bartal 2001, Kelly and Fussell 2015).

\section{Chronic obstructive pulmonary disease (COPD)}

The link between exposure to respiratory toxicants and disease development is most evident for COPD, a disorder that is characterized by chronic and incompletely reversible airflow limitation. While there is a genetic aspect to COPD risk, the major risk factor is smoking (Salvi and Barnes 2009, Lamprecht et al. 2011). In patients without significant smoking history, indoor air pollution from burning of biomass fuels, outdoor air pollution and occupational exposures are thought to form environmental triggers for disease development (Salvi and Barnes 2009, Lamprecht et al. 2011). Repeated exposure over long periods of time ultimately results in the development of COPD, which is hallmarked by airway inflammation (chronic bronchitis), fibrosis, and degradation of the lung tissue (emphysema) (Demedts et al. 2006). Once COPD is established, accelerated lung function decline may be brought about by acute exacerbations, which are sudden deteriorations of COPD symptoms that are often elicited by respiratory infections (Beasley et al. 2012) or exposure to high levels of air pollution (Song et al. 2014).

\section{Cardiovascular disease (CVD)}

The relative risk of morbidity and mortality of CVD is increased by exposure to cigarette smoke (CS) or high levels of air pollution, especially in individuals with obesity and type II diabetes (Rigotti and Clair 2013, Dunbar et al. 2013, Franklin et al. 2015, Weichenthal et al. 2014). In particular, the risk for vascular diseases such as atherosclerosis and venous thromboembolism is elevated in smokers compared to non-smokers (Severinsen et al. 2009). The most serious complications of 
atherosclerosis are myocardial infarction and ischemic stroke and the most serious complication of venous thrombosis is pulmonary embolism. These form the three leading causes of cardiovascular mortality worldwide (Lozano et al. 2012, ISTH Steering Committee for World Thrombosis Day 2014). While the mechanisms underlying respiratory exposure-induced CVD are incompletely understood, inflammation, endothelial dysfunction and hypercoagulability are involved (Csordas and Bernhard 2013, Piazza and Goldhaber 2010).

\section{Asthma and occupational asthma}

Asthma is characterized by reversible airflow obstruction that is initiated by chronic and oftentimes allergic bronchial wall inflammation and bronchial wall remodeling (Palgan and Bartuzi 2015). CS and air pollution were found to enhance the risk for developing asthma (Ferrante et al. 2014) and are thought to trigger acute exacerbations in patients with established asthma (Guarnieri and Balmes 2014, Wang et al. 2015). Moreover, occupational respiratory exposures, such as toluene diisocyanate and possibly nanoparticles are etiological factors for the development of occupational asthma (Tarlo and Lemiere 2014, Sharma 2010).

\section{Lung cancer}

Exposure to respiratory toxicants predisposes to developing lung cancer, which has been and will continue to be the most common cause of cancer-related death for several decades (Malvezzi et al. 2015, Rahib et al. 2014). A large proportion of lung cancer deaths are attributed to CS and male as well as female smokers have a 25 times higher risk of dying of lung cancer than never-smokers (Ezzati and Lopez 2003, Thun et al. 2013). Lung cancer develops when chronic exposure to respiratory toxicants produces cell damage and consequently a dysfunction of DNA repair mechanisms and cell cycle control. Respiratory toxicant-induced inflammation further aggravates this effect. Besides uncontrolled cell proliferation, both tissue remodeling and neoangiogenesis are involved in tumor growth (Pickup et al. 2014, Folkman 1971).

\section{Extracellular vesicles}

Importantly, there is a high rate of comorbidity between different diseases associated with exposure to respiratory toxicants (Decramer and Janssens 2013). Further, these diseases share chronic inflammation and oxidative stress as common hallmarks (Crotty Alexander et al. 2015, Barua et al. 2015, Siasos et al. 2014, 
Valavanidis et al. 2013, Kelly and Fussell 2015), suggesting some overlap in the biological processes underlying disease development. Extracellular vesicles (EV) are secreted signaling entities whose production is modulated by pro-inflammatory and oxidative stimuli in vitro. It is well-known that EV are involved in the pathogeneses of CVD and cancer, and they were also proposed to contribute to development of chronic lung disease (Minciacchi et al. 2015, Loyer et al. 2014, Fujita et al. 2015b). The purpose of this review was to examine the relationship of EV secretion, composition and function with airborne environmental risk factors for developing lung disease, CVD and cancer.

EV are small membrane-enclosed vesicles that are postulated to be released by all cell types and that have been detected in a variety of human body fluids, including nasal lavage fluid (NLF) (Lasser et al. 2011), bronchoalveolar lavage fluid (BALF) (Admyre et al. 2003) and blood (Wolf 1967). These vesicles carry a complex cargo of proteins, RNA and lipids that makes them potent entities of intercellular communication (van Niel et al. 2018). EV-borne proteins bind to cell surface receptors and trigger intracellular signal transduction (Camussi et al. 2011). In addition, EV fuse with the membrane of their target cells and thereby deliver functional RNA and proteins that modulate target cellular activity (Camussi et al. 2011). Finally, certain EV-bound proteins exert functions in the extracellular space, such as remodeling of the extracellular matrix (Lacroix and Dignat-George 2013).

\section{Heterogeneity of extracellular vesicles}

Importantly, EV are not a homogenous population (Kowal et al. 2016). While EV nomenclature is still controversial (Gould and Raposo 2013), it is generally recognized that there are three major EV subtypes. The first subtype, exosomes, is formed by inward budding of the endosomal membrane to form intraluminal vesicles, and subsequently released to the extracellular space by fusion of multivesicular endosomes (MVE) with the plasma membrane (Abels et al. 2016). The second subtype, commonly referred to as microvesicles (or microparticles or ectosomes), arises by outward budding of the plasma membrane (Abels et al. 2016). The third EV type is apoptotic bodies, large membrane vesicles which are formed by apoptotic membrane blebbing and which contain DNA fragments and cellular organelles (Thery et al. 2009). This review focuses on the first two EV subtypes, exosomes and microvesicles, whose key properties are summarized in Table 1. Apoptotic bodies are not considered because they are formed only during apoptotic cell fragmentation. 
Table 1 - Key properties of exosomes and microvesicles. ESCRT, endosomal complex required for transport; NTA, nanoparticle tracking analysis; TRPS, tunable resistive pulse sensing

\begin{tabular}{|c|c|c|}
\hline & Exosomes & Microvesicles \\
\hline $\begin{array}{l}\text { Alternative } \\
\text { nomenclature }\end{array}$ & Extracellular vesicles & $\begin{array}{l}\text { Extracellular vesicles, } \\
\text { microparticles, ectosomes }\end{array}$ \\
\hline Subcellular origin & Multivesicular endosomes & Plasma membrane \\
\hline Diameter & $50-150 \mathrm{~nm}$ & $100-1000 \mathrm{~nm}$ \\
\hline $\begin{array}{l}\text { Sedimentation } \\
\text { speed }\end{array}$ & $100,000 \times g$ & $10,000 \times g$ \\
\hline Molecular markers & $\begin{array}{l}\text { Tetraspanins (e.g. CD63, } \\
\text { CD81,CD9), ESCRT proteins } \\
\text { (TSG101, Alix), }\end{array}$ & $\begin{array}{l}\text { Phosphatidylserine, integrins, } \\
\text { selectins }\end{array}$ \\
\hline Detection & $\begin{array}{l}\text { NTA, TRPS, bead-based flow } \\
\text { cytometry, fluorescence- } \\
\text { triggered flow cytometry }\end{array}$ & $\begin{array}{l}\text { Conventional scatter-triggered } \\
\text { flow cytometry }\end{array}$ \\
\hline
\end{tabular}

\section{Exosomes}

Due to their endosomal origin, exosomes (50-150 $\mathrm{nm}$ ) are smaller than microvesicles (100-1000 $\mathrm{nm}$ ). Further, exosomes are enriched in members of the endosomal sorting complexes required for transport (ESCRT, e.g. Alix, TSG101) and in tetraspanins such as CD9, CD63 and CD81. As exosomes are generally smaller than the resolution limit of conventional optical techniques (light microscopy, flow cytometry scatter) (van der Pol et al. 2010), highly dedicated technology is required for their detection, including electron microscopy, nanoparticle tracking analysis (NTA) (Sokolova et al. 2011), tunable resistive pulse sensing (TRPS) (Maas et al. 2014) and fluorescencetriggered high resolution flow cytometry (Nolte-'t Hoen et al. 2012). Alternatively, exosomes may be characterized by bulk analysis techniques, such as Western blotting or bead-based flow cytometry, a technique in which EV are linked to large beads and subsequently stained for exosome marker proteins (Volgers et al. 2017, Suarez et al. 2017). The most common method for isolation of exosomes is ultracentrifugation at 100,000 x g (Gardiner et al. 2016). 


\section{Microvesicles}

While all the techniques that are used for exosome characterization may also be applied to microvesicles, this is performed less frequently because microvesicles larger than $300 \mathrm{~nm}$ may be more easily detected employing conventional scattertriggered flow cytometry (van der Pol et al. 2010). Fluorescent stains commonly used for flow cytometric microvesicle detection include annexin $\mathrm{V}$ for detection of the negatively charged phospholipid phosphatidylserine (PS), as well as antibodies against selectins, integrins and cell adhesion molecules, which may provide clues regarding the cell of origin (summarized in Table 2). Microvesicles are most commonly isolated by centrifugation at 10,000 $\mathrm{x}$.

Table 2 - Overview of surface molecules that are commonly used to identify the cellular origin of microvesicles in complex biological fluids such as plasma.

\begin{tabular}{ll}
\hline Cellular origin & marker proteins \\
\hline Endothelial & CD105, CD62E, CD146 \\
endothelial/platelet & CD31, CD144, CD51 \\
Platelet & CD41, CD42a, CD42b, CD61 \\
Epithelial & CD326 \\
total leukocytes & CD45 \\
monocyte/macrophage & CD14 \\
Neutrophil & MPO, CD66 \\
Erythrocyte & Ter119 \\
T cell & CD154 \\
\hline
\end{tabular}

\section{Methodology}

Publications published before September 2017 were searched using Pubmed and Google Scholar. The search terms were (cigarette smoke OR tobacco smoke OR air pollution OR particulate matter) AND (extracellular vesicles OR exosomes OR microvesicles OR microparticles OR ectosomes). Abstracts and keywords were screened to assess whether effects of CS, CS components, PM or other air pollutants on EV were reported. All original research articles fulfilling these criteria were included. Moreover, relevant references referred to in these publications were considered. 


\section{Systematic evaluation of the published literature}

EV research is a relatively novel and rapidly developing field. As one begins to understand that the results of some early EV studies may be attributed to methodological artefacts rather than reflecting true biological properties of EV, the following criteria were examined (1) experimental approaches and techniques used in identified studies and (2) number of studies suggesting an involvement of respiratory exposure-induced $\mathrm{EV}$ in certain biological processes as an indicator for the strength of evidence. In total, 50 original research articles from 36 independent research groups were identified that assessed effects of respiratory exposures on EV. Of these, 30 studies focused on CS or CS components and 20 on PM or other air pollutants. Detailed information on each of the 50 studies is given in the supplementary material (Table $S_{1}$ and Table $S_{2}$ ).

The two oldest articles dated from 2004. Starting from the publication of the third article in 2008, there was a consistent increase in number of articles published per year, peaking at 11 articles in 2016 (Figure $1 \mathrm{~A}$ ). This highlights a growing interest in the topic over the past decade. The majority of the studies were performed in vitro (26), followed by human (25) and animal studies (6) with several articles using a combination of different study types (Figure $1 \mathrm{~B}$ ). Congruently, the most common fluids in which EV were studied were cell culture media (22; with varying percentages of untreated or EV-depleted fetal calf serum; FCS), followed by plateletdepleted plasma (13; most commonly citrated, followed by EDTA and heparinized plasma) and BALF (3; Figure $1 \mathrm{C})$. 
A

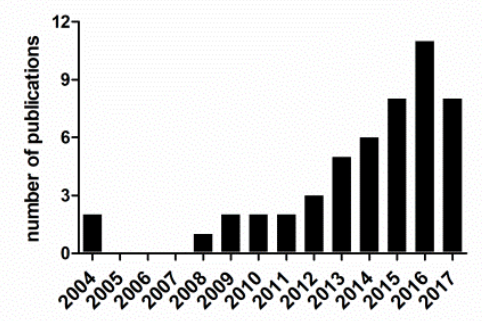

D
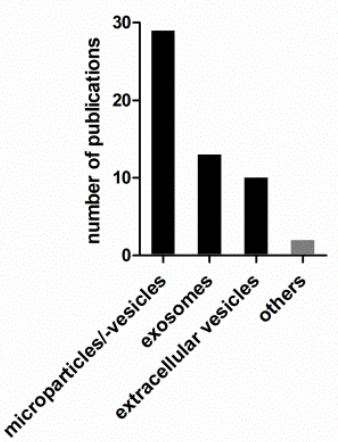

G
$\mathbf{E}$

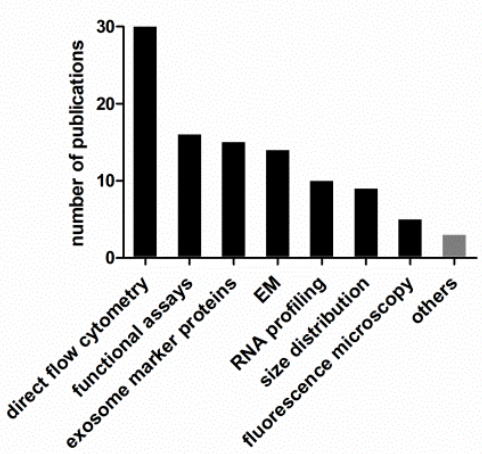

H
C
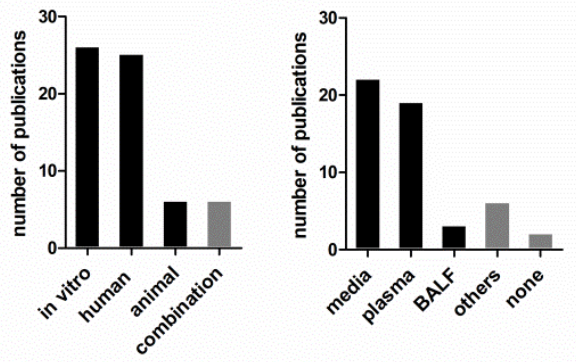

$\mathbf{F}$

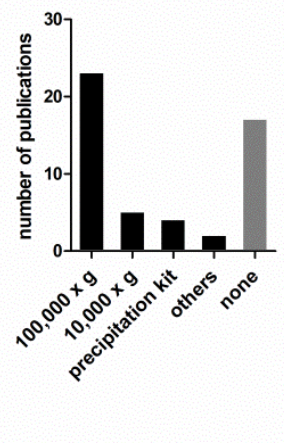

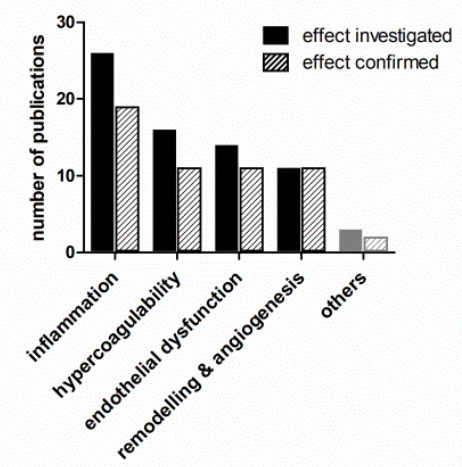

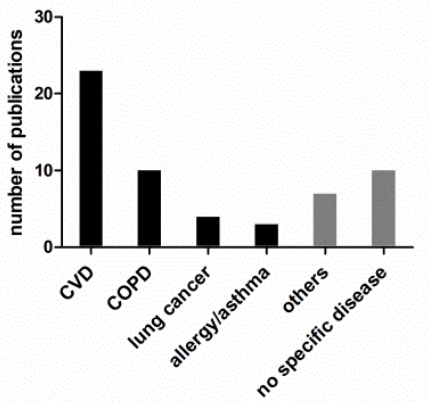

Figure 1 - Results of the literature search. The graphs show the number of publications (A) per year since the first publication in 2004 (B) that report on in vitro, human and animal experiments, (C) according to the biological material in which EV were studied, (D) according to the EV nomenclature used by the authors, (E) that used a specific EV characterization technique, (F) that used a specific EV isolation technique, $(\mathrm{G})$ that investigated and confirmed the involvement of respiratory exposure-induced EV in the specified biological processes, and $(\mathrm{H})$ according to the pathology for which the authors considered the described changes to be relevant 
Most investigators referred to the EV in their studies as microparticles or microvesicles (29), followed by exosomes (13) and extracellular vesicles (10) (Figure 1D). In line with this, the most commonly applied EV characterization method was direct flow cytometry of microvesicles (30), followed by functional analyses (16), bulk detection of exosome marker proteins (15) and electron microscopy (14; Figure $1 \mathrm{E}$ ). Strikingly, the majority of the studies (27 studies, i.e. 54\%) only applied a single EV characterization technique; whereas the current consensus in the field is that multiple complementary techniques need to be combined when studying EV (Lotvall et al. 2014). The by far most commonly employed EV isolation technique was ultracentrifugation at approximately 100,000 x $g$ (23; Figure $1 \mathrm{~F}$ ). This was often applied in experiments that referred to EV as microparticles, although it is well established that 100,000 $\mathrm{x} g$ centrifugation also sediments exosomes. The second most common isolation technique was centrifugation at approximately 10,000 x $g$ (5; Figure $\mathrm{iF}$ ), which is considered to preferentially sediment microvesicles, with a smaller proportion of exosomes than 100,000 $\mathrm{x} g$ centrifugation. A number of investigations applied commercial EV precipitation kits $\left(4\right.$; Figure $\left.{ }_{1} \mathrm{~F}\right)$, which coprecipitate soluble, non-EV bound molecules (Taylor and Shah 2015). All studies employed crude centrifugation pellets rather than performing additional EV purification by density-gradient centrifugation, which is required to deplete nonvesicular high molecular weight complexes. One third of studies (17, Figure $1 \mathrm{~F}$ ) did not isolate EV at all, but only measured their concentration by direct flow cytometry or observed vesicle budding at the plasma membrane by fluorescence microscopy.

Finally, the number of studies that investigated the involvement of respiratory exposure-induced EV in certain biological pathways was determined and the quantity of these studies that actually provided data in favor of such an involvement was noted. EV were proposed to be involved in biological processes such as inflammation (26/19), hypercoagulability (16/11), endothelial dysfunction (14/11) and tissue remodeling or angiogenesis (11/11; Figure $1 G)$. These biological processes were projected to be of relevance for development of CVD (23), COPD (10), cancer (4) or allergic asthma (3; Figure $1 \mathrm{H})$. Taken together, a substantial amount of findings suggests a role for respiratory exposure-induced EV in development of chronic disease.

While the available evidence is valuable, part of it was obtained using outdated and/or suboptimal methods which do not allow for attributing biological functions unambiguously to EV rather than to co-isolated contaminants. Moreover, because of non-stringent combinations of detection, isolation and characterization methods, it is currently unclear whether certain biological effects of respiratory 
exposure-induced EV are exerted by microvesicles, exosomes, or both. Therefore, the generic term EV will be used in the following sections, in which evidence will be presented comprehensively for involvement of respiratory exposure-induced EV in biological processes that promote development of chronic diseases.

\section{Inflammation and immunomodulation}

Inflammation is a universal attribute of respiratory exposure-associated diseases (Lee and Lawrence 2018). In total, 26 original research articles were identified that investigated whether and how respiratory exposure-induced EV modulated inflammatory responses.

\section{Interference with anti-inflammatory signaling}

In healthy lungs, alveolar macrophages and pulmonary epithelium act in concert to rapidly clear inhaled substances and maintain an anti-inflammatory state. EV from alveolar macrophages contribute to this anti-inflammatory state by delivering suppressor of cytokine signalling (SOCS) 1 and 3 to epithelial cells (Bourdonnay et al. 2015). Importantly, CS-exposed mice and human smokers exhibited decreased SOCS concentrations in BALF compared to non-smoking controls, suggesting a loss of EVdependent anti-inflammatory state in smokers (Bourdonnay et al. 2015). In addition, the anti-inflammatory effect of alveolar macrophage-derived EV depends upon their internalization by target cells, which is inhibited by the presence of CS extract (CSE) (Schneider et al. 2017).

\section{Promotion of pro-inflammatory signaling}

CS not only interferes with EV-dependent anti-inflammatory signaling, it also actively promotes EV-dependent pro-inflammatory signaling. Chen et al (2016) demonstrated that EV from CSE-exposed macrophages contain the proinflammatory alarmin high mobility group box 1 (HMGB1). Further, EV from CSEexposed macrophages and epithelial cells, as well as EV isolated from BALF of smokers trigger release of interleukin-(IL-)6, IL-8 and monocyte chemoattractant protein $1(\mathrm{MCP} 1)$ by naïve pulmonary epithelial cells (Cordazzo et al. 2014, Moon et al. 2014, Heliot et al. 2017). EV also promote upregulation of intercellular adhesion molecule 1 (ICAM-1) (Cordazzo et al. 2014) and thus may contribute to inflammation and immune cell recruitment towards EV target cells. 


\section{Interference with efferocytosis}

CS as well as PM exposure increase the release of phosphatidylserine (PS) ${ }^{+}$EV from different cell types in vitro and the concentrations of circulating $\mathrm{PS}^{+} \mathrm{EV}$ in vivo (Serban et al. 2016, Neri et al. 2016, Li et al. 2010, Emmerechts et al. 2012b). PS ${ }^{+}$EV may contribute to inflammation, as Serban et al. (2016) reported that CSE-induced $\mathrm{PS}^{+}$EV from endothelial cells prevent efferocytosis of apoptotic cells by PSdependent blocking of the phagocyte receptors for apoptotic cell engulfment. Importantly, deficient efferocytosis of apoptotic cells is postulated to contribute to sustained lung inflammation in COPD (McCubbrey and Curtis 2013) and to progression and destabilization of atherosclerotic plaques (Schrijvers et al. 2005, Foks et al. 2016).

\section{Indirect evidence for involvement in inflammation}

Exposure to CSE-, PM and other air pollutants was found to alter transcriptomic (microRNA) and, in one study, proteomic EV composition (Sheller et al. 2016, Rodosthenous et al. 2016, Pavanello et al. 2016, Pergoli et al. 2017, Lim et al. 2016, Heliot et al. 2017). Based on biological pathway analysis, these compositional changes were predicted to promote inflammation, although this was not experimentally confirmed. In one observational human study, PM exposure of young healthy individuals was associated with parallel increases in circulating endothelial cell-derived EV and various immune cells as well as pro-inflammatory molecules (Pope et al. 2016), yet a causal link between EV and inflammation was not established.

\section{Allergic inflammation}

Finally, respiratory exposure-induced EV may contribute to allergic inflammation and development of (occupational) asthma. In ovalbumin-sensitized mice, intratracheally instilled magnetic iron oxide nanoparticles triggered release of EV that promote dendritic cell maturation and $\mathrm{T}$ cell activation (Zhu et al. 2012). Brostrom et al (2015) found that treatment of pulmonary epithelial cells with the occupational respiratory toxicant toluene diisocyanate initiated release of autotaxin via $\mathrm{EV}$, an enzyme that has been implicated in allergic airway inflammation.

\section{Conflicting data}

While the majority of published studies suggest a role for respiratory exposureinduced EV in inflammation, several negative findings were also noted. Benedikter et 
al (2017) found that EV from CSE-stimulated pulmonary epithelial cells did not significantly modify IL-8 secretion by naïve cells. The same CSE-EV were less potent inducers of monocyte adhesion to endothelial cells than EV secreted by unexposed cells (Benedikter et al. 2017), questioning a role for CSE-induced EV in immune cell recruitment. Several human and animal studies that assessed in vivo effects of respiratory exposures were not able to link changes in circulating EV to alterations in inflammatory markers (Emmerechts et al. 2012a, Emmerechts et al. 2012b, Levanen et al. 2013, Mobarrez et al. 2014). Several investigators even found that smokers displayed decreased concentrations of circulating PS ${ }^{+}$EV compared to non-smokers (Grant et al. 2011, Badrnya et al. 2014, Enjeti et al. 2017). In part, the failure to detect pro-inflammatory changes in EV in response to respiratory toxicants in vivo may be due to (1) use of relatively mild and acute exposures (Mobarrez et al. 2014, Levanen et al. 2013) or (2) the fact that current methods are not sensitive enough to detect subtle changes in EV and inflammatory mediators in study populations without clinical disease.

The studies that report either induction (Cordazzo et al. 2014, Moon et al. 2014, Heliot et al. 2017) or no induction (Benedikter et al. 2017) of pro-inflammatory cytokines by CS(E)-induced EV in vitro have all used similar exposure times, EV isolation techniques and EV target cells (bronchial epithelial cells). Yet, the divergent results might be explained by the quantity of EV used in functional assays as Heliot et al. (2017) obtained their positive results with 10o-fold more EV than the concentration that resulted in negative results (Benedikter et al. 2017). The use of untreated versus EV-depleted FCS in the media for target cell stimulation may also be of influence. More transparent reporting of methodological details in future studies will improve comparability and allow identifying factors responsible for divergent results.

\section{Summary}

Taken together, the majority of data suggest that exposure to CSE or PM shifts the functionality of EV secreted by mononuclear, epithelial and endothelial cells from an anti-inflammatory towards a pro-inflammatory phenotype. Respiratory exposureinduced EV may promote monocyte and neutrophil recruitment towards EV target cells, activate pro-inflammatory signaling and impair clearance of apoptotic cells. Such pro-inflammatory effects of respiratory exposure-induced EV are of potential relevance for atherogenesis as well as development of COPD. Some of the described pro-inflammatory effects may also have implications for allergic asthma and lung carcinogenesis. Further research is required to validate and extend current findings 
as well as establish whether biological processes that were identified in vitro play a role in respiratory exposure-induced disease pathogenesis in vivo.

\section{Hypercoagulability}

Hypercoagulability is an abnormal tendency to develop blood clots and is postulated to contribute significantly to cardiovascular risk in smokers. Some EV express tissue factor (TF), which is able to trigger thrombin generation via the extrinsic coagulation pathway (van Es et al. 2015). The presence of PS and other negatively charged phospholipids in the membrane of EV enables assembly of coagulation factors on the EV surface and thus further promotes thrombin generation. In total, 16 studies were identified that investigated the influence of respiratory toxicants on $\mathrm{TF}^{+} \mathrm{EV}, \mathrm{PS}^{+} \mathrm{EV}$ or other changes in EV related to hypercoagulability.

\section{In vitro evidence}

Both short-term (15 min) and long-term (20 hr) exposure of monocytes and macrophages to CSE result in elevated release of $\mathrm{PS}^{+}$and $\mathrm{TF}^{+} \mathrm{EV}$, which is associated with increased procoagulant activity ( $\mathrm{Li}$ et al. 2010, Cordazzo et al. 2014). Similarly, endothelial cells respond to CSE or PM exposure by releasing more $\mathrm{PS}^{+}$and $\mathrm{TF}^{+}$ procoagulant EV (Neri et al. 2016, Serban et al. 2016). However, evidence for involvement of $\mathrm{TF}^{+}$and $\mathrm{PS}^{+} \mathrm{EV}$ in respiratory exposure-induced hypercoagulability in vivo is less clear.

\section{In vivo evidence for $\mathrm{TF}^{+}$extracellular vesicles}

A number of studies by one group assessed the influence of PM or ozone exposure on $\mathrm{TF}^{+} \mathrm{EV}$ in either healthy individuals (Frampton et al. 2015) or type II diabetics (Stewart et al. 2010, Frampton et al. 2012). Among these, only an observational study detected a significant positive association between subacute exposure ( 2 and 5 days prior to sampling; Frampton et al. 2012) and circulating $\mathrm{TF}^{+} \mathrm{EV}$, whereas the other, interventional studies with a single acute exposure showed at most a trend for a positive association (Frampton et al. 2015, Stewart et al. 2010). Badrnya et al. (2014) determined the concentration of $\mathrm{TF}^{+} \mathrm{EV}$ in plasma of young healthy smokers and non-smokers and found no significant difference. In another study with a broader age range, Enjeti et al (2017) reported that circulating $\mathrm{TF}^{+} \mathrm{EV}$ were decreased in smokers compared to non-smokers using univariate analysis, whereas there was a significant positive correlation for smoking status and $\mathrm{TF}^{+} \mathrm{EV}$ after correcting for age. This highlights the importance of correcting for confounding factors in 
translational studies.

The difficulty to detect increases in $\mathrm{TF}^{+} \mathrm{EV}$ in the response to in vivo respiratory exposures may partly be explained by the small sample size and lack of correction for confounding factors in most human studies. Another problem when studying $\mathrm{TF}^{+} \mathrm{EV}$ is the low sensitivity of antibody-based TF detection. TF concentrations required for procoagulant activity are considerably lower than the current detection limit of ELISA-based techniques (van Es et al. 2015). Conventional flow cytometry does not allow detection of small EV (<300 nm) which may also express TF. Further, fluorescence intensity may not be sufficient to detect all $\mathrm{TF}^{+} \mathrm{EV}$ $>300 \mathrm{~nm}$ as only a limited number of TF molecules may be present within an EV due to its small size (van Es et al. 2015). Thus, more sensitive methods for detection of procoagulant EV and larger or more controlled human studies are required to establish the importance of CS- and air pollution-induced circulating $\mathrm{TF}^{+} \mathrm{EV}$ for hypercoagulability in vivo.

\section{In vivo evidence for PS+ extracellular vesicles}

Only one study was identified that assessed the effect of PM-exposure on PS ${ }^{+}$EV in vivo. In this human observational cohort, short term PM exposure (hours to days) was associated with decreased, and long term exposure ( 3 months to 1 year) with increased concentrations of circulating $\mathrm{PS}^{+}$EV (Emmerechts et al. 2012b). For CS exposure, while all in vitro studies reported increased concentrations of PS ${ }^{+} \mathrm{EV}$ ( $\mathrm{Li}$ et al. 2010, Cordazzo et al. 2014, Serban et al. 2016), all in vivo studies reported decreased concentrations in the blood circulation of smokers compared to nonsmokers (Grant et al. 2011, Badrnya et al. 2014, Enjeti et al. 2017). Whether cells indeed mount a different EV response to CS in vitro than in their physiological environment or whether the divergent findings are explained by other factors remains unclear. In vivo, $\mathrm{PS}^{+} \mathrm{EV}$ may remain in the lung lumen rather than entering the circulation, meaning that they would not be detected in plasma samples. Alternatively, they may be rapidly phagocytosed (Serban et al. 2016) or absorbed by target tissues. Another potential explanation is that all in vitro studies investigated the effect of a single acute CS exposure, whereas the exposure in human smokers is repeated over a long time, and adaptation may take place in healthy individuals. To elucidate whether acute human CS exposure results in increased circulating $\mathrm{PS}^{+} \mathrm{EV}$, PS $^{+}$EV should be analysed in acute exposure studies such as those performed by Heiss et al. (2008) and Mobarrez et al. (2014). Finally, slower centrifugation speeds were used for EV isolation in the in vivo studies (ca. 10,00o $\mathrm{x} \mathrm{g}$ ) than in the in vitro studies (ca. 100,000 $\mathrm{x} \mathrm{g}$ ), which may have resulted in analysis of different EV 
subpopulations. Additional research is required to establish whether $\mathrm{PS}^{+} \mathrm{EV}$ can contribute to hypercoagulability in response to CS-exposure in vivo.

\section{Other changes in extracellular vesicles related to hypercoagulability}

Besides surface-exposed TF and PS, other EV parameters may reflect and/or promote hypercoagulability. Several investigators found that respiratory exposures are associated with increased circulating platelet-derived EV (Emmerechts et al. 2012a, Pergoli et al. 2017, Xu et al. 2013, Mobarrez et al. 2014), which are thought to reflect platelet activation and promote coagulation. Exposure to occupational and environmental PM was reported to produce changes in circulating EV microRNA cargo that were predicted to promote coagulation based upon bioinformatics analyses (Pavanello et al. 2016, Pergoli et al. 2017). Finally, respiratory exposureinduced alterations in circulating EV are associated with elevations of more classical markers for hypercoagulability such as increased coagulation factors, a greater number of platelet-leukocyte aggregates, decreased fibrinolytic factors and enhanced thrombin generation (Pergoli et al. 2017, Emmerechts et al. 2012b, Pope et al. 2016).

\section{Summary}

Taken together, in vitro studies suggest that several cell types secrete EV with PSand TF-dependent procoagulant activity when exposed to CS or PM. In addition to PS and TF, EV also carry other cargo molecules that might promote hypercoagulability. Additional translational studies of circulating EV and EV from BALF are required to establish the importance of procoagulant EV for respiratory exposure-associated CVD and lung disease.

\section{Endothelial dysfunction}

While the healthy endothelium maintains vascular tone and blood fluidity, endothelial dysfunction is highlighted by impaired endothelium-dependent vasodilation and a shift of the endothelial secretome from anti-inflammatory and anticoagulant towards more pro-inflammatory and procoagulant factors. CS and PM exposure are both well established to produce endothelial dysfunction (Messner and Bernhard 2014, Bourdrel et al. 2017). Endothelial dysfunction is one of the earliest vascular changes in atherosclerosis and proposed to actively promote atherogenesis (Gimbrone and Garcia-Cardena 2016). Emphysema formation in COPD patients is associated with endothelial cell stress and cell death in the pulmonary capillaries, leading to impaired vessel functions (McCubbrey and Curtis 2013, Takahashi et al. 
2012). Endothelial damage may actively contribute to the pathogenesis of COPD (Barr 2011). Hence, it may mechanistically explain the high rate of co-morbidity between COPD and CVD (Clarenbach et al. 2013). Increased concentrations of circulating endothelial-derived EV are thought to both result from and promote endothelial dysfunction (Sabatier et al. 2009). As such, EV are considered to act as surrogate markers for endothelial stress and may also reflect endothelial inflammation, coagulability, and vascular tone (Burger and Touyz 2012). A total of 14 studies were identified that assessed the influence of respiratory toxicants on circulating endothelial-derived EV in vivo or on EV secretion by endothelial cells in vitro.

\section{Induction of endothelial extracellular vesicles by respiratory exposures}

A relatively large body of evidence supports that respiratory exposures induce endothelial EV release. CS exposure of mice and rats enhanced the concentration of circulating endothelial-derived EV (Serban et al. 2016, Liu et al. 2014). Transient exposure of healthy humans to second hand or mainstream CS, and chronic smoking are associated with elevated numbers of circulating endothelial-derived EV (Heiss et al. 2008, Mobarrez et al. 2014, Gordon et al. 2011). Smoking cessation reverts the rise in endothelial-derived EV, but only in individuals where lung damage has not yet been established (Strulovici-Barel et al. 2016). PM exposure was found to increase EV release by cultured endothelial cells (Neri et al. 2016). Observational studies in healthy volunteers provided evidence that high levels of outdoor air pollution or PM occurred concomitantly with elevated concentrations of endothelial-derived EV, especially in subjects that were overweight (Pope et al. 2016, Bonzini et al. 2017).

\section{Association of endothelial extracellular vesicles with biomarkers of damage}

Increases in circulating endothelial-derived EV in response to human CS exposure were correlated with other markers of endothelial dysfunction, such as impaired flow mediated dilation and elevated circulating endothelial progenitor cells (Heiss et al. 20o8, Mobarrez et al. 2014). Some investigators proposed a link between elevated circulating endothelial-derived EV and endothelial apoptosis, especially for CD62 $\mathrm{E}^{+}$ endothelial EV (Liu et al. 2014, Strulovici-Barel et al. 2016, Gordon et al. 2011). It was also shown that endothelial-derived EV are associated with emphysematous lung damage and decreased lung function in smokers (Gordon et al. 2011, Strulovici-Barel et al. 2016). 


\section{Non-endothelial extracellular vesicles in endothelial dysfunction}

Finally, there is evidence that EV of non-endothelial origin contribute to endothelial dysfunction in response to respiratory exposures. Xu et al (2013) showed that mice exposed to carbon monoxide, an important component of CS and air pollution, exhibited increased endothelial permeability in the brain and skeletal muscle, which was mediated by neutrophil-derived EV.

\section{Summary}

Taken together, data suggest that exposure to respiratory toxicants is associated with elevated concentrations of circulating endothelial-derived EV in animals and humans, which was determined by direct flow cytometry for various endothelial marker proteins. While endothelial-derived EV were proposed as mediators of and surrogate markers for endothelial dysfunction, no functional characterization has yet been performed for endothelial-derived EV secreted in response to respiratory exposures.

\section{Tissue remodeling and angiogenesis}

Respiratory exposure-associated diseases are hallmarked by modifications of tissue structure. Epithelial-to-mesenchymal transition and remodeling of the extracellular matrix are important processes in COPD and lung cancer development (Houghton 2013). Thickening of the bronchial subepithelial layer and fibroblast-tomyofibroblast differentiation are also involved in COPD and asthma pathogenesis (Palgan and Bartuzi 2015, Salazar and Herrera 2011, Al-Muhsen et al. 2011). Finally, extracellular matrix degradation may contribute to (1) emphysema formation (Salazar and Herrera 2011) and (2) destabilization of atherosclerotic plaques, enhancing the risk for cardiovascular complications (Messner and Bernhard 2014). Another biological process that is related to and dependent upon tissue remodeling is neovascularization. In lung cancer, tumor-associated angiogenesis enables oxygen and nutrient supply to sustain tumor growth (Folkman 1971). In atherosclerosis, the formation of leaky intraplaque neovessels contributes to plaque destabilization (Michel et al. 2014). Finally, in asthma, subepithelial angiogenesis promotes thickening of the subepithelial layer and facilitates infiltration of immune cells into the bronchial wall (Palgan and Bartuzi 2015). Eleven studies were identified that investigated whether EV secreted in the response to respiratory exposures promote tissue degradation, remodeling or angiogenesis. The evidence is largely derived from in vitro studies using CSE exposure. 


\section{Extracellular vesicle-associated proteolytic enzymes}

Several studies demonstrated that cell exposure to CSE produced an increased release of proteolytic enzymes in an EV-associated form. Li et al. (2013) noted that CSE exposure of monocytes and monocyte-derived macrophages induced a 3 -fold rise in EV-associated matrix metalloproteinase (MMP) 14-dependent gelatinolytic and collagenolytic activity. Folkesson et al (2015) found that, when exposed to CSE, neutrophil-like HL6o cells secreted EV-associated and proteolytically active a disintegrin and metalloproteinase (ADAM)10 and ADAM17. Finally, EV released by lung epithelial cells in response to CSE promoted production of MMPı by EV target cells (Moon et al. 2014). Xu and Deng (2004) demonstrated that CS-induced secretion of EV-bound proteolytic calpains was associated with increased migration and invasiveness of the EV-secreting lung carcinoma cells.

\section{Fibroblast-to-myofibroblast differentiation}

A proteinase-independent contribution of CSE-induced EV to tissue remodeling was also proposed. Fujita et al (2015a) found that lung epithelial cells stimulated with CSE secrete EV that are enriched in microRNA-210. EV-dependent delivery of the microRNA to pulmonary fibroblasts resulted in inhibition of autophagy and subsequent differentiation of the fibroblasts into myofibroblasts.

\section{Respiratory exposure-induced extracellular vesicles and angiogenesis}

Concerning angiogenesis, enhanced release of proteolytic enzymes in an EVassociated form may promote endothelial cell migration by degrading the extracellular matrix. Further, EV from CSE-treated lung epithelial cells promote secretion of the proangiogenic vascular endothelial growth factor (VEGF) by EV target cells (Moon et al. 2014, Liu et al. 2014). Liu et al (2014) demonstrated that VEGF induction was mediated by EV-associated microRNA-21 and was able to trigger endothelial tube formation.

\section{Summary}

Taken together, CSE-exposure results in increased release of proteolytic enzymes by various cell types in either an EV-associated or EV-dependent manner. These EVbound or EV-induced proteolytic enzymes may promote tissue remodeling by degrading extracellular matrix constituents. CSE-induced EV may further promote tissue remodeling by initiating fibroblast to myofibroblast differentiation and endothelial tube formation. Yet, no apparent studies were identified that 
investigated the effect of air pollution on EV-dependent tissue remodeling. Further, there is currently a lack of translational studies on the implications of respiratory exposure-induced proteolytic EV for tissue remodeling in vivo.

\section{Synopsis and identification of knowledge gaps}

Respiratory exposures such as CS and PM promote the release of EV from various cell types including lung epithelial cells, monocytes and endothelial cells. Further, respiratory exposures produce alterations in EV composition, which promote inflammation, hypercoagulability, endothelial dysfunction, tissue remodeling and neovascularization. While most of the cited studies focused on relevance of respiratory toxicant-induced EV for one specific respiratory exposure-associated disorder, this review provides an integrative view of the findings from different fields. Importantly, respiratory exposure-induced EV may be involved in the pathogeneses of COPD, CVD, asthma and lung cancer by modulating each of the above-mentioned biological processes (illustrated in Figure 2). 


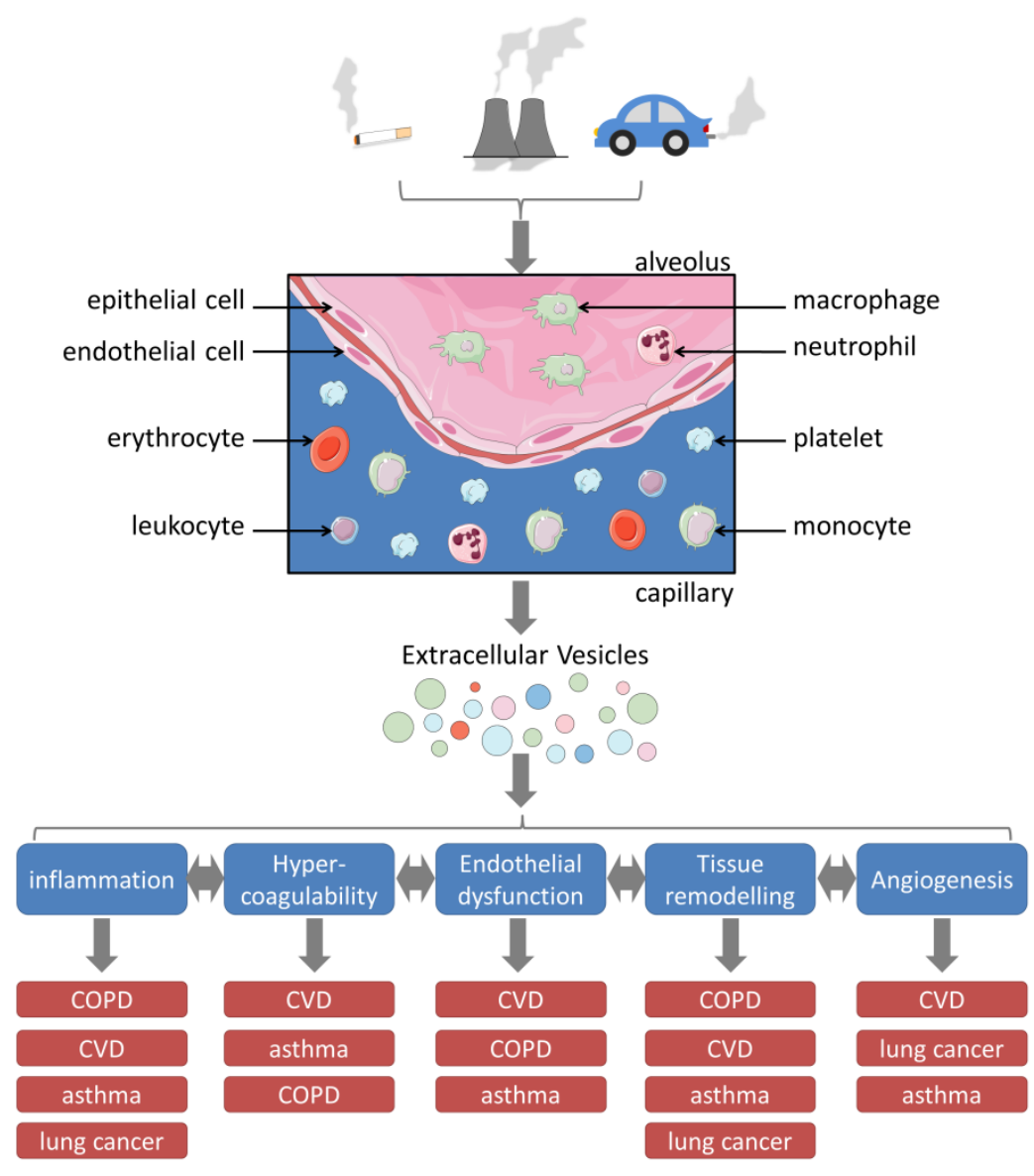

Figure 2 - Schematic representation of how respiratory exposure-induced EV may contribute to the pathogenesis of chronic diseases. Respiratory toxicants arise from CS, as well as occupational or environmental sources. Upon inhalation, they come in contact with several cell types of the lungs, including epithelial cells, endothelial cells, alveolar macrophages, monocytes and circulating blood cells. Exposure to respiratory toxicants causes increased release and altered composition of EV from different cellular sources. The respiratory exposure-induced EV may either remain in the lung lumen or are disseminated via the blood circulation. Locally at the site of exposure as well as systemically, they may promote inflammation, hypercoagulability, endothelial dysfunction, tissue remodeling and angiogenesis, all of which are interrelated and can further enhance each other. By promoting these biological processes, EV may contribute to the mechanistic link between respiratory exposures and the pathogenesis of respiratory exposure-associated diseases such as COPD, CVD, asthma and lung cancer. For each biological process, the diseases are sorted according to the strength of evidence for involvement of the respective process in their pathogenesis. This Figure contains elements from Servier Medical Art. 


\section{Technical requirements for future studies}

Although the presented findings are highly intriguing, it needs to be kept in mind that part of the studies were performed with outdated and/or suboptimal methodology for EV characterization and should be validated using more up-to-date methodology according to recent recommendations (Lotvall et al. 2014, Coumans et al. 2017). Similar effects to the ones reviewed here for EV are also mediated directly by respiratory exposures or by non-EV associated molecules such as proinflammatory cytokines, coagulation factors and proteolytic enzymes. Therefore, an important challenge for future studies will be establishing the relative importance of EV and free secreted molecules, which will require extensive side-by-side comparisons of isolated EV and EV-depleted biological fluids.

\section{Requirement for translational studies}

Another aspect that should be in the focus of future studies is strengthening of the translational link between functional in vitro experiments and observational human studies. It is striking that the literature largely consists of mechanistic in vitro studies that have not been verified in vivo on the one hand and observational human studies without strong mechanistic foundation on the other hand. The integrative view that this review provides of studies from different fields may help to determine relevant biological read-outs for future translational studies, which should focus on the functional characterization of circulating EV as well as EV from the lung lumen.

\section{Circulating extracellular vesicles}

There is ample evidence showing that toxic respiratory exposures enhance the concentrations of circulating EV. This has been most thoroughly investigated for EV of endothelial origin, but also leukocyte-, erythrocyte- and platelet-derived EV appear to be affected. However, functional analyses of circulating EV lack almost completely. Moreover, no clear link has yet been established between concentration and composition of circulating EV in healthy exposed individuals and the risk of developing respiratory exposure-associated diseases. It should also be explored whether circulating EV causally contribute to the high rate of comorbidity between COPD, lung cancer and CVD. With improved techniques for detection, isolation and characterization, circulating EV may develop into valuable biomarkers for cardiovascular risk in healthy individuals and patients with other chronic inflammatory disorders. 


\section{Extracellular vesicles from the lung lumen}

Translational studies investigating the contribution of respiratory exposure-induced EV to the pathogenesis of pulmonary diseases also need to focus on EV in the lung lumen, for instance by isolating them from BALF or sputum. In this context, $\mathrm{TF}^{+} \mathrm{EV}$ are of particular interest as they may promote fibrin deposition in alveoli and activation of pro-inflammatory signaling via protease activated receptors (PAR) (Witkowski et al. 2016, Bastarache et al. 2009). In the lung, EV may be derived from other cellular sources than in plasma, with a larger proportion of EV from epithelial cells and alveolar macrophages. Therefore, these EV may have different functions than circulating EV.

\section{Conclusions}

Two lines of evidence point towards an involvement of EV in respiratory exposureassociated diseases, such as CVD, COPD and lung cancer. First, in vitro studies demonstrated that exposures such as CS and PM enhance EV release and modify EV composition and functions, promoting inflammation, tissue remodeling and hypercoagulability. Second, observational human studies reported that circulating EV, particularly of endothelial origin, are elevated in individuals exposed to CS or PM. Yet, functional implications of these circulating EV have not been evaluated. Translational studies are required to bridge these findings and establish whether EV are important etiological factors in respiratory-exposure induced disease. 


\section{Funding}

This research was funded by the Netherlands Organization for Scientific Research (NWO) under grant 022.003.011 with the title NWO NUTRIM graduate programme awarded to BJB.

\section{Declaration of interest}

The authors declare that they have no actual or potential competing financial or other interests. 


\section{References}

Abels, E. R., and X. O. Breakefield. 2016. "Introduction to extracellular vesicles: Biogenesis, rna cargo selection, content, release, and uptake." Cell Mol Neurobiol 36: 301-312. doi: 10.1007/s10571016-0366-z.

Admyre, C., J. Grunewald, J. Thyberg, S. Gripenback, G. Tornling, A. Eklund, A. Scheynius, and S. Gabrielsson. 2003. "Exosomes with major histocompatibility complex class ii and co-stimulatory molecules are present in human bal fluid." Eur Respir J 22: 578-583.

Al-Muhsen, S., J. R. Johnson, and Q. Hamid. 2011. "Remodeling in asthma." J Allergy Clin Immunol 128: 451462; quiz 463-454. doi: 10.1016/j.jaci.2011.04.047.

Badrnya, S., R. Baumgartner, and A. Assinger. 2014. "Smoking alters circulating plasma microvesicle pattern and microrna signatures." Thromb Haemost 112: 128-136. doi: 10.1160/TH13-11-0977.

Barr, R. G. 2011. "The epidemiology of vascular dysfunction relating to chronic obstructive pulmonary disease and emphysema." Proc Am Thorac Soc 8: 522-527. doi: 10.1513/pats.201101-008MW.

Bartal, M. 2001. "Health effects of tobacco use and exposure." Monaldi Arch Chest Dis 56: 545-554.

Barua, R. S., M. Sharma, and K. N. Dileepan. 2015. "Cigarette smoke amplifies inflammatory response and atherosclerosis progression through activation of the h1r-tlr2/4-cox2 axis." Front Immunol 6: 572. doi: 10.3389/fimmu.2015.00572.

Bastarache, J. A., R. D. Fremont, J. A. Kropski, F. R. Bossert, and L. B. Ware. 2009. "Procoagulant alveolar microparticles in the lungs of patients with acute respiratory distress syndrome." Am J Physiol Lung Cell Mol Physiol 297: L1035-1041. doi: 10.1152/ajplung.00214.2009.

Beasley, V., P. V. Joshi, A. Singanayagam, P. L. Molyneaux, S. L. Johnston, and P. Mallia. 2012. "Lung microbiology and exacerbations in copd." Int J Chron Obstruct Pulmon Dis 7: 555-569. doi: 10.2147/COPD.S28286.

Benedikter, B. J., F. G. Bouwman, T. Vajen, A. C. A. Heinzmann, G. Grauls, E. C. Mariman, E. F. M. Wouters, P. H. Savelkoul, C. Lopez-Iglesias, R. R. Koenen, et al. 2017. "Ultrafiltration combined with size exclusion chromatography efficiently isolates extracellular vesicles from cell culture media for compositional and functional studies." Sci Rep 7: 15297. doi: 10.1038/s41598-017-15717-7.

Bonzini, M., L. Pergoli, L. Cantone, M. Hoxha, A. Spinazze, L. Del Buono, C. Favero, M. Carugno, L. Angelici, L. Broggi, et al. 2017. "Short-term particulate matter exposure induces extracellular vesicle release in overweight subjects." Environ Res 155: 228-234. doi: 10.1016/j.envres.2017.02.014.

Bourdonnay, E., Z. Zaslona, L. R. Penke, J. M. Speth, D. J. Schneider, S. Przybranowski, J. A. Swanson, P. Mancuso, C. M. Freeman, J. L. Curtis, et al. 2015. "Transcellular delivery of vesicular socs proteins from macrophages to epithelial cells blunts inflammatory signaling." J Exp Med 212: 729-742. doi: 10.1084/jem.20141675.

Bourdrel, T., M. A. Bind, Y. Bejot, O. Morel, and J. F. Argacha. 2017. "Cardiovascular effects of air pollution." Arch Cardiovasc Dis. doi: 10.1016/j.acvd.2017.05.003.

Brochu, P., J. F. Ducre-Robitaille, and J. Brodeur. 2006. "Physiological daily inhalation rates for free-living individuals aged 1 month to 96 years, using data from doubly labeled water measurements: A proposal for air quality criteria, standard calculations and health risk assessment." Human Ecol Risk Assess 12: 675-701. doi: 10.1080/10807030600801550.

Brostrom, J. M., Z. W. Ye, A. Axmon, M. Littorin, H. Tinnerberg, C. H. Lindh, H. Zheng, A. Ghalali, U. Stenius, B. A. Jonsson, et al. 2015. "Toluene diisocyanate: Induction of the autotaxin-lysophosphatidic acid axis and its association with airways symptoms." Toxicol Appl Pharmacol 287: 222-231. doi: 10.1016/j.taap.2015.06.006.

Burger, D., and R. M. Touyz. 2012. "Cellular biomarkers of endothelial health: Microparticles, endothelial progenitor cells, and circulating endothelial cells." J Am Soc Hypertens 6: 85-99. doi: 10.1016/j.jash.2011.11.003.

Camussi, G., M. C. Deregibus, S. Bruno, C. Grange, V. Fonsato, and C. Tetta. 2011. "Exosome/microvesiclemediated epigenetic reprogramming of cells." Am J Cancer Res 1: 98-110.

Chen, C. C., and C. Y. Yang. 2018. "Association between gaseous air pollution and hospital admissions for hypertension in taipei, taiwan." J Toxicol Environ Health A 81: 53-59. doi: 10.1080/15287394.2017.1395573.

Chen, Y., G. Li, Y. Liu, V. P. Werth, K. J. Williams, and M. L. Liu. 2016. "Translocation of endogenous danger signal hmgb1 from nucleus to membrane microvesicles in macrophages." J Cell Physiol 231: 23192326. doi: $10.1002 /$ jcp. 25352 .

Clarenbach, C. F., O. Senn, N. A. Sievi, G. Camen, A. J. van Gestel, V. A. Rossi, M. A. Puhan, R. Thurnheer, E. W. Russi, and M. Kohler. 2013. "Determinants of endothelial function in patients with copd." Eur Respir J 42: 1194-1204. doi: 10.1183/09031936.00144612. 
Cordazzo, C., S. Petrini, T. Neri, S. Lombardi, Y. Carmazzi, R. Pedrinelli, P. Paggiaro, and A. Celi. 2014. "Rapid shedding of proinflammatory microparticles by human mononuclear cells exposed to cigarette smoke is dependent on ca2+ mobilization." Inflamm Res 63: 539-547. doi: 10.1007/s00011-0140723-7.

Coumans, F. A. W., A. R. Brisson, E. I. Buzas, F. Dignat-George, E. E. E. Drees, S. El-Andaloussi, C. Emanueli, A. Gasecka, A. Hendrix, A. F. Hill, et al. 2017. "Methodological guidelines to study extracellular vesicles." Circ Res 120: 1632-1648. doi: 10.1161/CIRCRESAHA.117.309417.

Crotty Alexander, L. E., S. Shin, and J. H. Hwang. 2015. "Inflammatory diseases of the lung induced by conventional cigarette smoke: A review." Chest 148: 1307-1322. doi: 10.1378/chest.15-0409.

Csordas, A., and D. Bernhard. 2013. "The biology behind the atherothrombotic effects of cigarette smoke." Nat Rev Cardiol 10: 219-230. doi: 10.1038/nrcardio.2013.8.

Decramer, M., and W. Janssens. 2013. "Chronic obstructive pulmonary disease and comorbidities." Lancet Respir Med 1: 73-83. doi: 10.1016/S2213-2600(12)70060-7.

Demedts, I. K., T. Demoor, K. R. Bracke, G. F. Joos, and G. G. Brusselle. 2006. "Role of apoptosis in the pathogenesis of copd and pulmonary emphysema." Respir Res 7: 53. doi: 10.1186/1465-9921-753.

Dunbar, A., W. Gotsis, and W. Frishman. 2013. "Second-hand tobacco smoke and cardiovascular disease risk: An epidemiological review." Cardiol Rev 21: 94-100. doi: 10.1097/CRD.0b013e31827362e4.

Emmerechts, J., V. De Vooght, S. Haenen, S. Loyen, S. Van kerckhoven, B. Hemmeryckx, J. A. Vanoirbeek, P. H. Hoet, B. Nemery, and M. F. Hoylaerts. 2012a. "Thrombogenic changes in young and old mice upon subchronic exposure to air pollution in an urban roadside tunnel." Thromb Haemost 108: 756768. doi: 10.1160/TH12-03-0161.

Emmerechts, J., L. Jacobs, S. Van Kerckhoven, S. Loyen, C. Mathieu, F. Fierens, B. Nemery, T. S. Nawrot, and M. F. Hoylaerts. 2012b. "Air pollution-associated procoagulant changes: The role of circulating microvesicles." J Thromb Haemost 10: 96-106. doi: 10.1111/j.1538-7836.2011.04557.x.

Enjeti, A. K., A. Ariyarajah, A. D'Crus, M. Seldon, and L. F. Lincz. 2017. "Circulating microvesicle number, function and small rna content vary with age, gender, smoking status, lipid and hormone profiles." Thromb Res 156: 65-72. doi: 10.1016/j.thromres.2017.04.019.

Ezzati, M., and A. D. Lopez. 2003. "Estimates of global mortality attributable to smoking in 2000." Lancet 362: 847-852. doi: 10.1016/S0140-6736(03)14338-3.

Ferrante, G., R. Antona, V. Malizia, L. Montalbano, G. Corsello, and S. La Grutta. 2014. "Smoke exposure as a risk factor for asthma in childhood: A review of current evidence." Allergy Asthma Proc 35: 454461. doi: 10.2500/aap.2014.35.3789.

Foks, A. C., D. Engelbertsen, F. Kuperwaser, N. Alberts-Grill, A. Gonen, J. L. Witztum, J. Lederer, P. Jarolim, R. H. DeKruyff, G. J. Freeman, et al. 2016. "Blockade of tim-1 and tim-4 enhances atherosclerosis in low-density lipoprotein receptor-deficient mice." Arterioscler Thromb Vasc Biol 36: 456-465. doi: 10.1161/ATVBAHA.115.306860.

Folkesson, M., C. Li, S. Frebelius, J. Swedenborg, D. Wagsater, K. J. Williams, P. Eriksson, J. Roy, and M. L. Liu. 2015. "Proteolytically active adam 10 and adam 17 carried on membrane microvesicles in human abdominal aortic aneurysms." Thromb Haemost 114: 1165-1174. doi: 10.1160/TH14-10-0899.

Folkman, J. 1971. "Tumor angiogenesis: Therapeutic implications." N Engl J Med 285: 1182-1186. doi: 10.1056/NEJM197111182852108.

Frampton, M. W., J. Bausch, D. Chalupa, P. K. Hopke, E. L. Little, D. Oakes, J. C. Stewart, and M. J. Utell. 2012. "Effects of outdoor air pollutants on platelet activation in people with type 2 diabetes." Inhal Toxicol 24: 831-838. doi: 10.3109/08958378.2012.724117.

Frampton, M. W., A. Pietropaoli, M. Dentler, D. Chalupa, E. L. Little, J. Stewart, L. Frasier, D. Oakes, J. Wiltshire, R. Vora, et al. 2015. "Cardiovascular effects of ozone in healthy subjects with and without deletion of glutathione-s-transferase m1." Inhal Toxicol 27: 113-119. doi: 10.3109/08958378.2014.996272.

Franklin, B. A., R. Brook, and C. Arden Pope, 3rd. 2015. "Air pollution and cardiovascular disease." Curr Probl Cardiol 40: 207-238. doi: 10.1016/j.cpcardiol.2015.01.003.

Frohlich, E., A. Mercuri, S. Wu, and S. Salar-Behzadi. 2016. "Measurements of deposition, lung surface area and lung fluid for simulation of inhaled compounds." Front Pharmacol 7: 181. doi: 10.3389/fphar.2016.00181.

Fujita, Y., J. Araya, S. Ito, K. Kobayashi, N. Kosaka, Y. Yoshioka, T. Kadota, H. Hara, K. Kuwano, and T. Ochiya. 2015a. "Suppression of autophagy by extracellular vesicles promotes myofibroblast differentiation in copd pathogenesis." J Extracell Vesicles 4: 28388. doi: 10.3402/jev.v4.28388. 
Fujita, Y., N. Kosaka, J. Araya, K. Kuwano, and T. Ochiya. 2015b. "Extracellular vesicles in lung microenvironment and pathogenesis." Trends Mol Med 21: 533-542. doi: 10.1016/j.molmed.2015.07.004.

Gardiner, C., D. Di Vizio, S. Sahoo, C. Thery, K. W. Witwer, M. Wauben, and A. F. Hill. 2016. "Techniques used for the isolation and characterization of extracellular vesicles: Results of a worldwide survey." $J$ Extracell Vesicles 5: 32945. doi: 10.3402/jev.v5.32945.

Gimbrone, M. A., Jr., and G. Garcia-Cardena. 2016. "Endothelial cell dysfunction and the pathobiology of atherosclerosis." Circ Res 118: 620-636. doi: 10.1161/CIRCRESAHA.115.306301.

Gordon, C., K. Gudi, A. Krause, R. Sackrowitz, B. G. Harvey, Y. Strulovici-Barel, J. G. Mezey, and R. G. Crystal. 2011. "Circulating endothelial microparticles as a measure of early lung destruction in cigarette smokers." Am J Respir Crit Care Med 184: 224-232. doi: 10.1164/rccm.201012-20610C.

Gould, S. J., and G. Raposo. 2013. "As we wait: Coping with an imperfect nomenclature for extracellular vesicles." J Extracell Vesicles 2. doi: 10.3402/jev.v2i0.20389.

Grant, R., E. Ansa-Addo, D. Stratton, S. Antwi-Baffour, S. Jorfi, S. Kholia, L. Krige, S. Lange, and J. Inal. 2011. "A filtration-based protocol to isolate human plasma membrane-derived vesicles and exosomes from blood plasma." J Immunol Methods 371: 143-151. doi: 10.1016/j.jim.2011.06.024.

Guarnieri, M., and J. R. Balmes. 2014. "Outdoor air pollution and asthma." Lancet 383: 1581-1592. doi: 10.1016/S0140-6736(14)60617-6.

Heiss, C., N. Amabile, A. C. Lee, W. M. Real, S. F. Schick, D. Lao, M. L. Wong, S. Jahn, F. S. Angeli, P. Minasi, et al. 2008. "Brief secondhand smoke exposure depresses endothelial progenitor cells activity and endothelial function: Sustained vascular injury and blunted nitric oxide production." J Am Coll Cardiol 51: 1760-1771. doi: 10.1016/j.jacc.2008.01.040.

Heliot, A., Y. Landkocz, F. Roy Saint-Georges, P. Gosset, S. Billet, P. Shirali, D. Courcot, and P. J. Martin. 2017. "Smoker extracellular vesicles influence status of human bronchial epithelial cells." Int J Hyg Environ Health 220: 445-454. doi: 10.1016/j.ijheh.2016.12.010.

Houghton, A. M. 2013. "Mechanistic links between copd and lung cancer." Nat Rev Cancer 13: 233-245. doi: $10.1038 / \mathrm{nrc} 3477$.

ISTH Steering Committee for World Thrombosis Day. 2014. " Thrombosis: A major contributor to the global disease burden." J Thromb Haemost 12: 1580-1590. doi: 10.1111/jth.12698.

Kelly, F. J., and J. C. Fussell. 2015. "Air pollution and public health: Emerging hazards and improved understanding of risk." Environ Geochem Health 37: 631-649. doi: 10.1007/s10653-015-9720-1.

Kermanizadeh, A., I. Gosens, L. MacCalman, H. Johnston, P. H. Danielsen, N. R. Jacobsen, A. G. Lenz, T. Fernandes, R. P. Schins, F. R. Cassee, et al. 2016. "A multilaboratory toxicological assessment of a panel of 10 engineered nanomaterials to human health--enpra project--the highlights, limitations, and current and future challenges." J Toxicol Environ Health B Crit Rev 19: 1-28. doi: 10.1080/10937404.2015.1126210.

Kowal, J., G. Arras, M. Colombo, M. Jouve, J. P. Morath, B. Primdal-Bengtson, F. Dingli, D. Loew, M. Tkach, and C. Thery. 2016. "Proteomic comparison defines novel markers to characterize heterogeneous populations of extracellular vesicle subtypes." Proc Natl Acad Sci U S A 113: E968-977. doi: 10.1073/pnas.1521230113.

Lacroix, R., and F. Dignat-George. 2013. "Microparticles: New protagonists in pericellular and intravascular proteolysis." Semin Thromb Hemost 39: 33-39. doi: 10.1055/s-0032-1333310.

Lamprecht, B., M. A. McBurnie, W. M. Vollmer, G. Gudmundsson, T. Welte, E. Nizankowska-Mogilnicka, M. Studnicka, E. Bateman, J. M. Anto, P. Burney, et al. 2011. "Copd in never smokers: Results from the population-based burden of obstructive lung disease study." Chest 139: 752-763. doi: 10.1378/chest.10-1253.

Lasser, C., S. E. O'Neil, L. Ekerljung, K. Ekstrom, M. Sjostrand, and J. Lotvall. 2011. "Rna-containing exosomes in human nasal secretions." Am J Rhinol Allergy 25: 89-93. doi: 10.2500/ajra.2011.25.3573.

Lee, F., and D. A. Lawrence. 2018. "From infections to anthropogenic inflicted pathologies: Involvement of immune balance." J Toxicol Environ Health B Crit Rev 21: 24-46. doi: 10.1080/10937404.2017.1412212.

Lee, S. B., J. H. Kim, M. H. Cho, E. S. Choe, K. S. Kim, and S. M. Shim. 2017. "Impact of commercial cigarette smoke condensate on brain tissue co-cultured with astrocytes and blood-brain barrier endothelial cells." J Toxicol Environ Health A 80: 533-541. doi: 10.1080/15287394.2017.1355863.

Levanen, B., N. R. Bhakta, P. Torregrosa Paredes, R. Barbeau, S. Hiltbrunner, J. L. Pollack, C. M. Skold, M. Svartengren, J. Grunewald, S. Gabrielsson, et al. 2013. "Altered microrna profiles in bronchoalveolar lavage fluid exosomes in asthmatic patients." J Allergy Clin Immunol 131: 894903. doi: 10.1016/j.jaci.2012.11.039. 
Li, M., D. Yu, K. J. Williams, and M. L. Liu. 2010. "Tobacco smoke induces the generation of procoagulant microvesicles from human monocytes/macrophages." Arterioscler Thromb Vasc Biol 30: 18181824. doi: 10.1161/ATVBAHA.110.209577.

Li, C. J., Y. Liu, Y. Chen, D. Yu, K. J. Williams, and M. L. Liu. 2013. "Novel proteolytic microvesicles released from human macrophages after exposure to tobacco smoke." Am J Pathol 182: 1552-1562. doi: 10.1016/j.ajpath.2013.01.035.

Lim, Jung-hee, Mi-Kyung Song, Yoon Cho, Woong Kim, Sung Ok Han, and Jae-Chun Ryu. 2016. "Expression of exosomal and cellular micrornas: As biomarkers for toluene, ethylbenzene, xylene (tex) exposure." Molecular \& Cellular Toxicology 12: 359-369. doi: 10.1007/s13273-016-0040-z.

Liu, H., L. Ding, Y. Zhang, and S. Ni. 2014. "Circulating endothelial microparticles involved in lung function decline in a rat exposed in cigarette smoke maybe from apoptotic pulmonary capillary endothelial cells." J Thorac Dis 6: 649-655. doi: 10.3978/j.issn.2072-1439.2014.06.26.

Lotvall, J., A. F. Hill, F. Hochberg, E. I. Buzas, D. Di Vizio, C. Gardiner, Y. S. Gho, I. V. Kurochkin, S. Mathivanan, P. Quesenberry, et al. 2014. "Minimal experimental requirements for definition of extracellular vesicles and their functions: A position statement from the international society for extracellular vesicles." J Extracell Vesicles 3: 26913. doi: 10.3402/jev.v3.26913.

Loyer, X., A. C. Vion, A. Tedgui, and C. M. Boulanger. 2014. "Microvesicles as cell-cell messengers in cardiovascular diseases." Circ Res 114: 345-353. doi: 10.1161/CIRCRESAHA.113.300858.

Lozano, R., M. Naghavi, K. Foreman, S. Lim, K. Shibuya, V. Aboyans, J. Abraham, T. Adair, R. Aggarwal, S. Y. Ahn, et al. 2012. "Global and regional mortality from 235 causes of death for 20 age groups in 1990 and 2010: A systematic analysis for the global burden of disease study 2010." Lancet 380: 2095-2128. doi: 10.1016/S0140-6736(12)61728-0.

Maas, S. L., J. De Vrij, and M. L. Broekman. 2014. "Quantification and size-profiling of extracellular vesicles using tunable resistive pulse sensing." J Vis Exp: e51623. doi: 10.3791/51623.

Malvezzi, M., P. Bertuccio, T. Rosso, M. Rota, F. Levi, C. La Vecchia, and E. Negri. 2015. "European cancer mortality predictions for the year 2015: Does lung cancer have the highest death rate in eu women?" Ann Oncol 26: 779-786. doi: 10.1093/annonc/mdv001.

McCubbrey, A. L., and J. L. Curtis. 2013. "Efferocytosis and lung disease." Chest 143: 1750-1757. doi: 10.1378/chest.12-2413.

Messner, B., and D. Bernhard. 2014. "Smoking and cardiovascular disease: Mechanisms of endothelial dysfunction and early atherogenesis." Arterioscler Thromb Vasc Biol 34: 509-515. doi: 10.1161/ATVBAHA.113.300156.

Michel, J. B., J. L. Martin-Ventura, A. Nicoletti, and B. Ho-Tin-Noe. 2014. "Pathology of human plaque vulnerability: Mechanisms and consequences of intraplaque haemorrhages." Atherosclerosis 234: 311-319. doi: 10.1016/j.atherosclerosis.2014.03.020.

Minciacchi, V. R., M. R. Freeman, and D. Di Vizio. 2015. "Extracellular vesicles in cancer: Exosomes, microvesicles and the emerging role of large oncosomes." Semin Cell Dev Biol 40: 41-51. doi: 10.1016/j.semcdb.2015.02.010.

Mobarrez, F., L. Antoniewicz, J. A. Bosson, J. Kuhl, D. S. Pisetsky, and M. Lundback. 2014. "The effects of smoking on levels of endothelial progenitor cells and microparticles in the blood of healthy volunteers." PLoS One 9: e90314. doi: 10.1371/journal.pone.0090314.

Moon, H. G., S. H. Kim, J. Gao, T. Quan, Z. Qin, J. C. Osorio, I. O. Rosas, M. Wu, Y. Tesfaigzi, and Y. Jin. 2014. "Ccn 1 secretion and cleavage regulate the lung epithelial cell functions after cigarette smoke." Am J Physiol Lung Cell Mol Physiol 307: L326-337. doi: 10.1152/ajplung.00102.2014.

Neri, T., L. Pergoli, S. Petrini, L. Gravendonk, C. Balia, V. Scalise, A. Amoruso, R. Pedrinelli, P. Paggiaro, V. Bollati, et al. 2016. "Particulate matter induces prothrombotic microparticle shedding by human mononuclear and endothelial cells." Toxicol In Vitro 32: 333-338. doi: 10.1016/j.tiv.2016.02.001.

Nolte-'t Hoen, E. N., E. J. van der Vlist, M. Aalberts, H. C. Mertens, B. J. Bosch, W. Bartelink, E. Mastrobattista, E. V. van Gaal, W. Stoorvogel, G. J. Arkesteijn, et al. 2012. "Quantitative and qualitative flow cytometric analysis of nanosized cell-derived membrane vesicles." Nanomedicine 8: 712-720. doi: 10.1016/j.nano.2011.09.006.

Paciencia, I., J. Madureira, J. Rufo, A. Moreira, and O. Fernandes Ede. 2016. "A systematic review of evidence and implications of spatial and seasonal variations of volatile organic compounds (voc) in indoor human environments." J Toxicol Environ Health B Crit Rev 19: 47-64. doi: 10.1080/10937404.2015.1134371.

Palgan, K., and Z. Bartuzi. 2015. "Angiogenesis in bronchial asthma." Int J Immunopathol Pharmacol 28: 415420. doi: $10.1177 / 0394632015580907$. 
Pavanello, S., M. Bonzini, L. Angelici, V. Motta, L. Pergoli, M. Hoxha, L. Cantone, A. C. Pesatori, P. Apostoli, A. Tripodi, et al. 2016. "Extracellular vesicle-driven information mediates the long-term effects of particulate matter exposure on coagulation and inflammation pathways." Toxicol Lett 259: 143150. doi: 10.1016/j.toxlet.2016.08.002.

Pergoli, L., L. Cantone, C. Favero, L. Angelici, S. Iodice, E. Pinatel, M. Hoxha, L. Dioni, M. Letizia, B. Albetti, et al. 2017. "Extracellular vesicle-packaged mirna release after short-term exposure to particulate matter is associated with increased coagulation." Part Fibre Toxicol 14: 32. doi: 10.1186/s12989017-0214-4.

Piazza, G., and S. Z. Goldhaber. 2010. "Venous thromboembolism and atherothrombosis: An integrated approach." Circulation 121: 2146-2150. doi: 10.1161/CIRCULATIONAHA.110.951236.

Pickup, M. W., J. K. Mouw, and V. M. Weaver. 2014. "The extracellular matrix modulates the hallmarks of cancer." EMBO Rep 15: 1243-1253. doi: 10.15252/embr.201439246.

Pope, C. A., 3rd, A. Bhatnagar, J. P. McCracken, W. Abplanalp, D. J. Conklin, and T. O'Toole. 2016. "Exposure to fine particulate air pollution is associated with endothelial injury and systemic inflammation." Circ Res 119: 1204-1214. doi: 10.1161/CIRCRESAHA.116.309279.

Rahib, L., B. D. Smith, R. Aizenberg, A. B. Rosenzweig, J. M. Fleshman, and L. M. Matrisian. 2014. "Projecting cancer incidence and deaths to 2030: The unexpected burden of thyroid, liver, and pancreas cancers in the united states." Cancer Res 74: 2913-2921. doi: 10.1158/0008-5472.CAN-14-0155.

Rigotti, N. A., and C. Clair. 2013. "Managing tobacco use: The neglected cardiovascular disease risk factor." Eur Heart J 34: 3259-3267. doi: 10.1093/eurheartj/eht352.

Rodosthenous, R. S., B. A. Coull, Q. Lu, P. S. Vokonas, J. D. Schwartz, and A. A. Baccarelli. 2016. "Ambient particulate matter and micrornas in extracellular vesicles: A pilot study of older individuals." Part Fibre Toxicol 13: 13. doi: 10.1186/s12989-016-0121-0.

Sabatier, F., L. Camoin-Jau, F. Anfosso, J. Sampol, and F. Dignat-George. 2009. "Circulating endothelial cells, microparticles and progenitors: Key players towards the definition of vascular competence." J Cell Mol Med 13: 454-471. doi: 10.1111/j.1582-4934.2008.00639.x.

Salazar, L. M., and A. M. Herrera. 2011. "Fibrotic response of tissue remodeling in copd." Lung 189: 101-109. doi: 10.1007/s00408-011-9279-2.

Salvi, S. S., and P. J. Barnes. 2009. "Chronic obstructive pulmonary disease in non-smokers." Lancet 374: 733-743. doi: 10.1016/S0140-6736(09)61303-9.

Schneider, D. J., J. M. Speth, L. R. Penke, S. H. Wettlaufer, J. A. Swanson, and M. Peters-Golden. 2017. "Mechanisms and modulation of microvesicle uptake in a model of alveolar cell communication." $J$ Biol Chem. doi: 10.1074/jbc.M117.792416.

Schrijvers, D. M., G. R. De Meyer, M. M. Kockx, A. G. Herman, and W. Martinet. 2005. "Phagocytosis of apoptotic cells by macrophages is impaired in atherosclerosis." Arterioscler Thromb Vasc Biol 25: 1256-1261. doi: 10.1161/01.ATV.0000166517.18801.a7.

Serban, K. A., S. Rezania, D. N. Petrusca, C. Poirier, D. Cao, M. J. Justice, M. Patel, I. Tsvetkova, K. Kamocki, A. Mikosz, et al. 2016. "Structural and functional characterization of endothelial microparticles released by cigarette smoke." Sci Rep 6: 31596. doi: 10.1038/srep31596.

Severinsen, M. T., S. R. Kristensen, S. P. Johnsen, C. Dethlefsen, A. Tjonneland, and K. Overvad. 2009. "Smoking and venous thromboembolism: A danish follow-up study." J Thromb Haemost 7: 12971303. doi: $10.1111 / \mathrm{j} .1538-7836.2009 .03490 . x$.

Sharma, M. 2010. "Understanding the mechanism of toxicity of carbon nanoparticles in humans in the new millennium: A systemic review." Indian J Occup Environ Med 14: 3-5. doi: 10.4103/00195278.64607.

Sheller, S., J. Papaconstantinou, R. Urrabaz-Garza, L. Richardson, G. Saade, C. Salomon, and R. Menon. 2016. "Amnion-epithelial-cell-derived exosomes demonstrate physiologic state of cell under oxidative stress." PLoS One 11: e0157614. doi: 10.1371/journal.pone.0157614.

Siasos, G., V. Tsigkou, E. Kokkou, E. Oikonomou, M. Vavuranakis, C. Vlachopoulos, A. Verveniotis, M. Limperi, V. Genimata, A. G. Papavassiliou, et al. 2014. "Smoking and atherosclerosis: Mechanisms of disease and new therapeutic approaches." Curr Med Chem 21: 3936-3948.

Sokolova, V., A. K. Ludwig, S. Hornung, O. Rotan, P. A. Horn, M. Epple, and B. Giebel. 2011. "Characterisation of exosomes derived from human cells by nanoparticle tracking analysis and scanning electron microscopy." Colloids Surf B Biointerfaces 87: 146-150. doi: 10.1016/j.colsurfb.2011.05.013.

Song, Q., D. C. Christiani, XiaorongWang, and J. Ren. 2014. "The global contribution of outdoor air pollution to the incidence, prevalence, mortality and hospital admission for chronic obstructive pulmonary disease: A systematic review and meta-analysis." Int J Environ Res Public Health 11: 11822-11832. doi: 10.3390/ijerph111111822. 
Stewart, J. C., D. C. Chalupa, R. B. Devlin, L. M. Frasier, L. S. Huang, E. L. Little, S. M. Lee, R. P. Phipps, A. P. Pietropaoli, M. B. Taubman, et al. 2010. "Vascular effects of ultrafine particles in persons with type 2 diabetes." Environ Health Perspect 118: 1692-1698. doi: 10.1289/ehp.1002237.

Strulovici-Barel, Y., M. R. Staudt, A. Krause, C. Gordon, A. E. Tilley, B. G. Harvey, R. J. Kaner, C. Hollmann, J. G. Mezey, H. Bitter, et al. 2016. "Persistence of circulating endothelial microparticles in copd despite smoking cessation." Thorax 71: 1137-1144. doi: 10.1136/thoraxjnl-2015-208274.

Suarez, H., A. Gamez-Valero, R. Reyes, S. Lopez-Martin, M. J. Rodriguez, J. L. Carrascosa, C. Cabanas, F. E. Borras, and M. Yanez-Mo. 2017. "A bead-assisted flow cytometry method for the semiquantitative analysis of extracellular vesicles." Sci Rep 7: 11271. doi: 10.1038/s41598-01711249-2.

Takahashi, T., S. Kobayashi, N. Fujino, T. Suzuki, C. Ota, M. He, M. Yamada, S. Suzuki, M. Yanai, S. Kurosawa, et al. 2012. "Increased circulating endothelial microparticles in copd patients: A potential biomarker for copd exacerbation susceptibility." Thorax 67: 1067-1074. doi: 10.1136/thoraxjnl-2011201395.

Tarlo, S. M., and C. Lemiere. 2014. "Occupational asthma." $N$ Engl J Med 370: 640-649. doi: 10.1056/NEJMra1301758.

Taylor, D. D., and S. Shah. 2015. "Methods of isolating extracellular vesicles impact down-stream analyses of their cargoes." Methods 87: 3-10. doi: 10.1016/j.ymeth.2015.02.019.

Thery, C., M. Ostrowski, and E. Segura. 2009. "Membrane vesicles as conveyors of immune responses." Nat Rev Immunol 9: 581-593. doi: 10.1038/nri2567.

Thun, M. J., B. D. Carter, D. Feskanich, N. D. Freedman, R. Prentice, A. D. Lopez, P. Hartge, and S. M. Gapstur. 2013. "50-year trends in smoking-related mortality in the united states." $N$ Engl J Med 368: 351364. doi: 10.1056/NEJMsa1211127.

Umbright, C., R. Sellamuthu, J. R. Roberts, S. H. Young, D. Richardson, D. Schwegler-Berry, W. McKinney, B. Chen, J. K. Gu, M. Kashon, et al. 2017. "Pulmonary toxicity and global gene expression changes in response to sub-chronic inhalation exposure to crystalline silica in rats." J Toxicol Environ Health A 80: 1349-1368. doi: 10.1080/15287394.2017.1384773.

Valavanidis, A., T. Vlachogianni, K. Fiotakis, and S. Loridas. 2013. "Pulmonary oxidative stress, inflammation and cancer: Respirable particulate matter, fibrous dusts and ozone as major causes of lung carcinogenesis through reactive oxygen species mechanisms." Int J Environ Res Public Health 10: 3886-3907. doi: 10.3390/ijerph10093886.

van der Pol, E., A. G. Hoekstra, A. Sturk, C. Otto, T. G. van Leeuwen, and R. Nieuwland. 2010. "Optical and non-optical methods for detection and characterization of microparticles and exosomes." $J$ Thromb Haemost 8: 2596-2607. doi: 10.1111/j.1538-7836.2010.04074.x.

van Es, N., S. Bleker, A. Sturk, and R. Nieuwland. 2015. "Clinical significance of tissue factor-exposing microparticles in arterial and venous thrombosis." Semin Thromb Hemost 41: 718-727. doi: $10.1055 / \mathrm{s}-0035-1556047$.

van Niel, G., G. D'Angelo, and G. Raposo. 2018. "Shedding light on the cell biology of extracellular vesicles." Nat Rev Mol Cell Biol 19: 213-228. doi: 10.1038/nrm.2017.125.

Volgers, C., B. J. Benedikter, G. E. Grauls, P. H. M. Savelkoul, and F. R. M. Stassen. 2017. "Bead-based flowcytometry for semi-quantitative analysis of complex membrane vesicle populations released by bacteria and host cells." Microbiol Res 200: 25-32. doi: 10.1016/j.micres.2017.04.003.

Wang, Z., S. M. May, S. Charoenlap, R. Pyle, N. L. Ott, K. Mohammed, and A. Y. Joshi. 2015. "Effects of secondhand smoke exposure on asthma morbidity and health care utilization in children: A systematic review and meta-analysis." Ann Allergy Asthma Immunol 115: 396-401 e392. doi: 10.1016/j.anai.2015.08.005.

Weichenthal, S., J. A. Hoppin, and F. Reeves. 2014. "Obesity and the cardiovascular health effects of fine particulate air pollution." Obesity (Silver Spring) 22: 1580-1589. doi: 10.1002/oby.20748.

Witkowski, M., U. Landmesser, and U. Rauch. 2016. "Tissue factor as a link between inflammation and coagulation." Trends Cardiovasc Med 26: 297-303. doi: 10.1016/j.tcm.2015.12.001.

Wolf, P. 1967. "The nature and significance of platelet products in human plasma." Br J Haematol 13: 269288.

Xu, J., M. Yang, P. Kosterin, B. M. Salzberg, T. N. Milovanova, V. M. Bhopale, and S. R. Thom. 2013. "Carbon monoxide inhalation increases microparticles causing vascular and cns dysfunction." Toxicol Appl Pharmacol 273: 410-417. doi: 10.1016/j.taap.2013.09.019.

$\mathrm{Xu}, \mathrm{L}$., and X. Deng. 2004. "Tobacco-specific nitrosamine 4-(methylnitrosamino)-1-(3-pyridyl)-1-butanone induces phosphorylation of mu- and m-calpain in association with increased secretion, cell migration, and invasion." J Biol Chem 279: 53683-53690. doi: 10.1074/jbc.M409889200. 
Review article - EVs in respiratory exposure-induced diseases | 51

Zhu, M., Y. Li, J. Shi, W. Feng, G. Nie, and Y. Zhao. 2012. "Exosomes as extrapulmonary signaling conveyors for nanoparticle-induced systemic immune activation." Small 8: 404-412. doi: 10.1002/smll.201101708. 
Table $\mathrm{S}_{1}$ - Overview of all identified articles in which the effects of CS and related exposures on EV were investigated. AMD, age-related macular degenration; B(a)P, Benzo(a)Pyrene; BALF, bronchoalveolar lavage fluid; CS, cigarette smoke; CSE, cigarette smoke extract; CVD, cardiovascular disease; COPD, chronic obstructive pulmonary disease; EM, electron microscopy; EV, extracellular vesicle; FA, functional assays; FC, flow cytometry; FCS, fetal calf serum; MS, mass spectrometry; NNK, Nitrosamine 4-(Methylnitrosamino)-1-(3-pyridyl)-1- butanone; PPP, platelet-poor plasma

\begin{tabular}{|c|c|c|c|c|c|c|c|c|c|c|c|c|}
\hline Reference & $\begin{array}{l}\text { Study } \\
\text { type }\end{array}$ & Exposure & $\begin{array}{l}\text { study population (in vivo)/ } \\
\text { cell type (in vitro) }\end{array}$ & EV source & EV isolation & EV characterization & $\begin{array}{l}\text { EV termi- } \\
\text { nology }\end{array}$ & $\begin{array}{l}\text { Inflamma } \\
\text {-tion }\end{array}$ & $\begin{array}{l}\text { Hyper- } \\
\text { coagula- } \\
\text { bility }\end{array}$ & $\begin{array}{l}\text { Endothe- } \\
\text { lial dys- } \\
\text { function }\end{array}$ & $\begin{array}{l}\text { tissue } \\
\text { remo- } \\
\text { delling }\end{array}$ & $\begin{array}{l}\text { Investigated } \\
\text { pathology }\end{array}$ \\
\hline $\begin{array}{l}\text { Casey et al. } \\
(2004)\end{array}$ & human & CS & $\begin{array}{l}\text { healthy male non-smokers }(n=9) \\
\text { healthy male smokers }(n=10)\end{array}$ & $\begin{array}{c}\text { platelet } \\
\text { supernatants }\end{array}$ & no isolation & direct FC & $\begin{array}{c}\text { micro- } \\
\text { particles }\end{array}$ & n.d. & $\rightarrow$ & $\rightarrow$ & n.d. & CVD \\
\hline $\begin{array}{l}\mathrm{Xu} \text { and Deng } \\
(2004)\end{array}$ & in vitro & NNK & human lung carcinoma cells & $\begin{array}{l}\text { media, } \\
0.1 \% \text { FCS }\end{array}$ & $100,000 \times g$ & FA & $\begin{array}{l}\text { (media) } \\
\text { vesicles }\end{array}$ & n.d. & n.d. & n.d. & $\uparrow$ & lung cancer \\
\hline $\begin{array}{l}\text { Heiss et al. } \\
\text { (2008) }\end{array}$ & human & $\begin{array}{l}\text { second } \\
\text { hand CS }\end{array}$ & $\begin{array}{l}\text { healthy non-smokers }(n=10) \\
\text { randomized crossover }\end{array}$ & PPP, citrate & no isolation & direct FC & $\begin{array}{c}\text { micro- } \\
\text { particles }\end{array}$ & n.d. & n.d. & $\uparrow$ & n.d. & CVD \\
\hline $\begin{array}{l}\text { Wang et al. } \\
\text { (2009) }\end{array}$ & $\begin{array}{l}\text { in vitro } \\
\text { animal }\end{array}$ & $B(a) P$ & $\begin{array}{l}\text { human retinal pigment epithelial cells } \\
\text { murine eyes }(n=5)\end{array}$ & not applicable & no isolation & exosome markers & $\begin{array}{l}\text { exo- } \\
\text { somes }\end{array}$ & $\uparrow$ & n.d. & n.d. & n.d. & AMD \\
\hline $\begin{array}{l}\text { Alcazar et al. } \\
\text { (2009) }\end{array}$ & in vitro & $\begin{array}{c}\text { Hydro- } \\
\text { quinone }\end{array}$ & human retinal pigment epithelial cells & media, $0.1 \%$ FCS & $\begin{array}{l}\text { others } \\
(100 \times \mathrm{g})\end{array}$ & $\begin{array}{c}\text { fluorescene } \\
\text { microscopy } \\
\text { exosome markers } \\
\text { MS } \\
\text { FA }\end{array}$ & $\begin{array}{l}\text { mem- } \\
\text { brane } \\
\text { blebs }\end{array}$ & $\uparrow$ & n.d. & n.d. & $\uparrow$ & AMD \\
\hline $\begin{array}{l}\text { Li et al. } \\
(2010)\end{array}$ & in vitro & CSE & $\begin{array}{l}\text { human monocytes and monocyte-derived } \\
\text { macrophages }\end{array}$ & media, FCS-free & no isolation & direct FC & $\begin{array}{l}\text { micro- } \\
\text { vesicles }\end{array}$ & n.d. & $\uparrow$ & n.d. & n.d. & CVD \\
\hline $\begin{array}{l}\text { Gordon et } \\
\text { al. (2011) }\end{array}$ & human & CS & $\begin{array}{l}\text { non-smokers ( } \mathrm{n}=32 / 10 \text {; discovery/validation) } \\
\text { smokers }(\mathrm{n}=41 / 20 \text {; discovery/validation) } \\
\text { smokers with low DLCO }(\mathrm{n}=19 / 15 ; \\
\text { discovery/validation) }\end{array}$ & PPP, citrate & no isolation & direct FC & $\begin{array}{c}\text { micro- } \\
\text { particles }\end{array}$ & n.d. & n.d. & $\uparrow$ & $\uparrow$ & COPD \\
\hline $\begin{array}{l}\text { Grant et al. } \\
\quad(2011)\end{array}$ & $\begin{array}{l}\text { human } \\
\text { in vitro }\end{array}$ & $\begin{array}{c}\mathrm{CS} \\
\text { nicotine }\end{array}$ & $\begin{array}{l}\text { healthy volunteers }(\mathrm{n}=57) \text { including smokers } \\
(\mathrm{n}=\text { ?) } \\
\text { monocytes }\end{array}$ & $\begin{array}{c}\text { PPP, citrate } \\
\text { media, FCS-free }\end{array}$ & $10,000 \times g$ & $\begin{array}{l}\text { direct FC } \\
\text { EM }\end{array}$ & $\begin{array}{l}\text { micro- } \\
\text { vesicles }\end{array}$ & $\downarrow$ & $\downarrow$ & n.d. & n.d. & none \\
\hline $\begin{array}{l}\text { Li et al. } \\
\text { (2013) }\end{array}$ & in vitro & CSE & human monocyte-derived macrophages & media, FCS-free & $100,000 \times g$ & $\begin{array}{c}\text { direct FC } \\
\text { functional analysis }\end{array}$ & $\begin{array}{l}\text { micro- } \\
\text { vesicles }\end{array}$ & n.d. & n.d. & n.d. & $\uparrow$ & $\begin{array}{l}\text { CVD } \\
\text { COPD }\end{array}$ \\
\hline $\begin{array}{l}\text { Takahashi et } \\
\text { al. (2013) }\end{array}$ & in vitro & CSE & $\begin{array}{l}\text { human lung microvascular endothelial cells } \\
\text { human aortic endothelial cells }\end{array}$ & media, $5 \%$ FCS & $10,000 \times g$ & direct FC & $\begin{array}{c}\text { micro- } \\
\text { particles }\end{array}$ & n.d. & n.d. & $\uparrow$ & n.d. & COPD \\
\hline $\begin{array}{l}\text { Cordazzo et } \\
\text { al. (2014) }\end{array}$ & in vitro & CSE & human peripheral blood mononuclear cells & media, FCS-free & $100,000 \times g$ & $\begin{array}{l}\text { direct FC } \\
\text { FA }\end{array}$ & $\begin{array}{c}\text { micro- } \\
\text { particles }\end{array}$ & $\uparrow$ & $\uparrow$ & n.d. & n.d. & $\begin{array}{l}\text { COPD } \\
\text { CVD }\end{array}$ \\
\hline $\begin{array}{l}\text { Badrnya et } \\
\text { al. (2014) }\end{array}$ & human & CS & $\begin{array}{l}\text { healthy non-smokers }(n=20) \\
\text { healthy smokers }(n=20)\end{array}$ & PPP, citrate & $10,000 \times g$ & direct FC & $\begin{array}{l}\text { micro- } \\
\text { vesicles }\end{array}$ & $\downarrow$ & $\downarrow \rightarrow$ & $\rightarrow$ & n.d. & CVD \\
\hline $\begin{array}{l}\text { Mobarrez et } \\
\text { al. (2014) }\end{array}$ & human & CS & intermittent smokers ( $\mathrm{n}=12$ ) & PPP, citrate & no isolation & direct FC & $\begin{array}{l}\text { micro- } \\
\text { particles }\end{array}$ & $\rightarrow$ & n.d. & $\uparrow$ & n.d. & CVD \\
\hline $\begin{array}{l}\text { Liu et al. } \\
\text { (2014) }\end{array}$ & animal & CS & $\begin{array}{l}\text { Wistar rats; } 6 \text { groups, } n=10 \text { per group } \\
\text { CS-exposed vs. air-exposed for } 2,4 \text { and } 6\end{array}$ & PPP, citrate & no isolation & direct FC & $\begin{array}{c}\text { micro- } \\
\text { particles }\end{array}$ & n.d. & n.d. & $\uparrow$ & n.d. & COPD \\
\hline
\end{tabular}




\begin{tabular}{|c|c|c|c|c|c|c|c|c|c|c|c|c|}
\hline Reference & $\begin{array}{l}\text { Study } \\
\text { type }\end{array}$ & Exposure & $\begin{array}{l}\text { study population (in vivo)/ } \\
\text { cell type (in vitro) }\end{array}$ & EV source & $\mathrm{EV}$ isolation & $\mathrm{EV}$ characterization & $\begin{array}{l}\text { EV termi- } \\
\text { nology }\end{array}$ & $\begin{array}{l}\text { Inflamma } \\
\text {-tion }\end{array}$ & $\begin{array}{l}\text { Hyper- } \\
\text { coagula- } \\
\text { bility }\end{array}$ & $\begin{array}{l}\text { Endothe- } \\
\text { lial dys- } \\
\text { function }\end{array}$ & $\begin{array}{l}\text { tissue } \\
\text { remo- } \\
\text { delling }\end{array}$ & $\begin{array}{l}\text { Investigated } \\
\text { pathology }\end{array}$ \\
\hline \multicolumn{13}{|c|}{ months } \\
\hline $\begin{array}{l}\text { Moon et al. } \\
\text { (2014) }\end{array}$ & in vitro & CSE & human bronchial epithelial cells & media, $10 \%$ FCS & $100,000 \times g$ & $\begin{array}{c}\text { EM } \\
\text { exosome markers } \\
\text { direct FC } \\
\text { FA }\end{array}$ & $\begin{array}{l}\text { exo- } \\
\text { somes }\end{array}$ & $\uparrow$ & n.d. & n.d. & $\uparrow$ & COPD \\
\hline $\begin{array}{l}\text { Bourdonnay } \\
\text { et al. (2015) }\end{array}$ & in vitro & CS & rat alveolar macrophages & $\begin{array}{l}\text { media, FCS-free } \\
\text { (?) }\end{array}$ & $\begin{array}{l}10,000 \times g- \\
\text { microparticles } \\
100,000 \times g- \\
\text { exosomes }\end{array}$ & $\begin{array}{l}\text { direct FC } \\
\text { fluorescence } \\
\text { microscopy } \\
\text { FA }\end{array}$ & $\begin{array}{l}\text { micro- } \\
\text { particles } \\
\text { exo- } \\
\text { somes }\end{array}$ & $\uparrow$ & n.d. & n.d. & n.d. & $\begin{array}{l}\text { no specific } \\
\text { disease }\end{array}$ \\
\hline $\begin{array}{l}\text { Scruggs et } \\
\text { al. (2015) }\end{array}$ & in vitro & CSE & $\begin{array}{l}\text { human pulmonary microvascular endothelial } \\
\text { cells, } \\
\text { pulmonary artery endothelial cells, } \\
\text { aortic endothelial cells, } \\
\text { pulmonary artery smooth muscle cells }\end{array}$ & media, FCS-free & $100,000 \times g$ & $\begin{array}{c}\text { EM } \\
\text { direct FC }\end{array}$ & $\begin{array}{l}\text { micro- } \\
\text { particles }\end{array}$ & n.d. & n.d. & n.d. & n.d. & $\begin{array}{c}\text { no specific } \\
\text { disease }\end{array}$ \\
\hline $\begin{array}{l}\text { Liu et al. } \\
\text { (2016) }\end{array}$ & in vitro & CSE & human bronchial epithelial cells & media, $10 \%$ FCS & precipitation & $\begin{array}{l}\text { EM } \\
\text { exosome markers } \\
\text { FA }\end{array}$ & $\begin{array}{c}\text { exo- } \\
\text { somes }\end{array}$ & n.d. & n.d. & n.d. & $\uparrow$ & lung cancer \\
\hline $\begin{array}{l}\text { Fujita et al. } \\
\text { (2015) }\end{array}$ & in vitro & CSE & human bronchial epithelial cells & media, FCS-free & $100,000 \times g$ & $\begin{array}{c}\text { EM } \\
\text { exosome markers } \\
\text { RNA profiling } \\
\text { size distribution } \\
\text { FA }\end{array}$ & $\begin{array}{l}\text { EV/exo- } \\
\text { somes }\end{array}$ & n.d. & n.d. & n.d. & $\uparrow$ & COPD \\
\hline $\begin{array}{l}\text { Folkesson et } \\
\text { al. (2015) }\end{array}$ & $\begin{array}{l}\text { human } \\
\text { in vitro }\end{array}$ & CSE & $\begin{array}{c}\text { intraluminal thrombi from patients } \\
\text { with abdominal aortic aneurysm }(n=21) \\
\text { HL60 neutrophils }\end{array}$ & $\begin{array}{l}\text { media, FCS-free } \\
\text { intraluminal } \\
\text { thrombi }\end{array}$ & $100,000 \times g$ & direct FC & $\begin{array}{l}\text { micro- } \\
\text { vesicles }\end{array}$ & n.d. & n.d. & n.d. & $\uparrow$ & CVD \\
\hline $\begin{array}{l}\text { Chen et al. } \\
\text { (2016) }\end{array}$ & in vitro & CSE & monocyte-derived macrophages & media, FCS-free & $100,000 \times g$ & $\begin{array}{l}\text { fluorescence } \\
\text { microscopy } \\
\text { direct FC }\end{array}$ & $\begin{array}{l}\text { micro- } \\
\text { vesicles }\end{array}$ & $\uparrow$ & n.d. & n.d. & n.d. & $\begin{array}{l}\text { no specific } \\
\text { disease }\end{array}$ \\
\hline $\begin{array}{l}\text { Sheller et al. } \\
\text { (2016) }\end{array}$ & in vitro & CSE & human amnion epithelial cells & $\begin{array}{l}\text { media, } 10 \% \mathrm{EV}- \\
\text { depleted FCS }\end{array}$ & $100,000 \times g$ & $\begin{array}{c}\mathrm{EM} \\
\text { size distribution } \\
\text { exosome markers }\end{array}$ & $\begin{array}{c}\text { exo- } \\
\text { somes }\end{array}$ & $\uparrow$ & n.d. & n.d. & n.d. & $\begin{array}{l}\text { preterm } \\
\text { parturition }\end{array}$ \\
\hline $\begin{array}{l}\text { Baek et al. } \\
\text { (2016) }\end{array}$ & human & CS & $\begin{array}{l}\text { healthy volunteers ( } \mathrm{n}=161) \text { including smokers } \\
\qquad(\mathrm{n}=51)\end{array}$ & PPP, EDTA & no isolation & exosome markers & $\begin{array}{l}\text { EV/exo- } \\
\text { somes }\end{array}$ & n.d. & n.d. & n.d. & n.d. & $\begin{array}{l}\text { no specific } \\
\text { disease }\end{array}$ \\
\hline $\begin{array}{l}\text { Strulovici- } \\
\text { Barel et al. } \\
\text { (2016) }\end{array}$ & human & CS & $\begin{array}{l}\text { healthy non-smokers }(n=28) \text {, healthy smokers } \\
(n=61) \text { and smoking COPD patients }(n=49) \\
\text { smoking cessation after baseline visit }(\geq 12 \\
\text { months): } \\
\text { healthy ex-smokers }(n=17) \text {, COPD ex-smokers } \\
\qquad(n=18)\end{array}$ & PPP, citrate & no isolation & direct FC & $\begin{array}{c}\text { micro- } \\
\text { particles }\end{array}$ & n.d. & n.d. & $\uparrow$ & $\uparrow$ & COPD \\
\hline $\begin{array}{l}\text { Serban et al. } \\
\text { (2016) }\end{array}$ & $\begin{array}{l}\text { human } \\
\text { animal } \\
\text { in vitro }\end{array}$ & CS, CSE & $\begin{array}{l}\text { human pulmonary miscrovascular and artery } \\
\text { endothelial cells } \\
\text { non-smokers without COPD }(\mathrm{n}=8)\end{array}$ & $\begin{array}{c}\text { PPP, citrate } \\
\text { media, } 2 \% \text { FCS }\end{array}$ & $100,000 \times g$ & $\begin{array}{l}\text { direct FC } \\
\text { EM } \\
\text { fluorescence }\end{array}$ & $\begin{array}{l}\text { micro- } \\
\text { particles }\end{array}$ & $\uparrow$ & $\uparrow$ & n.d. & n.d. & COPD \\
\hline
\end{tabular}




\begin{tabular}{|c|c|c|c|c|c|c|c|c|c|c|c|c|}
\hline Reference & $\begin{array}{l}\text { Study } \\
\text { type }\end{array}$ & Exposure & $\begin{array}{l}\text { study population (in vivo)/ } \\
\text { cell type (in vitro) }\end{array}$ & EV source & EV isolation & $\mathrm{EV}$ characterization & $\begin{array}{l}\text { EV termi- } \\
\text { nology }\end{array}$ & $\begin{array}{l}\text { Inflamma } \\
\text {-tion }\end{array}$ & $\begin{array}{l}\text { Hyper- } \\
\text { coagula- } \\
\text { bility }\end{array}$ & $\begin{array}{l}\text { Endothe- } \\
\text { lial dys- } \\
\text { function }\end{array}$ & $\begin{array}{l}\text { tissue } \\
\text { remo- } \\
\text { delling }\end{array}$ & $\begin{array}{l}\text { Investigated } \\
\text { pathology }\end{array}$ \\
\hline & & & $\begin{array}{l}\text { non-smoking COPD patients }(n=9) \\
\text { smoking COPD patients }(n=8)\end{array}$ & & & $\begin{array}{c}\text { microscopy } \\
\text { size distribution } \\
\text { FA }\end{array}$ & & & & & & \\
\hline $\begin{array}{l}\text { Antoniewicz } \\
\text { et al. (2016) }\end{array}$ & human & $\begin{array}{l}\text { E-cigarette } \\
\text { vapor }\end{array}$ & $\begin{array}{c}\text { healthy intermittent smokers }(n=16) \\
\text { randomized crossover ( } E \text { cigarette } \\
\text { vapor/room air) }\end{array}$ & PPP, citrate & no isolation & direct FC & $\begin{array}{l}\text { micro- } \\
\text { vesicles }\end{array}$ & $\rightarrow$ & n.d. & $\uparrow$ & n.d. & CVD \\
\hline $\begin{array}{l}\text { Heliot et al. } \\
\text { (2017) }\end{array}$ & $\begin{array}{l}\text { human } \\
\text { in vitro }\end{array}$ & CS & $\begin{array}{l}\text { healthy non-smokers }(n=10) \\
\text { healthy smokers }(n=10)\end{array}$ & BALF & $100,000 \times g$ & $\begin{array}{l}\text { size distribution } \\
\text { EM } \\
\text { exosome markers } \\
\text { RNA profiling }\end{array}$ & EV & $\uparrow$ & n.d. & n.d. & n.d. & $\begin{array}{l}\text { lung cancer } \\
\text { COPD }\end{array}$ \\
\hline $\begin{array}{l}\text { Benedikter } \\
\text { et al. } \\
\text { (2017b) }\end{array}$ & in vitro & $\begin{array}{l}\text { CSE, } \\
\text { acrolein, } \\
\mathrm{H}_{2} \mathrm{O}_{2}\end{array}$ & bronchial epithelial cells & $\begin{array}{l}\text { media, } 0.1 \% \text { EV- } \\
\text { depleted FCS }\end{array}$ & $100,000 \times g$ & $\begin{array}{l}\text { exosome markers } \\
E M \\
\text { size distribution }\end{array}$ & $\begin{array}{l}\text { EV/exo- } \\
\text { somes }\end{array}$ & n.d. & n.d. & n.d. & n.d. & $\begin{array}{l}\text { no specific } \\
\text { disease }\end{array}$ \\
\hline $\begin{array}{l}\text { Enjeti et al. } \\
\text { (2017) }\end{array}$ & human & CS & $\begin{array}{l}\text { healthy volunteers }(\mathrm{n}=143) \text { including smokers } \\
\qquad(\mathrm{n}=21)\end{array}$ & PPP, citrate & no isolation & direct FC & $\begin{array}{l}\text { micro- } \\
\text { vesicles }\end{array}$ & n.d. & $\uparrow \downarrow$ & n.d. & n.d. & CVD \\
\hline $\begin{array}{l}\text { Benedikter } \\
\text { et al. } \\
\text { (2017a) }\end{array}$ & in vitro & CSE & bronchial epithelial cells & $\begin{array}{l}\text { media, } 0.1 \% \text { EV- } \\
\text { depleted FCS }\end{array}$ & $\begin{array}{l}100,000 \times \mathrm{g} / \\
\text { others (SEC) }\end{array}$ & $\begin{array}{c}\text { exosome markers } \\
\text { EM } \\
\text { MS } \\
\text { size distribution } \\
\text { FA }\end{array}$ & EV & $\rightarrow$ & n.d. & n.d. & n.d. & $\begin{array}{l}\text { no specific } \\
\text { disease }\end{array}$ \\
\hline
\end{tabular}


Table S2 - Overview of all identified articles in which the effects of PM and related exposures on EV were investigated. BALF, bronchoalveolar lavage fluid; CO, carbon monoxide; COPD, chronic obstructive pulmonary disease; CVD, cardiovascular disease; EDTA, ethylenediaminetetraacetic acid; EM, electron microscopy; EV, extracellular vesicles; FC, flow cytometry; FCS, fetal calf serum; MION, magnetic iron oxide nanoparticles; OVA, ovalbumin; PBS, phosphate buffered saline; PM, particulate matter; PPP, platelet-depleted plasma

\begin{tabular}{|c|c|c|c|c|c|c|c|c|c|c|c|c|}
\hline Reference & $\begin{array}{l}\text { Study } \\
\text { type }\end{array}$ & Exposure & $\begin{array}{l}\text { study population (in vivo)/ } \\
\text { cell type (in vitro) }\end{array}$ & EV source & $\mathrm{EV}$ isolation & $\mathrm{EV}$ characterization & $\begin{array}{l}\text { EV } \\
\text { termino- } \\
\text { logy }\end{array}$ & $\begin{array}{l}\text { inflam- } \\
\text { mation }\end{array}$ & $\begin{array}{l}\text { Hypercoa } \\
\text { gulability }\end{array}$ & $\begin{array}{c}\text { Endo- } \\
\text { thelial } \\
\text { dysfunc- } \\
\text { tion } \\
\end{array}$ & $\begin{array}{l}\text { tissue } \\
\text { remo- } \\
\text { delling }\end{array}$ & $\begin{array}{l}\text { Investi- } \\
\text { gated } \\
\text { pathology }\end{array}$ \\
\hline $\begin{array}{l}\text { Stewart et al. } \\
\quad(2010)\end{array}$ & human & PM & Type 2 diabetics $(n=19)$ & $\begin{array}{l}\text { whole blood, } \\
\text { citrate }\end{array}$ & no isolation & direct FC & $\begin{array}{l}\text { micro- } \\
\text { particles }\end{array}$ & n.d. & $\rightarrow$ & $\rightarrow$ & n.d. & CVD \\
\hline $\begin{array}{l}\text { Emmerechts et } \\
\text { al. (2012b) }\end{array}$ & human & PM & type 1 or 2 diabetics $(n=233)$ & PPP, citrate & no isolation & direct FC & $\begin{array}{l}\text { micro- } \\
\text { vesicles }\end{array}$ & $\rightarrow$ & $\downarrow \uparrow$ & n.d. & n.d. & CVD \\
\hline $\begin{array}{l}\text { Zhu et al. } \\
\text { (2012) }\end{array}$ & $\begin{array}{l}\text { animal } \\
\text { in vitro }\end{array}$ & MION & $\begin{array}{c}\text { BALB/c mice; } 6 \text { groups; } n=8 \text { per group } \\
\text { OVA sensitized vs. Unsensitized } \\
\text { intratracheal challenge: OVA vs. Low MION } \\
\text { vs. High MION }\end{array}$ & BALF & $100,000 \times g$ & $\begin{array}{c}\text { EM } \\
\text { exosome markers } \\
\text { FA }\end{array}$ & $\begin{array}{c}\text { exo- } \\
\text { somes }\end{array}$ & $\uparrow$ & n.d. & n.d. & n.d. & $\begin{array}{l}\text { occupa- } \\
\text { tional } \\
\text { asthma }\end{array}$ \\
\hline $\begin{array}{l}\text { Emmerechts et } \\
\text { al. (2012a) }\end{array}$ & animal & $\begin{array}{c}\text { traffic } \\
\text { emissions }\end{array}$ & $\begin{array}{l}\text { C57BI6/j mice; } 6 \text { groups; } n=7-8 \text { per group } \\
\text { young ( } 10 \text { weeks) vs. old ( } 20 \text { months) } \\
\text { clean air vs. } 0.4 \mu \mathrm{m} \text {-filtered tunnel air vs. } \\
\text { unfiltered tunnel air }\end{array}$ & PPP, citrate & no isolation & direct FC & $\begin{array}{l}\text { micro- } \\
\text { vesicles }\end{array}$ & $\rightarrow$ & $\uparrow$ & n.d. & n.d. & CVD \\
\hline $\begin{array}{l}\text { Frampton et al. } \\
\quad(2012)\end{array}$ & human & $\begin{array}{l}\text { PM, ozone, } \\
\text { carbon } \\
\text { monoxide }\end{array}$ & Type 2 diabetics $(n=19)$ & $\begin{array}{l}\text { whole blood, } \\
\text { citrate }\end{array}$ & no isolation & direct FC & $\begin{array}{c}\text { micro- } \\
\text { particles }\end{array}$ & n.d. & $\uparrow$ & n.d. & n.d. & CVD \\
\hline $\begin{array}{l}\text { Levanen et al. } \\
\quad(2013)\end{array}$ & human & PM & $\begin{array}{l}\text { healthy controls }(n=10) \\
\text { indivduals with mild asthma }(n=10)\end{array}$ & BALF & $100,000 \times g$ & $\begin{array}{l}\text { RNA profiling } \\
\text { exosome markers }\end{array}$ & $\begin{array}{l}\text { exo- } \\
\text { somes }\end{array}$ & $\rightarrow$ & n.d. & n.d. & n.d. & asthma \\
\hline Xu et al. (2013) & animal & $\begin{array}{c}\text { carbon } \\
\text { monoxide }\end{array}$ & $\begin{array}{c}\text { C57BL/6J mice; } \\
\text { breathed different CO concentrations for } 60 \\
\text { min }\end{array}$ & $\begin{array}{l}\text { whole blood, } \\
\text { heparin }\end{array}$ & $100,000 \times g$ & $\begin{array}{c}\text { direct FC } \\
\text { FA }\end{array}$ & $\begin{array}{c}\text { micro- } \\
\text { particles }\end{array}$ & $\uparrow$ & $\uparrow$ & $\uparrow$ & n.d. & $\begin{array}{l}\text { Neurologi- } \\
\text { cal damage }\end{array}$ \\
\hline $\begin{array}{l}\text { Bollati et al. } \\
\quad(2015)\end{array}$ & human & PM & $\begin{array}{l}\text { healthy male steel production workers } \\
\qquad(n=55)\end{array}$ & $\begin{array}{l}\text { media, } 10 \% \text { FCS } \\
\text { PPP, EDTA }\end{array}$ & $100,000 \times g$ & RNA profiling & $\begin{array}{l}\text { micro- } \\
\text { vesicles }\end{array}$ & n.d. & n.d. & n.d. & n.d. & CVD \\
\hline $\begin{array}{l}\text { Frampton et al. } \\
\text { (2015) }\end{array}$ & human & ozone & $\begin{array}{l}\text { GSTM1-WT never-smokers }(n=12) \\
\text { GSTM1-null never-smokers }(n=12) \\
\text { 3x3 crossover trial: filtered air vs. } 100 \mathrm{ppb} \\
\text { vs. } 200 \mathrm{ppb} \text { ozone for } 3 \mathrm{~h}\end{array}$ & $\begin{array}{l}\text { whole blood, } \\
\text { citrate }\end{array}$ & no isolation & direct FC & $\begin{array}{l}\text { micro- } \\
\text { particles }\end{array}$ & n.d. & $\rightarrow$ & n.d. & n.d. & $\begin{array}{l}\text { CVD } \\
\text { lung } \\
\text { function }\end{array}$ \\
\hline $\begin{array}{l}\text { Rodosthenous } \\
\text { et al. (2016) }\end{array}$ & human & PM & elderly men ( $n=22)$ & PPP, EDTA & $100,000 \times g$ & $\begin{array}{l}\text { EM } \\
\text { exosome markers } \\
\text { RNA profiling }\end{array}$ & EV & $\uparrow$ & n.d. & n.d. & n.d. & CVD \\
\hline $\begin{array}{l}\text { Brostrom et al. } \\
\quad(2015)\end{array}$ & in vitro & $\begin{array}{l}\text { toluene } \\
\text { diiso- } \\
\text { cyanate }\end{array}$ & $\begin{array}{c}\text { alveolar epithelial cells } \\
\text { bronchial epithelial cells } \\
\text { employees from } 9 \text { isocyanate companies } \\
(n=118)\end{array}$ & not applicable & no isolation & $\begin{array}{l}\text { fluorescence } \\
\text { microscopy }\end{array}$ & $\begin{array}{l}\text { micro- } \\
\text { vesicles }\end{array}$ & $\uparrow$ & n.d. & n.d. & n.d. & $\begin{array}{l}\text { occupa- } \\
\text { tional } \\
\text { asthma }\end{array}$ \\
\hline
\end{tabular}




\begin{tabular}{|c|c|c|c|c|c|c|c|c|c|c|c|c|}
\hline Reference & $\begin{array}{l}\text { Study } \\
\text { type }\end{array}$ & Exposure & $\begin{array}{l}\text { study population (in vivo)/ } \\
\text { cell type (in vitro) }\end{array}$ & EV source & EV isolation & EV characterization & $\begin{array}{l}\text { EV } \\
\text { termino- } \\
\text { logy }\end{array}$ & $\begin{array}{l}\text { inflam- } \\
\text { mation }\end{array}$ & $\begin{array}{l}\text { Hypercoa } \\
\text { gulability }\end{array}$ & $\begin{array}{l}\text { Endo- } \\
\text { thelial } \\
\text { dysfunc- } \\
\text { tion }\end{array}$ & $\begin{array}{l}\text { tissue } \\
\text { remo- } \\
\text { delling }\end{array}$ & $\begin{array}{l}\text { Investi- } \\
\text { gated } \\
\text { pathology }\end{array}$ \\
\hline Liu et al. (2015) & in vitro & PM & human monocyte-derived macrophages & media, FCS-free & precipitation & FA & EV & n.d. & n.d. & n.d. & n.d. & $\begin{array}{c}\text { Neurological } \\
\text { damage }\end{array}$ \\
\hline $\begin{array}{l}\text { Neri et al. } \\
\text { (2016) }\end{array}$ & in vitro & PM & $\begin{array}{l}\text { peripheral blood mononuclear cells } \\
\text { human umbilical vein endothelial cells }\end{array}$ & $\begin{array}{l}\text { media, } 5-10 \% \\
\text { FCS }\end{array}$ & $100,000 \times g$ & $\begin{array}{l}\text { size distribution } \\
\text { FA }\end{array}$ & $\begin{array}{l}\text { micro- } \\
\text { particles }\end{array}$ & $\uparrow$ & $\uparrow$ & n.d. & n.d. & CVD \\
\hline $\begin{array}{l}\text { Pavanello et al. } \\
\text { (2016) }\end{array}$ & human & PM & $\begin{array}{l}\text { healthy male steel production workers } \\
\qquad(n=55)\end{array}$ & PPP, EDTA & $100,000 \times g$ & RNA profiling & EV & $\uparrow$ & $\uparrow$ & n.d. & n.d. & $\begin{array}{l}\text { CVD } \\
\text { neurologi- } \\
\text { cal disease }\end{array}$ \\
\hline $\begin{array}{l}\text { Pope et al. } \\
\text { (2016) }\end{array}$ & human & PM & healthy young non-smokers $(n=72)$ & PPP, citrate & $10,000 \times g$ & direct FC & $\begin{array}{l}\text { micro- } \\
\text { particles }\end{array}$ & $\uparrow$ & n.d. & $\uparrow$ & n.d. & CVD \\
\hline $\begin{array}{l}\text { Lim et al. } \\
\text { (2016) }\end{array}$ & in vitro & $\begin{array}{c}\text { toluene, } \\
\text { xylene, } \\
\text { ethyl- } \\
\text { benzene }\end{array}$ & HL-60 promyeloblast cells & $\begin{array}{l}\text { media, } 10 \% \text { EV- } \\
\text { depleted FCS }\end{array}$ & precipitation & $\begin{array}{l}\text { EM } \\
\text { exosome markers } \\
\text { RNA profiling }\end{array}$ & $\begin{array}{l}\text { exo- } \\
\text { somes }\end{array}$ & $\uparrow$ & n.d. & n.d. & n.d. & $\begin{array}{l}\text { sick building } \\
\text { sydrome } \\
\text { cancer }\end{array}$ \\
\hline $\begin{array}{l}\text { Lim et al. } \\
\text { (2017) }\end{array}$ & in vitro & toluene & HL60 promyeloblast cells & $\begin{array}{c}\text { media, } 10 \% \text { EV- } \\
\text { depleted FCS }\end{array}$ & precipitation & $\begin{array}{c}\text { EM } \\
\text { exosome markers } \\
\text { RNA profiling }\end{array}$ & $\begin{array}{l}\text { exo- } \\
\text { somes }\end{array}$ & n.d. & n.d. & n.d. & n.d. & $\begin{array}{l}\text { no specific } \\
\text { disease }\end{array}$ \\
\hline $\begin{array}{l}\text { Bonzini et al. } \\
\quad(2017)\end{array}$ & human & PM & $\begin{array}{l}\text { healhty volunteers, normal weight }(n=26) \\
\text { healthy volunteers, overweight }(n=24)\end{array}$ & PPP, EDTA & $100,000 \times g$ & $\begin{array}{l}\text { size distribution } \\
\text { direct FC }\end{array}$ & EV & n.d. & n.d. & $\uparrow$ & n.d. & CVD \\
\hline $\begin{array}{l}\text { Pergoli et al. } \\
\quad \text { (2017) }\end{array}$ & human & PM & $\begin{array}{l}\text { overweight and obese subjects }(n=1630) \\
\text { discovery cohort } n=883 \text { /validation cohort } \\
n=747\end{array}$ & PPP, EDTA & $100,000 \times g$ & $\begin{array}{l}\text { direct FC } \\
\text { size distribution } \\
\text { RNA profiling }\end{array}$ & EV & $\uparrow$ & $\uparrow$ & $\uparrow$ & n.d. & CVD \\
\hline $\begin{array}{l}\text { Thom et al. } \\
\text { (2017) }\end{array}$ & in vitro & $\begin{array}{l}\text { carbon } \\
\text { dioxide }\end{array}$ & $\begin{array}{l}\text { primary human and murine neutrophils and } \\
\text { monocytes }\end{array}$ & $\begin{array}{l}\text { PPP, heparin } \\
\text { PBS or media, } \\
\text { FCS-free }\end{array}$ & $100,000 \times g$ & $\begin{array}{l}\text { direct FC } \\
\text { FA }\end{array}$ & $\begin{array}{l}\text { micro- } \\
\text { particles }\end{array}$ & $\uparrow$ & n.d. & n.d. & n.d. & $\begin{array}{l}\text { no specific } \\
\text { disease }\end{array}$ \\
\hline
\end{tabular}




\section{Supplementary References}

Alcazar, O., A. M. Hawkridge, T. S. Collier, S. W. Cousins, S. K. Bhattacharya, D. C. Muddiman, and M. E. MarinCastano. 2009. "Proteomics characterization of cell membrane blebs in human retinal pigment epithelium cells." Mol Cell Proteomics 8: 2201-2211. doi: 10.1074/mcp.M900203-MCP200.

Antoniewicz, L., J. A. Bosson, J. Kuhl, S. M. Abdel-Halim, A. Kiessling, F. Mobarrez, and M. Lundback. 2016. "Electronic cigarettes increase endothelial progenitor cells in the blood of healthy volunteers." Atherosclerosis 255: 179-185. doi: 10.1016/j.atherosclerosis.2016.09.064.

Badrnya, S., R. Baumgartner, and A. Assinger. 2014. "Smoking alters circulating plasma microvesicle pattern and microrna signatures." Thromb Haemost 112: 128-136. doi: 10.1160/TH13-11-0977.

Baek, R., K. Varming, and M. M. Jorgensen. 2016. "Does smoking, age or gender affect the protein phenotype of extracellular vesicles in plasma?" Transfus Apher Sci 55: 44-52. doi: 10.1016/j.transci.2016.07.012.

Benedikter, B. J., F. G. Bouwman, T. Vajen, A. C. A. Heinzmann, G. Grauls, E. C. Mariman, E. F. M. Wouters, P. H. Savelkoul, C. Lopez-Iglesias, R. R. Koenen, et al. 2017a. "Ultrafiltration combined with size exclusion chromatography efficiently isolates extracellular vesicles from cell culture media for compositional and functional studies." Sci Rep 7: 15297. doi: 10.1038/s41598-017-15717-7.

Benedikter, B. J., C. Volgers, P. H. van Eijck, E. F. Wouters, P. H. Savelkoul, N. L. Reynaert, G. R. Haenen, G. G. Rohde, A. R. Weseler, and F. R. Stassen. 2017b. "Cigarette smoke extract induced exosome release is mediated by depletion of exofacial thiols and can be inhibited by thiol-antioxidants." Free Radic Biol Med. doi: 10.1016/j.freeradbiomed.2017.03.026.

Bollati, V., L. Angelici, G. Rizzo, L. Pergoli, F. Rota, M. Hoxha, F. Nordio, M. Bonzini, L. Tarantini, L. Cantone, et al. 2015. "Microvesicle-associated microrna expression is altered upon particulate matter exposure in healthy workers and in a549 cells." J Appl Toxicol 35: 59-67. doi: 10.1002/jat.2987.

Bonzini, M., L. Pergoli, L. Cantone, M. Hoxha, A. Spinazze, L. Del Buono, C. Favero, M. Carugno, L. Angelici, L. Broggi, et al. 2017. "Short-term particulate matter exposure induces extracellular vesicle release in overweight subjects." Environ Res 155: 228-234. doi: 10.1016/j.envres.2017.02.014.

Bourdonnay, E., Z. Zaslona, L. R. Penke, J. M. Speth, D. J. Schneider, S. Przybranowski, J. A. Swanson, P. Mancuso, C. M. Freeman, J. L. Curtis, et al. 2015. "Transcellular delivery of vesicular socs proteins from macrophages to epithelial cells blunts inflammatory signaling." J Exp Med 212: 729-742. doi: 10.1084/jem.20141675.

Brostrom, J. M., Z. W. Ye, A. Axmon, M. Littorin, H. Tinnerberg, C. H. Lindh, H. Zheng, A. Ghalali, U. Stenius, B. A. Jonsson, et al. 2015. "Toluene diisocyanate: Induction of the autotaxin-lysophosphatidic acid axis and its association with airways symptoms." Toxicol Appl Pharmacol 287: 222-231. doi: 10.1016/j.taap.2015.06.006.

Casey, R. G., M. Joyce, G. Roche-Nagle, D. Cox, and D. J. Bouchier-Hayes. 2004. "Young male smokers have altered platelets and endothelium that precedes atherosclerosis." J Surg Res 116: 227-233. doi: 10.1016/S0022-4804(03)00343-3.

Chen, Y., G. Li, Y. Liu, V. P. Werth, K. J. Williams, and M. L. Liu. 2016. "Translocation of endogenous danger signal hmgb1 from nucleus to membrane microvesicles in macrophages." J Cell Physiol 231: 23192326. doi: $10.1002 /$ jcp.25352.

Cordazzo, C., S. Petrini, T. Neri, S. Lombardi, Y. Carmazzi, R. Pedrinelli, P. Paggiaro, and A. Celi. 2014. "Rapid shedding of proinflammatory microparticles by human mononuclear cells exposed to cigarette smoke is dependent on ca2+ mobilization." Inflamm Res 63: 539-547. doi: 10.1007/s00011-0140723-7.

Emmerechts, J., V. De Vooght, S. Haenen, S. Loyen, S. Van kerckhoven, B. Hemmeryckx, J. A. Vanoirbeek, P. H. Hoet, B. Nemery, and M. F. Hoylaerts. 2012a. "Thrombogenic changes in young and old mice upon subchronic exposure to air pollution in an urban roadside tunnel." Thromb Haemost 108: 756768. doi: 10.1160/TH12-03-0161.

Emmerechts, J., L. Jacobs, S. Van Kerckhoven, S. Loyen, C. Mathieu, F. Fierens, B. Nemery, T. S. Nawrot, and M. F. Hoylaerts. 2012b. "Air pollution-associated procoagulant changes: The role of circulating microvesicles." J Thromb Haemost 10: 96-106. doi: 10.1111/j.1538-7836.2011.04557.x.

Enjeti, A. K., A. Ariyarajah, A. D'Crus, M. Seldon, and L. F. Lincz. 2017. "Circulating microvesicle number, function and small rna content vary with age, gender, smoking status, lipid and hormone profiles." Thromb Res 156: 65-72. doi: 10.1016/j.thromres.2017.04.019.

Folkesson, M., C. Li, S. Frebelius, J. Swedenborg, D. Wagsater, K. J. Williams, P. Eriksson, J. Roy, and M. L. Liu. 2015. "Proteolytically active adam 10 and adam 17 carried on membrane microvesicles in human abdominal aortic aneurysms." Thromb Haemost 114: 1165-1174. doi: 10.1160/TH14-10-0899. 
Frampton, M. W., J. Bausch, D. Chalupa, P. K. Hopke, E. L. Little, D. Oakes, J. C. Stewart, and M. J. Utell. 2012. "Effects of outdoor air pollutants on platelet activation in people with type 2 diabetes." Inhal Toxicol 24: 831-838. doi: 10.3109/08958378.2012.724117.

Frampton, M. W., A. Pietropaoli, M. Dentler, D. Chalupa, E. L. Little, J. Stewart, L. Frasier, D. Oakes, J. Wiltshire, R. Vora, et al. 2015. "Cardiovascular effects of ozone in healthy subjects with and without deletion of glutathione-s-transferase m1." Inhal Toxicol 27: 113-119. doi: 10.3109/08958378.2014.996272.

Fujita, Y., J. Araya, S. Ito, K. Kobayashi, N. Kosaka, Y. Yoshioka, T. Kadota, H. Hara, K. Kuwano, and T. Ochiya. 2015. "Suppression of autophagy by extracellular vesicles promotes myofibroblast differentiation in copd pathogenesis." J Extracell Vesicles 4: 28388. doi: 10.3402/jev.v4.28388.

Gordon, C., K. Gudi, A. Krause, R. Sackrowitz, B. G. Harvey, Y. Strulovici-Barel, J. G. Mezey, and R. G. Crystal. 2011. "Circulating endothelial microparticles as a measure of early lung destruction in cigarette smokers." Am J Respir Crit Care Med 184: 224-232. doi: 10.1164/rccm.201012-20610C.

Grant, R., E. Ansa-Addo, D. Stratton, S. Antwi-Baffour, S. Jorfi, S. Kholia, L. Krige, S. Lange, and J. Inal. 2011. "A filtration-based protocol to isolate human plasma membrane-derived vesicles and exosomes from blood plasma." J Immunol Methods 371: 143-151. doi: 10.1016/j.jim.2011.06.024.

Heiss, C., N. Amabile, A. C. Lee, W. M. Real, S. F. Schick, D. Lao, M. L. Wong, S. Jahn, F. S. Angeli, P. Minasi, et al. 2008. "Brief secondhand smoke exposure depresses endothelial progenitor cells activity and endothelial function: Sustained vascular injury and blunted nitric oxide production." J Am Coll Cardiol 51: 1760-1771. doi: 10.1016/j.jacc.2008.01.040.

Heliot, A., Y. Landkocz, F. Roy Saint-Georges, P. Gosset, S. Billet, P. Shirali, D. Courcot, and P. J. Martin. 2017. "Smoker extracellular vesicles influence status of human bronchial epithelial cells." Int J Hyg Environ Health 220: 445-454. doi: 10.1016/j.ijheh.2016.12.010.

Levanen, B., N. R. Bhakta, P. Torregrosa Paredes, R. Barbeau, S. Hiltbrunner, J. L. Pollack, C. M. Skold, M. Svartengren, J. Grunewald, S. Gabrielsson, et al. 2013. "Altered microrna profiles in bronchoalveolar lavage fluid exosomes in asthmatic patients." J Allergy Clin Immunol 131: 894903. doi: 10.1016/j.jaci.2012.11.039.

Li, C. J., Y. Liu, Y. Chen, D. Yu, K. J. Williams, and M. L. Liu. 2013. "Novel proteolytic microvesicles released from human macrophages after exposure to tobacco smoke." Am J Pathol 182: 1552-1562. doi: 10.1016/j.ajpath.2013.01.035.

Li, M., D. Yu, K. J. Williams, and M. L. Liu. 2010. "Tobacco smoke induces the generation of procoagulant microvesicles from human monocytes/macrophages." Arterioscler Thromb Vasc Biol 30: 18181824. doi: 10.1161/ATVBAHA.110.209577.

Lim, J. H., M. K. Song, Y. Cho, W. Kim, S. O. Han, and J. C. Ryu. 2017. "Comparative analysis of microrna and mrna expression profiles in cells and exosomes under toluene exposure." Toxicol In Vitro 41: 92101. doi: 10.1016/j.tiv.2017.02.020.

Lim, Jung-hee, Mi-Kyung Song, Yoon Cho, Woong Kim, Sung Ok Han, and Jae-Chun Ryu. 2016. "Expression of exosomal and cellular micrornas: As biomarkers for toluene, ethylbenzene, xylene (tex) exposure." Molecular \& Cellular Toxicology 12: 359-369. doi: 10.1007/s13273-016-0040-z.

Liu, F., Y. Huang, F. Zhang, Q. Chen, B. Wu, W. Rui, J. C. Zheng, and W. Ding. 2015. "Macrophages treated with particulate matter pm2.5 induce selective neurotoxicity through glutaminase-mediated glutamate generation." J Neurochem 134: 315-326. doi: 10.1111/jnc.13135.

Liu, H., L. Ding, Y. Zhang, and S. Ni. 2014. "Circulating endothelial microparticles involved in lung function decline in a rat exposed in cigarette smoke maybe from apoptotic pulmonary capillary endothelial cells." J Thorac Dis 6: 649-655. doi: 10.3978/j.issn.2072-1439.2014.06.26.

Liu, Y., F. Luo, B. Wang, H. Li, Y. Xu, X. Liu, L. Shi, X. Lu, W. Xu, L. Lu, et al. 2016. "Stat3-regulated exosomal mir-21 promotes angiogenesis and is involved in neoplastic processes of transformed human bronchial epithelial cells." Cancer Lett 370: 125-135. doi: 10.1016/j.canlet.2015.10.011.

Mobarrez, F., L. Antoniewicz, J. A. Bosson, J. Kuhl, D. S. Pisetsky, and M. Lundback. 2014. "The effects of smoking on levels of endothelial progenitor cells and microparticles in the blood of healthy volunteers." PLoS One 9: e90314. doi: 10.1371/journal.pone.0090314.

Moon, H. G., S. H. Kim, J. Gao, T. Quan, Z. Qin, J. C. Osorio, I. O. Rosas, M. Wu, Y. Tesfaigzi, and Y. Jin. 2014. "Ccn 1 secretion and cleavage regulate the lung epithelial cell functions after cigarette smoke." Am J Physiol Lung Cell Mol Physiol 307: L326-337. doi: 10.1152/ajplung.00102.2014.

Neri, T., L. Pergoli, S. Petrini, L. Gravendonk, C. Balia, V. Scalise, A. Amoruso, R. Pedrinelli, P. Paggiaro, V. Bollati, et al. 2016. "Particulate matter induces prothrombotic microparticle shedding by human mononuclear and endothelial cells." Toxicol In Vitro 32: 333-338. doi: 10.1016/j.tiv.2016.02.001. 
Pavanello, S., M. Bonzini, L. Angelici, V. Motta, L. Pergoli, M. Hoxha, L. Cantone, A. C. Pesatori, P. Apostoli, A. Tripodi, et al. 2016. "Extracellular vesicle-driven information mediates the long-term effects of particulate matter exposure on coagulation and inflammation pathways." Toxicol Lett 259: 143150. doi: 10.1016/j.toxlet.2016.08.002.

Pergoli, L., L. Cantone, C. Favero, L. Angelici, S. Iodice, E. Pinatel, M. Hoxha, L. Dioni, M. Letizia, B. Albetti, et al. 2017. "Extracellular vesicle-packaged mirna release after short-term exposure to particulate matter is associated with increased coagulation." Part Fibre Toxicol 14: 32. doi: 10.1186/s12989017-0214-4.

Pope, C. A., 3rd, A. Bhatnagar, J. P. McCracken, W. Abplanalp, D. J. Conklin, and T. O'Toole. 2016. "Exposure to fine particulate air pollution is associated with endothelial injury and systemic inflammation." Circ Res 119: 1204-1214. doi: 10.1161/CIRCRESAHA.116.309279.

Rodosthenous, R. S., B. A. Coull, Q. Lu, P. S. Vokonas, J. D. Schwartz, and A. A. Baccarelli. 2016. "Ambient particulate matter and micrornas in extracellular vesicles: A pilot study of older individuals." Part Fibre Toxicol 13: 13. doi: 10.1186/s12989-016-0121-0.

Scruggs, A. K., E. A. Cioffi, D. L. Cioffi, J. A. King, and N. N. Bauer. 2015. "Lectin-based characterization of vascular cell microparticle glycocalyx." PLoS One 10: e0135533. doi: 10.1371/journal.pone.0135533.

Serban, K. A., S. Rezania, D. N. Petrusca, C. Poirier, D. Cao, M. J. Justice, M. Patel, I. Tsvetkova, K. Kamocki, A. Mikosz, et al. 2016. "Structural and functional characterization of endothelial microparticles released by cigarette smoke." Sci Rep 6: 31596. doi: 10.1038/srep31596.

Sheller, S., J. Papaconstantinou, R. Urrabaz-Garza, L. Richardson, G. Saade, C. Salomon, and R. Menon. 2016. "Amnion-epithelial-cell-derived exosomes demonstrate physiologic state of cell under oxidative stress." PLoS One 11: e0157614. doi: 10.1371/journal.pone.0157614.

Stewart, J. C., D. C. Chalupa, R. B. Devlin, L. M. Frasier, L. S. Huang, E. L. Little, S. M. Lee, R. P. Phipps, A. P. Pietropaoli, M. B. Taubman, et al. 2010. "Vascular effects of ultrafine particles in persons with type 2 diabetes." Environ Health Perspect 118: 1692-1698. doi: 10.1289/ehp.1002237.

Strulovici-Barel, Y., M. R. Staudt, A. Krause, C. Gordon, A. E. Tilley, B. G. Harvey, R. J. Kaner, C. Hollmann, J. G. Mezey, H. Bitter, et al. 2016. "Persistence of circulating endothelial microparticles in copd despite smoking cessation." Thorax 71: 1137-1144. doi: 10.1136/thoraxjnl-2015-208274.

Takahashi, T., S. Kobayashi, N. Fujino, T. Suzuki, C. Ota, Y. Tando, M. He, M. Yamada, S. Kurosawa, M. Yamaya, et al. 2013. "Differences in the released endothelial microparticle subtypes between human pulmonary microvascular endothelial cells and aortic endothelial cells in vitro." Exp Lung Res 39: 155-161. doi: 10.3109/01902148.2013.784932.

Thom, S. R., V. M. Bhopale, J. Hu, and M. Yang. 2017. "Increased carbon dioxide levels stimulate neutrophils to produce microparticles and activate the nucleotide-binding domain-like receptor 3 inflammasome." Free Radic Biol Med 106: 406-416. doi: 10.1016/j.freeradbiomed.2017.03.005.

Wang, A. L., T. J. Lukas, M. Yuan, N. Du, J. T. Handa, and A. H. Neufeld. 2009. "Changes in retinal pigment epithelium related to cigarette smoke: Possible relevance to smoking as a risk factor for agerelated macular degeneration." PLoS One 4: e5304. doi: 10.1371/journal.pone.0005304.

Xu, J., M. Yang, P. Kosterin, B. M. Salzberg, T. N. Milovanova, V. M. Bhopale, and S. R. Thom. 2013. "Carbon monoxide inhalation increases microparticles causing vascular and cns dysfunction." Toxicol Appl Pharmacol 273: 410-417. doi: 10.1016/j.taap.2013.09.019.

$\mathrm{Xu}, \mathrm{L}$., and X. Deng. 2004. "Tobacco-specific nitrosamine 4-(methylnitrosamino)-1-(3-pyridyl)-1-butanone induces phosphorylation of mu- and m-calpain in association with increased secretion, cell migration, and invasion." J Biol Chem 279: 53683-53690. doi: 10.1074/jbc.M409889200.

Zhu, M., Y. Li, J. Shi, W. Feng, G. Nie, and Y. Zhao. 2012. "Exosomes as extrapulmonary signaling conveyors for nanoparticle-induced systemic immune activation." Small 8: 404-412. doi: 10.1002/smll.201101708. 

Chapter 3

\section{Bead-based flow-cytometry for semi- quantitative analysis of complex membrane vesicle populations released by bacteria and host cells vesicles}

Charlotte Volgers, Birke J. Benedikter, Gert Grauls, Paul H.M. Savelkoul, Frank R.M. Stassen

Microbiolological Research. $2017 \mathrm{Jul}$;200:25-32.

doi: 10.1016/j.micres.2017.04.003. 


\section{Graphical Abstract}

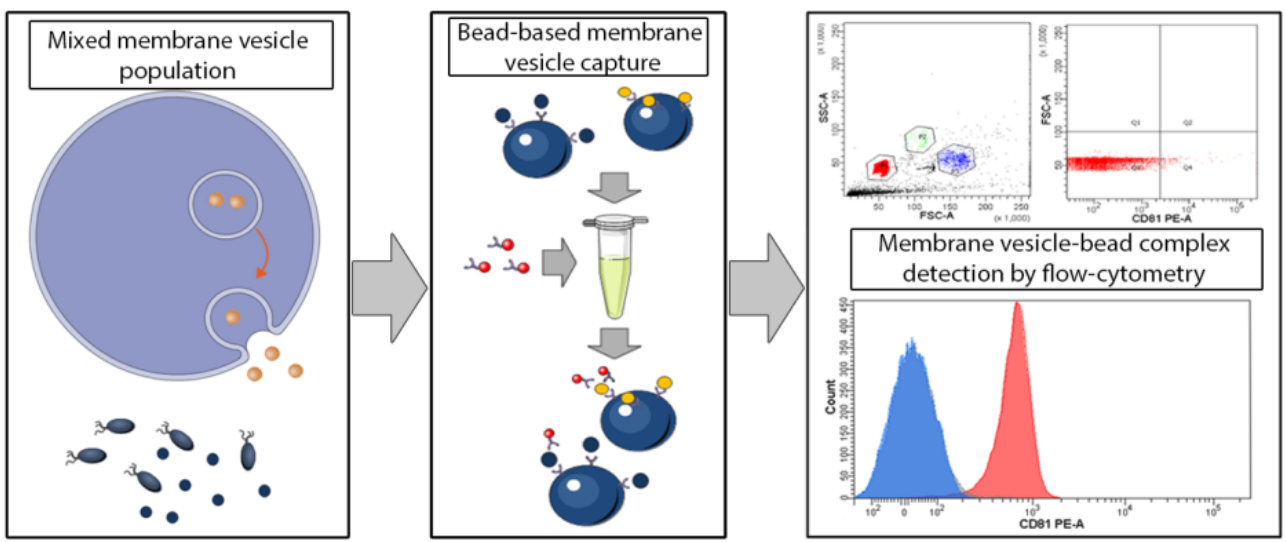

Sample processing time: 3-4 hours; incubation times: overnight and 1 hour; flow-cytometric analysis $\leq 2 \mathrm{~min} /$ sample. Graphical abstract was created using Servier Medical Art. 


\section{Abstract}

During infection, the release of nano-sized membrane vesicle is a process which is common both for bacteria and host cells. Host cellderived membrane vesicles can be involved in innate and adaptive immunity whereas bacterial membrane vesicles can contribute to bacterial pathogenicity. To study the contribution of both membrane vesicle populations during infection is highly complicated as most vesicles fall within a similar size range of $30-300 \mathrm{~nm}$. Specialised techniques for purification are required and often no single technique complies on its own. Moreover, techniques for vesicle quantification are either complicated to use or do not distinguish between host cellderived and bacterial membrane vesicle subpopulations. Here we demonstrate a bead-based platform that allows a semi-quantitatively analysis by flow-cytometry of bacterial and host-cell derived membrane vesicles. We show this method can be used to study heterogeneous and complex vesicle populations composed of bacterial and host-cell membrane vesicles. The easy accessible design of the protocol makes it also highly suitable for screening procedures to assess how intrinsic and environmental factors affect vesicle release. 


\section{Introduction}

The shedding of nano-sized (30-300 $\mathrm{nm}$ )-membrane vesicles is a highly conserved process amongst bacteria, archaea, and eukaryotes. Depending on their origin and the context for release, these membrane vesicles govern functions in survival, communication and defence [1]. Thus, membrane vesicles released during infection constitute a mixture of bacterial and host-cell vesicles that can operate in hostpathogen interactions [2-4].

To study vesicle release kinetics as well as their phenotypic and functional aspects, specialised techniques are required. Currently used assays for detection or quantitative analysis of individual particles include flow-cytometry and microscopybased methods as well as particle detection by nanoparticle tracking or tuneable resistive pulse sensing (TRPS) analysis [5-7]. Methods for the analysis of the gross vesicle population include Western blotting and conventional flow-cytometry. Amidst, there are flow-cytometry-based techniques for the analysis of vesicle subgroups that are more sensitive than methods for gross analysis, but less sensitive than approaches for single particle detection [7-10]. Each of these techniques has its own strengths and weaknesses and optimal vesicle analysis usually requires the use of a combination of techniques $[7,11]$. Assays that enable the quantification and comparison of membrane vesicle populations are essential but most techniques are either complicated to use, not able to distinguish between vesicle subpopulations, or both. A relatively easy to use technique for the detection of membrane vesicles is based on bead-based flow-cytometry. By using $4-\mu \mathrm{M}$-sized latex beads, this assay overturns the size-related problems which prevent membrane vesicle analysis by conventional flow-cytometry. As these beads are coated with antibodies directed against specific marker proteins, they can be used to capture specific membrane vesicle subpopulations. Bead-bound vesicles can subsequently be stained with fluorescently labelled detection antibodies whereupon the total complex can be analysed by flow-cytometry. The beads are gated on their forward and side scatter so that fluorescent intensity of the bead-bound vesicles can be determined. This assay has already proven its value in the semi-quantitative determination of host- cell membrane vesicle release [12-14].

In this study, we present a novel application for this methodology. We modified the assay and made it appropriate for assessing bacterial vesicle release, i.e. membrane vesicles from two common respiratory pathogens Moraxella catarrhalis (Mrc) and Pseudomonas aeruginosa (Psa). This modified assay can be used to 
distinguish bacterial and host-cell vesicle populations in complex samples such as obtained upon infection.

\section{Materials and methods}

\subsection{Reagents and antibodies}

Latex aldehyde beads $(4 \mu \mathrm{M})$ were purchased from Invitrogen (Paisley, UK). The antibody against Psa was from Aviva (OAMAo26o9, Aviva Systems Biology, San Diego, CA. USA). The rabbit serum against Mrc (strain A $1.39 \mathrm{~N}$, isolated from children in a primary school in Nieuwegein, the Netherlands, 1989) was kindly provided by Dr. J.P. Hays (Erasmus University Medical Centre, Rotterdam, the Netherlands). Antibodies were purified using the antibody serum purification kit based on protein A (Abcam, Cambridge, MA, USA). Hereafter, antibodies were quantified by the MicroBCA protein assay (Pierce, Rockford, IL, USA). Antibody conjugations were performed using a PE-labelling kit from Abcam (Cambridge, MA, USA). Antibodies (100 $\mu \mathrm{g}$ per conjugation) were PE-conjugated according the manufacturers' instructions (Abcam, Cambridge, MA, USA). Antibodies against $\mathrm{CD}_{3}$ (unconjugated, mouse-anti-human clone $\mathrm{H}_{5} \mathrm{C} 6$ ), $\mathrm{CD} 81$ (PE conjugated, mouseanti-human clone JS-81) and isotype control (PE mouse IgG1, $\kappa)$ antibodies were from BD (BD Bioscience, Franklin Lakes, NJ, USA). HRP-conjugated secondary antibodies were from R \& D systems (Minneapolis, MN, USA). For Western blot analysis all working dilutions were 1:10oo, except for Mrc where a dilution of 1:40 was used. Samples for Western blot analysis were diluted in sample buffer prepared with XT-sample buffer (Bio-Rad, Hercules, CA, USA), urea (8 M), protease inhibitor complete (Roche GmbH, Mannheim, Germany), and reducing agent TCEP (Bio-Rad, Hercules, CA, USA) or water, to obtain reducing or non-reducing conditions, respectively.

\subsection{Bacterial culture}

The bacterial strains used were Psa ATCC 27853 and a local clinical Mrc isolate (Maastricht University Medical Center, The Netherlands). All strains were cultured at $5 \% \mathrm{CO}_{2}$ and $37^{\circ} \mathrm{C}$ overnight on blood plates. After culture, several colonies were isolated and resuspended until an optical density of 0.5 McFarland $\left(1.5 \times 10^{8}\right.$ colony forming units $(\mathrm{cfu}) / \mathrm{ml})$ in RPMI1640. Bacteria were then cultured in complete vesicle-depleted culture medium with $5 \%$ foetal calf serum (FCS). Vesicle-depleted medium was obtained by the overnight centrifugation of RPMI1640 containing $30 \%$ FCS, glucose $(22.5 \%)$, and sodium pyruvate $(100 \mathrm{mM})$ at $100.000 \times g$ using a $70 \mathrm{Ti}$ 
rotor with a $\kappa$-factor of 44 in an Optima L-9oK ultracentrifuge (Beckman Coulter, Fullerton, CA, USA). This medium was then combined with FCS-free RPMI1640 with glucose and sodium pyruvate to obtain vesicle-depleted complete culture medium containing $5 \%$ FCS. Bacteria $\left(5 \times 10^{8} \mathrm{cfu} / \mathrm{ml}\right)$ were cultured in this vesicle-depleted medium for $4 \mathrm{~h}$ for flow-cytometric analysis.

\subsection{Cell culture}

The human monocytic THP-1 cell line (ATCC-TIB202) was maintained in RPMI1640 (Sigma, St. Louis, MO, USA) supplemented with 10\% FCS (Lonza, Verviers, Belgium), glucose $(12.5 \mathrm{mM})$, sodium pyruvate $(1 \mathrm{mM})$, and $\beta$-mercaptoethanol $(50 \mu \mathrm{M})$ and cultured at $5 \% \mathrm{CO}_{2}$ and $37{ }^{\circ} \mathrm{C}$. For monocyte differentiation, cells were seeded at 0.5 $\times 10^{6}$ cells per well in a 24 -wells plate or at $1 \times 10^{7}$ cells per flask in a T75 flask and stimulated for $72 \mathrm{~h}$ with $200 \mathrm{nM}$ phorbol 12-myristate 13-acetate (PMA; Sigma, St. Louis, MO, USA).

\subsection{Macrophage infection}

Prior to infection, PMA-differentiated monocytes were washed 3 times with PBS and the medium was replaced with complete vesicle-depleted culture medium with $5 \%$ FCS (prepared as described above). Hereupon, macrophages were infected for $6 \mathrm{~h}$ with either one of the bacteria or both at a multiplicity of infection of 10 . After infection, the medium was harvested, processed and used for bead-based flowcytometry as described below.

\subsection{Isolation of bacterial and macrophage-derived membrane vesicles}

For Western blotting analysis of the vesicles and the cell lysates, macrophages in $\mathrm{T}_{75}$ flasks and bacteria were cultured for $6 \mathrm{~h}$ after which the conditioned media were used for vesicle isolation. Cells were harvested by scraping in PBS, pelleted and lysed in NP-40 lysis buffer ( $150 \mathrm{mM} \mathrm{NaCl}, 1 \% \mathrm{NP}-40$, and $50 \mathrm{mM}$ Tris). Additionally, bacteria were cultured for $4 \mathrm{~h}$ at $4.5 \times 10^{8}$ cells $/ \mathrm{ml}$, hereafter the cells were pelleted and lysed in NP-40 and the conditioned media were used for vesicle isolation. Membrane vesicle isolation from the conditioned media was performed by ultracentrifugation. Herefore, the conditioned media were first cleared from cells and cell debris by sequential centrifugation at $300 \times g$ and $1200 \times g$ for $10 \mathrm{~min}$. Then, the supernatants were filtered using $0.22 \mu \mathrm{M}$ filters and transferred to ultraclear Quick-Seal tubes (Beckman Coulter, Fullerton, CA, USA) and centrifuged for 90 min at $100.000 \times g$ using a type $70 \mathrm{Ti}$ rotor, $\kappa$-factor 44 in an Optima L-9oK 
ultracentrifuge (both Beckman Coulter, Fullerton, CA, USA). The vesicle pellet was resuspended in $150 \mu \mathrm{PBS}$ and kept at $-80^{\circ} \mathrm{C}$ until further use. The protein content of the whole cell lysates (WCL) and the vesicle pellets was determined by the Micro BCA protein assay.

\subsection{Western blotting}

For Western blot analysis, ultracentrifugation pellets or cell lysates were diluted in sample buffer (Bio-Rad, Hercules, CA, USA, non-reducing for $\alpha$-CD81 and $\alpha$-CD63), and loaded on a $12 \%$ SDS-page gel. After electrophoresis and protein transfer to a nitrocellulose membrane (Fisher Scientific, Waltham, MA, USA), the membranes were blocked overnight in Tris-buffered saline (TBS) with $5 \%(\mathrm{w} / \mathrm{v})$ milk powder after which they were washed with TBS with $0.05 \%(\mathrm{v} / \mathrm{v})$ Tween and incubated with primary antibodies against CD63, CD81, Mrc (1:20) or Psa in TBS with $5 \%(w / v)$ BSA for $3 \mathrm{~h}$. Next, the membranes were washed and incubated with a horse radish peroxidase (HRP)-labelled secondary antibody in TBS for $2 \mathrm{~h}$. Antibodies were used at 1:100o unless otherwise indicated. After incubation, the membranes were washed and the detection was performed by using chemiluminescence substrate 3 (Sigma, St. Louis, MO, USA). Whole cell lysates were used as a positive control.

\subsection{Flow-cytometric analysis}

\subsubsection{Preparation of antibody-coated latex aldehyde beads}

This method is based on the assay developed by Ostrowski et al. and was used accordingly for the determination of $\mathrm{CD} 63 / \mathrm{CD}_{1} 1^{+}$host cell-derived vesicles or adopted for the determination of bacterial vesicle release [14] Overall, 3 different bead sets were prepared as follows: a total of $1 \times 10^{8} 4 \mu \mathrm{M}$ aldehyde-sulphate beads was washed in $150 \mu \mathrm{l}$ MES buffer (all washing steps were performed at $3000 x g$ for 10 $\mathrm{min}$ ) and coated with $35 \mu \mathrm{g}$ antibody against CD63, Mrc, or Psa (in a total of $250 \mu \mathrm{l}$ ), overnight at $4{ }^{\circ} \mathrm{C}$ while keeping the solution under constant agitation at $6500 \mathrm{rpm}$. Antibodies supplied as serum were purified before use (as described in the reagents and antibodies section). After coating, the remaining free binding sites on the beads were blocked by washing the beads 3 times with $0.22-\mu$ M filtered PBS with $4 \%(w / v)$ bovine serum albumin (BSA). Hereafter the beads were resuspended and kept in a total of $500 \mu$ storage buffer (PBS with $0.1 \%(\mathrm{v} / \mathrm{v})$ glycine and $0.1 \%(\mathrm{w} / \mathrm{v})$ sodium azide) at $4{ }^{\circ} \mathrm{C}$. 


\subsubsection{Bead-based flow-cytometry}

After culture or infection, the supernatants were processed by centrifugation. Supernatants from bacterial cultures were processed by 2 subsequent centrifugation steps at $1200 \times g$ while supernatants obtained after infection were processed by 2 centrifugation steps (300 $\times g$ followed by $1200 \times g$ both for $10 \mathrm{~min}$ ). Then, the supernatants were filtered using $0.22 \mu \mathrm{M}$ filters and a total of 50,00o (1 $\mu \mathrm{l})$ of $\alpha$-Mrcand $\alpha$-CD63-coated beads or 250,00o ( $5 \mu \mathrm{l})$ of $\alpha$-Psa-coated beads were added to 200 $\mu \mathrm{l}$ of the processed supernatants and incubated overnight at room temperature under constant agitation at $6500 \mathrm{rpm}$. The optimal number of beads was determined in earlier experiments. Several bead-bacteria ratios (with a range between 1:20 and 1:200) were tested to reach an amount that resulted in sufficient vesicle binding without reaching a saturation, as this would prevent to determine an increase in the vesicle concentration. This way, the optimal bead concentrations for each platform was established. After overnight vesicle capture, the beads were washed twice with $0.22 \mu \mathrm{m}$ filtered PBS with $2 \%(\mathrm{w} / \mathrm{v})$ BSA and incubated with an analogous secondary PE-conjugated antibody for $1 \mathrm{~h}$ at room temperature under constant agitation and protected from light. For the macrophage-derived vesicles, a PE-labelled isotype antibody was used as a control for non-specific Fc receptor binding and for the bacterial vesicles, unconditioned medium was used as a control. Then, the beads were washed twice in $0.22 \mu \mathrm{m}$ filtered PBS with $2 \%(\mathrm{w} / \mathrm{v}) \mathrm{BSA}$, whereafter the pellets were resuspended in $300 \mu \mathrm{PBS}$ and analysed by flow-cytometry on a FACSCanto ${ }^{\mathrm{TM}}$ (BD Bioscience, Franklin Lakes, NJ, USA). Analyses were performed using FACSDiva Software. Single beads were gated on their forward and side scatter. The quartile distribution within a dot plot, based on the fluorescent intensity of single beads, was then used to calculate the relative fluorescent intensity. Quartile gate 4 was set on $2 \%$ for beads incubated with unconditioned medium. The relative fluorescence intensity, expressed in arbitrary units (AU), was then calculated by multiplying the number and the fluorescence intensity of the positive beads in quartile 4 .

\subsection{Tuneable resistive pulse sensing (TRPS)-based analysis}

Prior to TRPS-based analysis, the media were concentrated to $500 \mu \mathrm{l}$ on Ultra-15 10kDa Amicon centrifugal filter units (Millipore, Billerica, MA, USA) by 15 min of centrifugation at $4000 \times g$ at room temperature. Then, the absolute vesicle concentration in the supernatants was determined by TRPS-based analysis using the qNano Gold (Izon Science Ltd., Oxford, UK) using Izon Control Suite Software v3.2. Measurements were conducted using an NP150 pore with a stretch of $47 \mathrm{~mm}$, a transmembrane voltage of $0.48 \mathrm{~V}$ (giving a baseline current of $\pm 100 \mathrm{nA}$ ), and a 
pressure of 6 mbar. Measurements were performed for $10 \mathrm{~min}$ and repeated when system instabilities occurred. The samples were calibrated with $114 \mathrm{~nm}$ polystyrene calibration beads that were diluted in culture medium at a concentration of $1 \times 10^{9}$ particles/ml. Concentration calculations were performed using Graph-Pad Prism 5 Software (Graph-Pad, San Diego, CA, USA) and Microsoft Office Excel (version 2010, Microsoft).

\subsection{Statistical analyses}

Linear regression was performed using Graph-Pad Prism 5 Software (Graph-Pad, San Diego, CA, USA). A non-parametric Mann-Whitney $U$ test was performed to determine the statistical significance. Differences were considered significant when $\mathrm{p}$ $\leq 0.05$.

\section{Results}

\subsection{Reactivity of the antibodies}

Western blotting analysis was performed to assess whether antibodies were reactive with epitopes on bacterial membrane vesicles isolated by ultracentrifugation. All antibodies were found to be reactive with whole cell lysates as well as the membrane vesicles (Fig. 1). The reactivity of the $\alpha-C D 63$ and $\alpha-C D 81$ antibodies (CD63 and CD81 are proteins that are highly enriched on extracellular vesicles) to macrophagederived membrane vesicles was confirmed while cell lysates remained negative. Hereafter, the antibodies were used to establish the platform for flow cytometric analysis. The first step was to validate each platform for its reactivity and its specificity. As is shown in Fig. 2, all assays were confirmed to be positive only for the corresponding MVs. 


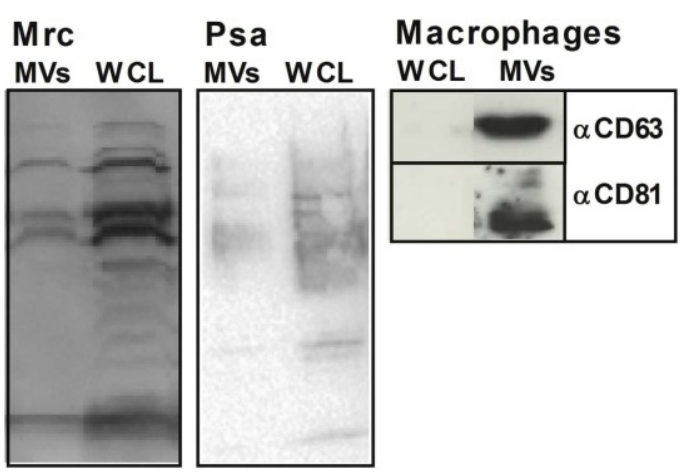

Figure 1 - Analysis of membrane vesicles and whole cells lysates of bacteria and macrophages by Western blotting. The reactivity of antibodies with bacterial membrane vesicles and host cell-derived vesicles (MVs) as well as whole bacterial and host cell lysates (WCL) was determined by Western blotting. Moraxella catarrhalis (Mrc)- and Pseudomonas aeruginosa (Psa)-derived bacterial membrane vesicles (respectively 10 and $25 \mu \mathrm{g}$ ) isolated from conditioned media from bacterial cultures by ultracentrifugation, were subjected to SDS-PAGE, transferred to nitrocellulose membranes and stained using antibodies against Mrc, Psa, CD63 and CD81. Whole bacterial and host cell lysates (5o $\mu \mathrm{g})$ were used as a positive control.
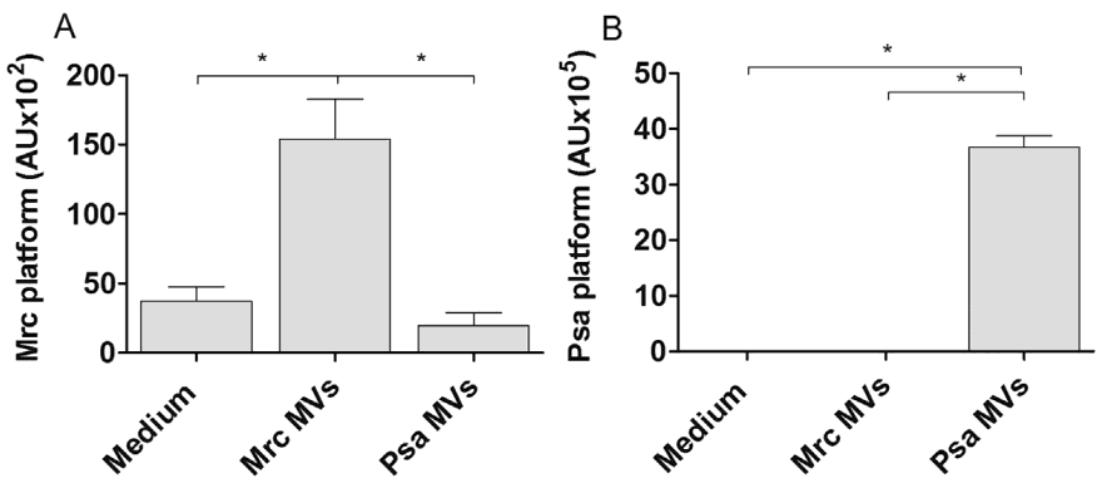

Figure 2 - Validation of the bead-based platforms by flow-cytometric analysis. Validation of the specificity of the bead-based platforms for detection of Mrc- and Psa-derived membrane vesicles by flow-cytometric analysis. Beads coated with antibodies directed against either Mrc or Psa were added to control medium or media that were conditioned by Mrc and Psa for $4 \mathrm{~h}$ at $0.5 \times 10^{8} \mathrm{CFU} / \mathrm{ml}$. The arbitrary units for the Mrc- (A) and Psa- (B) platforms were determined by flow-cytometry (mean \pm SEM, n $=3$ ). $\mathrm{p}<0.05$. 


\subsection{Analysis of purified bacterial vesicles by bead-based flow-cytometry}

Next, we aimed to determine if this platform qualifies for the semi- quantitative detection of bacterial membrane vesicles and to determine the experimental variation of this assay. To test this, conditioned media from bacterial suspensions at $0.5 \times 10^{8} \mathrm{CFU} / \mathrm{ml}$ were obtained, aliquoted in 3 portions to be tested in separate experiments. Then, the assay was applied on 4 sequential 1:1 serial dilutions. Fig. 3 shows a concentration dependent decrease in the fluorescence intensity and shows that there is a low inter-experimental variation. Moreover, these results show a high variation in the absolute fluorescence intensity among the vesicle-bead complexes from the different bacteria.
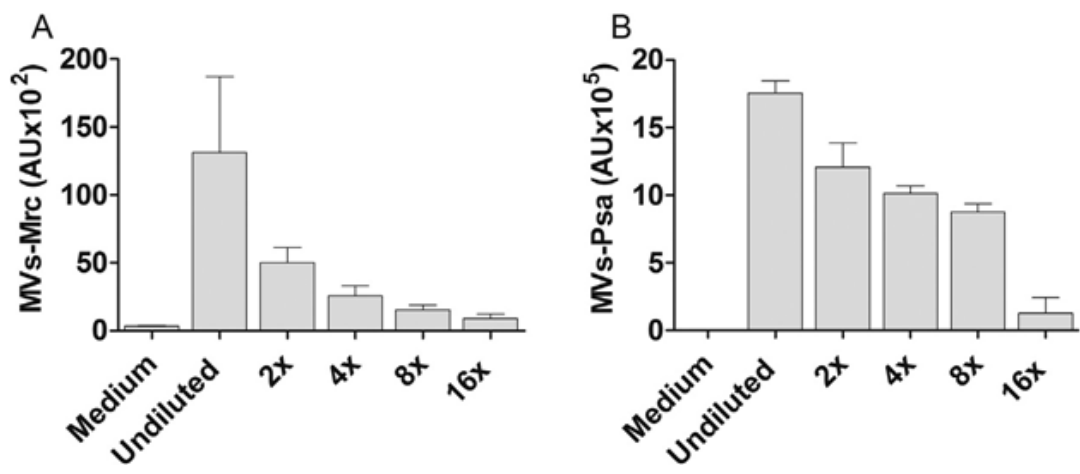

Figure 3 - Flow-cytometric analysis of bacterial vesicles. Beads were added to 2-fold dilution series with a total of 5 dilutions, using supernatants from Mrc or Psa monocultures, cultured for $4 \mathrm{~h}$ at $0.5 \times 10^{8}$ CFU/ml. After vesicle capture, the arbitrary units for Mrc-MVs (A) and Psa-MVs (B) were determined by flow-cytometry (mean \pm SEM, $\mathrm{n}=3$ ).

\subsection{Correlation between the relative and absolute concentration}

The correlation between the absolute and the relative concentration is shown in Fig. 4. Linear regression of the slopes revealed $R^{2}$ values close to 1 indicating that there is a strong correlation between both variables $\left(\mathrm{Mrc}: \mathrm{R}^{2}=0.954\right.$ and Psa: $\left.\mathrm{R}^{2}=0.967\right)$. These data demonstrate that the bead-based flow cytometry assay can indeed be used for semi-quantitative analyses. Moreover, the high correlation indicates that the combination of bead-based flow-cytometry with TRPS-based analysis can also be used to infer the absolute concentration of vesicle subpopulations. 

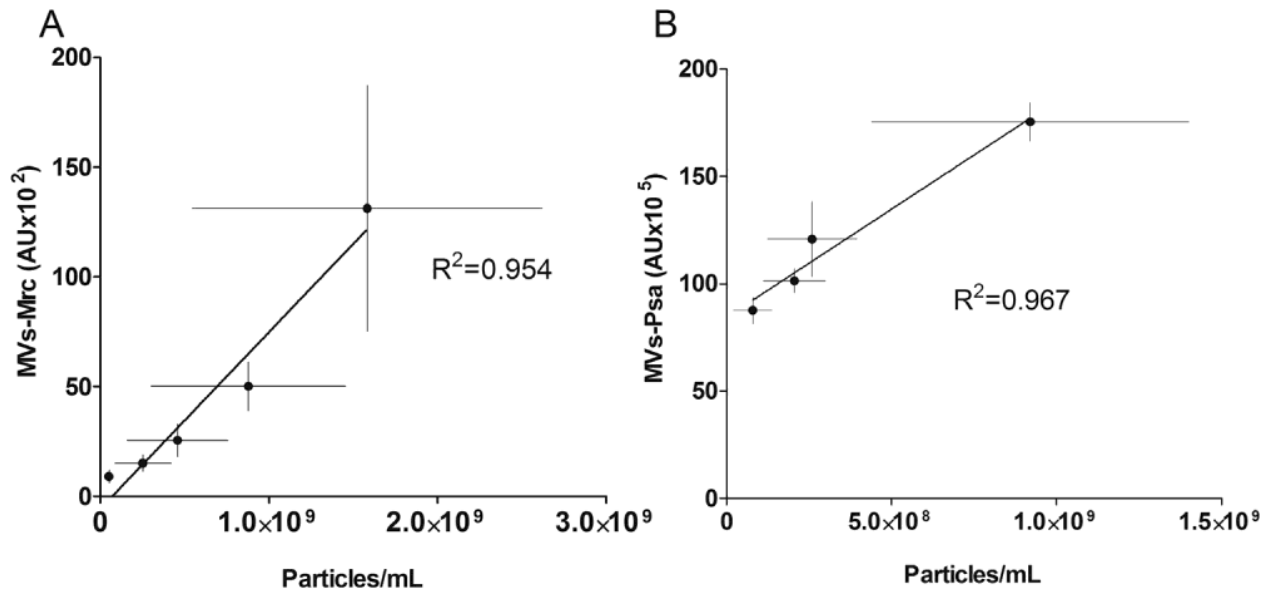

Figure 4 - Correlation between the absolute and the relative vesicle concentration. The absolute vesicle concentration was determined by TRPS-based analysis of supernatants from bacterial cultures that were concentrated (20-fold) on $10 \mathrm{kDa}$ Amicon filter units. The relative membrane vesicle concentration was then plotted against the absolute concentration to determine the correlation. Linear regression of the slopes revealed $\mathrm{R}^{2}$ correlations of 0.954 for Mrc-MVs (A) and 0.967 for Psa-MVs (B). Plots are based on the average values of 3 independent experiments.

\subsection{Bead-based flow-cytometry to determine bacterial and host-cell vesicle release upon (co-)infection}

For analysis of mixed populations we used an in vitro model based on THP-1 macrophages that were infected with Mrc, Psa, both Mrc and Psa or were left uninfected. To demonstrate that this assay indeed allows the semi-quantitative detection method of membrane vesicles, the harvested supernatants of Mrc- or Psainfected macrophages and uninfected macrophages were used undiluted or 2-and 4times diluted. Fig. $5 \mathrm{~A}-\mathrm{C}$ show dilution-dependent decreases in the amount of bacterial vesicles during infection and host cell-derived $\mathrm{CD} 63 / \mathrm{CD}^{+}{ }^{+}$vesicles by uninfected macrophages. Additionally, we demonstrate that infection results in a significantly increased release of $\mathrm{CD}_{3} / \mathrm{CD}{ }^{+}$host cell-derived vesicles, while coinfection significantly increased the release of Mrc-, Psa-, and CD63/CD81 ${ }^{+}$ membrane vesicles (Fig. 5D-F). 
A
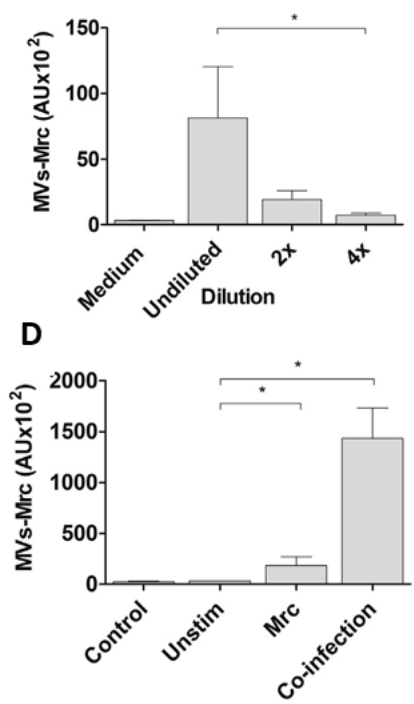

B

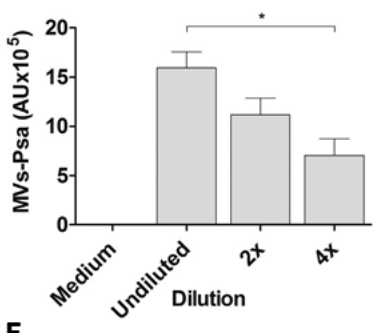

E

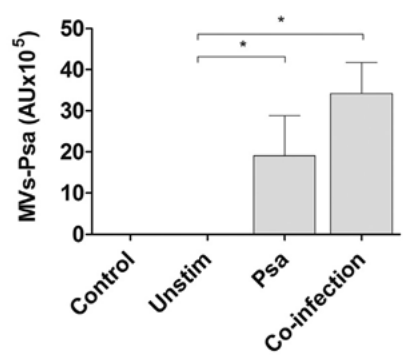

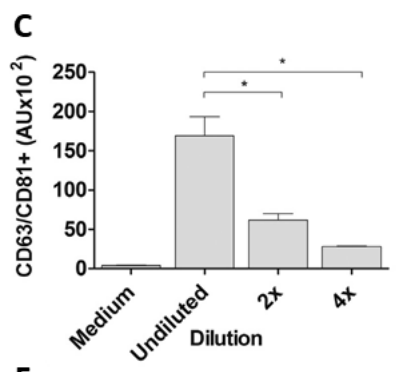

$\mathbf{F}$

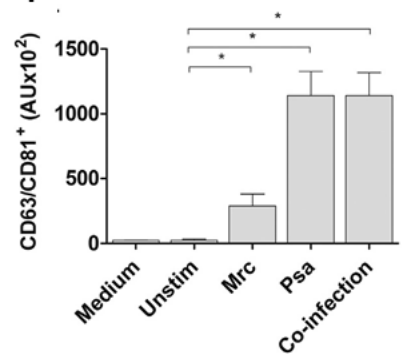

Figure 5 - Flow-cytometric analysis of bacterial and host cell vesicle release upon infection. Semiquantitative determination of bacterial and host-cell vesicles in supernatants of macrophages infected for 6 h. Supernatants obtained after infection with Mrc (A) or Psa (B) or supernatants of uninfected macrophages $(C)$ were used undiluted and 2- and 4-times diluted and assessed by flow-cytometry. The bacterial membrane vesicle release during infection with Mrc (D) and Psa (E) was compared to the release during co-infection. (F) shows the release of host cell vesicles by macrophages after infection by Mrc, Psa, or co-infection. Results are mean \pm SEM from 3 independent experiments. ${ }^{*} \mathrm{p}<0.05$

\subsection{Workflow and principle of bead based-flow-cytometry}

The typical workflow for the improved method is depicted in Fig. 6. After infection, the supernatants are harvested and processed by centrifugation and filtration whereupon antibody-coated beads are added for overnight vesicle capture. Then, the bead-vesicle complexes are washed and stained by PE-conjugated secondary antibodies after which the fluorescence intensity can be determined by flow cytometry. Scatter plots and fluorescence intensity histograms can subsequently be used for analysis. A scatter plot on the forward and side scatter of the bead-vesicle complexes allows to gate (gate 1) on single bead-vesicle complexes (the events in gate 2 and 3 are complexes clustered in duplicates or triplicates). A scatter plot of the fluorescence intensity of single complexes is then used to measure the percentage positive beads. The settings of the quartiles were adjusted using the plots of the unconditioned media for which the percentage of positive beads in quartile 4 was set 
at $2 \%$. Histograms on the beads in quartile 4 can then be used to determine the fluorescence intensity of the beads under experimental conditions, here shown for macrophage-derived vesicles released on infection with Mrc (red), together with histograms for the control conditions (unconditioned medium (grey) and the isotype control (blue)). Calculations are made using tables of statistics to determine the relative concentration in arbitrary units (AU) by multiplication of the percentage and median fluorescence intensity of the positive beads. 


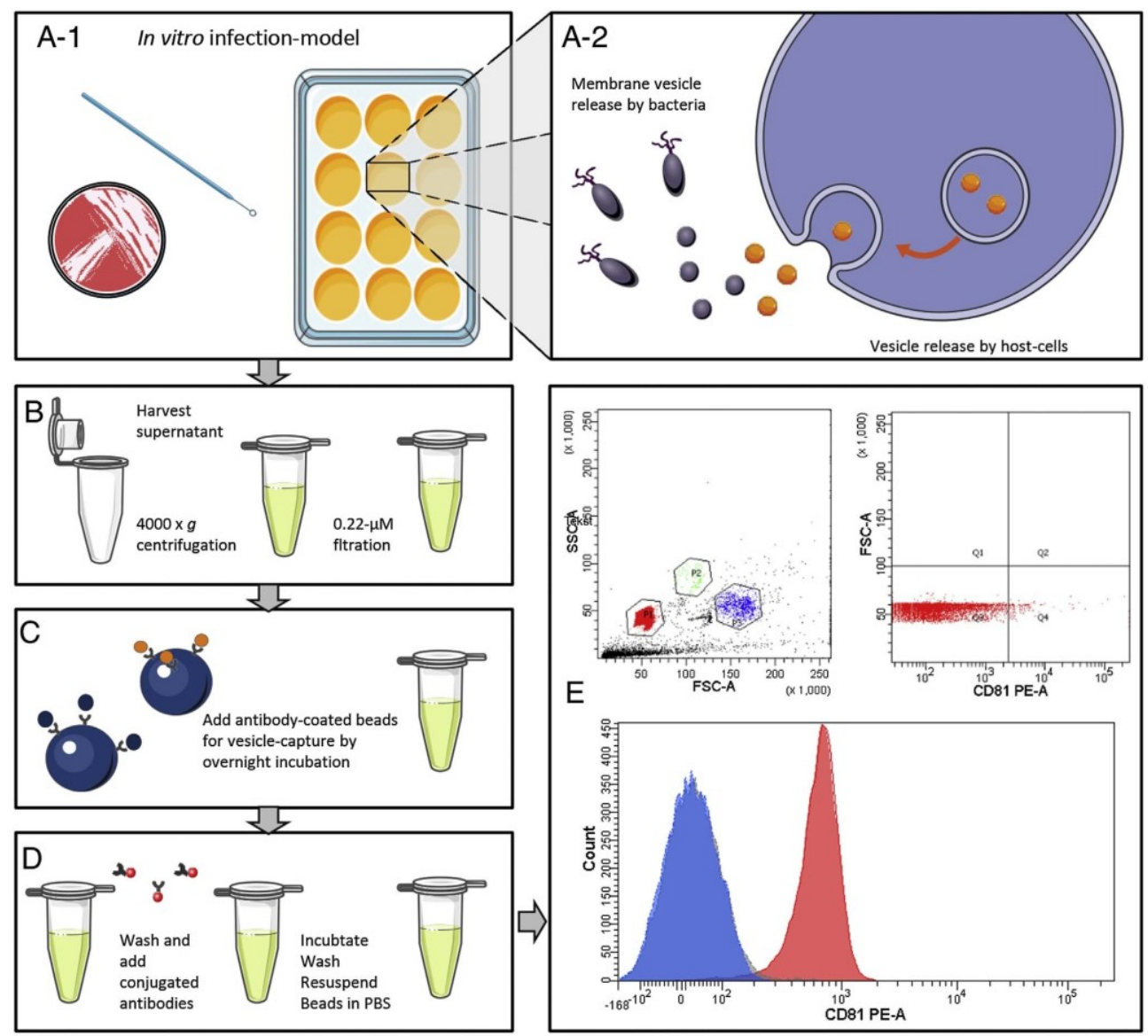

Figure 6 - Workflow and principle of bead-based flow cytometry for the analysis of complex membrane vesicle populations. Bead-based flow cytometric analysis for the semi-quantitative analysis of specific membrane vesicle populations within a complex vesicle population, such as released during bacterial infection (A-1/2). After infection, supernatants are harvested and processed by centrifugation and filtration (B). Then, antibody-coated beads are added and vesicles are captured during overnight incubation (C). Hereafter, the bead-vesicle complexes are washed and stained with conjugated secondary antibodies (D) and subjected to flow-cytometric analysis (E). The beads in gate 1 (gates 2 and 3 contain duplicate and triplicate complexes) are plotted in a scatter plot to determine the \% of positive beads in quartile 4 , adjusted to $2 \%$ using medium control beads. The fluorescence histogram on single beads can then be made, which is done here for an experimental condition based on macrophage vesicles released upon Mrc-infection (red), unconditioned medium (grey), and an isotype control (blue) (E). The relative intensity in arbitrary units (AU) can then be calculated by the multiplying the \% of positive beads in quartile 4 with the median fluorescence intensity. This figure was created using Servier Medical Art. 


\section{Discussion and conclusion}

In this paper, we present a novel application of the bead-based flow-cytometry assay for the semi-quantitative analysis of specific bacterial and host cell vesicle populations within complex samples, such as obtained after infection. Membrane vesicle shedding during infection is a putatively important process in host-pathogen interactions. A better understanding of mechanisms for release of membrane vesicles during infection and how these are affected by environmental factors is required. To assess this is complicated as most membrane vesicles fall within the same size range of $30-300 \mathrm{~nm}$. Conventional techniques that allow vesicle quantification at a single particle level generally have certain limitations as they may require highly specialised equipment $[5,15]$, extensive sample pre-processing, or are not able to distinguish between different vesicle subpopulations (as compared by [6, 7]).

The application presented in the present study was originally developed by Thery et al. for the analysis of exosomes and has since then shown to be useful to study the processes that drive exosome release [13, 14]. We found that the relative vesicle amount determined by flow cytometry correlated well with the absolute vesicle concentration determined by TRPS demonstrating that this bead-based method is a practical tool for semi- quantitative vesicle detection. We show that there was little variation between separate experiments, making this assay highly reproducible. When this assay is adopted for custom applications we recommend validation of this assay accordingly, since it is imperative to start with the assessment of the antibody reactivity and to test for linearity to establish the concentration range over which this assay can be applied. The upper detection limit is reached when the beads are saturated and display none or little variation in the fluorescent intensity. The lower detection limit is reached when the signal can no longer be distinguished from the background signal. To further decrease the lower limit, we suggest concentrating the samples. Apart from this, the platforms used in this study show a high variation in the absolute fluorescent intensity among the vesicle-bead complexes from the different bacteria. This variation could have been introduced by a higher affinity of the antibody to one or multiple vesicle-associated antigens per se or by the abundance of the antigen on the vesicle populations. Yet, as this assay can only be used to determine the relative abundance (relative to the control condition and other conditions based on the same platform), this does not affect the eventual interpretation of the results. 
In this study, we showed that this method can be used to study the release of specific membrane vesicle subpopulations in complex samples composed of multiple types of vesicles, e.g. following infection of host cells by bacteria. The application of this assay on undiluted and diluted supernatants resulted in a dilution-dependent decrease in relative fluorescence intensity, confirming that this method allows the detection of relative changes in the vesicle concentration. Given the strong correlation between the relative concentrations (bead-based flowcytometry) and the absolute numbers (TRPS), our data indicate that the methodology described here can be used to infer the absolute vesicle concentration of a specific vesicle population within a heterogeneous vesicle population. Determination of an absolute vesicle concentration can be performed with the use of a reference sample of the given specific vesicle population. So, to assess the release of vesicles by bacteria or host cells during infection, a condition that is solely based on vesicles released by bacteria or cells can be used as a reference.

The advantages of this technique are abundant. Firstly, no specialised and costly equipment is required, making this technique highly accessible. As this technique is based on the "in sample"-capture of vesicles, which also limits the processing time to 3-4 $\mathrm{h}$, the introduction of processing-related artefacts is circumvented. Also, smaller volumes can be used, and processing is eased by the use of $4 \mu \mathrm{m}$-sized beads, making this method cheaper and less laborious then most conventional methods. As the flow cytometric detection is based on the $4 \mu \mathrm{m}$-sized beads, the gates can be applied based on the forward and side scatter. Hence, signals that may interfere with other assays such as antibody aggregates, other aggregated proteins and soluble proteins do not complicate the measurements. Moreover, this assay offers a versatile platform that allows the simultaneous analysis of different phenotypic vesicle characteristics as beads can be coated with multiple antibodies. Also, labelling of bead-bound vesicles yields higher fluorescence intensity in comparison with individual vesicles and thereby allows the detection of less abundant vesicle populations.

Inevitably, this technique also has some disadvantages. By choosing (a set of) specific antibodies to coat the beads, it cannot be excluded that subsets of vesicles which do not express this specific marker will not be recognised. Therefore, when specific subsets of vesicles are to be detected, it is recommended to use a combination of the most common and well accepted membrane vesicle markers (e.g. CD9/63/81 for host cell derived vesicles). Also, it has been shown that the vesicle composition may change when the circumstances change, notably if this applies to an epitope that is targeted by the antibody of choice this can be crucial. This for 
example has been shown for $P$. aeruginosa where exposure to stressors including oxygen tension, hydrogen peroxide, and gentamycin has been shown to affect the vesicles' LPS phenotype. In these circumstances, it is important to determine if this has an effect on vesicle capture and detection.

Taken together, this method has been shown a valuable tool in assessing the release of membrane vesicles under a variety of conditions. In case of a homogeneous vesicle population, e.g. from a specific cell line, other techniques like high resolution flow-cytometry, dedicated flow-cytometry, nanoparticle tracking analysis, or TRPS may be found superior, but in more complex samples this method allows a rapid and accurate (semi-quantitative) analysis of specific vesicle subpopulations. Moreover, the versatility and ease of this platform may also be further exploited e.g. for vesicle arrays by using different coating-antibody and conjugated-antibody combinations or by using fluorescent or magnetic beads. Therefore, in our opinion this assay provides a valuable addition to the rapidly growing offer of techniques for vesicle detection as a fast and easy approach for the semi-quantitative assessment of vesicle subpopulations in complex samples.

\section{Acknowledgements}

The authors wish to thank dr. J. P. Hays from the Erasmus University Medical Centre (Erasmus MC), Rotterdam, the Netherlands for kindly providing the rabbit antisera to Moraxella catarrhalis used in this publication.

\section{Funding information}

This research did not receive any specific grant from funding agencies in the public, commercial, or not-for-profit sectors. 


\section{References}

1. Deatherage, B.L., et al., Biogenesis of bacterial membrane vesicles. Mol Microbiol, 2009. 72(6): p. $1395-407$.

2. Berleman, J. and M. Auer, The role of bacterial outer membrane vesicles for intra- and interspecies delivery. Environ Microbiol, 2013. 15(2): p. 347-54.

3. Schorey, J.S. and C.V. Harding, Extracellular vesicles and infectious diseases: new complexity to an old story. J Clin Invest, 2016. 126(4): p. 1181-9.

4. Schwechheimer, C. and M.J. Kuehn, Outer-membrane vesicles from Gram-negative bacteria: biogenesis and functions. Nat Rev Microbiol, 2015. 13(10): p. 605-19.

5. van der Vlist, E.J., et al., Fluorescent labeling of nano-sized vesicles released by cells and subsequent quantitative and qualitative analysis by high-resolution flow cytometry. Nat Protoc, 2012. $7(7)$ : p. 1311-26.

6. van der Pol, E., et al., Particle size distribution of exosomes and microvesicles determined by transmission electron microscopy, flow cytometry, nanoparticle tracking analysis, and resistive pulse sensing. J Thromb Haemost, 2014. 12(7): p. 1182-92.

7. Witwer, K.W., et al., Standardization of sample collection, isolation and analysis methods in extracellular vesicle research. J Extracell Vesicles, 2013. 2.

8. Inglis, H., P. Norris, and A. Danesh, Techniques for the analysis of extracellular vesicles using flow cytometry. J Vis Exp, 2015(97).

9. $\quad$ Pospichalova, V., et al., Simplified protocol for flow cytometry analysis of fluorescently labeled exosomes and microvesicles using dedicated flow cytometer. J Extracell Vesicles, 2015. 4: p. 25530.

10. Wieser, A., et al., Efficient quantification and characterization of bacterial outer membrane derived nano-particles with flow cytometric analysis. Int J Med Microbiol, 2014. 304(8): p. 1032-7.

11. Lacroix, R., et al., Overcoming limitations of microparticle measurement by flow cytometry. Semin Thromb Hemost, 2010. 36(8): p. 807-18.

12. Clayton, A., et al., Analysis of antigen presenting cell derived exosomes, based on immunomagnetic isolation and flow cytometry. J Immunol Methods, 2001. 247(1-2): p. 163-74.

13. Thery, C., et al., Isolation and characterization of exosomes from cell culture supernatants and biological fluids. Curr Protoc Cell Biol, 2006. Chapter 3: p. Unit 322.

14. Ostrowski, M., et al., Rab27a and Rab27b control different steps of the exosome secretion pathway. Nat Cell Biol, 2010. 12(1): p. 19-30; sup pp 1-13.

15. Nolte-'t Hoen, E.N., et al., Quantitative and qualitative flow cytometric analysis of nanosized cell-derived membrane vesicles. Nanomedicine, 2012. 8(5): p. 712-20. 



\section{Chapter 4}

\section{Ultrafiltration combined with size exclusion chromatography efficiently isolates extracellular vesicles from cell culture media for compositional and functional studies}

Birke J. Benedikter, Freek G. Bouwman, Tanja Vajen, Alexandra C.A. Heinzmann, Gert Grauls, Edwin C. Mariman, Emiel F. M. Wouters, Paul H.M. Savelkoul, Carmen LopezIglesias, Rory R. Koenen, Gernot G.U. Rohde, Frank R.M. Stassen 


\section{Abstract}

Appropriate isolation methods are essential for unravelling the relative contribution of extracellular vesicles (EVs) and the EV-free secretome to homeostasis and disease. We hypothesized that ultrafiltration followed by size exclusion chromatography (UF-SEC) provides well-matched concentrates of EVs and free secreted molecules for proteomic and functional studies. Conditioned media of BEAS-2B bronchial epithelial cells were concentrated on $10 \mathrm{kDa}$ centrifuge filters, followed by separation of EVs and free protein using sepharose CL-4B SEC. Alternatively, EVs were isolated by ultracentrifugation. EV recovery was estimated by bead-coupled flow cytometry and tuneable resistive pulse sensing. The proteomic composition of EV isolates and SEC protein fractions was characterised by nano LC-MS/MS. UF-SEC EVs tended to have a higher yield and EV-to-protein rate of purity than ultracentrifugation EVs. UF-SEC EVs and ultracentrifugation EVs showed similar foldenrichments for biological pathways that were distinct from those of UF-SEC protein. Treatment of BEAS-2B cells with UF-SEC protein, but not with either type of EV isolate increased the IL-8 concentration in the media whereas EVs, but not protein induced monocyte adhesion to endothelial cells. Thus, UF-SEC is a useful alternative for ultracentrifugation and allows comparing the proteomic composition and functional effects of EVs and free secreted molecules. 


\section{Introduction}

Extracellular vesicles (EVs) are secreted membrane vesicles that have emerged as important regulators of intercellular signalling. They are likely to contribute to homeostasis and disease via diverse functions, including the transfer of proteins and RNA between cells [1]. Adding to their importance, EVs are secreted by virtually all cells and are present in a variety of biological fluids, including blood [2] and bronchoalveolar lavage fluid [3]. In a recent worldwide survey, ultracentrifugation was the most commonly applied EV isolation technique (81\%) and washing of isolated EVs by ultracentrifugation the most common clean-up procedure (64\%) [4]. However, ultracentrifuges are not available in all laboratories and ultracentrifugation is associated with several disadvantages. It has been found to co-isolate non-vesicle associated macromolecules [5] and to cause EV aggregation [6], which may bias the compositional and functional characterisation of EVs. Recently, size exclusion chromatography (SEC) has been shown to provide high quality EV isolates from plasma [7], which were sufficiently pure for Mass Spectrometric analysis [8]. Advantages of SEC include that no specialised equipment is required and that there is little risk for damage or aggregation of EVs as the technique relies on gravity flow. However, while SEC purifies EVs, it also dilutes them. This makes SEC unsuitable as a standalone technique for EV isolation from cell culture media, which are often less concentrated in EVs than plasma. Yet, cell culture media are the most commonly used starting material for EV isolation (83\%) [4], and robust and easy alternatives to isolation by ultracentrifugation are urgently needed. Two recent studies have provided evidence that concentrating conditioned media by ultrafiltration before SEC allows isolating EVs from dilute cell culture media [9, 10]. These studies used a $100 \mathrm{kDa}$ cut-off for ultrafiltration, which does not concentrate small secreted molecules. Yet, one of the major challenges in EV research is to establish the relative roles of EVs and the non EV-associated secretome in intercellular communication. A molecular weight cut-off of $10 \mathrm{kDa}$ is expected to equally concentrate EVs and most free secreted signalling molecules. After separation using SEC, this should provide well-matched isolates of EVs and free protein from the same starting material for comparative studies. Here, we hypothesised that ultrafiltration followed by SEC (UFSEC) allows isolating EVs from cell culture media with comparable or superior yield and purity as compared to ultracentrifugation. We also hypothesised that UF-SEC isolated EVs are suitable for proteomic analysis and that the EV-low protein-rich SEC fractions provide a well-matched control for studying differences in the proteomic composition and biological effects between EVs and the non-EV associated secretome. As a cell culture model, we used BEAS-2B bronchial epithelial 
cells that were either untreated or exposed to cigarette smoke extract (CSE) to induce pro-inflammatory activation [11].

\section{Methods}

\section{Cell culture and cell stimulation}

BEAS-2B bronchial epithelial cells (CRL-96o9; ATCC, Manassas, VA, USA) were cultured, foetal calf serum (FCS; Lonza, Basel, Switzerland) was depleted of EVs and cigarette smoke extract (CSE) was prepared as described previously [12]. Human THP-1 cells (ACC-16; DSMZ, Braunschweig, Germany) were cultured at $37^{\circ} \mathrm{C}$ in RPMI-1640 supplemented with $10 \%$ FCS and $1 \%$ penicillin and streptomycin. Human umbilical vein endothelial cells (HUVEC, C-12203; PromoCell, Heidelberg, Germany) were cultured at passages $2-8$ at $37^{\circ} \mathrm{C}$ in endothelial cell growth medium (Lonza) constituted with endothelial supplement mix (Lonza) and $1 \%$ penicillin and streptomycin.

For EV-isolations, $4 \times 10^{6}$ BEAS-2B cells were seeded per T75 in RPMI-1640 (Gibco) containing 10\% FCS and allowed to attach overnight. After $2 \mathrm{~h}$ incubation in reduction medium (DMEM-F12 containing 0.1\% EV-depleted FCS), cells were washed twice with phosphate buffered saline (PBS) before $20 \mathrm{ml}$ reduction medium with either $1 \%(\mathrm{v} / \mathrm{v})$ PBS (vehicle control) or, for functional studies, $1 \%(\mathrm{v} / \mathrm{v})$ CSE was added. Three $\mathrm{T}_{75}$ flasks and a total medium volume of $60 \mathrm{ml}$ were used per condition for EV isolation by UF-SEC and two flasks (40 ml) for ultracentrifugation (UC) or ultracentrifugation including a PBS wash step (UC-wash). For nano LCMS/MS, 6 flasks $(120 \mathrm{ml}$ ) were used for both isolation methods and media were processed in 2 aliquots of $60 \mathrm{ml}$ (UF-SEC) or 3 aliquots of $40 \mathrm{ml}$ (UC).

\section{EV isolation}

After overnight incubation of BEAS-2B cells with $1 \%$ (v/v) PBS or CSE, conditioned media were harvested and centrifuged at $4^{\circ} \mathrm{C}$ to remove cells and cell debris $(15$ minutes at 5,000 $\times g$ ). Next, media were passed through a $0.22 \mu \mathrm{m}$ filter.

For UF-SEC, media (6o ml) were loaded onto Amicon Ultra-15 Centrifugal Filter Units with Ultracel-1o membrane (MWCO $=10 \mathrm{kDa}$; Merck Millipore, Billerica, MA, USA) and concentrated to $\leq 300 \mu$ l by repeated centrifugation at $4000 \times g$. The concentrate was collected, after which the filter membrane was washed with $200 \mu \mathrm{l}$ PBS, which was added to the concentrate. Where necessary, sample volume was adjusted to $500 \mu \mathrm{l}$. Media concentrates were fractionated by SEC as described by 
Böing et al [7] with some adaptations. In brief, $500 \mu$ of concentrated media was applied to a $10 \mathrm{ml}$ sepharose CL-4B column (GE healthcare, Little Chalfont, UK) and 24 fractions of $0.5 \mathrm{ml}$ were collected using PBS as an eluent. Protein content of the fractions was determined using the Bradford assay (Bio-Rad, Hercules, CA, USA) according to the manufacturer's instructions. The EV rich, protein-low fractions (6 until 10 or 11) and the protein- rich, EV-low fractions (14 until 19) were then pooled and concentrated to $250 \mu \mathrm{l}$ on an Amicon Ultra-4 Centrifugal Filter Unit with Ultracel-10 membrane ( $\mathrm{MWCO}=10 \mathrm{kDa}$; Merck Millipore) by centrifugation at 4,0oo $x g$ and stored at $-80^{\circ} \mathrm{C}$.

Alternatively, $0.22 \mu \mathrm{l}$ filtered media ( $40 \mathrm{ml}$ ) were centrifuged in an Optima L-9oK preparative ultracentrifuge (Beckman-Coulter, Brea, CA, USA) using a fixedangle Type 7oTi-rotor (Beckman-Coulter) and Quick-Seal tubes (Ultra-Clear, 39ml, Beckman-Coulter) at 40,00o rpm (Average RCF $=117,734 \times g$, k-Factor 133.7) for $2.5 \mathrm{~h}$ (optimal speed and duration as determined by Cvjetkovic et al. [13]). After ultracentrifugation, supernatant was poured off and the invisible EV-pellet was resuspended either in $200 \mu \mathrm{PBS}$ and stored at $-80^{\circ} \mathrm{C}$, or in $5 \mathrm{ml}$ PBS for further purification by a second $2.5 \mathrm{~h}$ ultracentrifugation step using an NVT9o rotor and Quick-Seal tubes (Ultra-Clear, 5.1 ml, Beckman-Coulter) at 40,00o rpm (Average RCF $=110,656 \times \mathrm{g}$, k-Factor 48.3). The PBS-washed EV pellet was resuspended in $200 \mu \mathrm{l}$ PBS and stored at $-80^{\circ} \mathrm{C}$.

\section{Assessment of EV recovery using $\mathrm{CD} 63^{+} \mathrm{CD} 81^{+}$bead- coupled flow cytometry}

Throughout the EV isolation procedures, samples were taken to determine the efficiency of isolation by $\mathrm{CD} 63^{+} \mathrm{CD} 81^{+}$bead-coupled flow cytometry [14]. Unfiltered and $0.22 \mu \mathrm{m}$-filtered conditioned media, as well as SEC-fractions and the UF flowthrough were assessed undiluted, while UF concentrates and final EV isolates from the UF-SEC, UC or UC-wash methods were diluted to the volume from which they were isolated. Beads $\left(3.5 \times 10^{8} \mathrm{ml}-1,4 \mu \mathrm{m}\right.$ aldehyde/sulphate latex beads $5 \%(\mathrm{w} / \mathrm{v})$; Thermo Fisher Scientific) were coated with $0.125 \mathrm{mg} / \mathrm{ml}$ mouse anti-human CD63 antibody (Clone $\mathrm{H}_{5} \mathrm{C} 6$; BD Biosciences, San Jose, CA, USA) by overnight incubation in MES buffer and stored at $4^{\circ} \mathrm{C}$ in PBS containing $0.1 \%(\mathrm{~m} / \mathrm{v})$ glycine and $0.1 \%$ $(\mathrm{m} / \mathrm{v})$ sodium azide. Two hundred microliter of each EV sample were incubated overnight with $1 \times 10^{6}$ beads. Beads were then washed twice by centrifugation in PBS$2 \%(\mathrm{~m} / \mathrm{v})$ BSA ( $5000 x \mathrm{~g}, 5 \mathrm{~min})$. This was followed by staining for $1 \mathrm{~h}$ in $50 \mu \mathrm{lBS}-2 \%$ $(\mathrm{m} / \mathrm{v})$ BSA containing $0.01 \mathrm{mg} / \mathrm{ml}$ PE-labelled mouse anti-human CD81 antibody (Clone JS-81; BD Biosciences). The stained EV-coupled beads were washed twice by 
centrifugation (500o $\times \mathrm{g}, 5 \mathrm{~min}$ ), resuspended in $150 \mu \mathrm{l}$ PBS and analysed using a BD FACSCanto (BD Biosciences) with FACS Diva V8.o.1 software (BD Biosciences). The quantity of EVs in relative fluorescent units (RFU) was calculated by multiplying the percentage of PE-positive beads with the median fluorescent intensity (MFI) of the positive bead population. For recovery calculations, all measurements were expressed as percentage of the unfiltered conditioned medium. For the flow cytometry stainings in Figure $2 \mathrm{C}$, beads were alternatively coated with mouse antihuman CD81 (clone JS-81; BD Biosciences) or mouse anti-human CD9 (clone M-L13; BD Biosciences), followed by detection using PE-labelled mouse anti-human CD81 (clone JS-81; BD Biosciences) or mouse anti-human CD9 (clone M-L13; BD Bisosciences), respectively. All volumes and concentrations were maintained identical as for the CD63/CD81 staining.

\section{Protein determination by Bradford microplate assay}

The Bradford microplate assay (Bio-Rad) was performed according to manufacturer's protocol with some modifications to allow improved sensitivity. The standard curve was a 2-fold serial dilution ranging from $100 \mu \mathrm{g} / \mathrm{ml}$ to $3.125 \mu \mathrm{g} / \mathrm{ml}$ bovine serum albumin (BSA). $50 \mu \mathrm{l}$ of each standard or protein sample were loaded on a 96 -well plate followed by addition of $250 \mu \mathrm{l}$ /well Bradford reagent. Absorption was measured at $595 \mathrm{~nm}$.

\section{Western blotting}

For Ponceau S staining and Western blotting, the 24 SEC fractions were precipitated with acetone containing $10 \%(\mathrm{v} / \mathrm{v})$ trichloric acid (TCA) and $20 \mathrm{mM}$ 1,4dithiothreitol (DTT). The protein pellets were resuspended in $30 \mu \mathrm{XT}$ sample buffer (Bio-Rad) containing $5 \mathrm{M}$ urea and cOmplete ${ }^{\mathrm{TM}}$ protease inhibitor cocktail (Roche Life Science, Penzberg, Germany) at the concentration recommended by the manufacturer. Fifteen microliter were loaded onto a $12 \%$ running gel for sodium dodecyl sulphate polyacrylamide gel electrophoresis (SDS-PAGE) according to standard protocol. Transfer to an AmershamTM ProtranTM $0.2 \mu \mathrm{m}$ nitrocellulose membrane (GE Healthcare) was performed by wet blotting and detection of general protein signal by Ponceau S staining. Next, non-specific binding sites were blocked using $5 \%(\mathrm{w} / \mathrm{v})$ BSA in tris-buffered saline, followed by immunostaining using one of the following antibodies: mouse anti-human $\mathrm{CD}_{3}$ (clone $\mathrm{H}_{5} \mathrm{C} 6, \mathrm{BD}$ Biosciences, $1000 \mathrm{x}$ diluted), mouse-anti human CD81 (clone JS-81; BD Biosciences, $1000 \mathrm{x}$ diluted), mouse anti-human MFGE8 (R\&D Systems, clone 278918, 50ox diluted) or mouse anti-human $\mathrm{HSC}_{70} / \mathrm{HSP}_{70}$ (Enzo Life Sciences, clone $\mathrm{N}_{27} \mathrm{~F}_{3}-4,500 \mathrm{x}$ diluted). 
A detailed description of the staining protocol, as well as of the image acquisition and processing is provided in the supplementary methods, along with uncropped images of the Ponceau S and immunostaining (Supplementary Figure $\mathrm{S} 1$ ).

\section{Cryo transmission electron microscopy (cryo-TEM)}

Five microliter of UF-SEC EV isolates was applied to a glow-discharged holey carbon grid. The grid was incubated for 4 minutes at room temperature before blotting against filter paper to leave only a thin film spanning the grid holes. The sample was kept at $95 \%$ humidity before plunge-freezing in liquid ethane using a Vitrobot (FEI, Eindhoven, The Netherlands). The vitreous sample films were transferred to a Tecnai T12 Spirit microscope (FEI) using a Gatan cryo-transfer. The images were taken at $120 \mathrm{kV}$ with a 4,096 x 4,096 pixel CCD Eagle camera (FEI) at a temperature between $-170^{\circ} \mathrm{C}$ and $-175^{\circ} \mathrm{C}$ and using low-dose imaging conditions.

\section{Tuneable resistive pulse sensing (TRPS)}

TRPS was performed using a qNano Gold with Izon Control Suite 3.2 Software, an NP150 nanopore and SKP2oo calibration beads (Izon, Chirstchurch, New Zealand). Cell-depleted unfiltered media and EV isolates were analysed after a single freezethaw cycle at $-80^{\circ} \mathrm{C}$. Media were diluted 2 -fold and $\mathrm{EV}$ isolates up to 20 -fold in Solution Q (Izon). To improve comparability between measurements, the following settings were used: For UF-SEC media and isolates, the stretch of the $\mathrm{NP}_{150}$ nanopore was adjusted to obtain a relative particle size of approximately 0.65 for the SKP2oo calibration beads. A concentration fraction from 80 to $250 \mathrm{~nm}$ was applied to these measurements. For UC and UC-wash media and isolates, the relative particle size for the SKP2oo calibration beads was adjusted to 0.25 , as smaller stretches resulted in pore obstruction. A concentration fraction from 110 to $300 \mathrm{~nm}$ was applied to these measurements. For all measurements, the voltage was adjusted to obtain a current between 120 and $130 \mathrm{nA}$. EV measurements of the dilute media were stopped after 10 minutes, while measurements of the more concentrated EV isolates were stopped after detecting 500 blockades.

\section{Proteomic analysis and database search}

UF-SEC EVs $(n=5)$, UC-EVs $(n=3)$ or UF-SEC protein $(n=3 ; 500 \mu l$ per sample for all sample types, isolated from $120 \mathrm{ml}$ of cell culture media) were precipitated by overnight incubation at $-20^{\circ} \mathrm{C}$ with $1.5 \mathrm{ml}$ acetone containing $10 \%(\mathrm{v} / \mathrm{v}) \mathrm{TCA}$ and 20 $\mathrm{mM}$ DTT followed by centrifugation for $10 \mathrm{~min}$ at $16,000 \times \mathrm{g}$ and $4^{\circ} \mathrm{C}$. After washing 
with ice cold acetone, the protein pellets were resuspended in $30 \mu \mathrm{l} 50 \mathrm{mM}$ ammonium bicarbonate (ABC; Sigma-Aldrich) containing $5 \mathrm{M}$ urea, and the protein concentration was determined using Bradford assay (Bio-Rad). To $5 \mu \mathrm{g}$ of protein per sample, DTT (20 mM) was added and incubated at room temperature for 45 minutes. Iodoacetamide $(40 \mathrm{mM})$ was then added to alkylate for 45 minutes at room temperature until quenching by a second addition of DTT. A mixture of trypsin/lysozyme $C(2 \mu \mathrm{g})$ was added and digestion was performed at $37^{\circ} \mathrm{C}$ for 2 hours. The mixture was diluted with $A B C$ without urea and incubation was continued at $37^{\circ} \mathrm{C}$ for 18 hours. The digestion mix was briefly centrifuged and the digest/peptide mixture diluted fourfold for nano-LC MS/MS analysis. A nanoflow HPLC instrument (Dionex ultimate 3000) was coupled in-line with a $Q$ Exactive mass spectrometer (Thermo Fisher Scientific) with a nano-electrospray Flex ion source (Proxeon, Thermo Fisher Scientific). Five microliter of the digest/peptide mixture was loaded onto a C18-reversed phase column (Acclaim PepMap C18 column, 75- $\mu \mathrm{m}$ inner diameter x $15 \mathrm{~cm}, 2-\mu \mathrm{m}$ particle size; Thermo Fisher Scientific). The peptides were separated with a 90 min linear gradient of $4-45 \%$ buffer $B(80 \%$ acetonitrile and $0.08 \%$ formic acid) at a flow rate of $300 \mathrm{nl} / \mathrm{min}$.

MS data was acquired using a data-dependent topı method, dynamically choosing the most abundant precursor ions from the survey scan $(250-1250 \mathrm{~m} / \mathrm{z})$ in positive mode. Survey scans were acquired at a resolution of 70,00o. Dynamic exclusion duration was $30 \mathrm{~s}$. Isolation of precursors was performed with a $4.0 \mathrm{~m} / \mathrm{z}$ window. Resolution for HCD spectra was set to 17,500 and the Normalised collision energy was $30 \mathrm{eV}$. The under fill ratio was defined as $1.0 \%$. The instrument was run with peptide recognition mode enabled, but exclusion of singly charged and charge states of more than five.

The data was analysed using Sequest HT Proteome Discoverer 2.1 search engine (Thermo Fisher Scientific), against the Uniprot database. The false discovery rate (FDR) was set to o.o1 for proteins and peptides, which had to have a minimum length of 6 amino acids. The precursor mass tolerance was set at $10 \mathrm{ppm}$ and the fragment tolerance at 0.2 Da. One miss-cleavage was tolerated, oxidation of methionine was set as a dynamic modification and carbamidomethylation of cysteine residues was a fixed modification. Proteins with a HT score $>10$ were considered as being identified with high confidence.

\section{Functional assays}

For assessing IL-8 release, $5 \times 10^{4}$ BEAS-2B cells/well were seeded on 48 -well plates and allowed to attach overnight. Cells were washed twice with PBS before 
stimulation with $2 \times 10^{8} \mathrm{EVs} / \mathrm{ml}$ obtained by UF-SEC, the volume-matched UF-SEC protein, or $2 \times 10^{8} \mathrm{UC}$ EVs. For cell-free controls, the same dilution of UF-SEC protein was incubated in cell-free wells of the 48 -well plate. After $48 \mathrm{~h}$ at $37^{\circ} \mathrm{C}$, media were harvested and depleted of cells and cell debris by centrifugation $(5,000 x$ $g$, 5min). IL-8 concentrations were assessed using ELISA (Ready-SET-Go; eBioscience, San Diego, USA) according to the manufacturer's instructions.

For flow chamber adhesion, HUVEC were seeded in $35-\mathrm{mm}, 30 \mu \mathrm{g} / \mathrm{ml}$ collagen-coated dishes and incubated with $7.5 \times 10^{7}$ UF-SEC EVs $/ \mathrm{ml}$, volumematched protein isolates, or $7.5 \times 10^{7} \mathrm{UC}$ EVs $/ \mathrm{ml}$ for $72 \mathrm{~h}$. THP-1 cells were labelled with $1 \mu \mathrm{M}$ green fluorescent nucleic acid stain (Syto 13 ) for $30 \mathrm{~min}$ at $37^{\circ} \mathrm{C}$, washed and perfused in Hank's buffer at $\mathrm{pH} 7.45$, containing $10 \mathrm{mM}$ HEPES, $3 \mathrm{mM} \mathrm{CaCl}$, and $2 \mathrm{mM} \mathrm{MgCl}$ and $0.2 \%$ human albumin for $2-6$ min minutes at 3 dynes $/ \mathrm{cm}^{2}$. Adherent fluorescent cells were manually counted in $>6$ fields and expressed as cells $/ \mathrm{mm}^{2}$.

\section{Data analysis}

All data are composed of at least three independent experiments. Data were analysed with Graphpad Prism 5.03 for Windows (GraphPad Software, Inc., La Jolla, CA, USA). Due to the small sample size, the data was analysed using the nonparametric Mann-Whitney test where two groups were compared and the nonparametric Kruskal-Wallis test followed by Dunn's posthoc test where more than two groups were compared. Unless indicated otherwise, each individual graphs depict each individual data point and lines indicate the medians. P-values $\leq 0.05$ were considered statistically significant and are indicated in the graphs as reported by the analysis software: * $\mathrm{p}$ 0.01-0.05, ${ }^{* *} \mathrm{p}$ o.001-0.01 and ${ }^{* * *} \mathrm{p}<0.001$. Functional enrichment analysis was performed using the hypergeometric test in the FunRich software version 2.1.2 [15].

\section{Data availability}

All data generated and analysed during this study are included in this article and its Supplementary Information files. The raw data of the nano LC-MS/MS analyses have been deposited to the public database ProteomeXchange (Project number: PXDoo6738). 


\section{Results}

\section{Efficiency of EV isolation using ultrafiltration followed by SEC compared to ultracentrifugation}

The aim of this study was to evaluate whether ultrafiltration combined with size exclusion chromatography (UF-SEC) can serve as an easy and robust protocol to obtain high quality EV isolates for compositional analysis and functional studies. For this purpose, conditioned cell culture media were processed either by UF-SEC or, for comparison, by ultracentrifugation (UC) or ultracentrifugation including a wash step (UC-wash; illustrated in Figure 1).

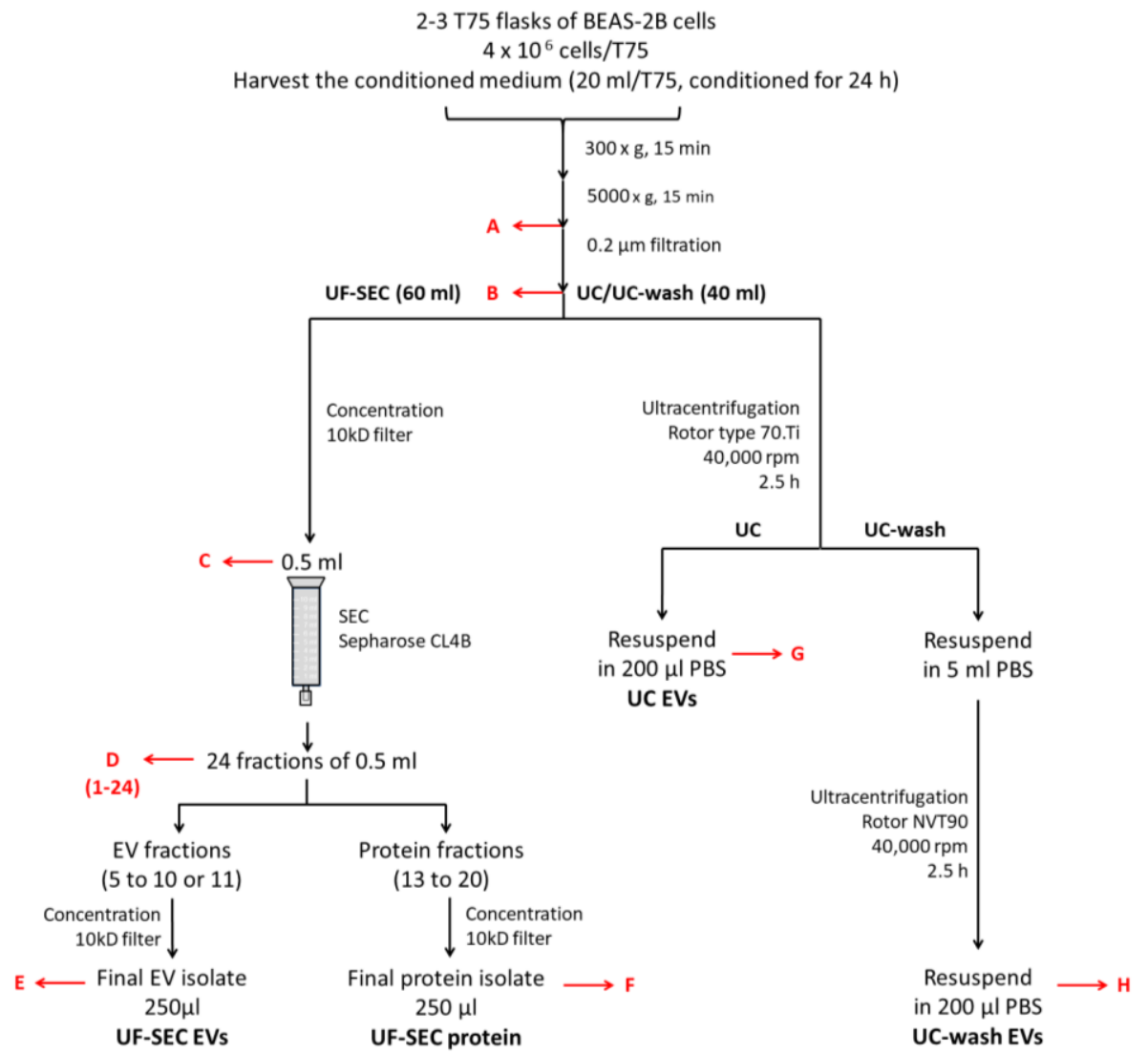

Figure 1 - Flow chart of the EV isolation protocols. Red arrows indicate where samples were taken for determination of EV recovery based on $\mathrm{CD}_{3}{ }^{+} \mathrm{CD}_{1}{ }^{+}$bead-coupled flow cytometry. For nano LC/MS-MS, the isolation protocols were scaled up to $120 \mathrm{ml}$ of cell culture medium as starting material. For UF-SEC, 
the $120 \mathrm{ml}$ were concentrated by $10 \mathrm{kDa}$ filtration and subsequently run over the SEC column in two aliquots of $0.5 \mathrm{ml}$. The EV containing fractions from both SEC runs (fractions 6 to 10 or 11) were then pooled and concentrated by $10 \mathrm{kDa}$ filtration. For UC, the $120 \mathrm{ml}$ were processed in 3 portions of $40 \mathrm{ml}$, corresponding to the maximal volume of the UC tubes.

First, we established that $\mathrm{CD}_{3}{ }^{+} \mathrm{CD}_{1}{ }^{+}$-bead coupled flow cytometry can be applied for semi-quantitative assessment of EV recovery, as the flow cytometry signal is linear over a broad range of EV concentrations for a serial dilution of isolated EVs (Figure 2A). There was no loss of $\mathrm{CD}_{3}{ }^{+} \mathrm{CD}_{1}{ }^{+} \mathrm{EVs}$ after $0.22 \mu \mathrm{m}$ filtration of the conditioned media (Figure $2 \mathrm{~B}$ ). Moreover, the recovery of $\mathrm{CD} 63^{+} \mathrm{CD} 81^{+} \mathrm{EVs}$ in the 10 $\mathrm{kDa}$ filter retentates was complete, while virtually no EVs were detectable in the flow through (Figure $2 \mathrm{~B}$ ). The $10 \mathrm{kDa}$ filter retentates $(0.5 \mathrm{ml})$ were run over a sepharose CL-4B SEC column and, per run, 24 fractions of $0.5 \mathrm{ml}$ were collected. Protein elution was assessed by Bradford assay or Ponceau S staining and EV elution by tuneable resistive pulse sensing (TRPS). Moreover, elution of several EV marker proteins was assessed by bead-coupled flow cytometry and immunoblotting. By Bradford assay, protein showed a bimodal elution pattern with a minor peak at fraction $8(10 \mu \mathrm{g} / \mathrm{ml})$ and a major peak at fraction $15(389 \mu \mathrm{g} / \mathrm{ml}$; Figure $2 \mathrm{C}$, detail in Supplementary Figure $\mathrm{S} 1$ ). Bead-coupled flow cytometry revealed slightly different elution patterns for $\mathrm{CD}_{3} 3^{+} \mathrm{CD}_{1} 1^{+}, \mathrm{CD}_{3} 3^{+}, \mathrm{CD}_{1} 1^{+}$and $\mathrm{CD} 9{ }^{+} \mathrm{EVs}$ (Figure $2 \mathrm{C}$, detail in Supplementary Figure $\mathrm{S}_{1}$ ). Yet, the peak elution of EVs coincided with the minor protein elution peak from fractions 7 to 10 irrespective of the detected EV marker protein (Figure $2 \mathrm{C}$, Supplementary Figure $\mathrm{S} 1$ ).

TRPS further confirmed that the EV peak elution was in fraction 8 and showed that EV size was identical throughout fractions 6 to 12 (Figure 2D). Using Ponceau $\mathrm{S}$ staining, total protein remained virtually undetectable until fraction 12, whereas immunoblots revealed the presence of the EV marker proteins CD63, CD81 and MFGE8 starting at fraction 7 and with a peak in fraction 8 (Figure $2 \mathrm{E}$ ). Of note, CD63 and CD81 were specifically enriched in the early fractions, whereas MFGE8 was detected at a similar intensity in all fractions (Figure $2 \mathrm{E}$ ). However, when the amount of protein loaded per fraction was standardised, MFGE8 was only detectable in fractions 7 to 10 , suggesting a relative enrichment in the EV fractions (Figure. ${ }_{2} \mathrm{C}$, lane MFGE8 s.p.). Unexpectedly, $\mathrm{HSP}_{70}$, which is also considered an EV marker protein, was detected in the protein-rich fractions 13 to 18 , rather than co-eluting with the other EV marker proteins (Figure $2 \mathrm{E}$ ). This questions the suitability of $\mathrm{HSP}_{70}$ as a universal and specific EV marker protein. Uncropped images of all immunoblots are available in Supplementary Figure S2. 
A

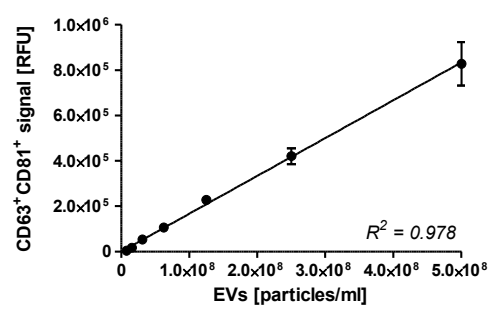

B

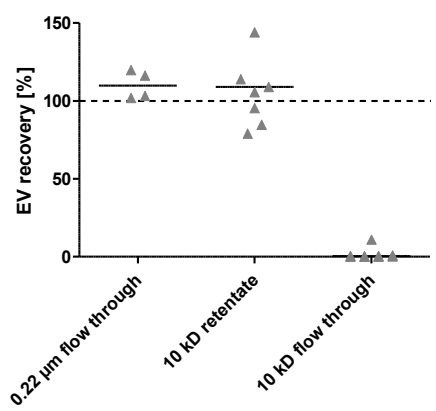

$\mathbf{E}$

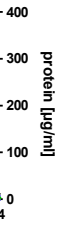

D

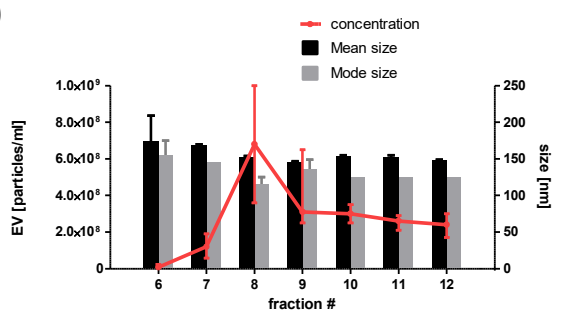

$\mathbf{F}$

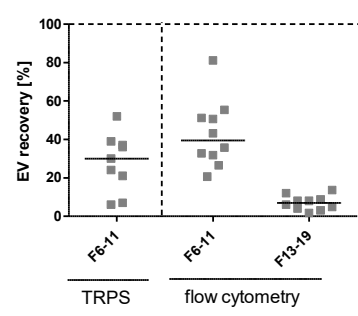

G

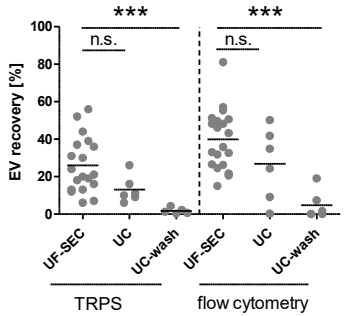

H

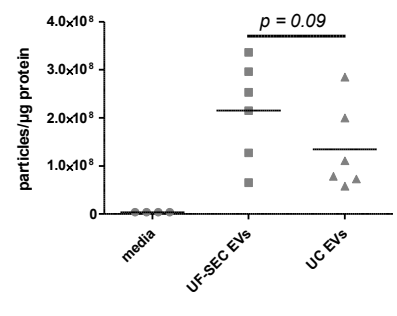

Figure 2 - Evaluation of the isolation protocol. (a) A representative standard curve demonstrating that the $\mathrm{CD}_{3}{ }^{+} \mathrm{CD}_{1}{ }^{+}$bead-coupled flow cytometry signal is proportional to the EV concentration determined by tuneable resistive pulse sensing (TRPS), allowing semi-quantitative EV measurements. (b) EV recovery after $0.22 \mu \mathrm{m}$ filtration of cell-depleted media. The data represents flow cytometry samples A and B in Fig. 1. EV quantity in unfiltered cell-depleted media was set to $100 \%$. (c) Protein concentration of the 24 SEC fractions determined by Bradford assay $(\mu \mathrm{g} / \mathrm{ml})$ and EV quantity determined by bead-coupled flow 
cytometry (relative fluorescent units; RFU) for the following combinations of antibodies (capture/detection): anti-CD63/anti-CD81, anti-CD63/anti-CD63, anti-CD81/anti-CD81, anti-CD9/antiCD9 (sampling step D indicated in Fig. 1). Graph shows medians without error bars, $\mathrm{n}=3$. (d) EV mode size, mean size and concentration for SEC fractions 6-12 as determined by TRPS. The graph shows the median and range, $n=3$. (e) Top: Ponceau $S$ total protein staining of SEC fractions 5 to 18; bottom: Western blot of SEC fractions 5 to 18 for EV marker proteins CD63, CD81, MFGE8 and HSP7o. For the lane MFGE8 s.p., a standardised protein concentration of $5 \mu \mathrm{g}$ was loaded for each fraction. For all other stainings, whole fractions were precipitated and loaded on the gel without standardisation of the protein content. (f) EV recovery in the final UF-SEC EV isolate (Fractions 6-11) and the final UF-SEC protein isolate (Fractions 13-19) as determined by TRPS or $\mathrm{CD}_{3} 3^{+} \mathrm{CD} 81^{+}$flow cytometry. The EV quantity in conditioned culture medium has been set as $100 \%$. (g) Comparison of the EV recovery for UF-SEC, UC or UC-wash, determined by TRPS (overall p-value $=0.0005$ ) and $\mathrm{CD} 63^{+} \mathrm{CD}_{1}{ }^{+}$bead-couple flow cytometry (overall $\mathrm{p}^{-}$ value $=0.0009$; sampling steps $\mathrm{E}, \mathrm{G}$ and $\mathrm{H}$, respectively). Data was analysed using the Kruskall Wallis test followed by Dunn's post-test. ${ }^{* *} \mathrm{p}<0.001$. (h) The EV-to-protein rate of purity base on TRPS and Bradford measurements of conditioned cell culture media, UF-SEC EVs and UC EVs. The statistical difference between UF-SEC EVs and UC EVs was assessed using the Mann-Whitney U test.

The EV-enriched, protein-low (6 to 10 or 11) and the protein-enriched, EVlow (14-19) SEC fractions were concentrated on $10 \mathrm{kDa}$ centrifuge filters to obtain EV and protein concentrates, respectively. The median EV recovery in the final UF-SEC EV isolate was $40 \%$ according to $\mathrm{CD}_{3}{ }^{+} \mathrm{CD}_{1}{ }^{+}$bead-coupled flow cytometry, while $7 \%$ of EVs was lost in the final protein concentrate (Figure $2 \mathrm{~F}$ ). By TRPS, the median recovery of EVs sized $80-250 \mathrm{~nm}$ was $30 \%$ (Figure $2 \mathrm{~F}$ ). The EV recovery of the UFSEC protocol was compared to that of UC or UC-wash. TRPS and $\mathrm{CD} 63^{+} \mathrm{CD} 81^{+}$beadcoupled flow cytometry both found that EV recovery was higher for UF-SEC than for UC and UC-wash. For UC-wash, this was statistically significant (Figure $2 \mathrm{G}$ ). The purity of an EV isolate can be estimated by dividing the EV concentration of the sample by its protein concentration [7]. UF-SEC EVs had a slightly higher EV-toprotein rate of purity compared to UC EVs, although this was not statistically significant (Figure $2 \mathrm{H}$ ).

Taken together, UF-SEC efficiently concentrates EVs from cell culture media and separates them from the bulk of free protein. The yield and purity of these UFSEC EVs tend to be superior to those of UC-EVs isolated using ultracentrifugation settings as optimised by Cvjetkovic et al. [13]. 


\section{Characterisation of the isolated EVs}

EV size and morphology were assessed by TRPS and cryo-TEM. TRPS revealed that the EV size distribution was similar for EVs in unfiltered conditioned media (Figure $3 \mathrm{~A}$ ), UF-SEC EVs (Figure ${ }_{3} \mathrm{~B}$ ) and UC EVs (Figure ${ }_{3} \mathrm{C}$ ). For all three sample types, the vast majority of EVs ranged between 80 and $250 \mathrm{~nm}$ in diameter, with mode sizes between 105 and $125 \mathrm{~nm}$. Although the UF-SEC and UC protocols both include a 0.22 $\mu \mathrm{m}$ filtration step, only UF-SEC EVs, but not UC-EVs contained significantly less particles larger than $200 \mathrm{~nm}$ compared to the unfiltered media (Figure $3 \mathrm{D}$ ), suggesting that aggregation may occur for the ultracentrifugation protocol. According to cryo-TEM, both UF-SEC EVs and UC EVs contained very small EVs below the detection limit of the qNano $(<8 \mathrm{o} \mathrm{nm})$. The EV diameters were similar for UF-SEC EVs and UC EVs with medians of 61.9 and $74.6 \mathrm{~nm}$, respectively (Figure 3D). Representative low and high magnification cryo-TEM images of UF-SEC EVs are shown in Figure ${ }_{3} \mathrm{E}$ and $\mathrm{F}$. We have previously published comparable cryo-TEM images of UC EVs [12].

Proteomic analysis was performed by nano LC-MS/MS for UF-SEC EVs, UC EVs or UF-SEC protein fractions. Proteins with a Score Sequest HT $>10$ were considered as identified with high confidence. For the UF-SEC EVs these were 388 proteins, for UC EVs 421 and for UF-SEC protein 264 (Supplementary Table S1). Figure $4 \mathrm{~A}$ shows a Venn diagram of the identified proteins. One hundred and nineteen proteins overlapped between all three datasets, and 147 between UF-SEC EVs and UC EVs, whereas the overlap between each individual type of EV isolate and the free secreted protein was relatively small (28 and 22 proteins for UF-SEC EVs and UC EVs, respectively). Table 1 shows 34 exosomal marker proteins compiled by de Menezes-Neto et al. [8] and their respective expression in the UF-SEC EV, UC EV and UF-SEC protein isolates. 
A
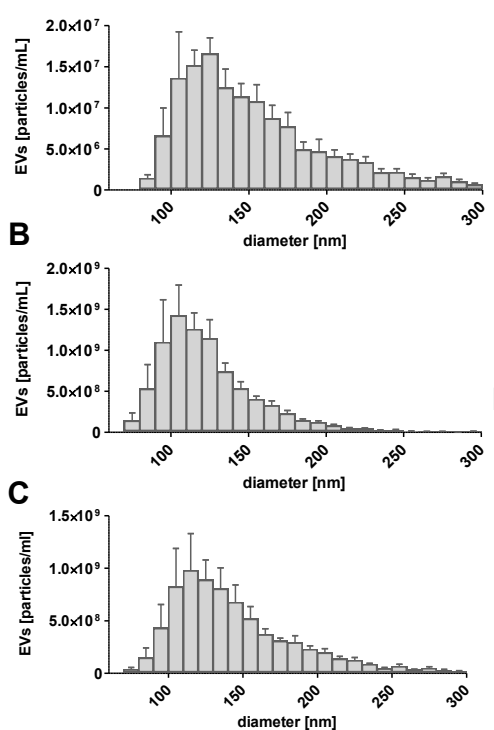

D

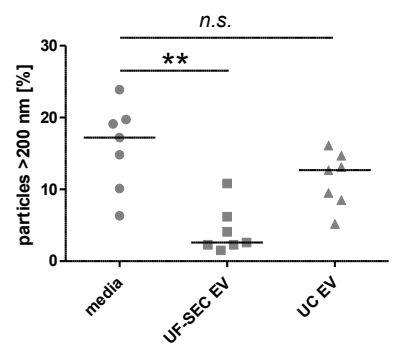

E

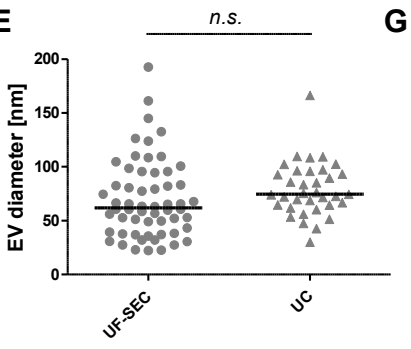

$\mathbf{F}$

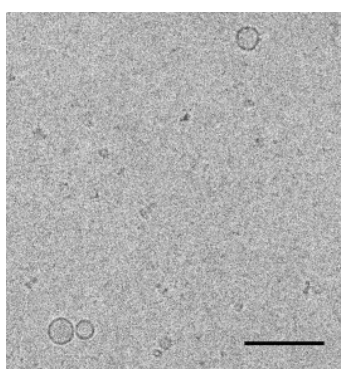

G
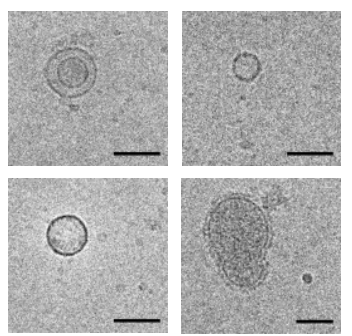

Figure 3 - Characterisation of EVs in unfiltered conditioned media, UF-SEC EVs and UC EVs. (a) Size distribution histogram of the EVs in (a) unfiltered conditioned media (b) UF-SEC EV isolates and (c) UC EV isolates as determined by TRPS. Graph shows the mean \pm SEM, $n=5$. (d) The percentage of particles $>200 \mathrm{~nm}$ in conditioned media, UF-SEC EVs and UC EVs according to TRPS. The bar indicates the median diameter. ${ }^{* *} \mathrm{p}$ o.0o1-o.o1 (e) Size distribution of EVs in UF-SEC and UC isolates based on cryoTEM. The bar indicates the median diameter. (f) Low magnification and (g) detail cryo-TEM recording of UF-SEC isolated EVs from BEAS-2B.

Table 1 List of EV marker proteins compiled by de Menezes-Neto et al. [9] and their presence or absence in EVs isolated from conditioned media of BEAS-2B cells using UF-SEC. The number of peptide spectral matches (\#PSM) gives an estimation of the relative protein abundance

\begin{tabular}{|c|c|c|c|c|c|c|c|}
\hline \multirow{2}{*}{ EV marker proteins } & \multirow{2}{*}{$\begin{array}{l}\text { Gene } \\
\text { symbol }\end{array}$} & \multicolumn{2}{|c|}{ UF-SEC EVs } & \multicolumn{2}{|c|}{ UC-EVs } & \multicolumn{2}{|c|}{$\begin{array}{l}\text { UF-SEC } \\
\text { protein }\end{array}$} \\
\hline & & identified & \#PSM & identified & \#PSM & identified & \#PSM \\
\hline Actin, cytoplasmic 1 & ACTB & yes & 79 & yes & 291 & yes & 297 \\
\hline $\begin{array}{l}\text { Fructose-bisphosphate aldolase } \\
\text { A }\end{array}$ & ALDOA & yes & 13 & yes & 65 & yes & 108 \\
\hline Annexin A2 & ANXA2 & yes & 42 & yes & 76 & yes & 6 \\
\hline Annexin $\mathrm{A}_{5}$ & $\mathrm{ANXA}_{5}$ & yes & 12 & yes & 10 & no & o \\
\hline Annexin A6 & ANXA6 & yes & 32 & yes & 33 & no & o \\
\hline CD63 antigen & $\mathrm{CD} 63$ & yes & 4 & yes & 5 & no & o \\
\hline CD81 antigen & CD81 & yes & 2 & yes & 9 & no & o \\
\hline
\end{tabular}




\begin{tabular}{|c|c|c|c|c|c|c|c|}
\hline \multirow{2}{*}{ EV marker proteins } & \multirow{2}{*}{$\begin{array}{l}\text { Gene } \\
\text { symbol }\end{array}$} & \multicolumn{2}{|c|}{ UF-SEC EVs } & \multicolumn{2}{|c|}{ UC-EVs } & \multicolumn{2}{|c|}{$\begin{array}{l}\text { UF-SEC } \\
\text { protein }\end{array}$} \\
\hline & & identified & \#PSM & identified & \#PSM & identified & \#PSM \\
\hline CD82 antigen & CD82 & yes & 3 & no & o & no & o \\
\hline CD9 antigen & CD9 & yes & 8 & yes & 13 & no & o \\
\hline Cofilin-1 & CFL1 & yes & 12 & yes & 18 & yes & 38 \\
\hline Clathrin heavy chain 1 & CLTC & yes & 142 & yes & 324 & yes & 4 \\
\hline Elongation factor 1 -alpha 1 & $\mathrm{EEF}_{1} \mathrm{~A}_{1}$ & yes & 20 & yes & 56 & yes & 25 \\
\hline Ezrin & EZR & yes & 22 & yes & 10 & yes & 20 \\
\hline Fatty acid synthase & FASN & yes & 76 & yes & 274 & yes & 3 \\
\hline $\begin{array}{c}\text { Glyceraldehyde-3-phosphate } \\
\text { dehydrogenase }\end{array}$ & GAPDH & yes & 26 & yes & 127 & yes & 43 \\
\hline $\begin{array}{l}\text { Rab GDP dissociation inhibitor } \\
\text { beta }\end{array}$ & GDI2 & yes & 3 & yes & 2 & yes & 19 \\
\hline $\begin{array}{l}\text { Heat shock cognate } 71 \mathrm{kDa} \\
\text { protein }\end{array}$ & HSPA8 & yes & 49 & yes & 30 & yes & 126 \\
\hline Lactadherin & MFGE8 & yes & 22 & yes & 40 & no & o \\
\hline Moesin & MSN & yes & 24 & yes & 9 & yes & 19 \\
\hline $\begin{array}{l}\text { Programmed cell death 6- } \\
\text { interacting protein }\end{array}$ & PDCD6IP & yes & 21 & yes & 12 & no & o \\
\hline Phosphoglycerate kinase 1 & PGK1 & yes & 15 & yes & 31 & yes & 113 \\
\hline Pyruvate kinase & PKM2 & yes & 51 & yes & 180 & yes & 86 \\
\hline Peroxiredoxin-1 & PRDX1 & yes & 4 & yes & 14 & yes & 28 \\
\hline Ras-related protein Rap-1b & $\mathrm{RAP} 1 \mathrm{~B}$ & yes & 8 & yes & 3 & no & o \\
\hline Radixin & RDX & yes & 12 & no & o & no & o \\
\hline Transforming protein RhoA & RHOA & yes & 9 & yes & 5 & no & o \\
\hline $\begin{array}{c}\text { Rho-related GTP-binding } \\
\text { protein RhoC }\end{array}$ & RHOC & no & o & yes & 2 & yes & 1 \\
\hline Syntenin-1 & SDCBP & yes & 8 & yes & 15 & no & o \\
\hline $\begin{array}{l}\text { Tumour susceptibility gene } 101 \\
\text { protein }\end{array}$ & TSG101 & no & o & no & o & no & o \\
\hline 14-3-3 protein beta/alpha & YWHAB & yes & 15 & yes & 11 & yes & 26 \\
\hline 14-3-3 protein epsilon & YWHAE & yes & 11 & yes & 11 & yes & 16 \\
\hline $14-3-3$ protein gamma & YWHAG & yes & 8 & yes & 17 & yes & 18 \\
\hline $14-3-3$ protein theta & YWHAQ & yes & 14 & yes & 8 & yes & 19 \\
\hline 14-3-3 protein zeta/delta & YWHAZ & yes & 11 & yes & 9 & yes & 40 \\
\hline
\end{tabular}

Strikingly, most of these proposed exosomal markers were detected in all three datasets. Only Annexin A5, Annexin A6, CD63, CD81, CD9, MFGE8, PDCD6IP/Alix and syntenin-1 were identified in both UF-SEC EVs and UC EVs, but not in UF-SEC 
protein, suggesting that these may be the most specific among the 34 proposed exosome markers. Of note, HSP7o (HSPA8) was identified with a higher number of peptide spectral matches (\#PSM) in the UF-SEC protein than in either UF-SEC EVs or UC EVs, in line with our finding that immunoblots stained positive for HSP7o in fractions 13 to 18 rather than in the early EV-fractions (Figure $2 \mathrm{E}$ ). Rab GTPases are enzymes that regulate membrane transport and fusion processes in the endosomal compartment that exosomes are derived from [16]. For UF-SEC EVs and UC EVs, but not UF-SEC protein, several Rab GTPases were identified (Supplementary Table S2). In all three sample types, most proteins considered as markers for contamination from intracellular organelles [17] were absent, except histones and the endoplasmic reticulum associated protein grp94 (Table 2 ).

Table 2 List of contamination marker proteins (adapted from [13]) and their presence or absence in UFSEC EVs, UV EVs or UF-SEC protein

\begin{tabular}{|c|c|c|c|c|c|}
\hline $\begin{array}{c}\text { contamination marker } \\
\text { proteins }\end{array}$ & $\begin{array}{l}\text { Gene } \\
\text { symbol }\end{array}$ & $\begin{array}{c}\text { Origin of } \\
\text { contamination }\end{array}$ & UF-SEC EVs & UC-EVs & $\begin{array}{l}\text { UF-SEC } \\
\text { protein }\end{array}$ \\
\hline endoplasmin / grp94 & HSP9oB1 & ER & yes & yes & yes \\
\hline calnexin & CANX & ER & no & no & no \\
\hline $\begin{array}{c}130 \mathrm{kDa} \text { cis-Golgi matrix } \\
\text { protein }\end{array}$ & GM13o & Golgi & no & no & no \\
\hline cytochrome cı & $\mathrm{CYC}_{1}$ & mitochondria & no & no & no \\
\hline histones & $\mathrm{HIST}^{*} \mathrm{H}^{*}$ & Nucleus & yes & yes & yes \\
\hline protein argonaut & AGO-* & $\begin{array}{l}\text { argonaut / RISC } \\
\text { complex }\end{array}$ & no & no & no \\
\hline
\end{tabular}

Next, functional enrichment analysis of the proteomics data was performed for cellular component gene ontology (GO) terms. Both UF-SEC EVs and UC-EVs showed a more than 5 -fold enrichment for the GO term exosomes (Figure ${ }_{4} \mathrm{~B}$ ). However, the UF-SEC protein dataset was similarly enriched for exosomes, thus questioning the specificity of the finding (Figure ${ }_{4} \mathrm{~B}$ ). All three datasets were similarly enriched for cytoplasm. Yet, UF-SEC EVs were most prominently enriched for membrane, whereas UF-SEC protein was most strongly enriched for extracellular, suggesting that there was an efficient separation of membrane-associated and free secreted proteins by UF-SEC (Figure $4 \mathrm{~B}$ ). Functional enrichment analysis was also performed for biological process $\mathrm{GO}$ terms (Figure ${ }_{4} \mathrm{C}$ ) and for manually curated biological pathways (Figure $4 \mathrm{D}$ ). For most biological processes and pathways, the 
fold enrichment was similar for UF-SEC EVs and UC EVs, but distinct from UF-SEC protein. This implies that EVs may exert distinct functions compared to free secreted proteins. EV-enriched biological pathways included metabolism of RNA, protein folding, regulation of mitotic cell cycle and several immunity related pathways, such as ER-phagosome pathway, antigen processing - cross presentation and adaptive immune system.

We then aimed to determine whether BEAS-2B derived EVs contain proteins that are specific for lung epithelium-derived EVs. Hurwitz et al. have recently analysed the proteomic composition of EVs derived from 6o cancer cell lines, including 9 of pulmonary epithelial origin [18]. They identified 3362 unique proteins that were expressed in at least one of the 9 lung cancer cell lines. These comprised 64 proteins that were absent in EVs from the 51 non-lung cancer cell lines. Here, we included 160 proteins that were detected in both UF-SEC EVs and UC EVs, but not in UF-SEC protein. We tested the overlap of these BEAS-2B EV-associated proteins with either the total lung cancer EV proteome or the lung-cancer specific proteins according to Hurwitz et al. While 140 of the 160 BEAS-2B EV proteins overlapped with the lung cancer EV proteome identified by Hurwitz et al., none of them overlapped with the 64 lung cancer EV-specific proteins. However, in a functional enrichment analysis for the site of expression, the BEAS-2B EVs showed a much stronger fold-enrichment for lung epithelial-related sites of expression than the 64 proteins that were proposed as lung cancer EV-specific by Hurwitz et al. (Figure $4 \mathrm{E}$ ). Thus, the BEAS-2B EV dataset contained no individual lung epithelial-specific proteins, but a complex protein signature that indicates their origin.

Taken together, our UF-SEC protocol yields small to very small EVs expressing exosomal marker proteins. Moreover, our data suggests that besides universal EV-associated proteins, EVs also carry a protein signature that may be specific for their cell of origin. 

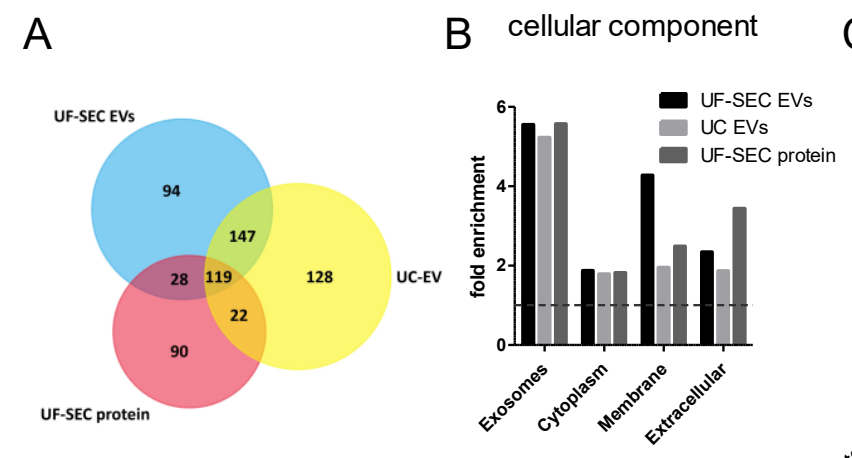

C biological process

$\mathrm{D}$

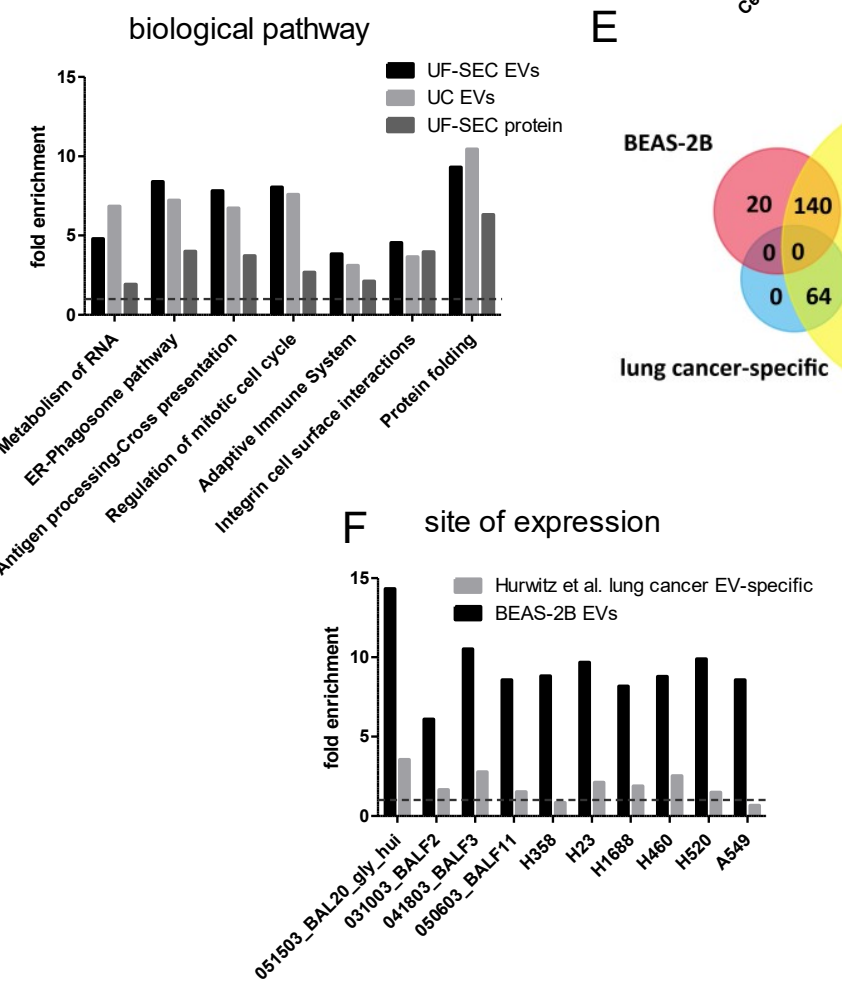

$E$

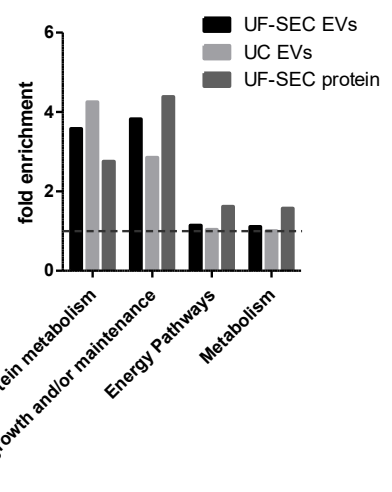

total lung cancer

BEAS-2B

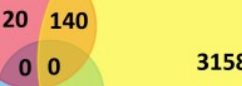

064

3158

Figure 4 - Proteomic characterisation of UF-SEC EVs, UC EVs and UF-SEC protein from BEAS-2B cells. (a) Venn diagram of the proteins identified for UF-SEC EVs, UC EVs and UF-SEC protein. (b) Functional enrichment analysis for cellular component GO terms. (c) Functional enrichment analysis for biological process GO terms. (d) Functional enrichment analysis for manually curated biological pathways. (e) Venn diagram of proteins identified in UF-SEC EVs and UC EVs but not UF-SEC protein from BEAS-2B cells (BEAS-2B EVS) compared to the total lung cancer EV associated proteome and the lung cancer specific proteome according to Hurwitz et al.[18]. (f) Functional enrichment analysis for the site of expression for the BEAS-2B EV proteome and the lung cancer-specific proteome proposed by Hurwitz et al.[18]. 


\section{Functional analysis}

Finally, we aimed to assess whether UF-SEC is a suitable isolation method for comparing biological effects of EVs and the non-EV associated secretome. As Moon et al. have previously found that EVs from BEAS-2B bronchial epithelial cells stimulated with cigarette smoke extract (CSE) enhance IL-8 release from naïve BEAS-2B cells [11], we first determined the effect of UF-SEC EVs, UC EVs and UF-SEC protein from unexposed or CSE-exposed BEAS-2B cells on naïve BEAS-2B cells. Cells were treated with $10^{8} \mathrm{EVs} / \mathrm{ml}$ or with volume-matched protein isolates from the UFSEC protocol. After $48 \mathrm{~h}$, supernatants were harvested and IL- 8 concentrations determined using ELISA. In contrast to the observations by Moon et al., only the UFSEC protein fractions, but neither UF-SEC EVs nor UC EVs resulted in increased IL-8 release (Figure $5 \mathrm{~A}$ ). To test whether UF-SEC protein truly induced IL-8 secretion in naïve BEAS-2B cells, we assessed the IL-8 content of UF-SEC protein samples that were incubated for $48 \mathrm{~h}$ without cells. Figure 5 A (UF-SEC protein without cells) shows that a substantial amount of IL- 8 was detected in these cell-free samples, suggesting that the elevated IL-8 concentrations after stimulation of BEAS-2B cells with UF-SEC protein largely result from a carryover of IL-8 protein. We also assessed the effect of UF-SEC EVs, UC EVs and UF-SEC protein on adhesion of THP-1 monocytes to human umbilical cord endothelial cells (HUVECs). For this purpose, HUVECs were treated with $7.5 \times 10^{7} \mathrm{EVs} / \mathrm{ml}$ or volume-matched protein isolates for $72 \mathrm{~h}$. After removal of the EV containing medium, adhesion of THP-1 monocytes to the HUVECs was assessed in a flow chamber. Only UF-SEC EVs and UC EVs from control and CSE-stimulated BEAS-2B cells, but not the protein isolates resulted in adhesion of the monocytes (Figure $5 \mathrm{~B}$ ). While results were comparable for UF-SEC EVs and UC EVs, the variance was greater for results obtained with the UC EVs (coefficient of variation $83.8 \%$ for o\% CSE UC EVs and $19.0 \%$ for o\% CSE UF-SEC EVs).

Thus, UF-SEC EVs yielded similar, but more reproducible results in our functional assays than UC EVs. Moreover, UF-SEC isolation provides well-matched EVs and non-EV-associated secreted protein samples, allowing comparative functional studies. 

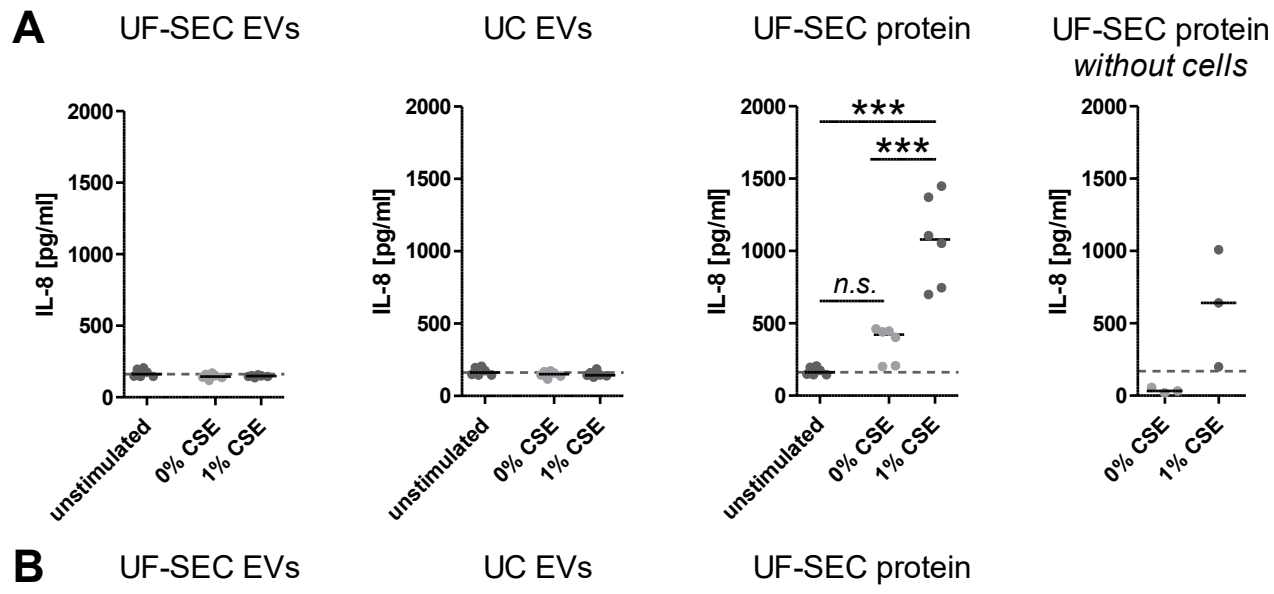

UC EVs

\section{UF-SEC protein}
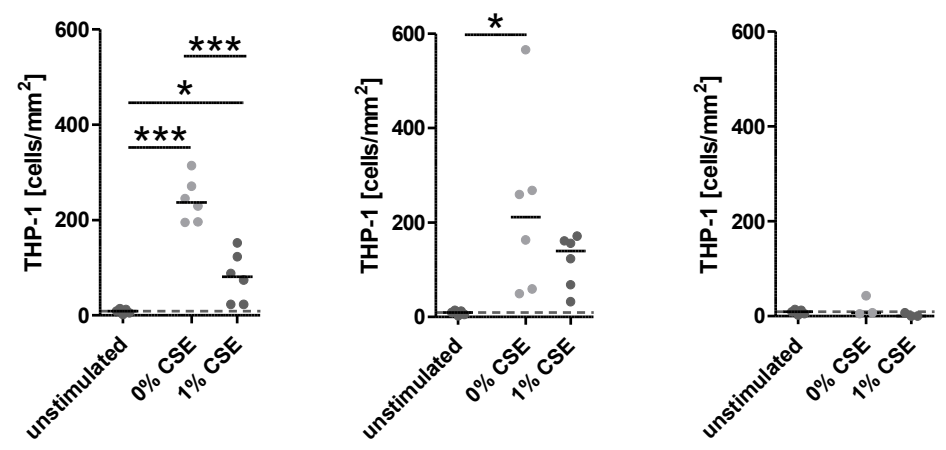

Figure 5 - Differential functional effects of EVs and free secreted protein. Effect of the EVs obtained by UF-SEC or the protein fractions from unexposed ( $0 \%$ CSE) or CSE-stimulated BEAS-2B cells on (a) the IL8 secretion of naïve BEAS-2B cells and (b) adhesion of THP-1 monocytes to HUVECs (overall pvalue $<0.0001$ ). Data was analysed by the Kruskall Wallis test followed by Dunn's posthoc test. ${ }^{*} \mathrm{p}=0.01-$ 0.05 , and ${ }^{* * *} \mathrm{p}<0.001$ compared to the unstimulated control.

\section{Discussion}

In this study, we established UF-SEC as an easy and robust method for obtaining EV isolates from cell culture media with sufficient yield and purity for compositional and functional characterisation. In 2014, Böing et al have demonstrated that SEC using $10 \mathrm{ml}$ sepharose $\mathrm{CL}-2 \mathrm{~B}$ columns efficiently isolates EVs from plasma [7]. However, the $10 \mathrm{ml}$ sepharose $\mathrm{CL}-2 \mathrm{~B}$ columns are only suitable for small sample volumes of about $0.5 \mathrm{ml}$. As cell culture media are relatively dilute in EVs, large volumes are required for EV isolation (often $>100 \mathrm{ml}[4]$ ). Therefore, protocols have 
been developed where media are concentrated by ultrafiltration prior to SEC [9, 10]. Unfortunately, neither the media volumes before and after ultrafiltration, nor the size of the SEC column were reported in these studies. Here, we aimed to report our protocols in a detailed and transparent way to allow easy reproduction of our methodology by other research groups.

The majority of EVs in unfiltered media of the bronchial epithelial cells used in this study were between 80 and $250 \mathrm{~nm}$ in diameter as estimated by TRPS. To specifically concentrate and purify these relatively small EVs, we introduced a $0.22 \mu \mathrm{m}$ filtration step, chose a small molecular weight cut-off for ultrafiltration and used a SEC matrix expected to efficiently separate small EVs from free protein. Instead of the $100 \mathrm{kDa}$ filters used for media concentration in previous studies [9, 19], we used 1o kDa filters, which resulted in complete EV recovery in the concentrate. Similarly, Vergauwen et al. have recently demonstrated that EVs can be concentrated with complete recovery on $10 \mathrm{kDa}$ filters, whereas recovery was only $40 \%$ for $100 \mathrm{kDa}$ filters [20]. Importantly, they have also shown that recovery was best with the regenerated cellulose Amicon Ultra Centrifugal filters from Millipore that were also used in this study, while EV yield was highly inferior when using ultrafiltration systems with different filtration membrane materials [20]. The matrix of our SEC columns was sepharose CL-4B, which has a smaller size exclusion limit than the classically used sepharose CL-2B ( 42 vs. $75 \mathrm{~nm}$ ) [21]. Using this matrix, all particles larger than $42 \mathrm{~nm}$ are expected to elute in early fractions, while smaller particles and molecules are delayed. This putatively provides a better separation of small EVs from free protein than matrices with a larger size exclusion limit. This is supported by the finding of Baranyai et al. that sepharose CL-4B provides a better separation of EVs from bovine serum albumin than sepharose CL-2B [22]. The improved separation does not appear to result in decreased yield as EV recovery in the early protein-low fractions is similar for sepharose CL-4B (40\%, this study) and CL-2B (43\%, [7]).

All in all, the combination of $0.22 \mu \mathrm{m}$ filtration, concentration on a $10 \mathrm{kDa}$ filter and CL-4B SEC in our isolation protocol yielded very small EVs (median size by cryo-TEM $61 \mathrm{~nm}$, mode size by TRPS $105 \mathrm{~nm}$ ). According to proteomics analysis, these EVs expressed several exosome marker proteins, including the tetraspanins CD63, CD81 and CD9, MFGE8 and several Rab GTPases that are suggestive of endosomal origin [16]. Moreover, most proteins considered to be contamination markers were absent, except for grp94 and several histones. However, grp94 currently has 109 entries in the EVpedia database [23, 24], as compared to 103 entries for the most commonly used exosome marker protein CD63. This suggests that, in contrast to the current consensus, grp94 may truly occur associated with EVs. 
Moreover, histones have been proposed to be sorted selectively into EVs by two independent studies [25, 26], questioning their categorisation as contamination markers. Thus, our UF-SEC protocol yields small EVs with exosome properties with sufficient purity for proteomic studies.

As UC is currently the most widely applied and accepted technique for EV isolation [4], we also compared the efficiency of our UF-SEC protocol to UC. Both, the EV-yield and the EV-to-protein rate of purity were similar for UF-SEC and UC, but tended to be superior for UF-SEC. Similarly, Mol et al. did not find any difference between SEC-isolated and UC-isolated EVs in terms of protein content and EV yield [10]. In contrast, Nordin et al. have reported a 5-fold higher EV-yield for UF-SEC than for UC [9]. This discrepancy may arise from divergences in the details of either the UF-SEC or the UC protocols that were applied in the different studies. Proteomics characterisation revealed that the proteomes of UF-SEC EVs and UC EVs overlapped to a similar extent with non-EV associated secreted proteins (UF-SEC protein). This further supports that there is no clear difference in EV-to-protein purity between the two techniques. Additionally, bovine serum albumin (BSA) was the most abundantly identified protein in both UF-SEC EVs and UC EVs (Supplementary Table $\mathrm{S}$ ), highlighting that contamination with soluble proteins still occurs for both isolation techniques. However, UF-SEC EVs were more strongly enriched for the cellular component membrane than UC EVs (4.3-fold vs. 2.o-fold), suggesting a higher enrichment in membrane vesicles. In biological pathway analysis, UF-SEC EVs and UC EVs showed a similar pattern of enrichment that was distinct from the UF-SEC protein fractions. Pathways that were enriched in both types of EV isolates included maintenance functions such as metabolism of RNA, regulation of mitotic cell cycle and protein folding, as well as several pathways related to immunity, including ER-phagosome pathway, antigen processing - cross presentation and adaptive immune system. Nordin et al. also found that UF-SEC isolated and UC isolated EVs show similar patterns in GO term enrichment analysis [9]. However, they did not investigate whether the EV enrichment pattern was specific in terms of differing from the enrichment pattern of free secreted protein.

Another aim of this study was to compare the functional effects of UF-SEC EVs and UC EVs and to investigate whether our UF-SEC protocol can be used to discriminate between the functional effects of EVs and of free secreted protein. The $10 \mathrm{kDa}$ ultrafiltration cut-off is anticipated to equally concentrate EVs and small secreted proteins. After separation using SEC, this should provide well-matched EV and protein concentrates for comparative functional analyses. We found that only UF-SEC protein fractions, but not UF-SEC EVs or UC EVs from cigarette smoke- 
exposed bronchial epithelial cells induce IL-8 release from naïve bronchial epithelial cells. In contrast, UF-SEC EVs and UC -EVs, but not UF-SEC protein promoted adhesion of THP-1 monocytes to endothelial cells. Thus, UF-SEC is an ideal method for directly comparing the biological effects of EVs to those of the non-EV associated secretome. Concerning the comparison of the two EV isolation techniques, results were similar for UF-SEC EVs and UC EVs. This is in contrast to findings of Mol et al. who reported a higher functionality of SEC-isolated EVs [10]. However, while the amplitude of the THP-1 adhesion to endothelial cells was similar for UF-SEC EVs and UC EVs, variability was higher for the UC EVs, leading to a higher p-value and less discriminative power in the statistical analysis. While it is premature to generalise this observation, the higher variability may be caused by the presence of aggregated EVs in the UC EVs.

When studying EVs in conditioned media of cell monocultures, it is obvious from what cell type the EVs are derived. However, in translational studies, EVs are investigated in complex body fluids such as plasma. A major challenge is to determine the origin of these EVs. Therefore, one of the side aims of this study was to explore whether BEAS-2B bronchial epithelial cell-derived EVs contain cell typespecific proteins. A similar attempt has previously been made by Hurwitz et al. who analysed the proteomic composition of 6o cancer cell lines, including 9 that were derived from the pulmonary epithelium [18]. They proposed a list of 64 potentially lung cancer-specific proteins that were identified in at least one of the 9 lung cancer cell lines, but in none of the other 51 cancer cell lines. None of these 64 proteins was found to be associated with BEAS-2B EVs in our study. However, the 160 proteins that were specifically EV-associated (i.e. identified in UF-SEC EVs and UC EVs but not in UF-SEC protein) were highly enriched for lung-related sites of expression, including bronchoalveolar lavage fluid and several pulmonary epithelial-derived cancer cell lines. Thus, our data suggests that pulmonary epithelial-derived EVs carry a unique protein signature. Such a protein signature may be useful for identifying EVs of pulmonary epithelial origin in complex biological fluids.

The UF-SEC EV isolation protocol described in this study provides several advantages. Here, we demonstrate that the technique can be used for proteomic and functional EV characterisation. Moreover, others have shown that SEC also allows discriminating between EV-associated and non EV-associated microRNAs [27]. While we estimate that the consumable costs of our technique are comparable to ultracentrifugation, EV isolation can be performed using a normal table top centrifuge. Thus, research groups that start working with EVs are not confronted with the high costs of purchasing an ultracentrifuge. Moreover, in our hands the EV 
yield and purity appear slightly superior using UF-SEC compared to UC and the technique provides very robust results when performed by inexperienced experimenters. In contrast, we have experienced that the yield of UC isolations strongly depends on the operator. Increasing the size of the $10 \mathrm{kDa}$ centrifuge filters and/or the SEC columns combined with automated fraction collection would allow scaling up the isolation protocol to obtain large amounts of EVs for clinical studies. However, our technique also bears limitations. The sepharose CL-4B matrix used in our study may not be suitable for isolating EVs from plasma as its low size exclusion limit may impair the resolution between EVs and high density lipoprotein (HDL). Moreover, our method may be unable to resolve EVs from very high molecular weight complexes with similar sizes to HDL, such as extracellular proteasome complexes. Variations of the protocol may be applied for isolating larger EVs from cell culture media or for isolating EVs from body fluids. These may include skipping the $0.22 \mu \mathrm{m}$ filtration, using a larger molecular weight cut-off for ultrafiltration and using a SEC matrix with a larger size exclusion limit.

In conclusion, this study demonstrates that ultrafiltration combined with SEC is an easy and robust method for isolating EVs with exosome properties from cell culture media. The yield and purity of EVs obtained with this method tended to be superior to ultracentrifugation and were sufficient for proteomic and functional analyses. Moreover, UF-SEC provides a well-matched concentrate of the non-EV associated secretome for differential functional analysis.

\section{Acknowledgements}

The authors would like to thank Hans Duimel for helping with the cryo-transmission electron microscopy.

This project was funded by the Netherlands Organisation for Scientific Research (NWO) grant 022.003.011 with the title "NUTRIM NWO Graduate Program: Metabolism and chronic disease" awarded to BJB. It was also supported by the NWO grant ZonMW VIDI 016.126.358 and the Landsteiner Foundation for Blood Transfusion Research grant LSBR Nr. 1638, both awarded to R.R.K. The funding sources were not involved in the study design, nor in the collection, analysis and interpretation of data or in the writing of the report.

\section{Competing financial interests statement}

The authors declare that they do not have any competing financial interests nor any other conflict of interests. 


\section{References}

1. Yanez-Mo, M., et al., Biological properties of extracellular vesicles and their physiological functions. J Extracell Vesicles, 2015. 4: p. 27066.

2. Cosselman, K.E., A. Navas-Acien, and J.D. Kaufman, Environmental factors in cardiovascular disease. Nat Rev Cardiol, 2015. 12(11): p. 627-42.

3. Admyre, C., et al., Exosomes with major histocompatibility complex class II and co-stimulatory molecules are present in human BAL fluid. Eur Respir J, 2003. 22(4): p. 578-83.

4. Gardiner, C., et al., Techniques used for the isolation and characterization of extracellular vesicles: results of a worldwide survey. J Extracell Vesicles, 2016. 5: p. 32945.

5. Webber, J. and A. Clayton, How pure are your vesicles? J Extracell Vesicles, 2013. 2.

6. Linares, R., et al., High-speed centrifugation induces aggregation of extracellular vesicles. J Extracell Vesicles, 2015. 4: p. 29509.

7. Boing, A.N., et al., Single-step isolation of extracellular vesicles by size-exclusion chromatography. J Extracell Vesicles, 2014. 3.

8. de Menezes-Neto, A., et al., Size-exclusion chromatography as a stand-alone methodology identifies novel markers in mass spectrometry analyses of plasma-derived vesicles from healthy individuals. J Extracell Vesicles, 2015. 4: p. 27378.

9. Nordin, J.Z., et al., Ultrafiltration with size-exclusion liquid chromatography for high yield isolation of extracellular vesicles preserving intact biophysical and functional properties. Nanomedicine, 2015. 11(4): p. 879-83.

10. Mol, E.A., et al., Higher functionality of extracellular vesicles isolated using size-exclusion chromatography compared to ultracentrifugation. Nanomedicine, 2017.

11. Zuo, L., et al., Interrelated role of cigarette smoking, oxidative stress, and immune response in COPD and corresponding treatments. Am J Physiol Lung Cell Mol Physiol, 2014. 307(3): p. L20518.

12. Benedikter, B.J., et al., Cigarette smoke extract induced exosome release is mediated by depletion of exofacial thiols and can be inhibited by thiol-antioxidants. Free Radic Biol Med, 2017.

13. Cvjetkovic, A., J. Lotvall, and C. Lasser, The influence of rotor type and centrifugation time on the yield and purity of extracellular vesicles. J Extracell Vesicles, 2014. 3.

14. Volgers, C., et al., Bead-based flow-cytometry for semi-quantitative analysis of complex membrane vesicle populations released by bacteria and host cells. Microbiol Res, 2017. 200: p. 2532.

15. Pathan, M., et al., FunRich: An open access standalone functional enrichment and interaction network analysis tool. Proteomics, 2015. 15(15): p. 2597-601.

16. Blanc, L. and M. Vidal, New insights into the function of Rab GTPases in the context of exosomal secretion. Small GTPases, 2017: p. 1-12.

17. Lotvall, J., et al., Minimal experimental requirements for definition of extracellular vesicles and their functions: a position statement from the International Society for Extracellular Vesicles. J Extracell Vesicles, 2014. 3: p. 26913.

18. Hurwitz, S.N., et al., Proteomic profiling of NCI-6o extracellular vesicles uncovers common protein cargo and cancer type-specific biomarkers. Oncotarget, 2016. 7(52): p. 86999-87015.

19. Mol, E.A., et al., Higher functionality of extracellular vesicles isolated using size-exclusion chromatography compared to ultracentrifugation. Nanomedicine, 2017. 13(6): p. 2061-2065.

20. Vergauwen, G., et al., Confounding factors of ultrafiltration and protein analysis in extracellular vesicle research. Sci Rep, 2017. 7(1): p. 2704.

21. Hagel, L., M. Ostberg, and T. Andersson, Apparent pore size distributions of chromatography media. Journal of Chromatography A, 1996. 743(1): p. 33-42.

22. Baranyai, T., et al., Isolation of Exosomes from Blood Plasma: Qualitative and Quantitative Comparison of Ultracentrifugation and Size Exclusion Chromatography Methods. PLoS One, 2015. 10(12): p. eo145686.

23. Kim, D.K., et al., EVpedia: an integrated database of high-throughput data for systemic analyses of extracellular vesicles. J Extracell Vesicles, 2013. 2. 
24. Kim, D.K., et al., EVpedia: A community web resource for prokaryotic and eukaryotic extracellular vesicles research. Semin Cell Dev Biol, 2015. 40: p. 4-7.

25. Nangami, G., et al., Fetuin-A associates with histones intracellularly and shuttles them to exosomes to promote focal adhesion assembly resulting in rapid adhesion and spreading in breast carcinoma cells. Exp Cell Res, 2014. 328(2): p. 388-40o.

26. Wang, Z., et al., Telomeric repeat-containing RNA (TERRA) constitutes a nucleoprotein component of extracellular inflammatory exosomes. Proc Natl Acad Sci U S A, 2015. 112(46): p. E6293-300.

27. Arroyo, J.D., et al., Argonautez complexes carry a population of circulating microRNAs independent of vesicles in human plasma. Proc Natl Acad Sci U S A, 2011. 108(12): p. 5003-8. 


\section{Supplementary Methods}

\section{Immunostaining and imaging equipment and settings}

After membrane transfer, the presence of protein, including the unstained low range SDS-PAGE standard (Bio-Rad) was revealed by Ponceau S staining and an image was recorded. For immunoblots where unstained SDS-PAGE standards were used, the molecular weight standard bands were marked with a pen before destaining. The membrane was blocked overnight at $4^{\circ} \mathrm{C}$ with $5 \%$ BSA $(\mathrm{m} / \mathrm{v})$ in tris-buffered saline (TBS). Next, the membrane was incubated for $2 \mathrm{~h}$ at room temperature with one of the following antibodies: mouse anti-human $\mathrm{CD}_{3}$ (clone $\mathrm{H}_{5} \mathrm{C} 6, \mathrm{BD}$ Biosciences, $1000 \mathrm{x}$ diluted), mouse-anti human CD81 (clone JS-81; BD Biosciences, $1000 \mathrm{x}$ diluted), mouse anti-human MFGE8 (R\&D Systems, clone 278918, $500 \mathrm{x}$ diluted) or mouse anti-human $\mathrm{HSC}_{70} / \mathrm{HSP}_{70}$ (Enzo Life Sciences, clone $\mathrm{N}_{27} \mathrm{~F}_{3}-4,500 \mathrm{x}$ diluted). For all primary antibodies, this was followed by $1 \mathrm{~h}$ incubation with a polyclonal HRP-labelled rabbit anti-mouse antibody (DAKO, $1000 \mathrm{x}$ diluted). Staining was revealed using chemiluminescence-peroxidase substrate-3 (Sigma-Aldrich). Images were recorded using a ChemidocTM XRS+ System (Bio-Rad) with the software Quantity One V 4.6.7 (Bio-Rad). For chemiluminescence recordings, the Chemi Hi Sensitivity mode was used ( 2 x 2 binning, no light, $2 \times$ gain), the iris was opened completely and the exposure time was set between 15 and $120 \mathrm{~s}$ according to the signal strength. The Ponceau S staining (uncropped in Supplementary Figure $1 \mathrm{~A}$, cropped in Figure $2 \mathrm{C}$ ) and marker bands were recorded with custom settings ( 2 x 2 binning, Epi white illumination, $2 \mathrm{x}$ gain) using the auto exposure time function. The multichannel viewer of the software was used to make an overlay of the chemiluminescence (green) and light signal (red). Using the software Irfanview V 4.25, the overlay image was then converted to grey scale, followed by a conversion to the negative in order to obtain dark bands on a light background. Uncropped immunoblots are shown in Supplementary Figure 2. These images were cropped in order to show only the relevant bands in Figure $2 \mathrm{E}$. 


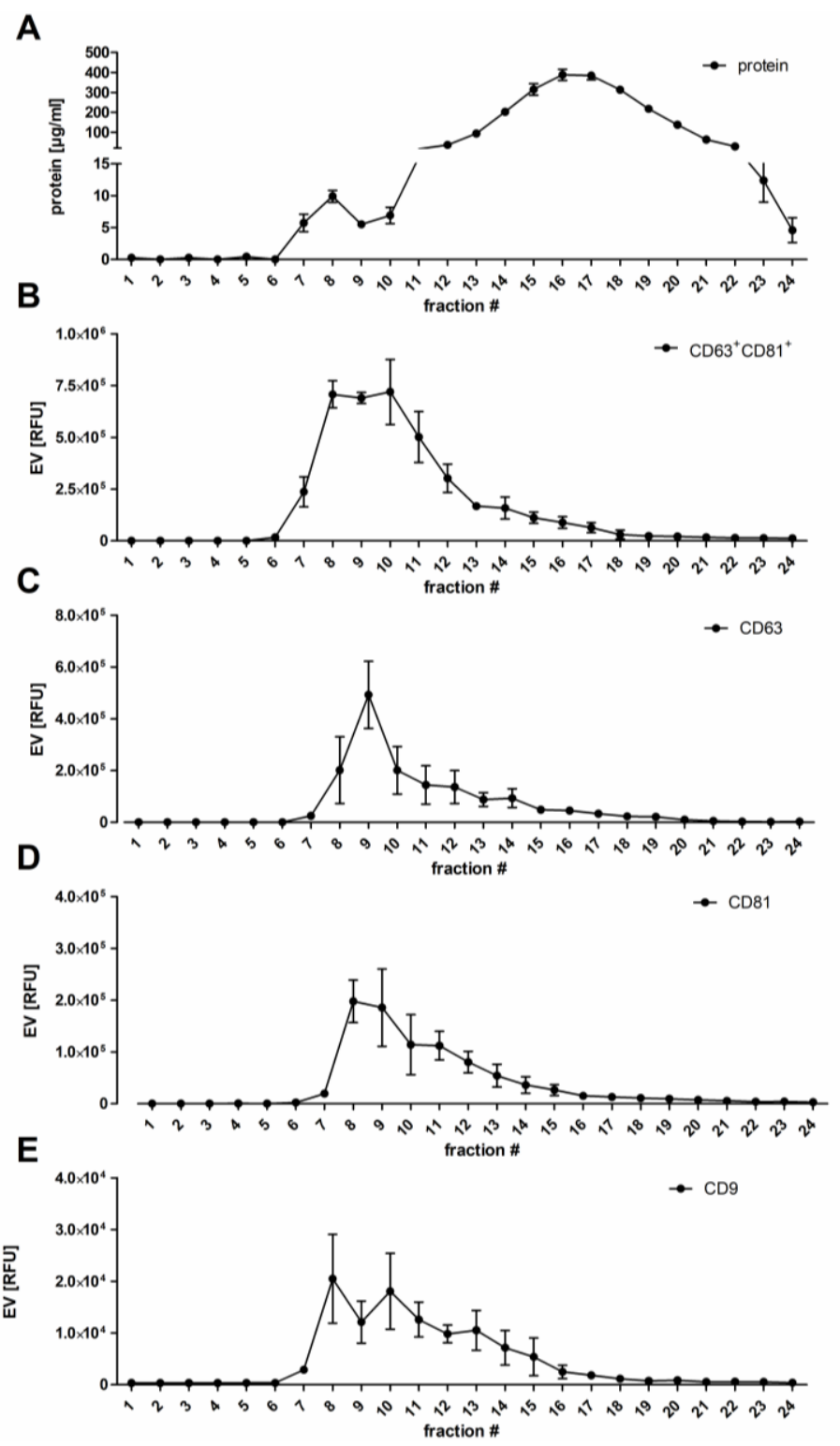

Supplementary Figure $\mathrm{S}_{1}$ - Protein and EV elution in the 24 SEC fractions according to Bradford assay and bead-coupled flow cytometry. The graphs show the means \pm standard error of 4 independent experiments. (A) The protein concentration according to Bradford microplate assay that was adapted for improved sensitivity. EVs detected by bead-coupled flow cytometry using (B) anti-CD63-coated beads and PElabelled anti-CD81 detection antibody; (C) anti-CD63-coated beads and PE-labelled anti-CD63 detection antibody; (D) anti-CD81-coated beads and PE-labelled anti-CD81 detection antibody or (E) anti-CD9coated beads and PE-labelled anti-CD9 detection antibody 
A

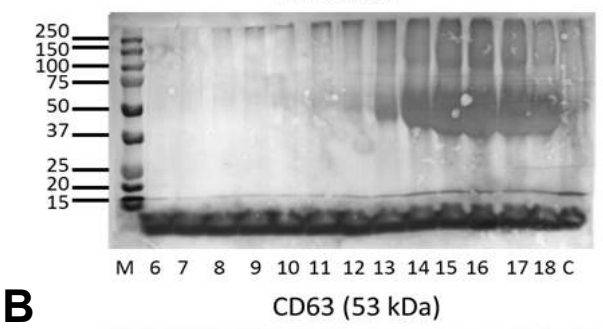

D
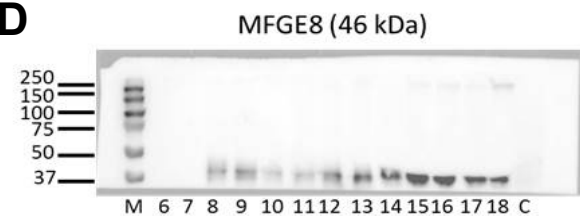

E

MFGE8 standardized protein (46 kDa)

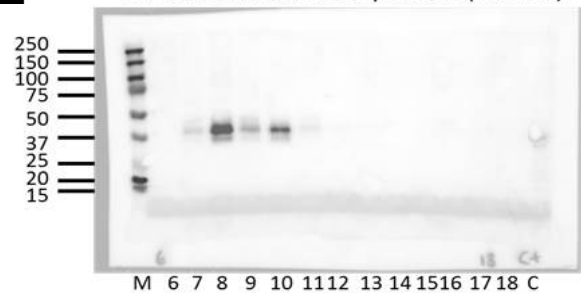

HSP70 (72-73 kDa)

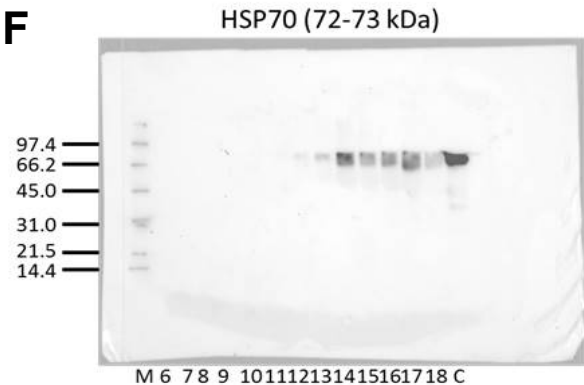

Supplementary Figure $\mathrm{S}_{2}$ - Uncropped images of the stainings in Figure $2 \mathrm{E}$ of the main article. (A) Ponceau S staining, (B) CD63 immunoblot, (C) CD81 immunoblot, (D) MFGE8 immunoblot, (E) MFGE8 immunoblot with a standardised amount of protein per fraction $(3 \mu \mathrm{g})$ and (F) HSP7o immunoblot. The numbers below the images indicate which SEC fraction was loaded into the respective lane. The lane where the molecular weight marker was loaded is marked with an M and the lane in which a BEAS-2B cell lysate was loaded as positive control is marked with a C. Between brackets, the predicted molecular weight of each protein according to the antibody manufacturer is given. For Figures A, C, D and E Precision Plus Dual Colour Standard \#161-0374 (Bio-Rad) was used, whereas Unstained SDS-Page standards, low range \#161-0304 was used for Figures B and F 
Supplementary Table S1 - All identified proteins for UF-SEC isolated EVs, UC-isolated EVs and UF-SEC protein fractions.

Available online at

https://static-content.springer.com/esm/art\%3A10.1038\%2Fs41598-017-15717-

7/MediaObjects/41598_2017_15717_MOESM2_ESM.xlsx 
Supplementary Table S2 - overview over Rab GTPases that were identified by nano LC-MS/MS in UF-SEC EVs, UC EVs and UF-SEC proteins. Proteins identified with a Score Sequest HT >10 were considered as identified with high confidence. In this table, proteins identified with a Score $<10$ are also included for completeness. The number of peptide spectral matches (\#PSM) gives an indication of the relative protein abundance

\begin{tabular}{|c|c|c|c|c|c|c|c|}
\hline \multirow{2}{*}{ EV marker proteins } & \multirow{2}{*}{$\begin{array}{l}\text { Gene } \\
\text { symbol }\end{array}$} & \multicolumn{2}{|c|}{ UF-SEC EVs } & \multicolumn{2}{|c|}{ UC EVs } & \multicolumn{2}{|c|}{ UF-SEC protein } \\
\hline & & identified & \#PSM & identified & \#PSM & identified & \#PSM \\
\hline Ras-related protein Rab-1A & $\mathrm{RAB1A}$ & Score $<10$ & 3 & No & o & No & o \\
\hline Ras-related protein $\mathrm{Rab}-{ }_{5} \mathrm{C}$ & $\mathrm{RAB}_{5} \mathrm{C}$ & Score $<10$ & 2 & No & o & No & o \\
\hline Ras-related protein Rab-7a & $\mathrm{RAB} 7 \mathrm{~A}$ & Yes & 5 & Score $<10$ & 2 & No & o \\
\hline Ras-related protein Rab-8B & RAB8B & Score $<10$ & 3 & Yes & 5 & No & o \\
\hline Ras-related protein Rab-10 & RAB1o & Score $<10$ & 4 & Yes & 6 & No & o \\
\hline Ras-related protein Rab-35 & $\mathrm{RAB}_{35}$ & yes & 6 & yes & 5 & no & o \\
\hline
\end{tabular}






\section{Chapter 5}

\section{Proteomic analysis reveals procoagulant properties of cigarette smoke-induced extracellular vesicles}

Birke J. Benedikter, Freek G. Bouwman, Alexandra C.A.

Heinzmann, Tanja Vajen, Edwin C. Mariman, Emiel F.M. Wouters, Paul H.M. Savelkoul, Rory R. Koenen, Gernot G.U.

Rohde, Rene van Oerle, Henri M. Spronk, Frank R.M. Stassen 


\section{Abstract}

Airway epithelial cells secrete extracellular vesicles (EVs) under basal conditions and when exposed to cigarette smoke extract (CSE). Getting insights into the composition of these EVs will help unravel their functions in homeostasis and smoking-induced pathology. Here, we characterized the proteomic composition of basal and CSEinduced airway epithelial EVs. BEAS-2B cells were left unexposed or exposed to $1 \%$ CSE for $24 \mathrm{~h}$, followed by EV isolation using ultrafiltration and size exclusion chromatography. Isolated EVs were labelled with tandem mass tags and their proteomic composition was determined using nano LC-MS/MS. Tissue factor activity was determined by a factor Xa generation assay; phosphatidylserine content by prothrombinase assay and thrombin generation using calibrated automated thrombogram (CAT). Nano LC-MS/MS identified 585 EV-associated proteins with high confidence. Of these, 201 were differentially expressed in the CSE-EVs according to the moderated t-test, followed by false discovery rate (FDR) adjustment with the FDR threshold set to o.1. Functional enrichment analysis revealed that 24 proteins of the pathway haemostasis were significantly upregulated in CSE-EVs, including tissue factor (TF). Increased TF expression on CSE-EVs was confirmed by bead-based flow cytometry and was associated with increased TF activity. CSEEVs caused faster and more thrombin generation in normal human plasma than control-EVs, which was partly TF-, but also phosphatidylserine-dependent. In conclusion, proteomic analysis allowed us to predict procoagulant properties of CSE-EVs which were confirmed in vitro. Cigarette smoke-induced EVs may contribute to the increased cardiovascular risk observed in smokers. 


\section{Introduction}

Tobacco consumption forms an important risk factor for several chronic diseases including lung cancer, chronic obstructive pulmonary disease (COPD) and cardiovascular disease (1). We and others have shown that cigarette smoke extract (CSE) causes increased release of extracellular vesicles (EVs) by different cell types in vitro (2-5). Moreover, smokers have increased concentrations of circulating EVs in vivo $(4,6,7)$. These EVs are secreted membrane vesicles that carry a versatile cargo of lipids, nucleotides and proteins (8). While EV nomenclature is currently controversial, it is generally accepted that two major subtypes with distinct biogenetic pathways exist, microvesicles and exosomes $(9,10)$. While the larger microvesicles are formed by direct shedding from the plasma membrane, the smaller exosomes are formed as intraluminal vesicles within multivesicular endosomes (MVEs) and released to the extracellular space when MVEs fuse with the plasma membrane $(11,12)$. Both types of EVs have been ascribed multiple functions by which they contribute to homeostasis, but also pathologies (8). As it is difficult to determine the biogenetic origin of EVs in complex biological fluids, exosomes ( $\sim 30-$ $150 \mathrm{~nm}$ ) and microvesicles ( $100-1000 \mathrm{~nm}$ ) have most commonly been distinguished based on their size and on the expression of marker proteins that are more frequently and abundantly expressed in exosomes than in microvesicles (e.g. CD63, CD81, CD9) (13). Here, the terms exosomes and microvesicles will be used according to these characteristics, and the general term EVs will be used when the characteristics are unknown.

The functions of microvesicles released by smoke-exposed monocytes and macrophages are relatively well studied. These microvesicles have been proposed to promote inflammation (3), proteolysis (14) and coagulation (15). However, EV functions can differ depending on the EV subtype, the secreting cell and its physiological state $(16,17)$. Although the airway epithelium forms the first line of contact with inhaled cigarette smoke, studies on the functions of EVs released by smoke-exposed airway epithelial cells are scarce. Previously, we have shown that airway epithelial cells secrete EVs with exosome properties, both at control conditions and when exposed to cigarette smoke extract (CSE) (5). Therefore, this study aimed to predict the functions of smoke-induced airway epithelial-derived exosomes. For this purpose, we isolated exosomes from conditioned media of unexposed or CSE-exposed airway epithelial cells using a combination of ultrafiltration and size exclusion chromatography (SEC). We then characterized their proteomic composition using nanoscale liquid chromatography coupled to 
tandem mass spectrometry (nano LC-MS/MS), with the hypothesis that exosome functions can be predicted based on their proteomic content.

\section{Materials and Methods}

\section{Cell culture and exposure}

BEAS-2B bronchial epithelial cells (ATCC CRL-96o9) were cultured and EV-depleted FCS and CSE were prepared as described previously (5). For flow cytometric analysis of EVs or cells, $2 \times 10^{5}$ cells per well were seeded on a 12-wells plate and for EVisolations, $4 \times 10^{6}$ cells were seeded per T75 and allowed to attach overnight. Cells were then washed twice with phosphate buffered saline (PBS) before $1 \mathrm{ml}$ (12-well plate) or $20 \mathrm{ml}\left(\mathrm{T}_{75}\right)$ of DMEM-F12 (Gibco) containing $0.1 \%$ EV-free FCS and either 1 $\%(\mathrm{v} / \mathrm{v})$ PBS (vehicle control) or $1 \%$ (v/v) CSE was added. For EV isolations, 3 T75 cell culture flasks and a total medium volume of $60 \mathrm{ml}$ were used per condition, except for nano LC-MS/MS, where $6 \mathrm{~T}_{75}$ and $120 \mathrm{ml}$ were used.

\section{EV isolation}

EV isolation was performed by a combination of $10 \mathrm{kDa}$ ultrafiltration and sepharose CL-4B size exclusion chromatography (SEC) as described previously (18). In brief, 6o $\mathrm{ml}$ of conditioned media were concentrated to $500 \mu \mathrm{l}$ on an Amicon Ultra-15 Centrifugal Filter Unit with Ultracel 10 membrane (10 kDa MWCO, Merck Millipore), followed by separation of EVs and free protein by SEC. The EVcontaining SEC fractions as well as the protein containing SEC fractions were then pooled and concentrated to $250 \mu \mathrm{l}$ on an Amicon Ultra-4 Centrifugal Filter Unit with Ultracel 10 membrane (10 kDa MWCO, Merck Millipore) to obtain EV isolates and protein concentrates, respectively. Unconditioned media isolates were the "EV" SEC fractions obtained by applying the isolation protocol to unconditioned media that were incubated for 24 hours with $1 \%(\mathrm{v} / \mathrm{v})$ PBS or CSE in the absence of cells.

\section{Characterization of EV size and morphology}

The morphology and size of the isolated EVs was visualized by cryo-transmission electron microscopy (TEM) as described previously (18). Additionally, the EV size distribution and concentration was determined by tuneable resistive pulse sensing (TRPS). TRPS was performed using a qNano Gold with Izon Control Suite 3.2 Software and SKP2oo calibration beads (Izon, Chirstchurch, New Zealand). EV isolates were analysed after a single freeze-thaw cycle at $-80^{\circ} \mathrm{C}$. Where possible, at least 500 blockades were detected per sample. To improve comparability between 
the different recordings, the pore stretch was adjusted to obtain a relative particle size of 0.65 for the SKP2oo calibration beads, and the voltage was adjusted to obtain a current between 125 and $130 \mathrm{nA}$. A size filter from 80 to $250 \mathrm{~nm}$ was applied for estimating EV concentrations.

\section{Processing of EV-associated protein, nano LC-MS/MS and database search}

Isolated EVs ( $500 \mu \mathrm{l}$, obtained from $120 \mathrm{ml}$ of conditioned media) were precipitated as described previously (18). Five microgram of precipitated protein per sample was incubated for 1 hour at $55^{\circ} \mathrm{C}$ with $50 \mathrm{mM}$ triethylammonium bicarbonate (TEAB; Sigma-Aldrich) and $10 \mathrm{mM}$ tris(2-carboxyethyl)phosphine (TCEP; Thermo Fisher Scientific). Next, protein was alkylated by incubation with $17 \mathrm{mM}$ iodoacetic acid (IAA, Sigma-Aldrich) for 30 min in the dark at room temperature. Samples were then incubated with six volumes of ice-cold acetone at $-20^{\circ} \mathrm{C}$ overnight before centrifugation at $8000 \mathrm{x} \mathrm{g}$ for $10 \mathrm{~min}$ at $4^{\circ} \mathrm{C}$. The dried pellet was resuspended in 50 $\mu \mathrm{l}$ of $100 \mathrm{mM}$ TEAB and samples were incubated with $20 \mathrm{ng} / \mu \mathrm{l}$ trypsin/endoproteinase lysC (Promega) for 2 hours at $37^{\circ} \mathrm{C}$. After addition of $75 \mu \mathrm{l}$ $100 \mathrm{mM}$ TEAB, samples were incubated for another 18 hours at $37^{\circ} \mathrm{C}$. Finally, samples were stained using the TMT1oplex ${ }^{\mathrm{TM}}$ Isobaric Label Reagent Set (Thermo Fisher Scientific) according to manufacturer's protocol. Twenty microliter from each of the ten samples ( 5 control isolates and 5 CSE isolates) was pooled.

A nanoflow HPLC instrument (Dionex ultimate 300) was coupled on-line to a Q Exactive (Thermo Scientific) with a nano-electrospray Flex ion source (Proxeon). The final concentration of the TMT labelled digest/peptide mixture was $0.2 \mu \mathrm{g} / \mu \mathrm{l}$ and $5 \mu \mathrm{l}$ of this mixture was loaded onto a C18-reversed phase column (Thermo Fisher Scientific, Acclaim PepMap C18 column, $75 \mu \mathrm{m}$ inner diameter x 15 cm, $5 \mu \mathrm{m}$ particle size). The peptides were separated with a 90 minutes linear gradient of 4-45 $\%$ buffer B (8o \% acetonitrile and $0.08 \%$ formic acid) at a flow rate of $300 \mathrm{~nL} / \mathrm{min}$.

The MS data acquisition and the data base search were performed using the Sequest HT Proteome Discoverer 2.1 as described previously (18), except that the resolution for HCD spectra was set to 35,00o and TMT reagent adducts $(+\mathbf{2 2 9 . 1 6 2 9 3 2}$ $\mathrm{Da}$ ) on lysine and peptide amino termini were set as fixed modifications. Sample abundances were normalized as to obtain an equal total peptide amount for all ten samples. The raw data of the nano LC-MS/MS analyses have been deposited to the public database ProteomeXchange (Project number: PXDoo6738). Proteins identified with a false discovery rate $($ FDR $)<0.01$ were considered of high confidence and included for downstream analysis. 


\section{EV detection using bead-coupled flow cytometry}

All antibodies were from BD Biosciences. EVs were detected by bead-coupled flow cytometry as described previously with some adaptations (5). Beads $\left(3.5 \times 10^{8} / \mathrm{ml} ; 4\right.$ $\mu \mathrm{m}$ aldehyde/sulphate latex beads; Thermo Fisher Scientific) were coated with 0.125 $\mathrm{mg} / \mathrm{ml}$ of mouse anti-human CD63 antibody (Clone $\mathrm{H}_{5} \mathrm{C} 6$ ), anti-human CD81 (clone JS-81), anti-human CD9 (Clone M-L13), or an equal mixture of all three antibodies. Then, $1 \times 10^{6}$ beads were incubated overnight with either $200 \mu \mathrm{l}$ of conditioned cell culture media or $200 \mu$ of isolated EVs suspended in PBS at a concentration of $2 \times 10^{8}$ particles/ml. Detection was performed as described previously (5) with either of the following phycoerythrin (PE)-labelled antibodies: mouse anti-human CD63, antihuman CD81, anti-human CD9 or anti-human tissue factor (TF; clone HTF-1). Alternatively, beads were stained for 15 minutes at room temperature with $50 \mu \mathrm{l}$ of Alexa Fluor 488 (AF488) conjugated annexin V (Thermo Fisher Scientific) diluted 50 $\mathrm{x}$ in annexin binding buffer (ABB) in order to detect phosphatidylserine (PS). Stained beads were suspended in $150 \mu \mathrm{l}$ PBS (antibody staining) or ABB (annexin V staining) and analysed using a BD FACSCanto II (BD Biosciences) with FACS Diva V8.o.1 software (BD Biosciences). The quantity of EVs in relative fluorescent units (RFU) was calculated by multiplying the percentage of $\mathrm{PE}$ or $\mathrm{AF}_{4} 88$-positive beads with the median fluorescent intensity (MFI) of the positive bead population.

\section{Cell viability and detection of cell surface-exposed TF and PS}

BEAS-2B cells $\left(2 \times 10^{5}\right)$ were incubated with $1 \%(\mathrm{v} / \mathrm{v})$ PBS or CSE on 12 -well plates. After $24 \mathrm{~h}$, cell viability was assessed by MTT assay as described previously (5). Alternatively, EDTA (250 mM, pH 6.14) was added to the wells to a final concentration of $10 \mathrm{mM}$ and incubated for 10 minutes at $37^{\circ} \mathrm{C}$. Cells were then gently detached by pipetting and sedimented by centrifugation (400 x g, $7 \mathrm{~min}$ ).

For detection of cell surface-exposed PS, cells were resuspended in $70 \mu \mathrm{l}$ annexin binding buffer (ABB) containing 3.6\% (v/v) AF488-labelled annexin V (AnxV) and $1 \mu \mathrm{g} / \mathrm{ml}$ propidium iodide (PI). After incubation for 15 minutes at room temperature, $100 \mu \mathrm{l}$ of $\mathrm{ABB}$ was added, followed by immediate measurement using a BD FACSCanto II (BD Biosciences) with FACS Diva V8.o.1 software (BD Biosciences). The percentages of AnxV'PI' (live, no cell surface-exposed PS), AnxV'PI' (apoptotic, cell surface-exposed PS) and $\mathrm{AnxV}^{+} \mathrm{PI}^{+}$(dead, impaired membrane integrity) were determined.

For TF detection, pelleted cells were resuspended in $100 \mu \mathrm{l}$ PBS containing $2 \%(\mathrm{w} / \mathrm{v})$ bovine serum albumin (BSA) and $2 \%(\mathrm{v} / \mathrm{v})$ PE-labelled mouse anti-human 
TF (clone HTF-1, BD Biosciences) or PE-labelled isotype control (clone MPC-21, BD Biosciences). After $45 \mathrm{~min}$ incubation at room temperature with gentle shaking, cells were sedimented at $400 \mathrm{x}$ g for 7 minutes, followed by resuspension in $150 \mu \mathrm{PBS}$ and measurement using a BD FACSCanto II (BD Biosciences) with FACS Diva V8.o.1 software (BD Biosciences). The gate was set so that $2 \%$ of the isotype-stained cells had a positive PE-signal.

\section{Blood collection for the normal human plasma pool}

Blood collection was performed as described previously with some adaptations (19). Written informed consent was obtained from all participants, and the study was approved by the institutional ethics committee of the Maastricht UMC+. Venous blood was collected from 122 healthy volunteers through antecubital venipuncture using 21-gauge needles, one discarding tube and 4 consecutive $3.2 \%(\mathrm{w} / \mathrm{v})$ citrated Vacutainer glass tubes (BD). Blood was centrifuged at 2,0oo x g for $5 \mathrm{~min}$, followed by a second centrifugation step at 5,00o $\mathrm{x} g$ for $10 \mathrm{~min}$ to obtain platelet poor plasma (PPP). PPP from all donors was pooled and aliquots of the thus obtained normal human plasma pool were snap-frozen in liquid nitrogen and stored at $-80{ }^{\circ} \mathrm{C}$ until use.

\section{Assessing procoagulant effects of EVS}

For blocking surface-exposed PS, $2.5 \times 10^{9} \mathrm{EVs} / \mathrm{ml}$ were incubated for $30 \mathrm{~min}$ at $37^{\circ} \mathrm{C}$ with $10 \mu \mathrm{g} / \mathrm{ml}$ annexin V (Thermo Fisher Scientific) in $50 \mu \mathrm{l}$ PBS containing $10 \%(\mathrm{v} / \mathrm{v})$ $10 \mathrm{x}$ ABB. Controls were mock-treated with $50 \mu \mathrm{l}$ PBS containing $10 \%(\mathrm{v} / \mathrm{v}) 10 \mathrm{x} \mathrm{ABB}$. EVs were then stored at $-80^{\circ} \mathrm{C}$.

Tissue factor (TF) activity was determined using an in house factor Xa generation assay as described previously (20). The assay is based on the principle that active TF forms a complex with factor VIIa, which activates factor X to Xa in the presence of $\mathrm{Ca}^{2+}$ and phospholipids. In brief, isolated EVs $\left(7.5 \times 10^{6}\right)$ and standards were incubated for 10 minutes at $37^{\circ} \mathrm{C}$ in the presence of recombinant factor VIIa (Novo Nordisk, Bagsværd, Denmark), $0.2 \mathrm{mM}$ 20/8o PS/phosphatidylcholine (PC) vesicles, $1 \mathrm{U} / \mathrm{mL}$ Bovine FX (Sigma-Aldrich) and $100 \mathrm{mM} \mathrm{Ca}^{2+}$. The formation of factor Xa was then measured kinetically using the chromogenic substrate 2765 (Chromogenix, final concentration of $0.7 \mathrm{mg} / \mathrm{mL}$ diluted in $50 \mathrm{mM}$ Tris- $\mathrm{HCl}, 175 \mathrm{nM}$ $\mathrm{NaCl}, 30 \mathrm{mM} \mathrm{Na}{ }_{2}$ EDTA, $\mathrm{pH} 7.4$ ) by measuring the OD at $405 \mathrm{~nm}$ each 15 seconds, for 15 minutes at $37^{\circ} \mathrm{C}$. 
Phosphatidylserine (PS)-dependent thrombin generation was determined using an in-house prothrombinase assay. In brief, in the presence of negatively charged phospholipids such as PS, factor Va and factor Xa assemble to form the active prothrombinase complex, which converts prothrombin into its active form thrombin. A reaction mix of $5 \mathrm{mg} / \mathrm{ml} \mathrm{BSA}$, $1.0 \mathrm{nM}$ bovine factor $\mathrm{Va}$, o.0 $5 \mathrm{nM}$ bovine factor $\mathrm{Xa}$ and $5 \mathrm{mM} \mathrm{CaCl}_{2}$ was prepared in HEPES-NaCl (HN) buffer (25 mM HEPES and $175 \mathrm{mM} \mathrm{NaCl}, \mathrm{pH} 7.7$ at room temperature). Ten microliter of phospholipid standard (10\% PS, 90\% PC; ranging from 10 to $250 \mathrm{nM}$ ), mock-treated EVs or annexin V-treated EVs $\left(5 \times 10^{8}\right.$ particles $\left./ \mathrm{ml}\right)$ were added to $190 \mu$ of the reaction mix. After 10 minutes incubation, human prothrombin (Haematologic Technologies Incorporated) was added to a final concentration of $500 \mathrm{nM}$ and incubated for 1 minute. Next, $50 \mu \mathrm{l}$ was subsampled and transferred to $150 \mu$ l cuvette buffer ( $50 \mathrm{mM}$ Tris, $175 \mathrm{mM} \mathrm{NaCl}, 20 \mathrm{mM}$ EDTA, $0.5 \mathrm{mg} / \mathrm{ml}$ ovalbumin, $\mathrm{pH}$ 7.9) and incubated for 7 min $37^{\circ} \mathrm{C}$. Thereafter, $50 \mu \mathrm{l}$ of the thrombin substrate S2238 (Chromogenix) was added and the absorption at 405 and $490 \mathrm{~nm}$ was measured every $30 \mathrm{~s}$ for $15 \mathrm{~min}$.

Thrombin generation in human plasma was determined by the Calibrated Automated Thrombogram method (CAT, Thrombinoscope BV). Untreated, mocktreated or annexin V-treated control EVs or CSE EVs $\left(2 \times 10^{8}\right.$ or $\left.1 \times 10^{8}\right)$ were added to $70 \mu$ of normal pooled PPP in the presence or absence of $30 \mathrm{nM}$ of the TF inhibitor active site inhibited factor VII (ASIS). The total reaction volume was $120 \mu \mathrm{l}$ and measurements were performed as described previously (21).

\section{Data analysis}

For a flow chart summarizing the data analysis steps performed on the proteomics data, see Supplementary Figure 1. The method proposed by Kammers et al. was used to detect significant changes in protein abundance between control EVs and CSE-induced EVs (22) using the limma packageV3.32.10 in R V3.4.1 with R studio (23). Abundance values of proteins identified by the Sequest HT Proteome Discoverer 2.1 with an FDR < 0.01 were imported into R. The log2 of the abundances was then calculated. Subsequently, the median $\log _{2}$ abundance of each protein was subtracted from each individual abundance value of that protein $(n=5$ for control EVs and $n=5$ for CSE-induced EVs) to obtain a normalized protein abundance with a median of $\mathrm{o}$. A moderated t-test was then performed to test for statistically significant differences in protein abundance between the control-EVs and the CSEEVs using a slight modification of the code published by Kammers et al (22) (supplementary file 1 ). This included calculation of the $\mathrm{p}$-value of the moderated $\mathrm{t}$ test as well as transformation into q-values according to the method of Storey and 
Tibshirani (24). Proteins that showed a differential expression with a q-value (i.e. FDR $)<0.1$ were included for downstream functional enrichment analysis for gene ontology (GO) terms and biological pathways. Functional enrichment analysis by hypergeometric test was performed using FunRich software version 2.1.2 and the human-specific integrated FunRich background database (25). For the functional enrichment analysis, the FDR was set to o.o1. Functional enrichment was determined for gene ontology (GO) terms from the three $\mathrm{GO}$ domains 'cellular component', 'molecular function' and 'biological process', as well as for biological pathways. The protein dataset was subdivided into three subsets; 1 ) proteins that were unchanged in CSE-EVs compared to control-EVs, 2) proteins that were significantly upregulated and 3) proteins that were significantly downregulated in CSE-EVs. GO terms and biological pathways were selected for display in the results section if they showed a strong enrichment in all three subsets or if they showed strong differences in enrichment between the subsets.

All other data analysis was performed using Graphpad Prism 5.03 for Windows using the Mann-Whitney test where two groups were compared and the Kruskall-Wallis test with Dunn's post-hoc test where more than two groups were compared.

\section{Results}

\section{Difference in proteomic composition between CSE-induced EVs and control-EVs}

The major aim of this study was to determine functionally relevant differences in the proteomic composition of EVs from unexposed or CSE-exposed BEAS-2B bronchial epithelial cells. Cells were either left untreated or exposed to $1 \%(\mathrm{v} / \mathrm{v})$ CSE for $24 \mathrm{~h}$. Exposure to CSE resulted in a moderate decrease in cell metabolic activity as determined by MTT assay (Figure $1 \mathrm{~A}$ ). This was associated with an increased release of EVs according to TRPS (Figure $1 \mathrm{~B}$ ). Bead-coupled flow cytometry using a cocktail of antibodies against the exosome marker proteins CD63, CD81 and CD9 confirmed that there was an overall increase in EV concentration in conditioned media of CSEexposed cells (Figure $1 \mathrm{C}$ ). Staining for each individual marker protein revealed that the overall increase in EV concentration was driven by $\mathrm{CD}_{1}{ }^{+}$and $\mathrm{CD}_{9}{ }^{+}$, but not $\mathrm{CD}_{3}{ }^{+}$EVs (Figure $1 \mathrm{C}$ ). The differential upregulation of some, but not all tested exosome marker proteins is suggestive of compositional changes. 
A

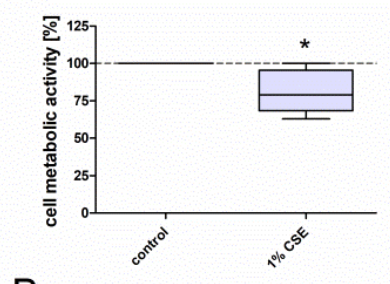

B

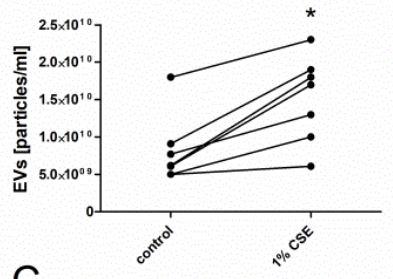

C

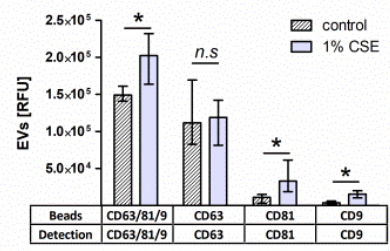

D

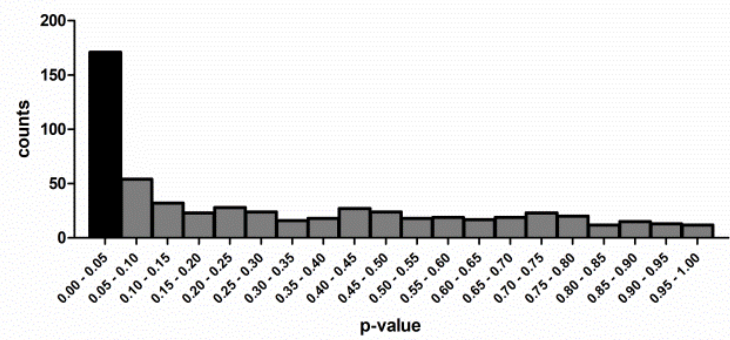

E

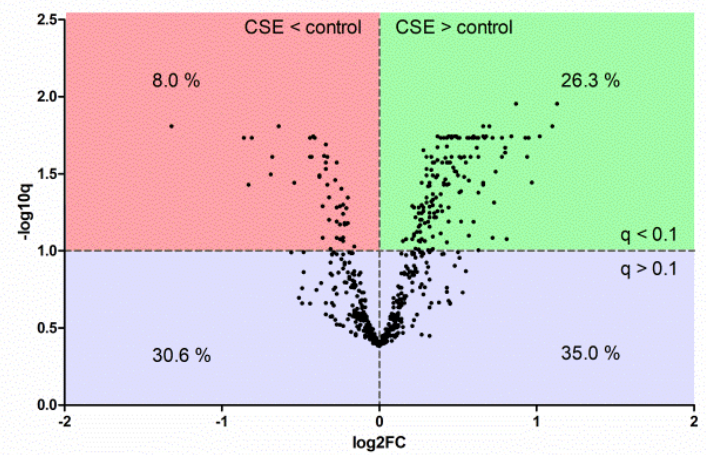

Figure 1 CSE-induced changes in BEAS-2B derived EVs. (A) Metabolic activity of BEAS-2B cells incubated for $24 \mathrm{~h}$ at control conditions or with addition of $1 \%(\mathrm{v} / \mathrm{v})$ CSE. The box and whisker plot shows the median (line in box), interquartile range (borders of box) and range (whiskers), $\mathrm{n}=8$. (B) Concentration of EV isolates obtained from conditioned media of BEAS-2B cells as measured by TRPS, $n=7$. A size filter of 80 to $250 \mathrm{~nm}$ was applied.

(C) EVs detected in conditioned media of BEAS-2B cells after $24 \mathrm{~h}$ under control conditions or exposure to CSE

as measured by bead-coupled flow cytometry using different combinations of capture beads and detection antibodies. The bar graph shows the median and interquartile range, $n=7$. (D-E) Differences in protein composition of EVs from unexposed or CSE-exposed BEAS-2B cells. (D) Histogram of p-values obtained by performing a moderated t-test to detect differences between control-EVs and CSE-EVs concerning the expression of proteins identified by nano LC-MS/MS, n=5. (E) Volcano plot. The $\mathrm{x}$-axis shows the log2 of the fold change (expression in CSE-EVs/expression in control EVs) and the y-axis shows the $-\log 10$ of the q-value.

EVs were isolated using a combination of ultrafiltration and size exclusion chromatography as described previously (18). Size and morphology of isolated control EVs and CSE-induced EVs were similar according to cryo-TEM and TRPS (Supplementary Figure 2). Isolated control-EVs and CSE-EVs $(\mathrm{n}=5)$ were precipitated, followed by protein digestion and isobaric labelling. Quantitative proteomic analysis was then performed using nano LC-MS/MS. Using this method, 732 proteins were identified, of which 633 with high FDR confidence $(\mathrm{q}<0.01)$ that 
were included in the linear model used for statistical testing by moderated t-test. No p-values could be calculated for 48 proteins due to too many missing values, resulting in $\mathrm{p}$-values and $\mathrm{q}$-values for 585 proteins in total. The $\mathrm{p}$-value histogram in Figure $1 \mathrm{D}$ shows that there were true differences in protein abundance between CSE-EVs and control EVs as illustrated by the clear peak for p-values < 0.05. All pvalues were transformed to q-values using the false discovery rate adjustment method described by Storey and Tibshirani and the 201 proteins with $\mathrm{q}<0.1$ were considered as differentially regulated in the downstream analyses (24). The q-values were plotted in a volcano plot, which shows that $26.3 \%$ of proteins were significantly upregulated and 8.0\% significantly downregulated in the CSE-EVs (Figure $1 \mathrm{E}$ ).

To identify functional changes in the EV composition due to CSE exposure, the 585 proteins were divided into 3 subsets: proteins that were unchanged $(384$; $65.6 \%$ ), up-regulated $(154 ; 26.3 \%)$ or down-regulated $(47 ; 8.0 \%)$ in CSE-EVs (Figure 2 A). For the total dataset, as well as the three subsets, functional enrichment analysis was performed for the three GO domains 'cellular component', 'molecular function' and 'biological process', as well as for manually curated biological pathways (results in Table 1). To allow graphical representation of the results, it was then calculated what percentage of the proteins representing each enriched GO term or biological pathway was unchanged, significantly up-regulated or significantly downregulated in the CSE-EVs. Proteins of the cellular component 'exosomes' showed a similar percentage of unchanged, up-regulated and down-regulated proteins as the total protein set (Figure $2 \mathrm{~B}$, Table 1 ). This indicates that the proteomic changes in CSE-EVs were not simply due to a different abundance of exosomal compared to contaminating protein. However, upon CSE exposure there was an up-regulation of proteins associated with the 'plasma membrane' and the 'cell surface' (Figure 2 B, Table 1). Concerning the molecular function, proteins representing 'extracellular matrix structural constituent', 'ubiquitin-specific protease activity' and 'chaperone activity' were mostly unchanged, whereas there was a clear upregulation of proteins with GTPase and receptor activity (Figure 2 C, Table 1). Finally, biological process (Figure 2 D, Table 1) and biological pathway analyses (Figure 2 E, Table 1) revealed that proteins involved in maintenance functions such as 'protein metabolism', 'cell growth and/or maintenance' and 'metabolism of RNA' tended to be unchanged or down-regulated. Yet, there was an up-regulation of proteins related to immunity ('immune response', 'adaptive immune system') and communication ('cell communication', 'signal transduction'; Figures 2 D and E, Table 1). Finally, there was a clear upregulation of proteins involved in 'hemostasis' and 'platelet activation, signaling and aggregation'. Supplementary Table 2 summarizes all identified 
proteins related to these two pathways, including the fold-change, p-value and qvalue.

A

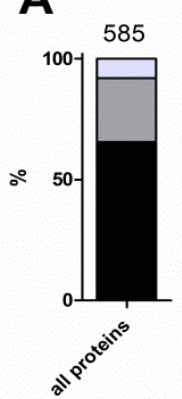

B

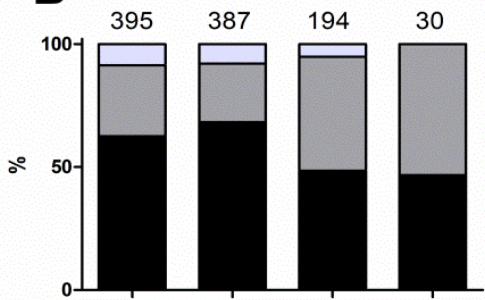

C
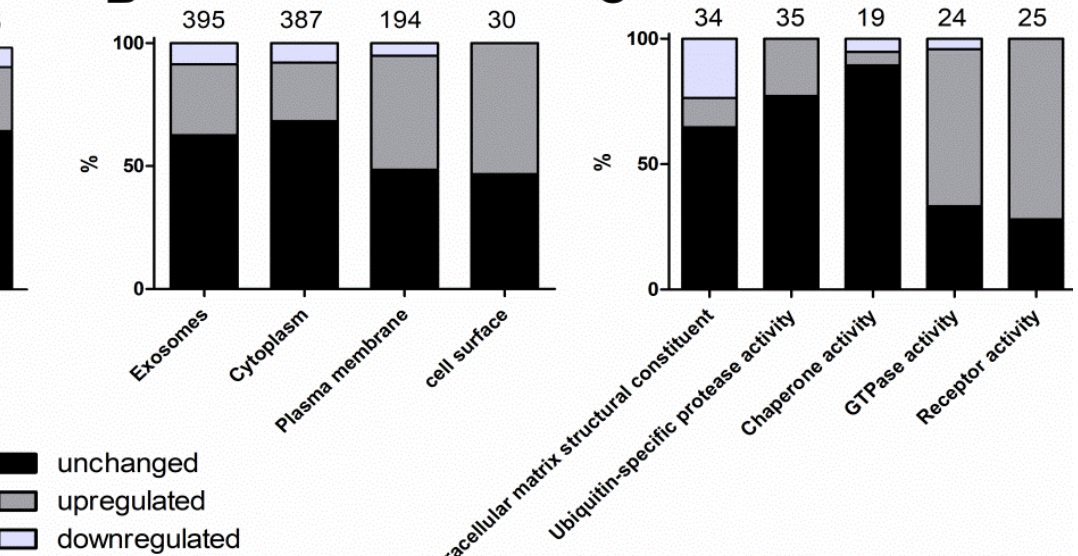

D
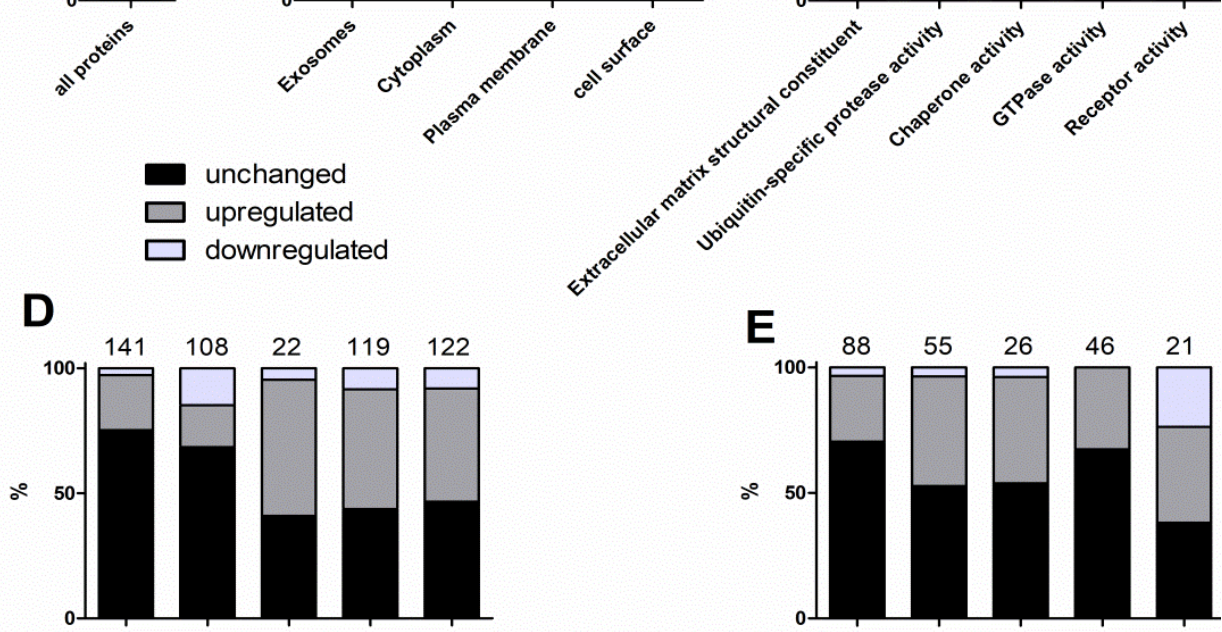

E
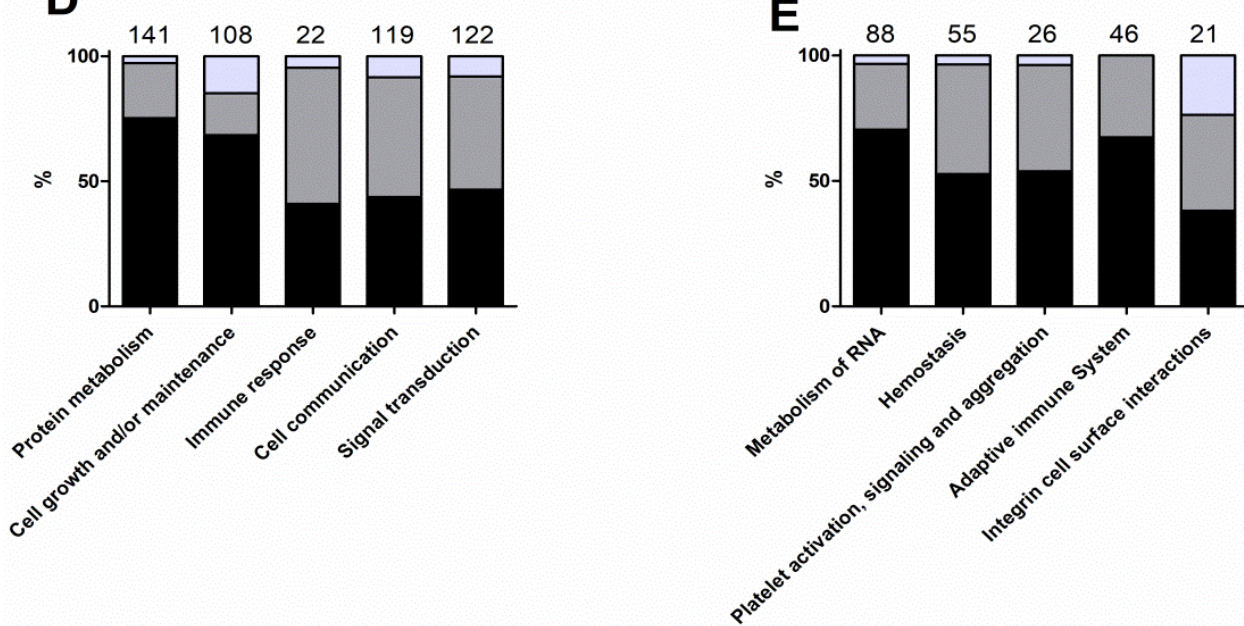

Figure 2 Results of the functional enrichment analysis. The graphs display how many percent of the proteins related to the enriched GO terms or pathways were unchanged, up-regulated or down-regulated in the CSE-EVs compared to control-EVs. Panel (A) shows a reference bar with the percentages of unchanged, up-regulated and down-regulated proteins for all 585 proteins included in the functional enrichment analysis. (B-E) show the percentages of proteins related to different cellular components (B), molecular functions (C), biological processes (D) or biological pathways (E) that were unchanged, upregulated or down-regulated in CSE-EVs compared to control-EVs. The numbers above the bars indicate the total number of proteins identified for each GO term or pathway. 
Table 1 Results of the functional enrichment analysis. Displayed are 1) the percentage of proteins within each dataset that represents a certain GO term or biological pathway, 2) the fold-enrichment of each dataset for each GO term or biological pathway and 3) the q-value of the hypergeometric test after false discovery rate adjustment according to the method of Storey and Tibshirani. 'All' designates all 585 proteins identified with high confidence in both controlEVs and CSE-EVs, 'unchanged' designates the 384 proteins whose expression was unaffected by CSE exposure, 'up' designates the 154 proteins that were upregulated in CSE-EVs compared to control EVs when assuming an FDR of o.1, and 'down' designates the 47 proteins that were downregulated in CSE-EVs compared to control-EVs. Significant q-values of the functional enrichment analysis are printed in italic (q<0.01). NA, not available

\begin{tabular}{|c|c|c|c|c|c|c|c|c|c|c|c|c|c|}
\hline & & \multicolumn{4}{|c|}{ percentage of proteins } & \multicolumn{4}{|c|}{ fold-enrichment } & \multicolumn{4}{|c|}{ q-value } \\
\hline & & all & unchanged & up & down & all & unchanged & up & down & all & unchanged & up & down \\
\hline \multirow{4}{*}{ 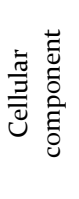 } & exosomes & 68,7 & 65,2 & 76,5 & 72,3 & 4,9 & 4,7 & 5,5 & 5,3 & $1,3 E-209$ & $1,2 E-119$ & $4,7 E-67$ & $9, o E-18$ \\
\hline & cytoplasm & 67,3 & 69,7 & 61,7 & 66,0 & 1,7 & 1,8 & 1,6 & 1,7 & $1,1 E-43$ & $1,4 E-33$ & $6,5 E-09$ & $8,4 E-04$ \\
\hline & plasma membrane & 33,7 & 24,8 & 60,4 & 21,3 & 1,4 & 1,0 & 2,5 & 1,0 & $3,7 E-08$ & $3,9 E-02$ & $2,2 E-21$ & $7,3 \mathrm{E}-\mathrm{ol}$ \\
\hline & cell surface & 5,2 & 3,7 & 10,7 & NA & 3,8 & 2,8 & 8,1 & NA & $4,5 E-10$ & $5,6 E-04$ & $2,2 E-10$ & NA \\
\hline \multirow{5}{*}{ 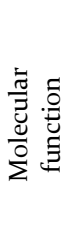 } & extracellular matrix structural constituent & 5,9 & 5,8 & 2,7 & 17,0 & 6,6 & 6,6 & 3,7 & 20,5 & $6,6 E-17$ & $1,1 E-10$ & $2,4 \mathrm{E}-\mathrm{O} 2$ & $8,9 E-08$ \\
\hline & ubiquitin-specific protease activity & 6,1 & 7,1 & 5,4 & NA & 3,0 & 3,5 & 2,9 & & $1,5 E-07$ & $2,3 E-07$ & $1,6 \mathrm{E}-\mathrm{O} 2$ & NA \\
\hline & chaperone activity & 3,3 & 4,5 & 0,7 & 2,1 & 4,0 & 6,9 & 2,1 & 6,7 & $1,5 E-07$ & $1,1 E-08$ & $1,8 \mathrm{E}-\mathrm{ol}$ & $1,3 \mathrm{E}-\mathrm{O} 1$ \\
\hline & GTPase activity & 4,2 & 2,1 & 10,1 & 2,1 & 3,5 & 2,0 & 8,7 & 3,7 & $1,4 E-06$ & $1,1 \mathrm{E}-\mathrm{ol}$ & 2,1E-09 & $1,5 \mathrm{E}-\mathrm{ol}$ \\
\hline & receptor activity & 4,4 & 1,9 & 12,1 & NA & 2,3 & 1,1 & 6,4 & NA & $8,3 E-04$ & 3,7E-O1 & 3,oE-o9 & NA \\
\hline
\end{tabular}




\begin{tabular}{|c|c|c|c|c|c|c|c|c|c|c|c|c|c|}
\hline & & \multicolumn{4}{|c|}{ percentage of proteins } & \multicolumn{4}{|c|}{ fold-enrichment } & \multicolumn{4}{|c|}{ q-value } \\
\hline & & all & unchanged & up & down & all & unchanged & up & down & all & unchanged & up & down \\
\hline \multirow{5}{*}{ 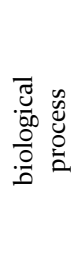 } & protein metabolism & 24,6 & 28,0 & 20,8 & 8,5 & 3,4 & 3,9 & 2,9 & 1,5 & $5,7 E-38$ & $9,5 E-34$ & $6,9 E-07$ & $2,3 \mathrm{E}-01$ \\
\hline & cell growth and/or maintenance & 18,8 & 19,6 & 12,1 & 30,0 & 3,0 & 3,2 & 2,1 & 5,7 & $8,6 E-25$ & $5,4 E-18$ & $7,5^{E-03}$ & $5,8 \mathrm{E}-\mathrm{o} 8$ \\
\hline & immune response & 3,8 & 2,4 & 8,1 & 2,1 & 1,3 & 0,9 & 2,8 & 1,5 & $1,6 \mathrm{E}-\mathrm{O} 1$ & $4,7 \mathrm{E}-\mathrm{Ol}$ & $4,5 E-03$ & $2,6 \mathrm{E}-\mathrm{O} 1$ \\
\hline & cell communication & 20,7 & 13,8 & 38,3 & 21,3 & 1,0 & 0,7 & 1,9 & 1,1 & $2,5^{\mathrm{E}-\mathrm{O} 1}$ & $4,8 \mathrm{E}-\mathrm{O} 1$ & $1,8 E-06$ & $2,4 \mathrm{E}-\mathrm{O} 1$ \\
\hline & signal transduction & 21,3 & 15,1 & 36,9 & 21,3 & 1,0 & 0,7 & 1,7 & 1,1 & $3, \mathrm{oE}-\mathrm{ol}$ & $4,8 \mathrm{E}-\mathrm{O} 1$ & $4,1 E-05$ & $2,4 \mathrm{E}-\mathrm{ol}$ \\
\hline \multirow{5}{*}{ 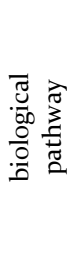 } & Metabolism of RNA & 21,1 & 22,6 & 21,7 & 7,9 & 4,6 & 5,0 & 4,9 & 2,3 & $5,6 E-35$ & $1,2 E-25$ & 2,9E-o9 & $1,4 E-02$ \\
\hline & hemostasis & 13,2 & 10,6 & 22,6 & 5,3 & 2,2 & 1,8 & 3,9 & 1,4 & $6,6 E-08$ & 2,1E-O3 & $4,3 E-08$ & $2,8 E-02$ \\
\hline & platelet activation, signalling and aggregation & 6,2 & 5,1 & 10,4 & 2,6 & 2,9 & 2,4 & 5,0 & 2,5 & $7,6 E-06$ & $3,6 E-03$ & $4,9 E-05$ & $2,5 E-02$ \\
\hline & adaptive immune system & 11,0 & 11,3 & 14,2 & NA & 2,9 & 3,0 & 3,8 & NA & 3,1E-10 & 1,3E-07 & $3,8 E-05$ & NA \\
\hline & integrin cell surface interactions & 5,0 & 2,9 & 7,5 & 13,2 & 4,4 & 2,8 & 7,1 & 13,0 & $4,2 E-08$ & $1,4 E-02$ & $5,5^{E-05}$ & $7,2 E-04$ \\
\hline
\end{tabular}




\section{Confirmation of the predicted procoagulant phenotype of CSE-EVS}

The most strongly enriched biological pathway in CSE-EVs was 'hemostasis'. One of the identified proteins of this pathway was tissue factor (TF), which was 1.4 -fold upregulated in CSE-EVs $(\mathrm{p}=0.03, \mathrm{q}=0.05$, Supplementary Table 2). Importantly, TF by itself is sufficient to trigger the extrinsic pathway of coagulation. To verify whether TF was indeed associated with the isolated EVs and not a co-isolated contaminant, we determined the presence of TF on tetraspanin-positive EVs using bead-coupled flow cytometry on conditioned cell culture media, and on a standardized number of isolated EVs $\left(10^{8}\right.$ particles $\left./ \mathrm{ml}\right)$. For cell culture media, we assessed the presence of TF on EVs captured using beads that were coated with antibodies against either a combination of tetraspanins (CD63, CD81, CD9), or each individual tetraspanin. For all bead types, we confirmed the presence of TF on control-EVs and CSE-EVs. Moreover, there was a statistically significant increase in $\mathrm{TF}^{+}$EVs using all bead types for the CSE-exposed condition (Figure $3 \mathrm{~A}$ ). This was also the case when TF was measured for a standardized concentration of isolated EVs $\left(10^{8}\right.$ particles/ml) using $\mathrm{CD}_{3} / \mathrm{CD}_{1} / \mathrm{CD}_{9}$ beads (Figure $3 \mathrm{~B}$ ). The increased TF expression on EVs was associated with increased TF activity as assessed by a factor $\mathrm{Xa}$ generation assay (Figure $3 \mathrm{C}$ ). The control conditions, namely the protein-rich EV-low SEC fractions (fractions 14-19) and unconditioned media isolates (UCM, corresponding to the EV-rich SEC fractions but obtained from media that have not been in contact with cells) had little and no detectable TF activity, respectively. The EV-secreting cells also showed an upregulation of cell surface exposed TF when exposed to CSE, similar to the increase observed on CSE-EVs (Figure $3 \mathrm{D}$ ). 

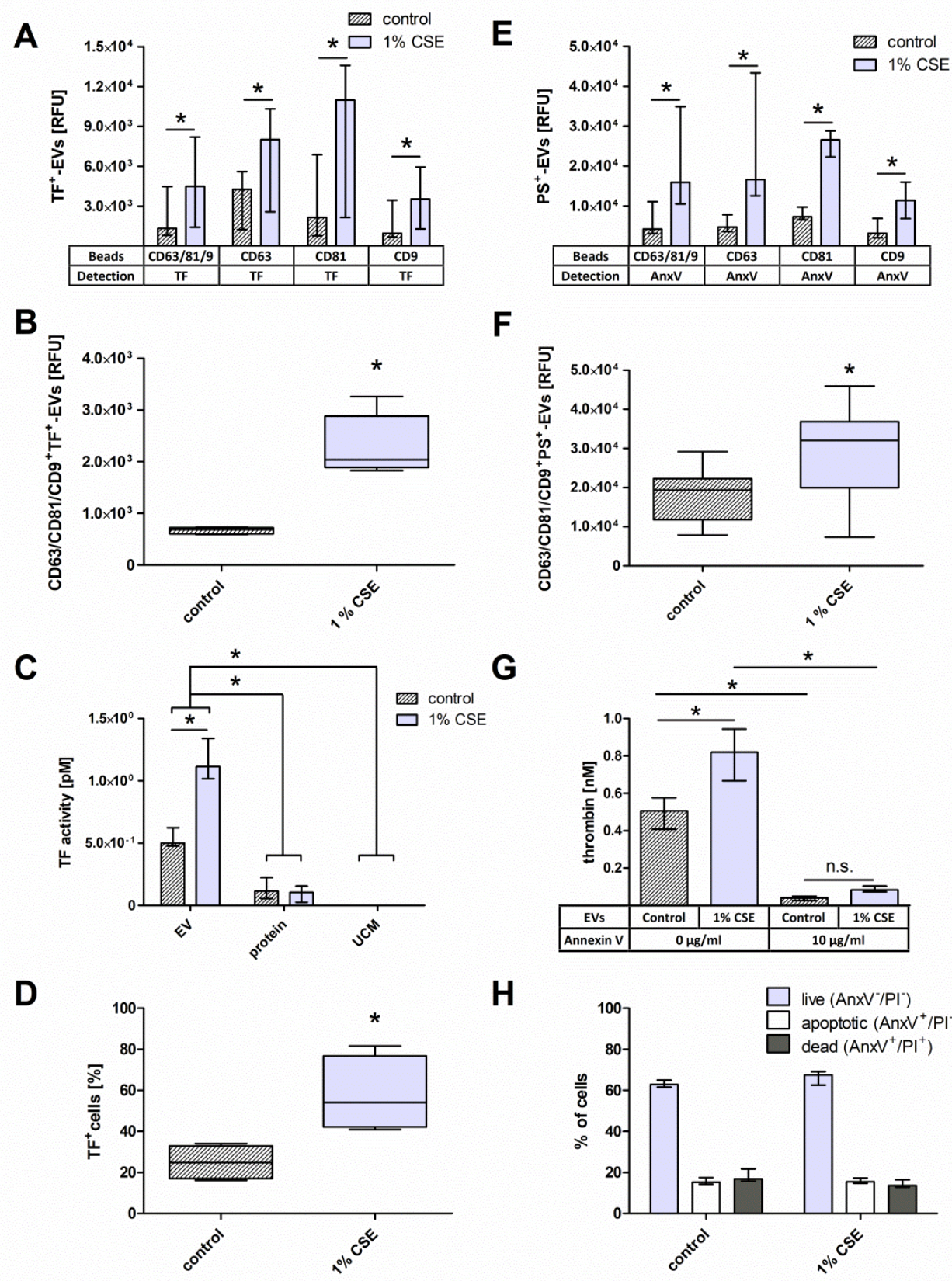

H

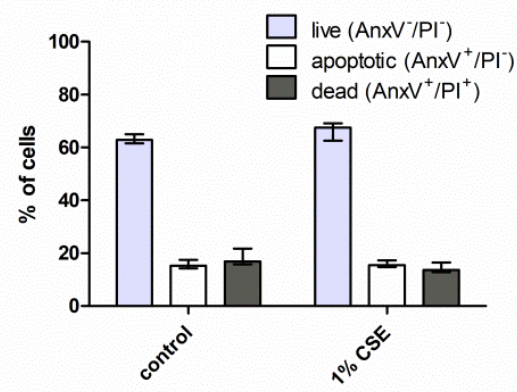

Figure 3 Confirmation of the presence of the procoagulant factors TF and phosphatidylserine (PS) on EVs. (A) Detection of TF+-EVs in conditioned cell culture media using bead-coupled flow cytometry with beads coated for different tetraspanins, $\mathrm{n}=7$. (B) $\mathrm{TF}$ expression on isolated $\mathrm{EVs}\left(10^{8}\right.$ particles $\left./ \mathrm{ml}\right)$ 
determined by bead-coupled flow cytometry with anti-CD63/CD81/CD9-coated beads, $n=6$. (C) TF activity of EV isolates obtained by UF-SEC $\left(10^{8}\right.$ particles $\left./ \mathrm{ml}\right)$, volume-matched protein isolates obtained by UFSEC and volume-matched sham EV isolated from unconditioned cell culture media, $n=5$. (D) Percentage of TF+ cells (the gate was set so that $98 \%$ of the cells stained with the isotype control were negative), $\mathrm{n}=4$. (E) Detection of PS+-EVs in conditioned cell culture media using bead-coupled flow cytometry with beads coated for different tetraspanins, $\mathrm{n}=7$. (F) PS expression on isolated EVs $\left(10^{8}\right.$ particles/ml) determined by bead-coupled flow cytometry with anti-CD63/CD81/CD9-coated beads, $\mathrm{n}=9$. (G) Thrombin generation as determined by prothrombinase assay in the absence or presence of the PS blocker annexin V; $n=4$. (H) PS externalization on the EV secreting BEAS-2B cells as determined by flow cytometry using annexin $\mathrm{V}$ and PI staining; $\mathrm{n}=6$.

Next, isolated EVs were added to normal human plasma and thrombin generation was assessed over time. As predicted, CSE-EVs induced more thrombin generation than control-EVs for a standardized number of EVs $\left(10^{8}\right.$ particles, Figure 4 A). When CSE-EVs were used at the double concentration in line with the approximately two-fold EV induction by CSE, this effect was further enhanced (Figure $4 \mathrm{~A}$ ). Neither the protein-rich SEC fractions, nor UCM were able to trigger thrombin generation, suggesting that this effect can be attributed specifically to the EVs (Figure $4 \mathrm{~A}$ ). Finally, thrombin generation was partly inhibited by addition of active site inhibited factor VIIa (ASIS), which traps TF in an inactive complex and thereby inhibits the extrinsic pathway (Figure $4 \mathrm{~B}$ ). Thus, TF accounts for a part of the procoagulant effect of CSE-EVs, but other factors are likely to contribute as well. 
A

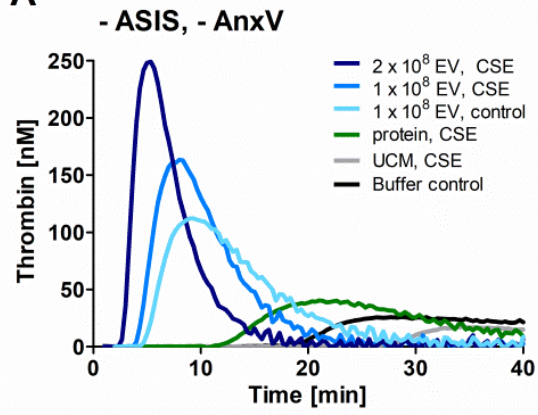

C

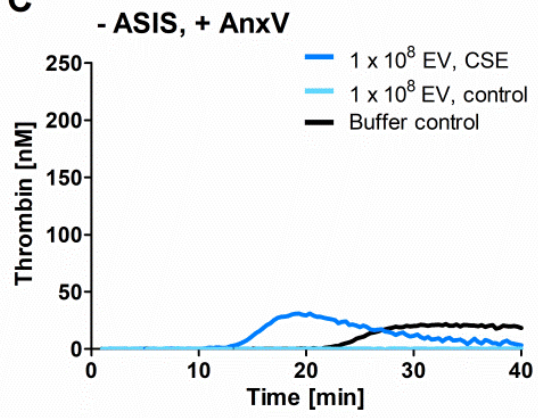

B

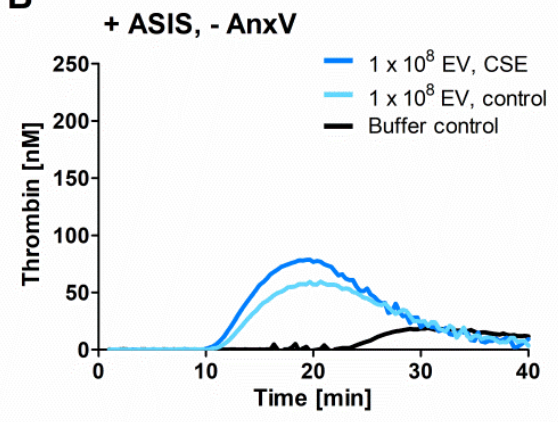

D

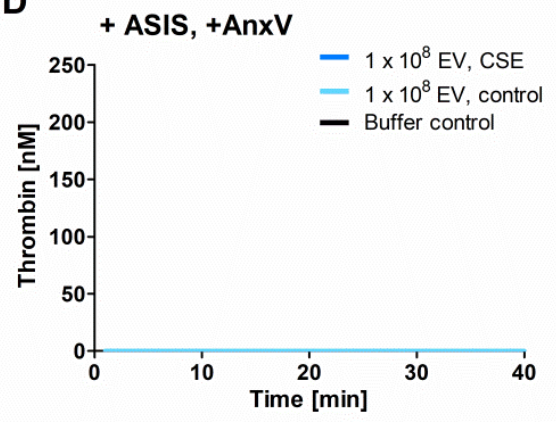

Figure 4 Time-dependent thrombin generation in normal human plasma. Thrombin generation upon (A) Addition of CSE-EVs, control-EVs, volume-matched free secreted molecules (SEC protein fraction) or sham EVs isolated from unconditioned media. (B) Addition of CSE-EVs or control EVs in the presence of the TF inhibitor ASIS. (C) Addition of CSE-EVs or control EVs that were pre-treated with $10 \mu \mathrm{g} / \mathrm{ml}$ annexin V. (D) Addition of CSE-EV and control EVs that were pre-treated with annexin V in the presence of the TF inhibitor ASIS. The graphs show representative thrombin generation curves for 4 independent experiments

Besides TF, the phospholipid phosphatidylserine (PS) is known to contribute to the procoagulant effects of EVs (26). Therefore, we assessed whether the remaining difference in procoagulant potential between CSE-EVs and controlEVs during TF-pathway inhibition could be due to increased surface-exposed PS on CSE-EVs. Bead-coupled flow cytometry of conditioned media revealed that PS was increased on EVs captured by beads coated with a cocktail of antibodies against CD63, CD81 and CD9 or against each individual protein (Figure $3 \mathrm{E}$ ). This was not purely due to increased EV release, as there was also increased PS signal for a standardized concentration of isolated CSE-EVs compared to control EVs (Figure 3 F). Additionally, PS was quantified by prothrombinase assay, for which purified 
coagulation factors $\mathrm{Va}$ and $\mathrm{Xa}$, the two subunits of the prothrombinase complex, were added to a fixed concentration of isolated EVs. In this assay, the EV membrane provides the phospholipid surface for the assembly of the prothrombinase complex. Prothrombin was added as a substrate and thrombin generation measured over time. CSE EVs resulted in significantly more thrombin generation than control EVs. The difference between CSE EVs and control EVs could be attributed to PS, as PS blockage with annexin $\mathrm{V}$ substantially decreased the thrombin generation and equalized the effect of CSE-EVs and control EVs (Figure $3 \mathrm{G}$ ). By flow cytometry, we showed that the increased PS exposure of CSE-EVs was not paralleled by PS externalization on the secreting cells, as there was no increase in $\mathrm{PS}^{+}$cells upon CSE exposure (Figure $3 \mathrm{H}$ ). Finally, it was assessed to what extent PS accounts for EVinduced thrombin generation in normal human plasma. Annexin V treatment of EVs completely abolished thrombin induction by control-EVs and strongly decreased the thrombin generation by CSE-EVs (Figure $4 \mathrm{C}$ ). When EVs were treated with Annexin-V and the TF inhibitor ASIS was added, thrombin generation was completely prevented for both control-EVs and CSE-EVs (Figure 4 D). Thus, TF and PS together appear to account for a large proportion of thrombin generation in normal human plasma in response to both, control EVs and CSE-induced EVs.

\section{Discussion}

The airway epithelium is constantly exposed to inhaled air, and airborne exposures modulate the behaviour of airway epithelial cells. We and others have recently shown that exposure to CSE stimulates airway epithelial cells to release EVs $(2,5)$. Here we extend this finding and present to our knowledge the first study which characterizes the proteomic composition of CSE-induced EVs and its functional implications. Using nano LC-MS/MS, we demonstrated that CSE-EVs show a notable up-regulation of proteins involved in 'hemostasis', including TF. We then confirmed a partly TF-dependent procoagulant effect for these EVs in vitro.

EVs were isolated from cell culture media by a combination of ultrafiltration and size exclusion chromatography, a protocol that we and others have shown to yield EVs with sufficient purity for proteomic characterization $(27,28)$. While no unique proteins were identified in either control EVs or CSE EVs, 33\% of the identified proteins were differentially expressed. Functional enrichment analysis of the EV proteome for GO terms of the 'cellular component' GO domain showed that the CSE-exposure caused an upregulation of proteins of the 'plasma membrane' and 'cell surface'. This might imply that CSE exposure results in a shift from the release of endosomal-derived exosomes to plasma membrane-derived microvesicles. 
Alternatively, there may have been a specific sorting of cell surface proteins into the EVs rather than a shift in EV subtype. This is supported by the fact that the size distribution of control EVs and CSE EVs was similar, whereas a shift towards microvesicle release would most likely be associated with an increase in the EV diameter. Moreover, control EVs and CSE EVs both showed a similar enrichment for the GO term 'exosomes' and CSE exposure even resulted in a significant upregulation of the exosome marker proteins CD81 and CD9, which further contradicts a shift towards microvesicle release. Concerning the GO domain 'molecular function', CSE EVs were enriched in proteins with 'GTPase activity' and 'receptor activity', in line with an involvement in cell signaling. Congruently, there was an upregulation of the biological processes 'immune response', 'cell communication' and 'signal transduction'. While we have not performed a functional evaluation of these enriched biological processes, others have previously proposed an involvement of CSE-induced airway epithelial-derived EVs in cell-to-cell communication. In particular, cells that were stimulated with CSE-EVs were shown to undergo pro-inflammatory and pro-fibrotic changes $(2,29)$.

Functional enrichment analysis for manually curated biological pathways revealed that 'hemostasis' and 'platelet activation, signaling and aggregation' were strikingly upregulated in the CSE-induced EVs, suggesting a potential involvement in thrombus formation. Using calibrated automated thrombogram, we confirmed a procoagulant effect of the CSE-EVs as they caused faster and more thrombin generation in normal human plasma than control-EVs. We showed that this effect could be partly attributed to EV-associated TF. We then went on to demonstrate that CSE-EVs are also enriched in the procoagulant phospholipid PS and that concomitant inhibition of TF and PS completely abolished CSE-EV-induced thrombin generation. It is well known that smokers have an elevated risk for thrombotic cardiovascular diseases (30) and that circulating microvesicles can contribute to hypercoagulability and thrombotic disease via expression of TF and PS (31). Moreover, it has previously been shown that CSE is able to induce the release of $\mathrm{TF}^{+}$procoagulant microvesicles from monocytes and macrophages $(3,15)$. Our study adds that also airway epithelial cells respond to CSE by releasing $\mathrm{TF}^{+}$procoagulant EVs and that, besides $\mathrm{TF}^{+}$, a number of other procoagulant factors are also associated with the EVs and upregulated upon CSE exposure. Moreover, we have shown that the procoagulant airway epithelial-derived EVs have exosome properties in terms of size and expression of marker proteins. This implies that either functions of exosomes and microvesicles overlap or that the EV populations as such overlap. The distinction of microvesicles and exosomes might to some extent reflect divergent 
methodologies of isolation and characterization rather than truly distinct EV properties. A side by side evaluation of the exosome- and microvesicle-associated TF release of CSE stimulated airway epithelial cells, monocytes and macrophages could help shed more light on this.

One question that remains unanswered here is whether airway epithelialderived procoagulant EVs actually enter the blood circulation and thus contribute to hypercoagulability in smokers. Although this seems plausible because smoking impairs the function of the epithelial-endothelial barrier in the lungs $(32,33)$, Badrnya et al. did not detect any significant changes in circulating $\mathrm{TF}^{+} \mathrm{EV}$ s between young healthy smokers and non-smokers (34). Besides exerting potential procoagulant effects in the systemic blood circulation, $\mathrm{TF}^{+} \mathrm{EVs}$ may also have local effects in the lungs. Intriguingly, elevated concentrations of $\mathrm{TF}^{+} \mathrm{EVs}$ have been detected in the lungs of patients with several lung diseases, including asthma, acute respiratory distress syndrome (ARDS) and interstitial lung disease (35-39). Moreover, TF is secreted by airway and alveolar epithelial cells in an EV-associated form in response to mechanical stress, pro-inflammatory mediators or oxidants (35-37). Besides its prominent role in coagulation, TF also exerts alternative functions, such as regulating inflammatory responses, promoting angiogenesis and wound repair (40-44). To date, these alternative functions are relatively poorly explored. It is thus a promising field for future research to investigate whether $\mathrm{TF}^{+} \mathrm{EV}$ s contribute to tissue remodelling in chronic lung diseases. Importantly, there is a high rate of comorbidity of the smoking-associated chronic lung disease COPD and cardiovascular disease (45). It would be relevant to investigate whether this can be mechanistically explained by an increased production of $\mathrm{TF}^{+} \mathrm{EVs}$ in response to cigarette smoking.

In conclusion, CSE-induced EVs from airway epithelial cells are - among others - enriched in proteins that are involved in cell communication, the immune response and hemostasis compared to control EVs. An enhanced procoagulant effect of CSE-induced EVs was confirmed in vitro and shown to depend largely on EVassociated TF and PS. Increased production of procoagulant EVs in response to airway epithelial cell stress could be a mechanistic explanation for the high degree of comorbidity between chronic lung diseases and cardiovascular diseases.

\section{Acknowledgements}

The authors would like to thank Stefanie Geleen for the blood sampling and Diane Fens for performing the CAT measurements. They would also like to thank Carmen 
Lopez Iglesias for performing the cryo-TEM imaging of the EVs. This project was funded by the Netherlands Organization for Scientific Research (NWO) grant 022.003.011 with the title "NUTRIM NWO Graduate Program: Metabolism and chronic disease" awarded to BJB. It was also supported by the NWO grant ZonMW VIDI 016.126.358 and the Landsteiner Foundation for Blood Transfusion Research grant LSBR Nr. 1638, both awarded to R.R.K. The funding sources were not involved in the study design or in the collection, analysis and interpretation of data or in the writing of the report.

\section{Conflict of interest disclosure}

The authors declare that they have no real or potential financial or other conflicts of interest. 


\section{References}

1. GBD 2015 Tobacco Collaborators. Smoking prevalence and attributable disease burden in 195 countries and territories, 1990-2015: a systematic analysis from the Global Burden of Disease Study 2015. Lancet 2017; 389(10082): 1885-906.

2. Moon HG, Kim SH, Gao J, et al. CCN1 secretion and cleavage regulate the lung epithelial cell functions after cigarette smoke. American journal of physiology Lung cellular and molecular physiology 2014; 307(4): L326-37.

3. Cordazzo C, Petrini S, Neri T, et al. Rapid shedding of proinflammatory microparticles by human mononuclear cells exposed to cigarette smoke is dependent on Ca2+ mobilization. Inflammation research : official journal of the European Histamine Research Society [et al] 2014; 63(7): 53947.

4. Serban KA, Rezania S, Petrusca DN, et al. Structural and functional characterization of endothelial microparticles released by cigarette smoke. Scientific reports 2016; 6: 31596.

5. Benedikter BJ, Volgers C, van Eijck PH, et al. Cigarette smoke extract induced exosome release is mediated by depletion of exofacial thiols and can be inhibited by thiol-antioxidants. Free radical biology \& medicine 2017.

6. Gordon C, Gudi K, Krause A, et al. Circulating endothelial microparticles as a measure of early lung destruction in cigarette smokers. American journal of respiratory and critical care medicine 2011; 184(2): 224-32.

7. Mobarrez F, Antoniewicz L, Bosson JA, et al. The effects of smoking on levels of endothelial progenitor cells and microparticles in the blood of healthy volunteers. PloS one 2014; 9(2): e90314.

8. Yanez-Mo M, Siljander PR, Andreu Z, et al. Biological properties of extracellular vesicles and their physiological functions. Journal of extracellular vesicles 2015; 4: 27066.

9. Gould SJ, Raposo G. As we wait: coping with an imperfect nomenclature for extracellular vesicles. Journal of extracellular vesicles 2013; 2 .

10. van der Pol E, Boing AN, Gool EL, et al. Recent developments in the nomenclature, presence, isolation, detection and clinical impact of extracellular vesicles. Journal of thrombosis and haemostasis : JTH 2016; 14(1): 48-56.

11. Abels ER, Breakefield XO. Introduction to Extracellular Vesicles: Biogenesis, RNA Cargo Selection, Content, Release, and Uptake. Cellular and molecular neurobiology 2016; 36(3): 301-12.

12. Dreyer F, Baur A. Biogenesis and Functions of Exosomes and Extracellular Vesicles. Methods in molecular biology 2016; 1448: 201-16.

13. Gyorgy B, Szabo TG, Pasztoi M, et al. Membrane vesicles, current state-of-the-art: emerging role of extracellular vesicles. Cellular and molecular life sciences : CMLS 2011; 68(16): 2667-88.

14. Li CJ, Liu Y, Chen Y, et al. Novel proteolytic microvesicles released from human macrophages after exposure to tobacco smoke. The American journal of pathology 2013; 182(5): 1552-62.

15. Li M, Yu D, Williams KJ, et al. Tobacco smoke induces the generation of procoagulant microvesicles from human monocytes/macrophages. Arteriosclerosis, thrombosis, and vascular biology 2010; 30(9): 1818-24.

16. Tripisciano C, Weiss R, Eichhorn T, et al. Different Potential of Extracellular Vesicles to Support Thrombin Generation: Contributions of Phosphatidylserine, Tissue Factor, and Cellular Origin Scientific reports 2017; 7(1): 6522.

17. Tkach M, Kowal J, Thery C. Why the need and how to approach the functional diversity of extracellular vesicles. Philosophical transactions of the Royal Society of London Series B, Biological sciences 2018; 373(1737).

18. Benedikter BJ, Bouwman FG, Vajen $\mathrm{T}$, et al. Ultrafiltration combined with size exclusion chromatography efficiently isolates extracellular vesicles from cell culture media for compositional and functional studies. Scientific reports 2017; 7(1): 15297.

19. Grottke $\mathrm{O}$, Rossaint R, Henskens $\mathrm{Y}$, et al. Thrombin generation capacity of prothrombin complex concentrate in an in vitro dilutional model. PloS one 2013; 8(5): e64100.

20. Borissoff JI, Heeneman S, Kilinc E, et al. Early atherosclerosis exhibits an enhanced procoagulant state. Circulation 2010; 122(8): 821-30.

21. Dielis AW, Castoldi E, Spronk HM, et al. Coagulation factors and the protein C system as determinants of thrombin generation in a normal population. Journal of thrombosis and haemostasis : JTH 2008; 6(1): 125-31. 
22. Kammers K, Cole RN, Tiengwe C, et al. Detecting Significant Changes in Protein Abundance. EuPA open proteomics 2015; 7: 11-9.

23. Ritchie ME, Phipson B, Wu D, et al. limma powers differential expression analyses for RNAsequencing and microarray studies. Nucleic acids research 2015; 43(7): e47.

24. Storey JD, Tibshirani R. Statistical significance for genomewide studies. Proceedings of the National Academy of Sciences of the United States of America 2003; 100(16): 9440-5.

25. Pathan M, Keerthikumar S, Ang CS, et al. FunRich: An open access standalone functional enrichment and interaction network analysis tool. Proteomics 2015; 15(15): 2597-601.

26. Wang L, Bi Y, Cao M, et al. Microparticles and blood cells induce procoagulant activity via phosphatidylserine exposure in NSTEMI patients following stent implantation. International journal of cardiology 2016; 223: 121-8.

27. de Menezes-Neto A, Saez MJ, Lozano-Ramos I, et al. Size-exclusion chromatography as a standalone methodology identifies novel markers in mass spectrometry analyses of plasma-derived vesicles from healthy individuals. Journal of extracellular vesicles 2015; 4: 27378.

28. Nordin JZ, Lee Y, Vader P, et al. Ultrafiltration with size-exclusion liquid chromatography for high yield isolation of extracellular vesicles preserving intact biophysical and functional properties. Nanomedicine : nanotechnology, biology, and medicine 2015; 11(4): 879-83.

29. Fujita Y, Araya J, Ito S, et al. Suppression of autophagy by extracellular vesicles promotes myofibroblast differentiation in COPD pathogenesis. Journal of extracellular vesicles 2015; 4 : 28388.

30. Ezzati M, Henley SJ, Thun MJ, et al. Role of smoking in global and regional cardiovascular mortality. Circulation 2005; 112(4): 489-97.

31. Owens AP, 3rd, Mackman N. Microparticles in hemostasis and thrombosis. Circulation research 2011; 108(10): 1284-97.

32. Lu Q, Sakhatskyy P, Grinnell K, et al. Cigarette smoke causes lung vascular barrier dysfunction via oxidative stress-mediated inhibition of RhoA and focal adhesion kinase. American journal of physiology Lung cellular and molecular physiology 2011; 301(6): L847-57.

33. Aghapour M, Raee P, Moghaddam SJ, et al. Airway Epithelial Barrier Dysfunction in COPD: Role of Cigarette Smoke Exposure. American journal of respiratory cell and molecular biology 2017.

34. Badrnya S, Baumgartner R, Assinger A. Smoking alters circulating plasma microvesicle pattern and microRNA signatures. Thrombosis and haemostasis 2014; 112(1): 128-36.

35. Novelli F, Neri T, Tavanti L, et al. Procoagulant, tissue factor-bearing microparticles in bronchoalveolar lavage of interstitial lung disease patients: an observational study. PloS one 2014; 9(4): e95013.

36. Park JA, Sharif AS, Tschumperlin DJ, et al. Tissue factor-bearing exosome secretion from human mechanically stimulated bronchial epithelial cells in vitro and in vivo. The Journal of allergy and clinical immunology 2012; 130(6): 1375-83.

37. Bastarache JA, Fremont RD, Kropski JA, et al. Procoagulant alveolar microparticles in the lungs of patients with acute respiratory distress syndrome. American journal of physiology Lung cellular and molecular physiology 2009; 297(6): L1035-41.

38. Gabazza EC, Taguchi 0, Tamaki S, et al. Thrombin in the airways of asthmatic patients. Lung 1999; 177(4): 253-62.

39. Brims FJ, Chauhan AJ, Higgins B, et al. Coagulation factors in the airways in moderate and severe asthma and the effect of inhaled steroids. Thorax 2009; 64(12): 1037-43.

40. Ahmad S, Ahmad A, Rancourt RC, et al. Tissue factor signals airway epithelial basal cell survival via coagulation and protease-activated receptor isoforms 1 and 2. American journal of respiratory cell and molecular biology 2013; 48(1): 94-104.

41. Chen J, Kasper M, Heck T, et al. Tissue factor as a link between wounding and tissue repair. Diabetes 2005; 54(7): 2143-54.

42. Cimmino G, Ciccarelli G, Golino P. Role of Tissue Factor in the Coagulation Network. Seminars in thrombosis and hemostasis 2015; 41(7): 708-17.

43. Giannarelli C, Alique M, Rodriguez DT, et al. Alternatively spliced tissue factor promotes plaque angiogenesis through the activation of hypoxia-inducible factor-1alpha and vascular endothelial growth factor signaling. Circulation 2014; 130(15): 1274-86.

44. Witkowski M, Landmesser U, Rauch U. Tissue factor as a link between inflammation and coagulation. Trends in cardiovascular medicine 2016; 26(4): 297-303. 
45. Chen W, Thomas J, Sadatsafavi M, et al. Risk of cardiovascular comorbidity in patients with chronic obstructive pulmonary disease: a systematic review and meta-analysis. The Lancet Respiratory medicine 2015; 3(8): 631-9. 


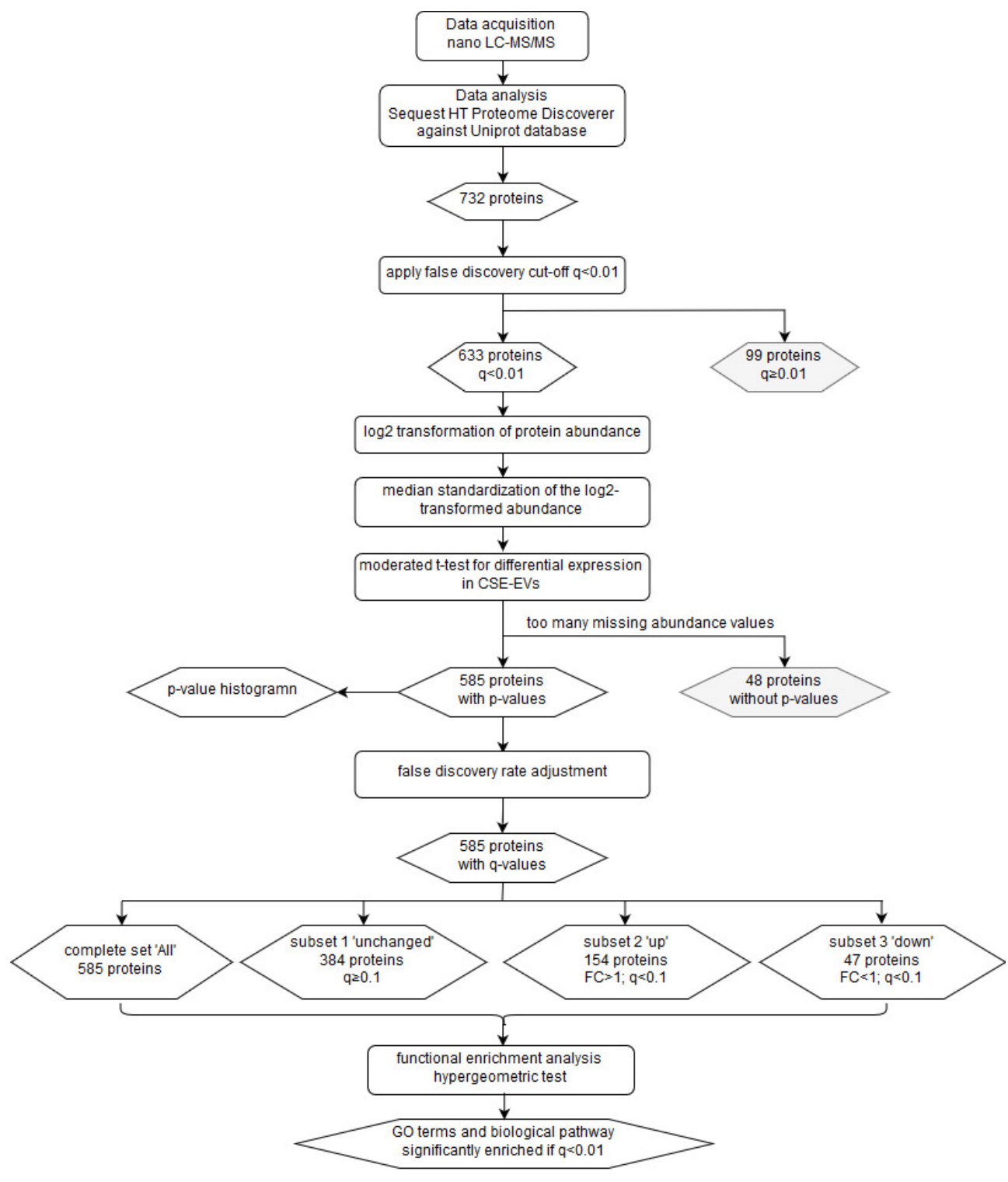

Supplementary Figure 1 - Flow chart of the proteomics data analysis. The chart summarizes the data analysis process starting from the data acquisition and ending at the GO terms and biological pathways that were found to be enriched. Rounded rectangles represent data handling steps, whereas rhombi represent (intermediate) results. 
A

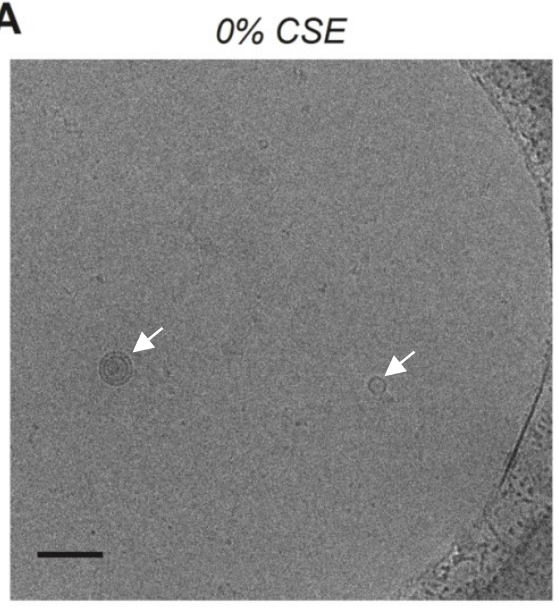

B

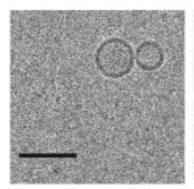

C

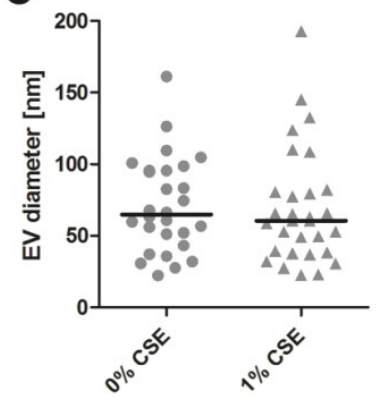

O\% CSE
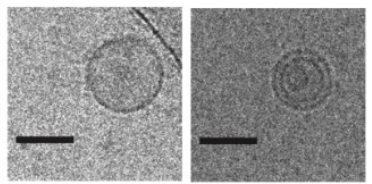

$1 \%$ CSE

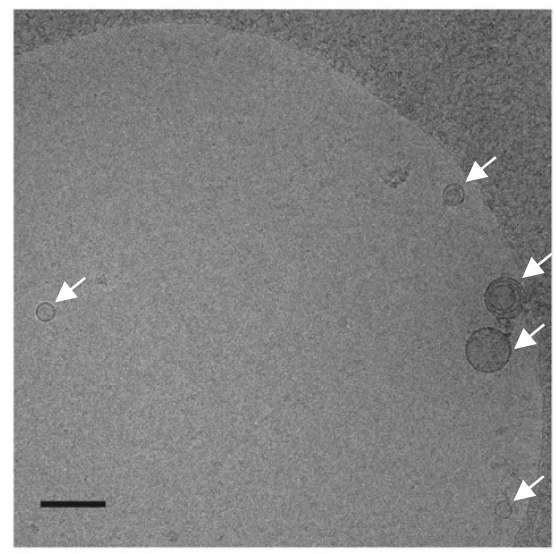

$1 \%$ CSE
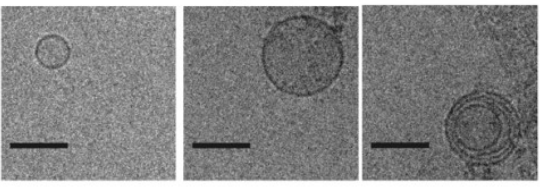

D

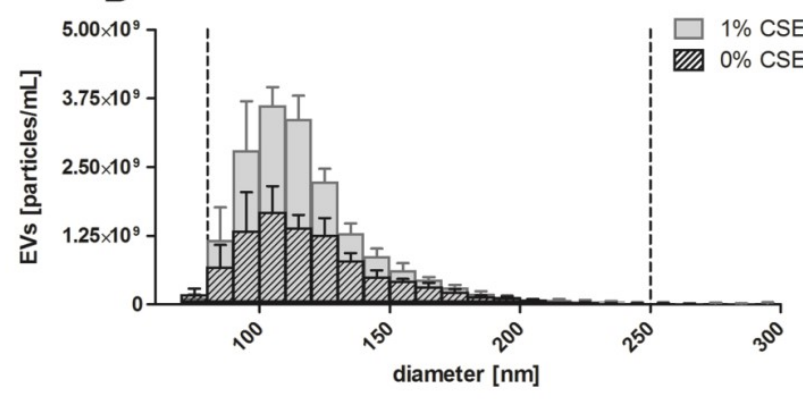

Supplementary Figure 1 - Size and morphology of EVs released by BEAS-2B cells under control conditions and when exposed to $1 \%(\mathrm{v} / \mathrm{v}$ ) CSE for $24 \mathrm{~h}$. (A) Low magnification (scale bar $200 \mathrm{~nm}$ ) and (B) detail (scale bar $100 \mathrm{~nm}$ ) cryo-TEM recordings of isolated EVs. White arrows in the low magnification recordings indicate structures which the authors considered to be EVs. (C) Diameter of isolated EV as determined by cryo-TEM. (D) Size distribution histogram of isolated EVs as determined by TRPS. Bars show the mean \pm $\mathrm{SEM}, \mathrm{n}=5$. The vertical dotted lines indicate the size filter that was applied to quantify EVs in order to normalize the input for EV characterization $(80-250 \mathrm{~nm})$. 
Supplementary Table 1 Complete list of proteins identified by nano LC-MS/MS. The first work sheet "Output Sequest HT" gives the list of proteins as exported from the Sequest HT Proteome Discoverer 2.1, which was used for MS data acquisition and database search against the Uniprot database. The second work sheet "output data analysis R" gives the data table that was obtained after importing the data in the first work sheet into R and analysing it using the R code provided as Supplementary file 1.

Available online at

https://docs.google.com/spreadsheets/d/1EMsqrsazjJCP89DOBLptmmDB33HZFxзоуC 3 QH-

dij4yk/edit?usp=sharing 
Supplementary Table 2 list of EV-associated proteins that represent the pathway hemostasis. Proteins were ordered according to the fold-change (FC; CSE-EVs/control-EVs) and significant q-values (<o.1) are printed in italic.

\begin{tabular}{|c|c|c|c|c|}
\hline Gene name & protein name & FC & $\mathrm{p}$ & q \\
\hline ITGB1 & Integrin beta-1 & 1.8 & 0.001 & 0.018 \\
\hline CD63 & CD63 antigen & 1.7 & 0.003 & 0.019 \\
\hline BSG & Basigin & 1.6 & 0.001 & 0.018 \\
\hline $\mathrm{SLC}_{1} 6 \mathrm{~A}_{3}$ & Monocarboxylate transporter 4 & 1.6 & 0.081 & 0.099 \\
\hline $\mathrm{CD}_{47}$ & Leukocyte surface antigen $\mathrm{CD}_{47}$ & 1.5 & 0.004 & 0.021 \\
\hline PRKAR2A & cAMP-dependent protein kinase type II-alpha regulatory subunit & 1.5 & 0.043 & 0.065 \\
\hline $\mathrm{RAC}_{1}$ & Isoform $B$ of Ras-related $C_{3}$ botulinum toxin substrate 1 & 1.5 & 0.002 & 0.019 \\
\hline CALM1 & Calmodulin & 1.5 & 0.006 & 0.025 \\
\hline ITGAV & Integrin alpha-V & 1.5 & 0.003 & 0.019 \\
\hline GNAS & Guanine nucleotide-binding protein $\mathrm{G}(\mathrm{s})$ subunit alpha isoforms Xlas & 1.5 & 0.006 & 0.025 \\
\hline GNAI2 & Guanine nucleotide-binding protein G(i) subunit alpha-2 & 1.4 & 0.006 & 0.025 \\
\hline GNB1 & Guanine nucleotide-binding protein $\mathrm{G}(\mathrm{I}) / \mathrm{G}(\mathrm{S}) / \mathrm{G}(\mathrm{T})$ subunit beta-1 & 1.4 & 0.001 & 0.018 \\
\hline $\mathrm{A}_{2} \mathrm{M}$ & Alpha-2-macroglobulin & 1.4 & 0.001 & 0.018 \\
\hline $\mathrm{ATP}_{2} \mathrm{~B}_{1}$ & Plasma membrane calcium-transporting ATPase 1 & 1.4 & 0.042 & 0.065 \\
\hline $\mathrm{F}_{3}$ & Tissue factor & 1.4 & 0.030 & 0.052 \\
\hline $\mathrm{RAP} 1 \mathrm{~B}$ & Ras-related protein Rap-1b & 1.3 & 0.008 & 0.027 \\
\hline $\mathrm{CDC}_{42}$ & Cell division control protein 42 homolog & 1.3 & 0.003 & 0.019 \\
\hline APOB & Apolipoprotein B-10o & 1.3 & 0.008 & 0.026 \\
\hline GNA13 & Guanine nucleotide-binding protein subunit alpha-13 & 1.3 & 0.025 & 0.048 \\
\hline PFNi & Profilin-1 & 1.2 & 0.015 & 0.036 \\
\hline GNA11 & Guanine nucleotide-binding protein subunit alpha-11 & 1.2 & 0.030 & 0.052 \\
\hline $\mathrm{ITGA}_{5}$ & Integrin alpha- 5 & 1.2 & 0.027 & 0.050 \\
\hline $\mathrm{F}_{2}$ & Prothrombin & 1.2 & 0.041 & 0.063 \\
\hline RHOA & Transforming protein RhoA & 1.2 & 0.053 & 0.076 \\
\hline GNAI1 & Guanine nucleotide-binding protein G(i) subunit alpha-1 & 1.4 & 0.121 & 0.125 \\
\hline EHD2 & EH domain-containing protein 2 & 1.4 & 0.275 & 0.211 \\
\hline PLAUR & Urokinase plasminogen activator surface receptor & 1.2 & 0.169 & 0.154 \\
\hline $\mathrm{COL1A2}$ & Collagen alpha-2(I) chain & 1.2 & 0.761 & 0.356 \\
\hline SERPINE1 & Plasminogen activator inhibitor 1 & 1.2 & 0.143 & 0.138 \\
\hline CFL1 & Cofilin-1 OS=Homo sapiens GN=CFL1 $P E=1 S V=3$ & 1.2 & 0.092 & 0.104 \\
\hline $\mathrm{F}_{5}$ & Coagulation factor $\mathrm{V}$ & 1.2 & 0.187 & 0.165 \\
\hline APOA1 & Apolipoprotein A-I & 1.2 & 0.139 & 0.137 \\
\hline $\mathrm{AP}_{2} \mathrm{M}_{1}$ & AP-2 complex subunit mu & 1.1 & 0.152 & 0.143 \\
\hline $\mathrm{CAV}_{1}$ & Caveolin-1 & 1.1 & 0.234 & 0.188 \\
\hline ITGA2 & Integrin alpha-2 & 1.1 & 0.285 & 0.216 \\
\hline $\mathrm{STX}_{4}$ & Syntaxin-4 & 1.1 & 0.671 & 0.340 \\
\hline CAP1 & Adenylyl cyclase-associated protein 1 & 1.1 & 0.473 & 0.281 \\
\hline YWHAZ & $14-3-3$ protein zeta/delta & 1.1 & 0.614 & 0.323 \\
\hline FLNA & Filamin-A & 1.1 & 0.331 & 0.233 \\
\hline SERPINC1 & Antithrombin-III & 1.1 & 0.619 & 0.324 \\
\hline HBB & Hemoglobin subunit beta & 1.0 & 0.799 & 0.364 \\
\hline WDR1 & WD repeat-containing protein 1 & 1.0 & 0.974 & 0.410 \\
\hline MAPK1 & Mitogen-activated protein kinase 1 & 1.0 & 0.927 & 0.397 \\
\hline CAPZA2 & F-actin-capping protein subunit alpha-2 & 1.0 & 0.716 & 0.349 \\
\hline $\mathrm{COLL}_{1} \mathrm{~A}_{1}$ & Collagen alpha-1(I) chain & 0.9 & 0.799 & 0.364 \\
\hline TLN1 & Talin-1 & 0.9 & 0.270 & 0.208 \\
\hline SERPINF2 & Alpha-2-antiplasmin & 0.9 & 0.569 & 0.312 \\
\hline PRKARıA & cAMP-dependent protein kinase type I-alpha regulatory subunit & 0.9 & 0.250 & 0.197 \\
\hline $\mathrm{HSPA}_{5}$ & $78 \mathrm{kDa}$ glucose-regulated protein & 0.9 & 0.340 & 0.238 \\
\hline CAPZB & Isoform 2 of F-actin-capping protein subunit beta & 0.9 & 0.153 & 0.143 \\
\hline
\end{tabular}




\begin{tabular}{ccccc}
\hline Gene name & protein name & FC & p & $\mathrm{q}$ \\
\hline VCL & Vinculin & 0.8 & 0.095 & 0.105 \\
EHD1 & EH domain-containing protein 1 & 0.8 & 0.403 & 0.265 \\
TF & Serotransferrin & 0.7 & 0.089 & 0.102 \\
\hline TUBA4A & Tubulin alpha-4A chain & 0.0 & 0.004 & 0.020 \\
FN1 & Fibronectin & 0.7 & 0.003 & 0.019 \\
\hline
\end{tabular}


Supplementary File 1 - R code used for analysing the differential expression of proteins in CSE-induced EVs compared to control EVs.

\#Check whether the required packages are installed, if not install them

if("samr" \%in\% rownames(installed.packages()) == FALSE) \{install.packages("samr")\}

if("Biobase" \%in\% rownames(installed.packages()) == FALSE) \{install.packages("Biobase")\}

if("qvalue" \%in\% rownames(installed.packages ()$)==$ FALSE) \{

source("http://bioconductor.org/biocLite.R")

biocLite("qvalue") \}

\#read.csv(): reads data from a .csv file

\#file.choose(): let's the user select the file to be opened by clicking on it. Alternatively a

location can be used such as "C:|user\documents \...|file.csv"

\#header = TRUE: the first row that is read will be set as column names

\#sep=";" : sets ";" as list separator. As a standard, this is set to "," but this can cause problems when reading tables that contain commas

\#dec="." : defines how decimals are given, with a "," or "."

\#skip = 2; skips the first two rows of the table because these do not contain relevant information

\#na.strings = c("', "NA", "\#NUM!") : empty cells, missing values and error messages, will be noted NA

File <- read.csv(file.choose(), header = TRUE, sep = ";", dec = ".", skip = 2, na.strings=c("', "NA", "\#NUM!"))

File $<-$ subset(File, select $=-c(X))$ \# remove empty column with the title $\mathrm{x}$

File <- File[rowSums(is.na(File[ ,4:13])) != 10, ] \#remove rows that do not have any abundance values

\#Data frame creates a matrix of values. A column of File can be selected using ' $\$$ '.

corrections $<-$ data.frame $\left(C S E 1=\right.$ File $\$ X_{127} N_{-}$CSE,

$$
\begin{aligned}
& \mathrm{CSE} 2=\text { File\$X128N_CSE, } \\
& \mathrm{CSE}_{3}=\text { File\$X129N_CSE, } \\
& \mathrm{CSE}_{4}=\text { File\$X130N_CSE, } \\
& \mathrm{CSE}_{5}=\text { File\$X131N_CSE, } \\
& \mathrm{ctrl}_{1}=\text { File\$X126C_Control, } \\
& \mathrm{ctrl}_{2}=\text { File\$X127C_Control, } \\
& \mathrm{ctrl}_{3}=\text { File\$X128C_Control, }
\end{aligned}
$$




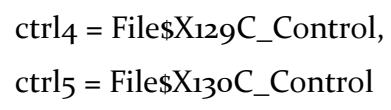


$\operatorname{dim}$ (analysis) \# gives the number of proteins with an FDR $<=0,01$

\# boxplot: intensities of all eight channels after data preprocessing and normalization $\operatorname{par}(\operatorname{mfrow}=\mathrm{c}(1,1)$, font.lab=2, cex.lab=1.2, font.axis=2, cex.axis=1.2)

boxplot(analysis[, 4:13], ylim =c(-3, 3), main="Boxplot normalized Intensities")

\# define design according to syntax of limma package

design <- model.matrix ( factor $(c(2,2,2,2,2,1,1,1,1,1)))$

design

colnames(design) <- c("Intercept", "Diff")

\# eb.fit performs two sample unmoderated and moderated t-test

\# outputs a data frame that contains for each protein: its $\log _{2}-\mathrm{FC}$, ordinary and moderated pvalues and q-values, sorted by moderated $\mathrm{p}$-values in increasing order

eb.fit.bb $<-$ function(analysis, design) \{

$\mathrm{n}<-\operatorname{dim}($ analysis) [1]

fit $<-\operatorname{lm}$ Fit(analysis[,4:13], design)

fit.eb.bb <- eBayes(fit)

$\log \mathrm{FC}<-$ fit.eb.bb\$coefficients[, 2]

$\log \mathrm{FC}<--\log \mathrm{FC}$

df.r $<-$ fit.eb.bb\$df.residual

df.o <- rep(fit.eb.bb\$df.prior, n)

s2.o <- rep(fit.eb.bb\$s2.prior, n)

s2 <- (fit.eb.bb\$sigma) $\wedge_{2}$

s2.post <- fit.eb.bb\$s2.post

t.ord <- fit.eb.bb\$coefficients[, 2]/fit.eb.bb\$sigma/fit.eb.bb\$stdev.unscaled[, 2]

t.mod $<-$ fit.eb.bb\$t[, 2]

p.ord $<-2^{*}$ pt(-abs(t.ord), fit.eb.bb\$df.residual)

p.mod <- fit.eb.bb\$p.value[, 2]

q.ord <- qvalue(p.ord) $\$$ q

q.mod $<-$ qvalue(p.mod) $\$$ q

results.eb.bb <- data.frame(analysis,logFC, t.ord, t.mod, p.ord, p.mod, q.ord, q.mod, df.r, df.o, s2.o, s2, s2.post)

results.eb.bb <- results.eb.bb[order(results.eb.bb\$p.mod), ]

return(results.eb.bb) 
getwd()

results.eb.bb\$Ratio=as.vector(results.eb.bb\$Ratio)

results.eb.bb\$Ratio=gsub(",","\\.",results.eb.bb\$Ratio)

results.eb.bb\$Ratio=as.numeric(results.eb.bb\$Ratio)

write.csv(results.eb.bb, file="MS_moderated_t_4.csv")

\#\#The rownames of the generated data frame res.eb correspond to protein groups accessions numbers provided by the original raw data set. Each protein (row) has the following columns: \#logFC estimate of the log2-fold-change corresponding to the effect size

\#t.ord vector of ordinary t-statistic

\#t.mod moderated t-statistic

\#p.ord ordinary p-value corresonding to the ordinary t-statistic

\#p.mod moderated p-value corresonding to the moderated t-statistic

\#q.ord ordinary q-value corresonding to the ordinary t-statistic

\#q.mod moderated q-value corresonding to the moderated t-statistic

\#df.r residual degrees of freedom assiciated with ordinary t-statistic and p-value

\#df.o degrees of freedom associated with s2.o

\#s2.o estimated prior value for the variance

\#s2 sample variance

\#s2.post posterior value for the variance 




\section{Chapter 6}

\section{Detection of extracellular vesicles in plasma of healthy smokers}

Birke J. Benedikter, Alexandra C.A. Heinzmann, Tanja Vajen, Emiel F.M. Wouters, Paul H.M. Savelkoul, Rory R. Koenen, Gernot G.U. Rohde, Rene van Oerle, Henri M. Spronk, Frank R.M. Stassen 


\section{Abstract}

We have shown by bead-based flow cytometry that cultured bronchial epithelial cells secrete an increased quantity of total, tissue factor $(\mathrm{TF})^{+}$, and phosphatidylserine (PS) ${ }^{+}$extracellular vesicles (EVs) when exposed to cigarette smoke extract. In this pilot study, we tested whether bead-based flow cytometry can be used for detecting EVs in human plasma. We then aimed to translate our in vitro findings by comparing EV concentrations in young healthy smokers before and after smoking, as well as between smokers and nonsmoking controls. PS content of isolated EVs was assessed by prothrombinase assay and plasma thrombogenicity by calibrated automated thrombrogram. While many bead-based flow cytometry stainings were unspecific or too insensitive when applied to human plasma, the following capture/detection combinations provided a specific signal: CD81/CD81, CD81/TF and CD81/EpCAM. No significant differences in circulating EVs were found in smokers before and after smoking. Yet, in baseline samples, there was a trend for a positive association between the number of cigarettes smoked per day and $\mathrm{CD}^{+}{ }^{+} \mathrm{TF}^{+}$EVs. When analysing the data from male samples only, there was a significant negative association between smoking status and $\mathrm{CD}^{+}{ }^{+} \mathrm{EpCAM}^{+} \mathrm{EVs}$. $\mathrm{CD} 81^{+} \mathrm{EpCAM}^{+} \mathrm{EV}$ s showed a moderate negative correlation with the time required for thrombin formation. In conclusion, bead-based flow cytometry can be used for detecting EVs in human plasma, but this requires extensive validation and optimisation. This pilot study does not provide evidence for smoking-induced procoagulant changes in circulating $\mathrm{TF}^{+} \mathrm{EVs}$. 


\section{Introduction}

In chapter 5, we have shown that, when exposed to cigarette smoke extract (CSE), bronchial epithelial cells secrete increased concentrations of total, tissue factor (TF) ${ }^{+}$ and phosphatidylserine (PS) ${ }^{+}$extracellular vesicles (EVs). These results were largely obtained using bead-based flow cytometry for EVs that express exosome marker proteins such as $\mathrm{CD} 63, \mathrm{CD} 81$ and $\mathrm{CD} 9$. This sub-chapter describes a pilot study, in which we aimed to 1) validate bead-based flow cytometry for the detection of EVs in human plasma, 2) determine whether smoking modifies the concentrations of total, $\mathrm{TF}^{+}$and $\mathrm{PS}^{+}$circulating EVs and 3 ) investigate whether concentrations of circulating EVs are correlated with plasma thrombogenicity.

\section{Materials and Methods}

\section{Healthy volunteers, blood sampling and platelet poor plasma}

Written informed consent was obtained from all participants, and the study was approved by the institutional ethics committee of the Maastricht UMC+. To study the acute effects of smoking, 6 young (18-35 years) healthy smokers and 6 age- and sex-matched controls were included. A baseline blood sample was taken after overnight abstinence from smoking and eating. All participants then received a standardised breakfast and were encouraged to follow their normal smoking behaviour. After 3 hours, a second blood sample was drawn. To study medium term effects of smoking, 8 additional young (18-35 years) healthy smokers and age- and sex-matched controls were included for the baseline blood sample only (total $n=14$ per group). Participants filled in a short questionnaire about their smoking behaviour, health status and medication use. Blood collection was performed as described previously with some adaptations [1]. Venous blood was collected by antecubital venepuncture using 21-gauge needles, one discarding tube and 2 consecutive $3.2 \%(\mathrm{w} / \mathrm{v})$ citrated Vacutainer glass tubes (BD). Blood was centrifuged twice at $1,550 \times g$ for 20 min to obtain platelet poor plasma (PPP). PPP was aliquoted and stored at $-80^{\circ} \mathrm{C}$ until use.

\section{Bead-based flow cytometry}

Bead-based flow cytometry was performed as described in chapter 5 with some adaptations. Various combinations of capture beads and detection antibodies were tested. CD63-, CD63/CD81/CD9- and CD81-beads were coated as described in 
chapter 5. Additionally, beads $\left(3.5 \times 10^{8} / \mathrm{ml}\right)$ were coated with $0.25 \mathrm{mg} / \mathrm{ml}$ Annexin V unlabelled recombinant protein (eBioscience), $0.125 \mathrm{mg} / \mathrm{ml}$ mouse anti-human TF (BD; clone HTF-1), $0.125 \mathrm{mg} / \mathrm{ml}$ mouse anti-human EpCAM (Thermo Fisher Scientific; clone ${ }_{1 B} 7$ ) or $0.125 \mathrm{mg} / \mathrm{ml}$ mouse IgG1,k isotype control (clone MOPC-21; $\mathrm{BD})$ by overnight incubation in 2-(N-morpholino)ethanesulfonic acid (MES) buffer. After coating, all beads were incubated for 8 hours with $4 \%$ (w/v) BSA in PBS to block unspecific binding sites.

PPP and positive controls ( 24 hour conditioned media from BEAS-2B cells) were thawed at room temperature, followed by vortexing and centrifugation for 2 minutes at 10,000 $x g$, after which the supernatant was transferred into a fresh tube. Plasma samples were diluted using PBS with $0.32 \%(\mathrm{w} / \mathrm{v})$ sodium citrate. Next, 1 x $10^{6}$ beads were incubated overnight with either undiluted $(400 \mu \mathrm{l})$ or $5 \mathrm{x}$ diluted $(200 \mu \mathrm{l})$ PPP or with the volume-matched positive control. Detection was performed as described previously [2] with either of the following phycoerythrin (PE)-labelled antibodies: mouse anti-human CD81 (BD; clone JS-81), mouse anti-human TF (BD; clone HTF-1), or mouse anti-human EpCAM (cloneiB7). Alternatively, beads were stained for 15 minutes at room temperature with $50 \mu \mathrm{l}$ of Alexa Fluor $488\left(\mathrm{AF}_{4} 88\right)$ conjugated annexin V (Thermo Fisher Scientific) diluted $50 \mathrm{x}$ in annexin binding buffer (ABB) in order to detect PS.

\section{Tuneable resistive pulse sensing}

Total circulating nanoparticles were measured by tuneable resistive pulse sensing (TRPS) using a qNano Gold (Izon) and Izon Control Suite Software Version 3.2. Plasma was diluted $50 \mathrm{x}$ in $0.2 \mu \mathrm{m}$-filtered PBS with $0.32 \%(\mathrm{w} / \mathrm{v})$ sodium citrate and measured using an $\mathrm{NP}_{300}$ nanopore (Izon) with SKP40o calibration beads (Izon) to detect particles of $200-400 \mathrm{~nm}$ in diameter. Alternatively, $50 \mathrm{x}$ diluted plasma was filtered through a $0.4 \mu \mathrm{m}$ syringe filter and measured on an NP150 nanopore (Izon) with SKP2oo calibration beads (Izon) to detect particles of $85-250 \mathrm{~nm}$ in diameter. For each pore type, the stretch was adjusted as to maintain the blockade height of the calibration beads constant and the voltage was adjusted to maintain the current between 125 and $135 \mathrm{nA}$. The pressure was maintained at 15 mbar for all measurements.

\section{EV isolation and prothrombinase assay}

EVs were isolated from PPP by size exclusion chromatography (SEC). In brief, $500 \mu \mathrm{l}$ of PPP were thawed at room temperature and vortexed, followed by application to a qEV SEC column (Izon). Using PBS with $0.32 \%(w / v)$ sodium citrate as elution 
buffer, 8 fractions of $1.5 \mathrm{ml}$ were collected. By bead-based flow cytometry, the majority of EVs was found to elute in fraction 3 (data not shown). Therefore, fraction 3 of each plasma sample was collected and concentrated to $400 \mu \mathrm{l}$ on an Amicon Ultra-4 Centrifugal Filter Unit with Ultracel 10 membrane (10 kDa MWCO, Merck Millipore). The obtained EV isolates were aliquoted and stored at $-80^{\circ} \mathrm{C}$ until PS quantification. PS quantification was performed using the prothrombinase assay as described in chapter 5, except that all EV isolates were tested $10 \mathrm{x}$ and $100 \mathrm{x}$ diluted rather than at a fixed $\mathrm{EV}$ concentration.

\section{Thrombin generation}

Thrombin generation was determined using the calibrated automated thrombogram method (CAT, Thrombinoscope BV) as described in chapter 5 with some adaptations. Instead of in the normal human plasma pool, thrombin generation was assessed in PPP of the healthy smokers and controls. Either $20 \mu \mathrm{l}$ of calibrator or 20 $\mu \mathrm{l}$ of phospholipids (MP reagent, Thrombinoscope BV) was added to $80 \mu \mathrm{l}$ of plasma. Measurements were performed as described previously [3].

\section{Data analysis}

Data was analysed using $\mathrm{R}$ version 3.4.1 for Windows with $\mathrm{R}$ studio. Comparisons between baseline and post-exposure samples of smokers or non-smokers were performed using the Wilcoxon signed rank test. To compare baseline samples of non-smokers and smokers, univariate analysis was performed using the independent 2-group Mann-Whitney U test. Multivariate analysis was performed using linear regression, including testing for interaction. Multicollinearity was tested using the mctest package. Spearman correlation coefficients were calculated using $\mathrm{R}$ and plotted using the heatmap.2 function of the gplots package.

\section{Results}

\section{Validation of bead-based flow cytometry stainings for the detection of EVs in human plasma}

We first evaluated whether bead-based flow cytometry can be used for detecting EVs in human plasma. For this purpose, baseline PPP from 12 study participants (6 smokers and 6 controls) was pooled and incubated with various capture beads and detection antibodies. As a positive control, 24 h-conditioned media of BEAS-2B bronchial epithelial cells were used. The results are shown in Figure 1. While all tested stainings except for CD81/EpCAM (Figure 1 D) provided a specific signal for 


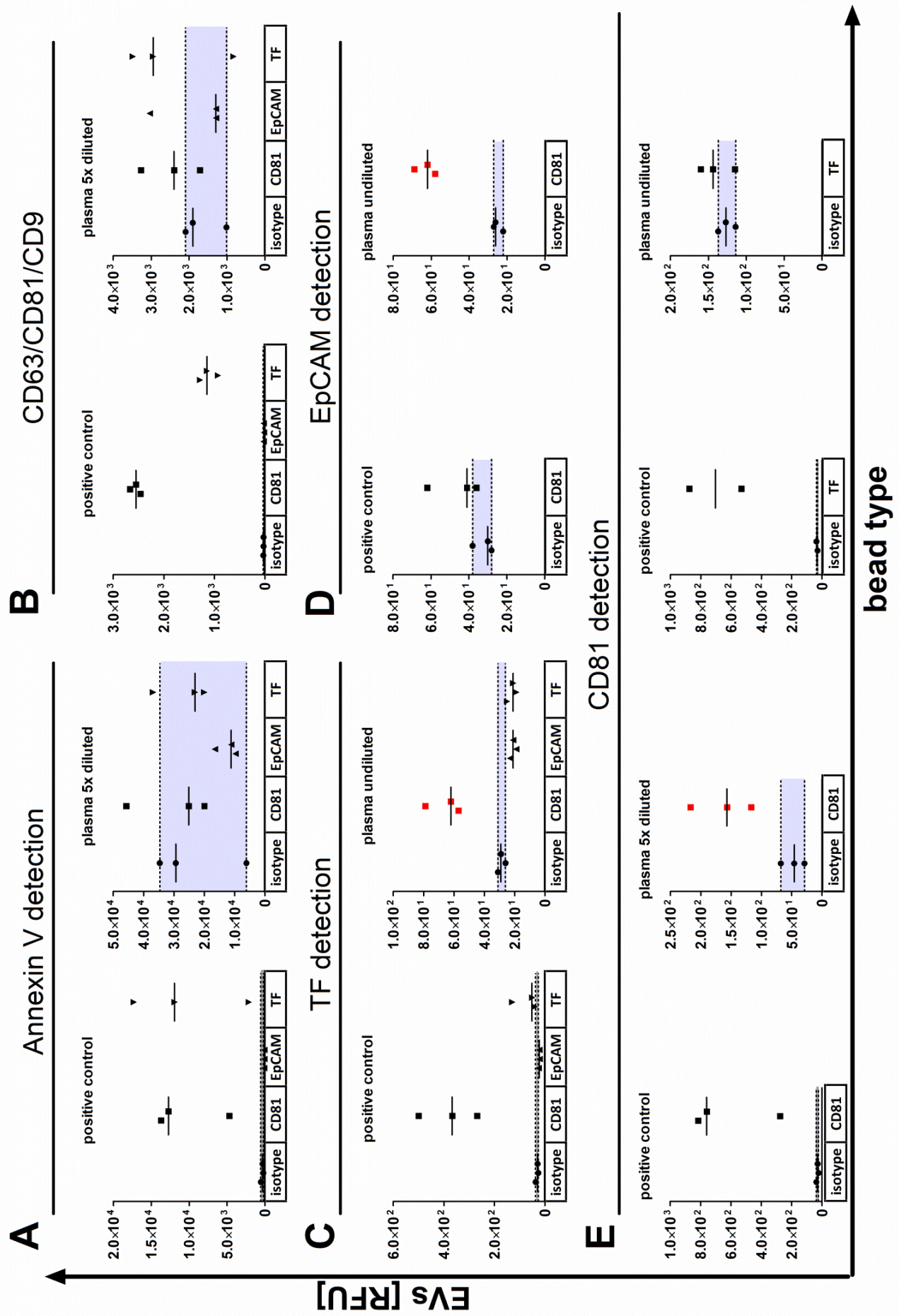


Figure 1 - Validation of different bead/detection combinations for measurement of EVs in human plasma. As a positive control, 24 h-conditioned medium of BEAS-2B bronchial epithelial cells was used. Grey zones indicate the spread of the background signal measured with isotype beads. The stainings that were selected for comparing circulating EVs of non-smokers and smokers are highlighted in red. (A) Detection using Alexa Fluor 488-labelled Annexin V, (B) Detection using a combination of PE-labelled anti-CD63, anti-CD81 and anti-CD9, (C) Detection using PE-labelled, (D) Detection using PE-labelled anti-EpCAM and (E) Detection using PE-labelled anti-CD81

the positive control, several problems were encountered when applying the method to plasma samples. Beads coated with anti-CD63, annexin V, or a combination of anti-CD63, anti-CD81 and anti-CD9 were excluded from analysis because these beads agglutinated irreversibly when incubated with plasma. Anti-CD9 beads were not included because we previously found platelet-derived EVs to be rich in CD9 compared to BEAS-2B bronchial epithelial cell-derived EVs [4], suggesting that these beads would not target the EV population of interest. For all bead types, EV detection using annexin $\mathrm{V}$ (Figure $1 \mathrm{~A}$ ) or using a mixture of PE-labelled anti-CD63, anti-CD81 and anti-CD9 (Figure $1 \mathrm{~B}$ ) provided a high unspecific signal when using isotype-coated beads. In both cases, the high background signal was not improved by isolating EVs using UF-SEC prior to bead-based flow cytometry (data not shown). Finally, anti-TF (Figure ${ }_{1 C}$ ), anti-EpCAM (Figure $1 \mathrm{D}$ ) and anti-CD81 (Figure $1 \mathrm{E}$ ) detection provided a specific signal for plasma when combined with CD81 capture beads. Therefore, the following capture/detection combinations were chosen for studying the effects of smoking on circulating EVs: 1) CD81/CD81 for detection of total $\mathrm{CD}_{1}{ }^{+} \mathrm{EVs}$; $\mathrm{CD} 81 / \mathrm{TF}$ for detection of $\mathrm{CD}_{1}{ }^{+} \mathrm{TF}^{+}$procoagulant EVs; and 3) $\mathrm{CD} 81 / \mathrm{EpCAM}$ for detection of $\mathrm{CD}_{1}{ }^{+} \mathrm{EpCAM}^{+}$epithelial-derived EVs

\section{Effects of acute smoke exposure on circulating EVs}

To assess acute effects of smoking, we compared circulating EVs in baseline and post-exposure samples of 6 smokers. Additionally, 6 non-smokers were included to control for diurnal or diet-induced variations in EV concentrations. All subjects were sampled in the morning after overnight abstinence from smoking and eating, after which they received a standardised breakfast. Smokers were then encouraged to follow their normal smoking behaviour and a second blood sample was drawn from all participants after 3 hours. The participant characteristics are summarised in table 1 (before-after). The median number of cigarettes smoked per person in the smoker group was 3 and no participant smoked less than 2 cigarettes between the two sampling time points, whereas no cigarettes were smoked by the participants of the 
control group.

Circulating EVs were detected by bead-based flow cytometry with the optimal capture/detection combinations. Additionally, circulating EVs were measured using TRPS with an NP150 nanopore for particles with a diameter of 85$250 \mathrm{~nm}$ and with an NP30o for particles with a diameter of $200-400 \mathrm{~nm}$. Box plots of the results are shown in Figure 2. Neither in smokers nor in non-smokers was there any significant difference in $\mathrm{CD}_{1}{ }^{+}, \mathrm{CD}_{1}{ }^{+} \mathrm{TF}^{+}$or $\mathrm{CD}_{1}{ }^{+} \mathrm{EpCAM}^{+} \mathrm{EV}$ s between the two sampling time points (Figure $2 \mathrm{~A}-\mathrm{C}$ ). Circulating nanoparticles of $85-250 \mathrm{~nm}$ were significantly increased between baseline and post-exposure samples in smokers as well as non-smokers (Figure $2 \mathrm{D}$ ). For both groups, there was also an increase in nanoparticles with a diameter of $200-400 \mathrm{~nm}$ (Figure $2 \mathrm{E}$ ). For non-smokers, this was statistically significant (Figure $2 \mathrm{E}$ ). There were no significant differences in the delta (concentration post-exposure - concentration at baseline) for any of the assessed EV outcomes. While we found no acute effect of smoking on circulating EVs in beforeafter samples, potential differences in the baseline values between non-smokers and smokers were perceived for $\mathrm{CD}_{1}{ }^{+}, \mathrm{CD}_{1}{ }^{+} \mathrm{TF}^{+}$and $\mathrm{CD}_{1}{ }^{+} \mathrm{EpCAM}^{+} \mathrm{EVs}$. Additional participants were therefore included for the baseline measurements in order to examine whether these differences were reproducible and statistically significant.

Table 1 - Characteristics of the participants included for testing the acute (before-after) and medium term (baseline only) effects of smoking on circulating EVs. Values are given as median with interquartile range.

\begin{tabular}{lccccc}
\hline & \multicolumn{2}{c}{ before-after } & & \multicolumn{2}{c}{ baseline only } \\
\cline { 2 - 3 } $\mathrm{n}$ & smokers & non-smokers & smokers & non-smokers \\
age & 6 & 6 & 14 & 14 \\
females & $28(27-29 \cdot 75)$ & $30.5(28.5-31)$ & $26(24.25-28.5)$ & $28(24 \cdot 5-31)$ \\
years of smoking & 1 & 1 & 6 & 6 \\
cigarettes per day & $7(6.25-9.25)$ & 0 & $7.5(6-10)$ & 0 \\
pack-years & $20(12.5-20)$ & 0 & $13.75(10-20)$ & 0 \\
cigarettes between samplings & $3(3-3.75)$ & 0 & $5.5(3.38-7)$ & 0 \\
\hline
\end{tabular}


A

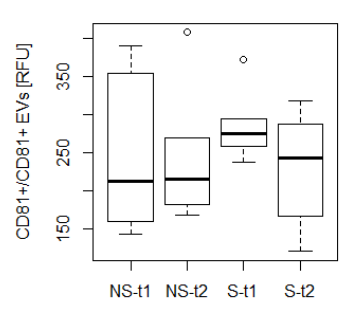

c
B
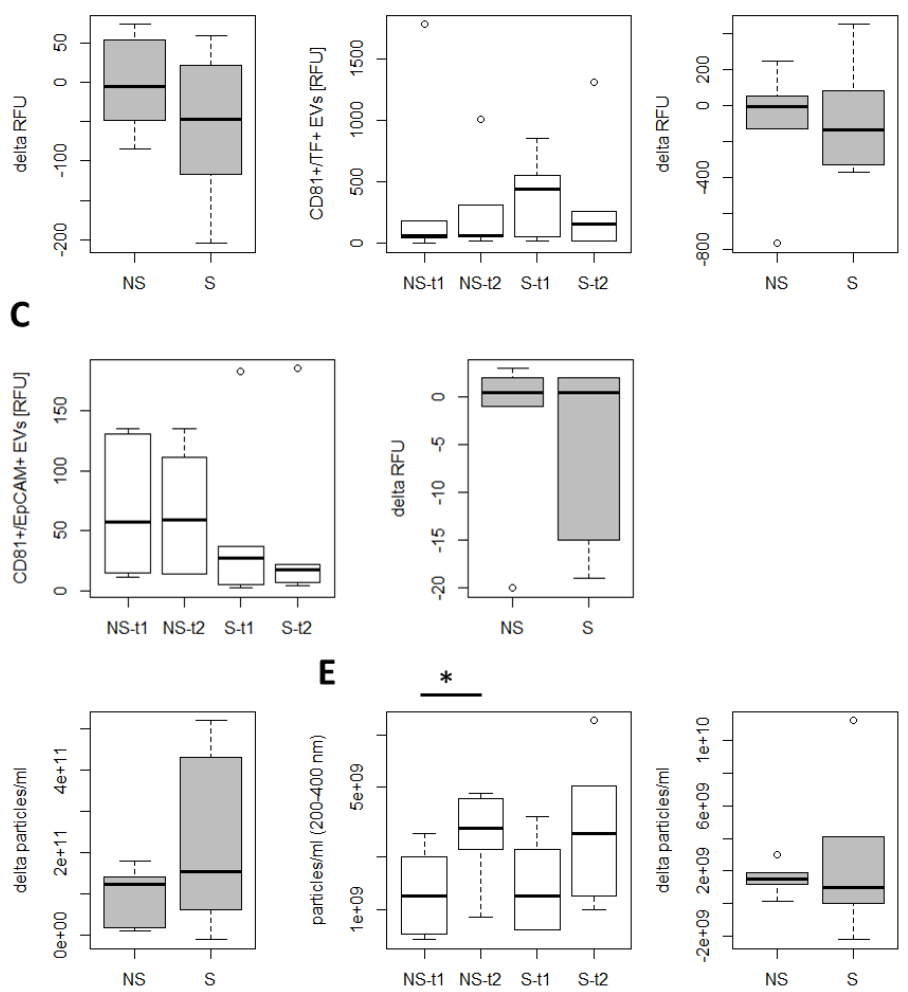

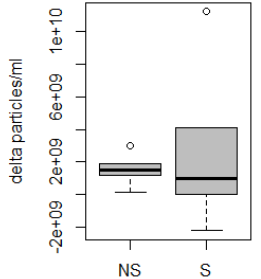

Figure 2 - Box plots of the different EV measurements in baseline (t1) and 'post-exposure' ( $\mathrm{t}_{2}$ ) samples. White box plots show the absolute values for non-smokers and smokers at both time points and grey box plots show the delta (t2-t1) for non-smokers and smokers. (A) CD81 ${ }^{+} \mathrm{EVs}$, (B) $\mathrm{CD} 81^{+} \mathrm{TF}^{+} \mathrm{EVs}$, (C) $\mathrm{CD}_{1}{ }^{+} \mathrm{EpCAM}^{+} \mathrm{EVs}$, (D) nanoparticles with a diameter of 85-250 nm, (E) nanoparticles with a diameter of 200-40o $\mathrm{nm}$. Statistical differences were tested for all datasets using the Wilcoxon signed rank test to compare the $\mathrm{t}_{1}$ and $\mathrm{t} 2$ time points within each group and using the Mann-Whitney $\mathrm{U}$ test to compare the deltas of the two groups to each other. ${ }^{*} \mathrm{p}=0.01-0.05$. NS, non-smokers; $\mathrm{S}$, smokers; t1, time point 1 (baseline); t2, time point 2 ('post-exposure')

\section{Cross-sectional effects of smoking on circulating EVs}

To determine effects of smoking on circulating EVs in a cross-sectional setup, we compared EV measurements in baseline samples of smokers and non-smoking controls ( $n=14$ per group), i.e. in samples that were taken in the morning after overnight abstinence from smoking and eating. The participant characteristics are summarised in table 1 (baseline only). Univariate analysis by Mann-Whitney U test 
revealed no significant differences between smokers and non-smokers for any of the assessed EV parameters, i.e. $\mathrm{CD}_{1}{ }^{+} \mathrm{EVs}$ (Figure $3 \mathrm{~A}$ ), $\mathrm{CD}_{1}{ }^{+} \mathrm{TF}^{+} \mathrm{EVs}$ (Figure ${ }_{3} \mathrm{~B}$ ), $\mathrm{CD}_{1}{ }^{+} \mathrm{EpCAM}^{+} \mathrm{EVs}_{\mathrm{s}}$ (Figure ${ }_{3} \mathrm{C}$ ) and EV-associated PS (Figure ${ }_{3} \mathrm{D}$ ). There were also no differences in phospholipid-induced thrombin generation between smokers and non-smokers in terms of lagtime (Figure ${ }_{3} \mathrm{E}$ ), endogenous thrombin potential (ETP; Figure $3 \mathrm{~F}$ ), thrombin peak concentration (Figure $3 \mathrm{G}$ ) and the time to peak (ttPeak; Figure $3 \mathrm{H}$ ).

A

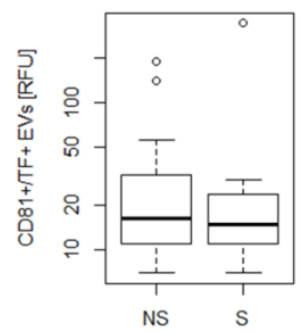

$\mathbf{E}$

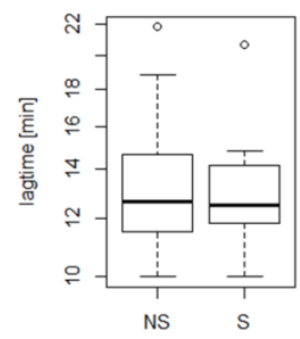

B

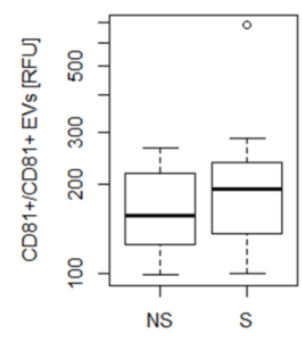

$\mathbf{F}$

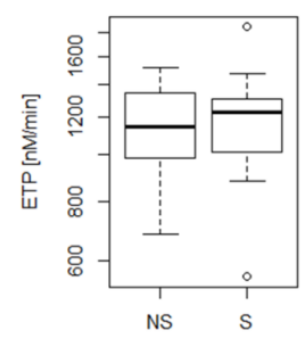

C

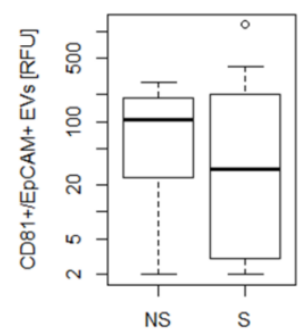

G

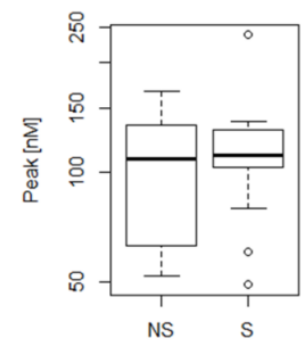

\section{D}

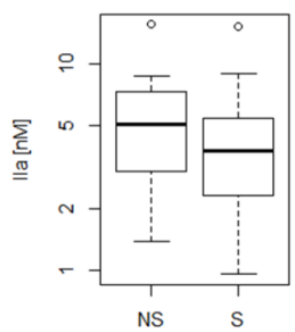

H

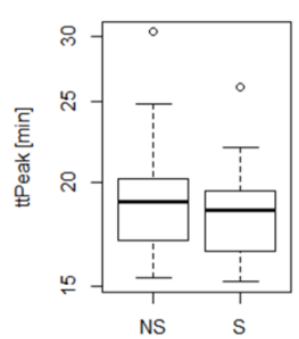

Figure 3 - Box plots of the different EV measurements for baseline samples, divided into non-smokers (NS) and smokers (S). (A) CD81 ${ }^{+} \mathrm{TF}^{+}$EVs. (B) CD81 ${ }^{+}$EVs. (C) $\mathrm{CD}_{1} 1^{+} \mathrm{EpCAM}^{+}$EVs. (D) EV-associated PS. (E) Lagtime. (F) ETP. (G) Thrombin peak concentration. (H) ttPeak. Statistical differences were tested for all datasets using the Mann-Whitney $U$ test to compare the values in non-smokers and smokers to each other. NS, non-smokers; S, smokers; t1, time point 1 (baseline); t2, time point 2 ('post-exposure')

To adjust for the age and sex of the study participants, a multivariate linear regression was used. Linear regression models with the smoking status as predictor variable were built for the whole study population $(n=28)$. Linear regression models with either pack-years or the number of cigarettes smoked per day were built for smokers only $(\mathrm{n}=14)$ because inclusion of the non-smokers would lead to a highly skewed distribution of the predictor variables (with half of the values being null), 
violating the assumption of normality. We first tested whether there was a significant interaction between smoking status and sex as predictors for all outcome variables. For $\mathrm{CD}^{+}{ }^{+} \mathrm{EpCAM}^{+} \mathrm{EVs}$, sex was a significant effect modifier. Therefore, separate linear models were built for males and females for $\mathrm{CD}_{1}{ }^{+} \mathrm{EpCAM}^{+} \mathrm{EVs}$ as outcome variable. Moreover, we tested for multicollinearity and found that packyears and age were significantly correlated. Therefore, age was excluded from the model when predicting outcome variables based on the pack-years.

Table 2- Results of the multivariate linear regression analysis. ${ }^{\circ} \mathrm{p}=0.05-0.1 ;{ }^{*} \mathrm{p}=0.01-0.05 ;{ }^{* *} \mathrm{p}=0.001-0.01 ;{ }^{* * *} \mathrm{p}<0.001$

\begin{tabular}{|c|c|c|c|c|c|c|c|c|c|}
\hline & \multicolumn{3}{|c|}{$\begin{array}{c}\text { total, } \mathrm{n}=\mathbf{2 8} \\
16 \text { males, } 12 \text { females }\end{array}$} & \multicolumn{3}{|c|}{$\begin{array}{c}\text { smokers, } \mathrm{n}=14 \\
8 \text { males, } 6 \text { females }\end{array}$} & \multicolumn{3}{|c|}{$\begin{array}{c}\text { smokers, } \mathrm{n}=14 \\
8 \text { males, } 6 \text { females }\end{array}$} \\
\hline & & beta & $\mathrm{p}$ & & beta & $\mathrm{p}$ & & beta & $\mathrm{p}$ \\
\hline \multirow[t]{3}{*}{$\mathrm{CD} \mathrm{1}^{+} \mathrm{EVs}$} & smoking status & 44.98 & 0.284 & cigarettes/day & 10.93 & 0.216 & pack-years & 4.73 & 0.647 \\
\hline & female sex & 66.50 & 0.117 & female sex & 95.61 & 0.247 & female sex & $99 \cdot 94$ & 0.242 \\
\hline & age & $-4 \cdot 39$ & 0.365 & age & -10.74 & 0.453 & & & \\
\hline \multirow[t]{3}{*}{$\mathrm{CD}^{+} \mathrm{1}^{+} \mathrm{TF}^{+} \mathrm{EVs}$} & smoking status & $-3 \cdot 96$ & 0.882 & cigarettes/day & $9 \cdot 41$ & $0.070^{\circ}$ & pack-years & 0.09 & 0.989 \\
\hline & female sex & 53.87 & $0.051^{\circ}$ & female sex & 42.37 & 0.354 & female sex & 55.13 & 0.296 \\
\hline & age & -2.73 & 0.380 & age & -9.43 & 0.249 & & & \\
\hline \multicolumn{10}{|l|}{$\mathrm{CD}_{1}{ }^{+} \mathrm{EpCAM}^{+} \mathrm{EVs}$} \\
\hline \multirow[t]{2}{*}{ males } & smoking status & -106.07 & $0.009^{* *}$ & cigarettes/day & -1.12 & 0.544 & pack-years & -3.75 & 0.274 \\
\hline & age & -0.69 & o.874 & age & -2.21 & 0.481 & & & \\
\hline \multirow[t]{2}{*}{ females } & smoking status & 226.32 & 0.273 & cigarettes/day & 50.22 & 0.292 & pack-years & -0.88 & 0.983 \\
\hline & age & $-15 \cdot 39$ & 0.473 & age & -75.84 & 0.325 & & & \\
\hline \multirow[t]{3}{*}{ PS } & smoking status & -0.79 & 0.570 & cigarettes/day & -0.09 & 0.683 & pack-years & -0.18 & 0.485 \\
\hline & female sex & -1.60 & 0.254 & female sex & -1.76 & 0.425 & female sex & -1.72 & 0.423 \\
\hline & age & -0.17 & 0.299 & age & 0.30 & 0.447 & & & \\
\hline \multirow[t]{3}{*}{ Lagtime } & smoking status & $-0.5^{8}$ & 0.633 & cigarettes/day & -0.02 & 0.903 & pack-years & 0.13 & 0.478 \\
\hline & female sex & -0.63 & 0.602 & female sex & -1.88 & 0.262 & female sex & -2.23 & 0.161 \\
\hline & age & -0.13 & 0.358 & age & 0.07 & 0.790 & & & \\
\hline \multirow[t]{3}{*}{ ETP } & smoking status & 81.99 & 0.470 & cigarettes/day & 21.26 & 0.292 & pack-years & -3.85 & o.870 \\
\hline & female sex & 136.93 & 0.229 & female sex & 142.89 & 0.448 & female sex & 163.07 & 0.400 \\
\hline & age & $15 \cdot 41$ & 0.238 & age & -14.95 & 0.644 & & & \\
\hline \multirow[t]{3}{*}{ Peak } & smoking status & 13.20 & 0.438 & cigarettes/day & $3 \cdot 38$ & 0.269 & pack-years & -2.20 & 0.531 \\
\hline & female sex & 6.73 & 0.689 & female sex & 15.24 & 0.589 & female sex & $24 \cdot 56$ & 0.393 \\
\hline & age & 1.43 & 0.460 & age & -4.81 & 0.334 & & & \\
\hline \multirow[t]{3}{*}{ ttPeak } & smoking status & -1.15 & 0.418 & cigarettes/day & -0.04 & 0.817 & pack-years & 0.20 & 0.333 \\
\hline & female sex & -0.19 & 0.891 & female sex & -1.67 & 0.359 & female sex & -2.24 & 0.192 \\
\hline & age & -0.16 & 0.335 & age & 0.15 & 0.627 & & & \\
\hline
\end{tabular}


The results of all linear regression analyses are summarised in table 2. For the total group $(\mathrm{n}=\mathbf{2 8})$, in the analysis for the smoking status, age and sex, female sex was positively associated with the concentration of $\mathrm{CD}^{+}{ }^{+} \mathrm{TF}^{+} \mathrm{EVs}$ with a near significant $\mathrm{p}$-value $(\mathrm{p}=\mathrm{0.051})$. While no association was found for the smoking status or pack-years and $\mathrm{CD}_{1}{ }^{+} \mathrm{TF}^{+} \mathrm{EVs}$, the number of cigarettes smoked per day tended to be positively associated with this procoagulant EV subtype $(\mathrm{p}=0.07)$. Moreover, there was a significant negative association between smoking status and $\mathrm{CD} 81^{+} \mathrm{EpCAM}^{+}$ EVs in the male subgroup $(n=16, p=0.009)$. Figure 4 shows two separate boxplots of the $\mathrm{CD}{ }^{+} \mathrm{EpCAM}^{+}$EVs for males (Figure $4 \mathrm{~A}$ ) and females (Figure ${ }_{4} \mathrm{~B}$ ). Similar to the linear regression model, the Mann-Whitney $U$ test confirmed a significant decrease of $\mathrm{CD}_{1}{ }^{+} \mathrm{EpCAM}^{+} \mathrm{EVs}$ in male smokers (Figure $4 \mathrm{~A}, \mathrm{p}=0.006$ ).

A

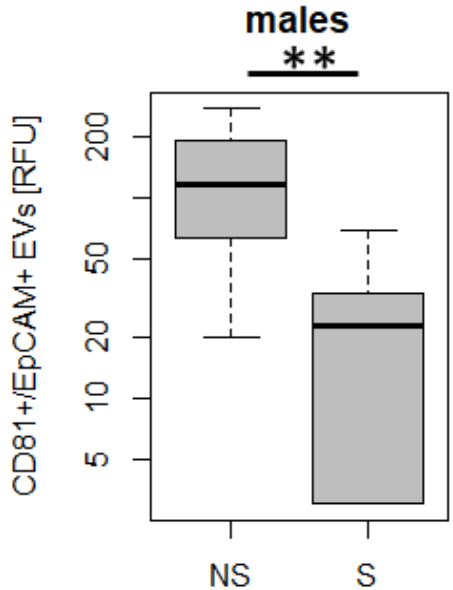

B

\section{B}

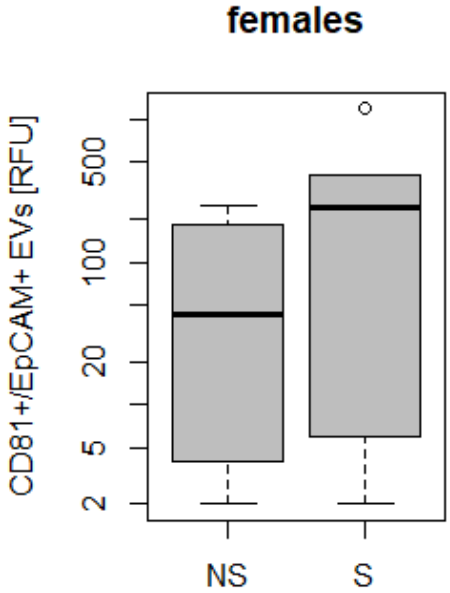

Figure 4 - Box plot for $\mathrm{CD}_{1}{ }^{+} \mathrm{EpCAM}^{+} \mathrm{EVs}$ for (A) the male and (B) the female subpopulation. Statistical differences were tested using the Mann-Whitney $U$ test to compare the median values of non-smokers and smokers to each other.

\section{Correlation between circulating EVs and plasma thrombogenicity}

Finally, we assessed whether measures of circulating EVs are correlated with plasma thrombogenicity irrespective of the participant characteristics and smoking behaviour. Non-parametric Spearman correlations were calculated for each of the four EV measures $\left(\mathrm{CD}_{1}{ }^{+} \mathrm{EVs}, \mathrm{CD}_{1}{ }^{+} \mathrm{TF}^{+} \mathrm{EVs}, \mathrm{CD}_{1}{ }^{+} \mathrm{EpCAM}^{+} \mathrm{EVs}\right.$ and $\mathrm{EV}$-associated PS) correlated to each of the four parameters of plasma thrombogenicity (lagtime, ETP, thrombin peak concentration and ttPeak). The results are plotted in a heatmap 
(Figure 5). Overall, the correlation between EV measures and parameters of thrombogenicity was low. However, $\mathrm{CD}{ }^{+} \mathrm{EpCAM}^{+} \mathrm{EVs}$ showed a moderate but statistically significant negative association with the lagtime $(\mathrm{rho}=-0.42, \mathrm{p}=0.031)$ and with the ttPeak (rho=-0.39, $\mathrm{p}=0.035$ ), implying faster thrombin formation in samples with higher concentrations of these EVs.

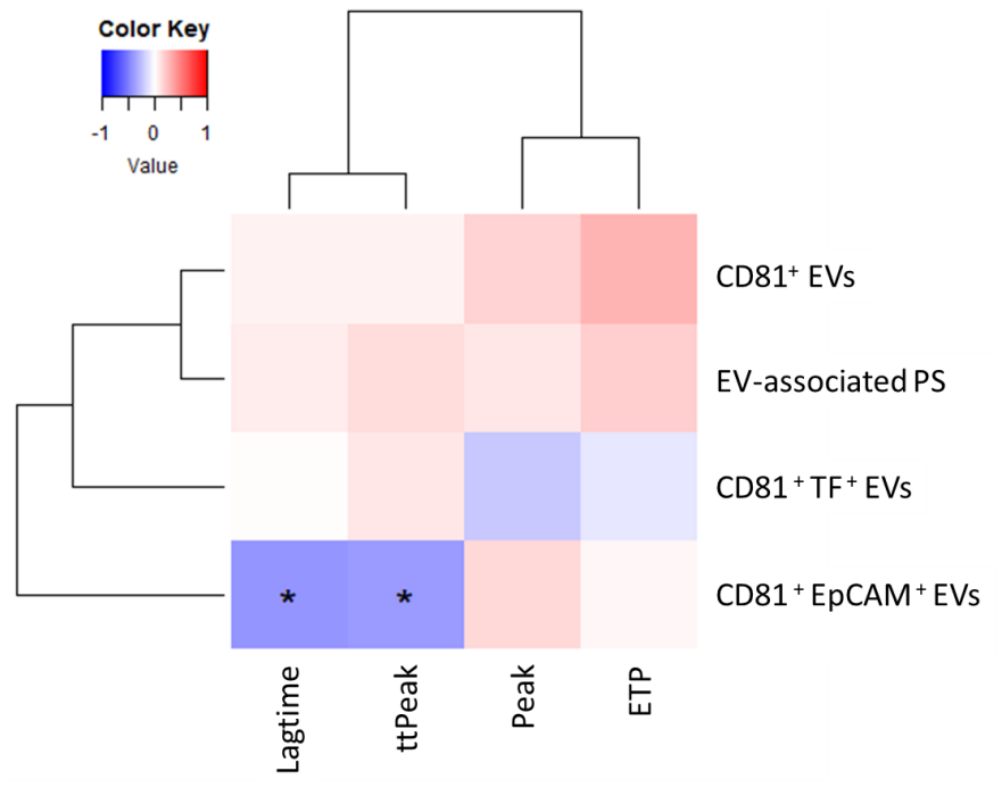

Figure 5 - Heat map of the spearman correlation coefficients for the different EV measurements and parameters of thrombin generation. The asterisks indicate statistically significant correlations. ${ }^{*} \mathrm{p}=0.01-$ 0.05

\section{Discussion}

In chapter 5, we have shown that, when exposed to cigarette smoke extract (CSE), bronchial epithelial cells secrete increased concentrations of total, tissue factor (TF) ${ }^{+}$ and phosphatidylserine (PS) ${ }^{+}$extracellular vesicles (EVs). In this sub-chapter, we aimed to set a first step towards translating these in vitro findings to the human situation.

We first tested whether bead-based flow cytometry can be used for detecting EVs in plasma samples. While this method provides a highly specific signal for EVs in conditioned cell culture media, many combinations of capture beads and detection antibodies resulted in irreversible agglutination of the beads or an unspecific signal for plasma samples. This could not be improved by isolating EVs 
using size exclusion chromatography prior to bead incubation, suggesting that the unspecific signal may arise from a 'sticky' EV surface rather than from the presence of plasma proteins. We finally found that the following capture/detection combinations provided a specific signal: $C D 81 / C D 81, C D 81 / T F$ and CD81/EpCAM. Yet, particularly for the $\mathrm{CD} 81 / \mathrm{TF}$ and $\mathrm{CD} 81 / \mathrm{EpCAM}$ measurements, the signal was close to the lower detection limit and it was required to work with $400 \mu$ of undiluted plasma to pick up a signal. This makes the technique suboptimal for EV detection in clinical studies, where often only small sample volumes are available. The majority of EVs in plasma are derived from platelets. Hypothesizing that $\mathrm{TF}^{+}$ EVs in smokers are mostly derived from lung epithelial cells, their detection may be improved by depleting the confounding highly abundant platelet-derived EVs. Finally, while the use of CD81 capture beads adds specificity to the measurement, it is also associated with the inherent disadvantage that only a subpopulation of EVs is analysed. This shortcoming could be overcome by detecting individual EVs using direct flow cytometry. Scatter triggered flow cytometry is commonly used for the detection of $\mathrm{TF}^{+}$EVs, but also only analyses a subset, as it is unable to detect EVs smaller than $300 \mathrm{~nm}[5,6]$. Fluorescence-triggered flow cytometry has recently been proposed as a broadly applicable method for sensitive EV detection and should be evaluated as a viable alternative for detection of $\mathrm{TF}^{+} \mathrm{EVs}$ in plasma samples [7].

The second aim of this study was to investigate whether smoking affects circulating EVs in young healthy volunteers using both acute exposure and crosssectional study designs. No significant differences in $\mathrm{CD}_{1}{ }^{+}, \mathrm{CD}_{1}{ }^{+} \mathrm{TF}^{+}$or $\mathrm{CD}_{1}{ }^{+} \mathrm{EpCAM}^{+} \mathrm{EVs}$ were found in smokers before and after smoking. Yet, there was an increase in circulating nanoparticles of $85-250 \mathrm{~nm}$ and $200-400 \mathrm{~nm}$ in diameter. For the smaller nanoparticles, this effect was statistically significant. However, a similar increase was observed in the non-smoking controls, suggesting that this reflects a diurnal effect or a response to the standardised breakfast rather than an effect of smoking. It is also important to note that total circulating nanoparticles are not only composed of EVs but may also comprise lipoproteins. Postprandial increases in circulating nanoparticles have been observed and are at least in part attributable to low density lipoprotein [8].

While we observed no effects of short term smoke exposure on circulating EVs according to bead-based flow cytometry, $\mathrm{CD}_{1}{ }^{+} \mathrm{TF}^{+}$EVs appeared to be elevated in baseline samples of smokers compared to non-smokers. A power calculation showed that inclusion of at least 6 additional participants would be sufficient to reach statistical significance for the observed effect size (effect size $d=1.39$ for the $\mathrm{CD}_{1}{ }^{+} \mathrm{TF}^{+}$EVs, data not shown). Therefore, 8 additional participants per group were 
included for the baseline sampling. Additionally to the bead-based flow cytometry measurements, we also determined the concentration of EV-associated PS and thrombin generation in all baseline samples. However, no significant differences were observed between smokers and non-smokers for any of the outcome variables according to univariate analysis. Yet, in the multivariate analysis, the number of cigarettes smoked per day tended to be associated with the $\mathrm{CD}_{1}{ }^{+} \mathrm{TF}^{+}$EVs. Surprisingly, $\mathrm{CD}_{1}{ }^{+} \mathrm{EpCAM}^{+} \mathrm{EVs}$ were significantly decreased rather than increased in male smokers, whereas there was no difference between female non-smokers and smokers. Interestingly, EVs positive for tetraspanins (CD63, CD81 and CD9) and EpCAM have previously been reported to be decreased in smokers compared to nonsmokers [9]. Yet, the biological explanation for this observation remains elusive. It should be tested whether CSE exposure decreases the release of EpCAM on CD81 ${ }^{+}$ EVs from cultured bronchial epithelial cells. Bronchial epithelial cells undergo epithelial-to-mesenchymal transition when exposed to CSE, and the associated shift from epithelial to fibroblast marker expression might explain the decreased release of EpCAM+ EVs [10].

Finally, we investigated whether circulating EV concentrations are correlated with thrombin generation in plasma of healthy volunteers irrespective of their smoking status. Such a correlation, particularly for $\mathrm{TF}^{+} \mathrm{EVs}$, would be in line with the hypothesis that EVs can promote coagulability. However, only $\mathrm{CD}^{+}{ }^{+} \mathrm{EpCAM}^{+}$EVs showed a moderate correlation with a decreased thrombin lagtime and time to the thrombin peak (ttPeak). This implies that higher $\mathrm{CD}_{1}{ }^{+} \mathrm{EpCAM}^{+} \mathrm{EV}$ concentrations are associated with faster thrombin generation. This finding was surprising because male smokers had significantly less $\mathrm{CD}_{1}{ }^{+} \mathrm{EpCAM}^{+} \mathrm{EVs}$ than male non-smokers, whereas it is well established that smoking results in activation of the coagulation cascade [11]. Larger studies with a more thorough profiling of circulating EV subpopulations are required to validate this observation and place it into context.

This pilot study has several limitations. First, our study population comprised only young and healthy individuals. Most of the participants only had a mild smoking history. Yet, the integrity of the epithelial-endothelial barrier in the lungs only becomes impaired in long-term smokers. Thus, even if there is an induction of $\mathrm{TF}^{+} \mathrm{EVs}$ in the lungs of young healthy smokers, the majority of these EVs may never reach the blood circulation but remain within the lung lumen. Moreover, a strong variation in $\mathrm{TF}^{+}$EVs was observed in women. It is well known that the menstrual cycle and the use of hormonal contraceptives influence coagulability [12-14]. These factors may also influence $\mathrm{TF}^{+} \mathrm{EVs}$, but have 
unfortunately not been controlled for in this pilot study. Additionally, the beadbased flow cytometry method that we used likely only detects a subset of $\mathrm{TF}^{+} \mathrm{EVs}$, as discussed above. Larger and better controlled translational studies in older and more severe smokers may yet reveal more pronounced effects of smoking on $\mathrm{TF}^{+} \mathrm{EVs}$, especially when using more comprehensive methods for EV detection.

In conclusion, we have shown that bead-based flow cytometry can be used for detecting certain EV subpopulations in plasma. However, careful validation of each staining combination is required and sensitivity for low abundant EV subpopulations is rather low, making bead-based flow cytometry suboptimal for the application in clinical studies. Fluorescence-triggered flow cytometry may be a preferable alternative. In this pilot study, smoking status had little influence on circulating EVs. The major outcome variable, $\mathrm{TF}^{+} \mathrm{EVs}$, tended to be positively associated with the number of cigarettes smoked per day but was not correlated with thrombin generation. Translational studies in older and more severe smokers may yet reveal effects of smoking on $\mathrm{TF}^{+} \mathrm{EVs}$, especially when using more comprehensive methods for EV detection.

\section{Acknowledgements}

The authors would like to thank Stefanie Geleen for her support with the blood sampling and Diane Fens for performing the CAT measurements. They would also like to thank John Penders, Brian van der Veer and Gianluca Galazzo for statistical advice and for helping with the data analysis using $\mathrm{R}$. 


\section{References}

1. Grottke, 0 ., et al., Thrombin generation capacity of prothrombin complex concentrate in an in vitro dilutional model. PLoS One, 2013. 8(5): p. e64100.

2. Benedikter, B.J., et al., Cigarette smoke extract induced exosome release is mediated by depletion of exofacial thiols and can be inhibited by thiol-antioxidants. Free Radic Biol Med, 2017.

3. Dielis, A.W., et al., Coagulation factors and the protein $C$ system as determinants of thrombin generation in a normal population. J Thromb Haemost, 2008. 6(1): p. 125-31.

4. Vajen, T., et al., Platelet extracellular vesicles induce a pro-inflammatory smooth muscle cell phenotype. J Extracell Vesicles, 2017. 6(1): p. 1322454.

5. van der Pol, E., et al., Optical and non-optical methods for detection and characterization of microparticles and exosomes. J Thromb Haemost, 2010. 8(12): p. 2596-607.

6. van Es, N., et al., Clinical Significance of Tissue Factor-Exposing Microparticles in Arterial and Venous Thrombosis. Semin Thromb Hemost, 2015. 41(7): p. 718-27.

7. Arraud, N., et al., Fluorescence triggering: A general strategy for enumerating and phenotyping extracellular vesicles by flow cytometry. Cytometry A, 2016. 89(2): p. 184-95.

8. Sodar, B.W., et al., Low-density lipoprotein mimics blood plasma-derived exosomes and microvesicles during isolation and detection. Sci Rep, 2016. 6: p. 24316.

9. Baek, R., K. Varming, and M.M. Jorgensen, Does smoking, age or gender affect the protein phenotype of extracellular vesicles in plasma? Transfus Apher Sci, 2016. 55(1): p. 44-52.

10. Eurlings, I.M., et al., Cigarette smoke extract induces a phenotypic shift in epithelial cells; involvement of HIF1alpha in mesenchymal transition. PLoS One, 2014. 9(10): p. e107757.

11. Csordas, A. and D. Bernhard, The biology behind the atherothrombotic effects of cigarette smoke. Nat Rev Cardiol, 2013. 10(4): p. 219-30.

12. Chaireti, R., et al., Endogenous thrombin potential is higher during the luteal phase than during the follicular phase of a normal menstrual cycle. Hum Reprod, 2013. 28(7): p. 1846-52.

13. de Bastos, M., et al., Combined oral contraceptives: venous thrombosis. Cochrane Database Syst Rev, 2014(3): p. CD010813.

14. Stegeman, B.H., et al., Different combined oral contraceptives and the risk of venous thrombosis: systematic review and network meta-analysis. BMJ, 2013. 347: p. f5298. 



\section{Chapter 7}

\section{Cigarette smoke extract-induced exosome release is mediated by depletion of exofacial thiols and can be inhibited by thiol-antioxidants}

Birke J. Benedikter, Charlotte Volgers, Pascalle H. van Eijck, Emiel F.M. Wouters, Paul H.M. Savelkoul, Niki L. Reynaert, Guido R.M.M. Haenen, Gernot G.U. Rohde, Antje R. Weseler, Frank R.M. Stassen 


\section{Graphical abstract}

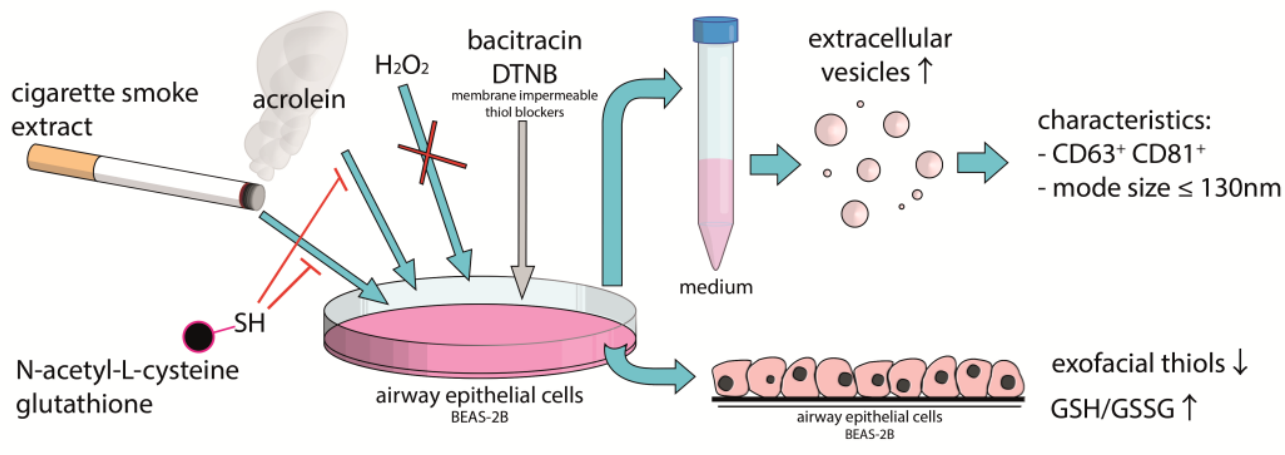




\section{Abstract}

Introduction: Airway epithelial cells have been described to release extracellular vesicles (EVs) with pathological properties when exposed to cigarette smoke extract (CSE). As CSE causes oxidative stress, we investigated whether its oxidative components are responsible for inducing EV release and whether this could be prevented using the thiol antioxidants $\mathrm{N}$-acetyl-L-cysteine (NAC) or glutathione (GSH).

Methods: BEAS-2B cells were exposed for 24 h to CSE, $\mathrm{H}_{2} \mathrm{O}_{2}$, acrolein, 5,5'-dithiobis-(2-nitrobenzoic acid) (DTNB), bacitracin, rutin or the anti-protein disulphide isomerase (PDI) antibody clone RL9o; with or without NAC or GSH. EVs in media were measured using $\mathrm{CD}_{3}{ }^{+} \mathrm{CD}_{1}{ }^{+}$bead-coupled flow cytometry or tuneable resistive pulse sensing (TRPS). For characterisation by Western Blotting, cryotransmission electron microscopy and TRPS, EVs were isolated using ultracentrifugation. Glutathione disulphide and GSH in cells were assessed by a GSH reductase cycling assay, and exofacial thiols using Flow cytometry.

Results: CSE augmented the release of the EV subtype exosomes, which could be prevented by scavenging thiol-reactive components using NAC or GSH. Among the thiol-reactive CSE components, $\mathrm{H}_{2} \mathrm{O}_{2}$ had no effect on exosome release, whereas acrolein imitated the NACreversible exosome induction. The exosome induction by CSE and acrolein was paralleled by depletion of cell surface thiols. Membrane impermeable thiol blocking agents, but not specific inhibitors of the exofacially located thiol-dependent enzyme PDI, stimulated exosome release.

Summary/conclusion: Thiol-reactive compounds like acrolein account for CSE-induced exosome release by reacting with cell surface thiols. As acrolein is produced endogenously during inflammation, it may influence exosome release not only in smokers, but also in ex-smokers with chronic obstructive pulmonary disease. NAC and GSH prevent acrolein- and CSE-induced exosome release, which may contribute to the clinical benefits of NAC treatment. 


\section{Introduction}

Situated at the vast interface between environment and lung tissue, the airway epithelium is crucial for maintaining pulmonary homeostasis. Not only does it act as a physical barrier, it also supports appropriate responses to inhaled pathogens and chemicals by sending signals towards immune and stromal cells in its vicinity (for a review, see [1]). Yet, epithelial integrity and function become impaired upon chronic exposure to noxious stimuli, for instance in long term cigarette smokers [2]. Cigarette smoke-induced epithelial damage is partly mediated by components that cause oxidative stress, such as the reactive oxygen species (ROS) hydrogen peroxide $\left(\mathrm{H}_{2} \mathrm{O}_{2}\right)[3,4]$ and the reactive carbonyl acrolein $[5,6]$. The oxidative stress exerted by cigarette smoke components is thought to contribute to the early pathogenesis of chronic obstructive pulmonary disease (COPD) [7]. Moreover, once COPD is established, markers of oxidative stress, as well as acrolein, remain elevated in the lungs even after patients stop smoking $[8,9]$. Recent studies have revealed that treatment with a high-dose of the thiol-group bearing mucolytic and antioxidant $\mathrm{N}$ acetyl-L-cysteine (NAC) improved small airway function in COPD patients [10] and lowered the frequency of acute exacerbations [11]. This suggests that oxidative stress causally contributes to small airway disease and worsening of COPD via acute exacerbations, even in ex-smokers.

A number of studies have suggested that oxidative stress influences the release of extracellular vesicles (EVs) by various cell types [12-14]. EVs are membrane vesicles secreted by nearly all cell types. They consist of a lipid bilayer surrounding an aqueous lumen, and act as carriers for molecules derived from their cell of origin, including membrane proteins, cytoplasmic proteins and RNA. EV functions include removing unnecessary or toxic molecules from their cell of origin $[15,16]$, as well as delivering complex messages between cells [17]. Thus, EVs regulate many biological processes, including immune responses and inflammation [17]. Although EV nomenclature is complex and still controversial [18], EVs are commonly classified into two major groups based on their size and marker expression, the larger microvesicles and the smaller exosomes. In the context of cigarette smoke-induced lung disease, microvesicles have been studied predominantly to evaluate their utility as biomarkers for early lung damage and exacerbation susceptibility [19, 20]. In contrast, the smaller exosomes have been investigated for functional properties that may contribute to COPD pathogenesis. Two recent in vitro studies have suggested that exosomes secreted by airway epithelial cells (AEC) exposed to cigarette smoke extract (CSE) cause inflammation [21] and tissue remodelling by inhibiting fibroblast autophagy [22]. Yet, it has not been clarified how CSE influences the exosome release 
by AEC and whether this can be manipulated. We hypothesised that oxidative CSE components, such as $\mathrm{H}_{2} \mathrm{O}_{2}$ or acrolein, mediate CSE-induced exosome release and that the exosome induction can be prevented by antioxidants.

\section{Materials and Methods}

\section{Cell culture}

BEAS-2B human bronchial epithelial cells (ATCC CRL-96o9) were cultured at 5\% $\mathrm{CO}_{2}$ and $37^{\circ} \mathrm{C}$ in T-75 culture flasks pre-coated with LHC basal medium (Gibco, Life Technologies, New York, NY, USA) supplemented with $0.1 \mathrm{mg} / \mathrm{mL}$ bovine serum albumin (BSA, Boehringer Mannheim GmbH, Mannheim, Germany), $0.03 \mathrm{mg} / \mathrm{ml}$ bovine collagen I (BD Biosciences, San Jose, CA, USA) and $0.01 \mathrm{mg} / \mathrm{ml}$ human fibronectin (BD Biosciences). Cells were subcultured twice per week in RPMI1640 (Gibco) containing $10 \%$ foetal calf serum (FCS, Lonza, Verviers, Belgium).

\section{EV-depletion of FCS}

To deplete confounding bovine EVs, FCS was diluted to $30 \%$ (v/v) in DMEM-F12 without phenol-red (Gibco) and centrifuged for $16 \mathrm{~h}$ at 40,0oo rpm (Average RCF $=$ $117,734 \times \mathrm{g}$ ), in a fixed-angle Type 7oTi-rotor in an Optima L-9oK preparative ultracentrifuge (Beckman-Coulter, Brea, CA, USA). The supernatant was collected without disturbing the concentrated layer at the bottom of the tube.

\section{Stimuli and cell exposures}

$\mathrm{N}$-acetyl-L-cysteine (NAC), $\mathrm{H}_{2} \mathrm{O}_{2}$, acrolein, 5,5'-dithiobis-(2-nitrobenzoic acid) (DTNB), bacitracin and rutin were from Sigma Aldrich (St. Louis, MO, USA). The monoclonal anti-protein disulphide isomerase (PDI) antibody clone RL9o was from Thermo Fisher Scientific (Waltham, MA, USA). To produce CSE, mainstream smoke of one cigarette (Reference Cigarette ${ }_{3} \mathrm{R}_{4} \mathrm{~F}$, Tobacco-Health Research, University of Kentucky, USA) without filter was drawn through $2 \mathrm{ml}$ phosphate buffered saline (PBS) using a vacuum-pump at constant speed. The obtained solution was filtered through a $0.22 \mu \mathrm{m}$ Acrodisk filter (Pall, Port Washington, NY, USA) and defined as $100 \%$ CSE. For quality control, the extinction of $100 \mu \mathrm{l} 100 \%$ CSE was measured in duplicate at wavelengths of $\lambda=320 \mathrm{~nm}$ (A320) and $\lambda=540 \mathrm{~nm}$ (A540). CSE quality was accepted if $\triangle \mathrm{OD}\left(\mathrm{A}_{320} \mathrm{O}-\mathrm{A}_{540} \mathrm{O}\right)$ was between 0.9 and 1.2. CSE was prepared freshly for each experiment and used within $15 \mathrm{~min}$. 
BEAS-2B cells were seeded in RPMI1640 $+10 \%(\mathrm{v} / \mathrm{v})$ FCS on pre-coated plates $\left(5 \times 10^{4}\right.$ cells $\left./ \mathrm{cm}^{2}\right)$ and allowed to attach for $24 \mathrm{~h}$. Cells were washed twice with PBS and incubated with reduction medium (DMEM-F12 + $0.1 \%(\mathrm{v} / \mathrm{v}) \mathrm{EV}-$ depleted FCS, $0.25 \mathrm{ml} / \mathrm{cm}^{2}$ ) for $2 \mathrm{~h}$. Next, cells were exposed to different concentrations of CSE, acrolein, $\mathrm{H}_{2} \mathrm{O}_{2}$, DTNB, bacitracin, rutin or RL9o in reduction medium for $24 \mathrm{~h}$. Where indicated, cells were treated with NAC (1 mM) or GSH $(62.5,125$ or $250 \mu \mathrm{M})$ for $2 \mathrm{~h}$. After these $2 \mathrm{~h}$, cells were washed with PBS to remove any pre-formed EVs. Then, NAC or GSH were added again to the cells in combination with either CSE, acrolein or $\mathrm{H}_{2} \mathrm{O}_{2}$ and co-incubated for $24 \mathrm{~h}$. Rutin was dissolved in DMSO, all other chemicals were dissolved and diluted in PBS. Vehicle controls were exposed to matched concentrations of DMSO or PBS. The vehicle control for RL9o contained $0.0005 \%(\mathrm{v} / \mathrm{v})$ sodium azide.

\section{MTT assay}

Cells were washed with PBS and $200 \mu \mathrm{l} / \mathrm{cm}^{2}$ reduction medium containing 0.5 $\mathrm{mg} / \mathrm{ml}$ thiazolyl blue tetrazolium bromide (MTT; Sigma Aldrich) was added. After 3 $\mathrm{h}$, medium was discarded and the formed formazan crystals were dissolved in 100 $\mu \mathrm{l} / \mathrm{cm}^{2}$ dimethyl sulfoxide (DMSO; Sigma Aldrich). Absorbance of the dissolved formazan was measured at $\lambda=540 \mathrm{~nm}$ and cell viability was expressed relative to a non-treated cells (100 \% cell viability) and triton-lysed cells (o \% viability).

\section{GSH measurements}

For determining GSH oxidation in cell-free conditions, different CSE dilutions were made in PBS containing $50 \mu \mathrm{M}$ reduced glutathione (Sigma Aldrich) and incubated for $24 \mathrm{~h}$ at $37^{\circ} \mathrm{C}$. Ten microliter of each solution was transferred to a 96 -well plate in triplicate. Ninety microliter of DTNB working reagent $(1 \mathrm{mM}$ DTNB and $2.5 \mathrm{mM}$ sodium acetate in o.1 M Tris-hydrochloride, $\mathrm{pH}$ 8.8) was then added. Absorbance was measured with a plate reader at $\lambda=412 \mathrm{~nm}$.

For analysing cellular GSH concentrations, $2 \times 10^{5}$ cells were washed twice with ice cold PBS. They were then incubated on ice with $250 \mu \mathrm{l}$ o.1 M potassium phosphate buffer containing $5 \mathrm{mM}$ ethylenediaminetetraacetic acid (EDTA) disodium salt and $0.1 \%(\mathrm{v} / \mathrm{v})$ Triton $\mathrm{X}-100, \mathrm{pH}=7.5$ for $30 \mathrm{~min}$. Next, cells were scraped and cellular debris was pelleted at $16,100 \times \mathrm{g}$ at $4^{\circ} \mathrm{C}$ for $15 \mathrm{~min}$. Supernatant was transferred to a new tube. Protein concentrations were determined using the Bradford assay according to the manufacturer's protocol (Bio-Rad, Hercules, CA, USA). The remaining supernatant was mixed $1: 1$ with $6 \%(\mathrm{~m} / \mathrm{v})$ sulfosalicylic acid. 
The samples were stored at $-80^{\circ} \mathrm{C}$ until analysis of $\mathrm{GSH}$ and the GSH oxidation product glutathione disulphide (GSSG) using an enzymatic cycling assay as previously described [23]. GSSG and GSH concentrations were normalised to the protein concentrations.

\section{Quantification of exofacial thiol groups}

Cells $\left(2 \times 10^{5}\right)$ were washed $3 \mathrm{x}$ with PBS and incubated for 10 min with $2 \mathrm{mM}$ EDTA in PBS before gentle scraping. Detached cells were pelleted at $400 \times g$ for 7 minutes at $4^{\circ} \mathrm{C}$ and resuspended in PBS. Alexa Fluor ${ }^{\circledR} 488 \mathrm{C}_{5}$ Maleimide (AFM; Thermo Fisher Scientific, Waltham, MA, USA ) was added to the homogenous cell suspension to a final concentration of $2.5 \mu \mathrm{M}$, followed by $15 \mathrm{~min}$ incubation on ice. Cells were pelleted again (400 $\times \mathrm{g}, 7 \mathrm{~min}, 4^{\circ} \mathrm{C}$ ), washed with $\mathrm{PBS}$, followed by a last centrifugation ( $400 \times \mathrm{g}, 7 \mathrm{~min}, 4^{\circ} \mathrm{C}$ ). For flow cytometry measurements using a BD FACSCanto and FACS Diva V8.o.1 software (BD Biosciences), cells were resuspended in PBS containing $1 \%(\mathrm{w} / \mathrm{v})$ bovine serum albumin (BSA; Sigma Aldrich). Just before measuring, $1 \mu \mathrm{g} / \mathrm{ml}$ propidium iodide (PI; Sigma Aldrich) was added in order to gate out cells with impaired membrane integrity. The relative quantity of exofacial thiol groups was determined as the median fluorescence intensity of AFM in the PI-low cell population.

\section{Processing conditioned cell culture medium}

Conditioned medium of BEAS-2B cells ( $1 \mathrm{ml}$ per condition for EV measurements using bead-coupled flow cytometry, $40 \mathrm{ml}$ for EV isolation using ultracentrifugation) was centrifuged at $300 \times g$ for 10 min at $4^{\circ} \mathrm{C}$ to pellet cells, then at $5000 \times g$ for $10 \mathrm{~min}$ at $4^{\circ} \mathrm{C}$ to pellet cell debris. Where indicated, the conditioned medium was filtered through a $0.22 \mu \mathrm{m}$ filter to remove larger membrane vesicles. Conditioned medium was always processed within one day without any freeze-thaw cycles.

\section{Analysis of EV release using bead-coupled flow cytometry}

EV detection using bead-coupled flow cytometry was performed as described previously $[24,25]$, with some adaptations: $3.5 \times 10^{8}$ beads/ml (4 $\mu \mathrm{m}$ aldehyde/sulphate latex beads 5\% (w/v); Molecular Probes Life Technologies, Waltham, MA, USA) were coated with $0.125 \mathrm{mg} / \mathrm{ml}$ mouse anti-human CD63 antibody (Clone $\mathrm{H}_{5} \mathrm{C6}$; BD Biosciences) by overnight incubation in MES buffer. These beads were stored in PBS containing $0.1 \%(\mathrm{~m} / \mathrm{v})$ glycine and $0.1 \%(\mathrm{~m} / \mathrm{v})$ sodium azide at $4{ }^{0} \mathrm{C}$ until use. For EV-coupling, $2 \times 10^{5} \mathrm{CD} 63$-coated beads were 
incubated with $400 \mu \mathrm{l}$ conditioned medium overnight. Beads were then washed twice with PBS containing $2 \%(\mathrm{~m} / \mathrm{v})$ BSA by centrifugation at $5000 \times \mathrm{g}$ for $10 \mathrm{~min}$. The bead pellet was resuspended in $50 \mu \mathrm{l}$ PBS-2 \% (m/v) BSA containing $0.01 \mathrm{mg} / \mathrm{ml}$ phycoerythrin (PE)-labelled mouse anti-human CD81 antibody (Clone JS-81; BD Biosciences) and incubated for $1 \mathrm{~h}$. Beads were washed twice with PBS - $2 \%(\mathrm{~m} / \mathrm{v})$ BSA by centrifugation at $5000 \mathrm{x} g$ for $10 \mathrm{~min}$. The final bead pellet was resuspended in $200 \mu \mathrm{l}$ PBS and analysed by flow cytometry using a BD FACSCanto (BD Biosciences) with FACS Diva V8.o.1 software (BD Biosciences). All incubations were carried out at room temperature and with vigorous shaking (10oo $\mathrm{min}^{-1}$ ). The quantity of EVs in relative fluorescent units (RFU) was calculated by multiplying the percentage of PE-positive beads with the median fluorescent intensity (MFI) of the positive bead population.

\section{EV analysis using tuneable resistive pulse sensing (TRPS)}

TRPS was performed using a qNano Gold with Izon Control Suite 3.2 Software and CPC10o calibration beads (Izon, Chirstchurch, New Zealand). Cell-depleted unfiltered medium was analysed after a single freeze-thaw cycle at $-80^{\circ} \mathrm{C}$. An $\mathrm{NP} 150$ nanopore (Izon) was coated using the Izon reagent kit for EV analysis according to the manufacturer's instructions. To obtain a stable baseline current, samples were diluted 1:2 in Solution Q (Izon) and to prevent frequent pore obstruction, $10 \%(\mathrm{v} / \mathrm{v})$ Solution G (Izon) was added. The NP150 nanopore was used at a stretch of $45-47 \mathrm{~mm}$ and a pressure of 10-12 mbar, keeping the current between 120 and $130 \mathrm{nA}$ for all measurements. Recordings were stopped after detection of 500 blockades or after 10 $\min$.

\section{EV isolation using ultracentrifugation}

Cell-depleted medium (40 ml/condition) was filtered through an Acrodisk $0.22 \mu \mathrm{m}$ filter (Pall) to remove larger membrane vesicles or particles. The filtered medium was centrifuged in an Optima L-9oK preparative ultracentrifuge (Beckman-Coulter) using a fixed-angle Type 7oTi-rotor (Beckman-Coulter) and Quick-Seal tubes (UltraClear, $39 \mathrm{ml}$, Beckman-Coulter) at 40,00o rpm (Average RCF $=117,734 \times g$ ) for $2.5 \mathrm{~h}$ (optimal speed and duration as determined by Cvjetkovic et al. [26]). After ultracentrifugation, supernatant was poured off and the invisible EV-pellet was resuspended in $70 \mu \mathrm{l}$ PBS for cryo-TEM, $70 \mu$ lysis buffer $(1.5 \%(\mathrm{~m} / \mathrm{v})$ sodium dodecyl sulphate (SDS), $50 \mathrm{mM}$ Tris, $\mathrm{pH}=6.8$ ) for Western blotting, or in $2.5 \mathrm{~mL}$ DMEM-F12 + 0.1\% (v/v) EV-depleted FCS for flow cytometric analysis. For cyro-TEM and flow cytometric analysis, isolated EVs were processed immediately. For Western 
blotting, samples were stored in lysis buffer at $-80^{\circ} \mathrm{C}$ until gel electrophoresis was performed.

\section{Western blotting}

Sodium dodecyl sulphate polyacrylamide gel electrophoresis (SDS-PAGE) was performed according to standard protocol, with a $12 \%$ running gel. Before loading, the protein concentration of all cell and EV lysates was standardised and samples were diluted 1:2 in 2 X XT sample buffer (Bio-Rad) containing $5 \mathrm{M}$ urea and cOmplete $^{\mathrm{TM}}$ protease inhibitor cocktail (Roche Life Science, Penzberg, Germany) at the concentration recommended by the manufacturer. Blots were stained for 2-3 $\mathrm{h}$ with $0.5 \mu \mathrm{g} / \mathrm{ml}$ mouse anti-human CD63 antibody (Clone $\mathrm{H}_{5} \mathrm{C} 6$; BD Biosciences), followed by $1 \mathrm{~h}$ incubation with HRP-conjugated rabbit anti-mouse antibody diluted 1:100o (Po26o; DAKO, Agilent Technologies, Santa Clara, CA, USA). The blots were incubated with chemiluminescent peroxidase substrate-3 (Sigma Aldrich) and signal was detected using an enhanced chemiluminescence system (ChemiDoc ${ }^{\mathrm{TM}} \mathrm{MP}$ System, Bio-Rad).

\section{Cryo-transmission electron microscopy}

To prepare vitrified EV specimens, a freshly glow-discharged Quantifoil R 2/2 grid (Quantifoil Micro Tools GmbH, Jena, Germany) was loaded into a FEI Mark IV Vitrobot (FEI Company, Eindhoven, The Netherlands). The Vitrobot environmental chamber was maintained at $22^{\circ} \mathrm{C}$ and $100 \%$ humidity. Three microliter of freshly isolated EV suspension was added to the grid. The grid was blotted immediately for 1 $\mathrm{s}$ before plunge-freezing in liquid ethane $\left(-180^{\circ} \mathrm{C}\right)$. For microscopy, grids were mounted in a Gatan cryoholder (Gatan, Pleasanton, CA, USA) in liquid nitrogen and images were acquired at $120 \mathrm{kV}$ using a Tecnai Biotwin iCorr 120KV (FEI Company).

\section{Statistics}

All data are composed of at least three independent experiments. Data were analysed with Graphpad Prism software (GraphPad Software, Inc., La Jolla, CA, USA). Because of the small sample size and the paired nature of the data, data was analysed using the non-parametric Wilcoxon matched-pairs signed rank test (where 2 groups were compared) or the non-parametric Friedman test, followed by Dunn's posthoc test (where more than 2 groups were compared) unless indicated differently. P-values below 0.05 were considered statistically significant. Values in the text are given as the median and interquartile range (IQR). 


\section{Results}

\section{CSE exposure enhances the release of EVs with exosome properties by AEC}

To determine the effect of CSE-exposure on EV release by AEC, BEAS-2B cells were exposed to CSE concentrations ranging from 0.75 to $1.5 \%(\mathrm{v} / \mathrm{v})$ for $24 \mathrm{~h}$. The quantity of $\mathrm{CD}_{3}{ }^{+} \mathrm{CD}_{1}{ }^{+} \mathrm{EVs}$ in the conditioned media was assessed using bead-coupled flow cytometry. A concentration-dependent increase in EV release was observed from 1.4 fold (IQR 1.3-1.6) at 0.75\% CSE up to 2.3 fold (IQR 1.6-2.7) at 1.5\% CSE (Figure 1A). This was associated with a decrease in cell viability ranging from 88.o \% (IQR 79.697.6) cell viability at $0.75 \%$ CSE to $52.7 \%$ (IQR 46.5-63.5) at $1.5 \%$ CSE (Figure $1 \mathrm{~B}$ ). Using TRPS, we confirmed an increased concentration of small EVs $(80-250 \mathrm{~nm}$ in diameter) after $24 \mathrm{~h}$ exposure to $1.5 \%(\mathrm{v} / \mathrm{v})$ CSE (Figure $1 \mathrm{C}, \mathrm{D})$. The EV induction was fast and sustained, as the EV concentration was increased for CSE-exposed cells at 30 $\min , 3 \mathrm{~h}$ and $24 \mathrm{~h}$ (Figure $\mathrm{IE}$ ). Moreover, the induction required the continuous presence of CSE, as there was no increased EV concentration compared to the unexposed control when cells were stimulated with CSE for $3 \mathrm{~h}$, followed by washing and $24 \mathrm{~h}$ incubation in CSE-free medium (Figure $1 \mathrm{E}$ ).

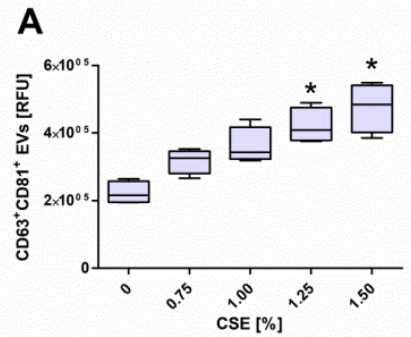

D

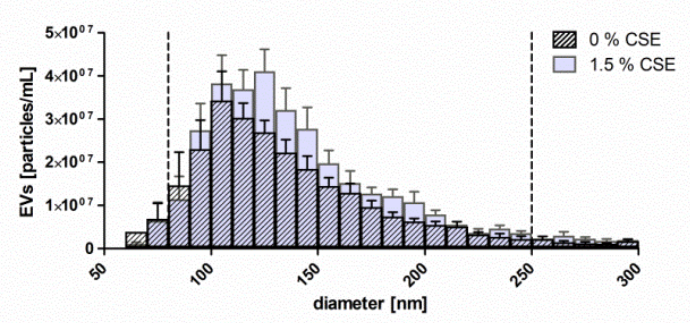

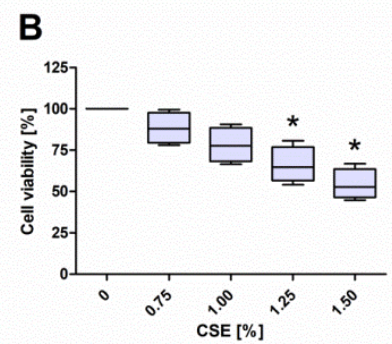

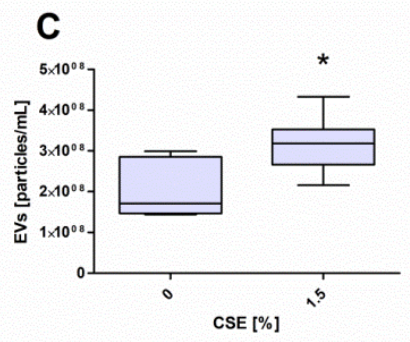

E

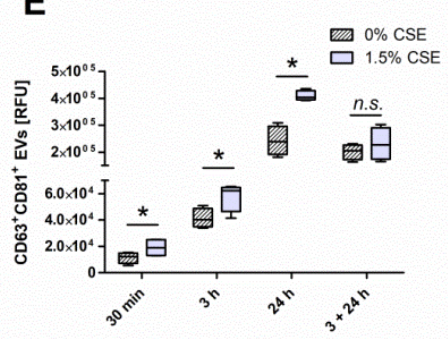

Fig. 1. Effect of CSE-exposure on EV release and cell viability of BEAS-2B cells. (A) EV concentrations (CD63 $3+\mathrm{CD} 81+$ bead-coupled flow cytometry) after $24 \mathrm{~h}$ exposure to $0.75-1.5 \%(\mathrm{v} / \mathrm{v}) \mathrm{CSE}, \mathrm{n}=4$. (B) Cell viability (MTT assay) after $24 \mathrm{~h}$ exposure to $0.75^{-1.5} \%(\mathrm{v} / \mathrm{v}) \mathrm{CSE}, \mathrm{n}=4$. (C) Concentration of EVs ranging 
from 80 to $250 \mathrm{~nm}$ (size range indicated by vertical dotted lines in Fig. $1 \mathrm{D}$ ) as determined by TRPS after exposing BEAS-2B cells for $24 \mathrm{~h}$ exposure to o or $1.5 \%$ (v/v) CSE, $n=6$. (C) TRPS size distribution histogram of EVs released by BEAS-2B cells exposed for $24 \mathrm{~h}$ exposure to o or $1.5 \%$ (v/v) CSE. Bars represent the mean \pm standard error of the mean (SEM), $\mathrm{n}=6$. The vertical dotted lines at 80 and $250 \mathrm{~nm}$ indicate the size limits between which EV concentration was determined for Fig. 1C. (E) EV concentrations in media of BEAS-2B cells exposed to CSE for $30 \mathrm{~min}, 3 \mathrm{~h}$ or $24 \mathrm{~h}$, or exposed to CSE for $3 \mathrm{~h}$ followed by $24 \mathrm{~h}$ incubation in CSE-free medium. Box and whisker plots (A-B,D-E) indicate the median (line in box), 25th and 75th percentiles (outer lines of box) and the minimal and maximal values (whiskers). Statistical differences were analysed using Friedmann's test with Dunn's posthoc test in Figs. A and $\mathrm{B}$ and using Wilcoxon matched-pairs signed rank test in figure $\mathrm{D}\left({ }^{*} \mathrm{p}<0.05\right.$ compared with o\% CSE).

The tetraspanins $\mathrm{CD}_{3}$ and $\mathrm{CD} 81$, which we used for flow cytometric EV detection, are classically considered specific marker proteins for the smallest EV type, exosomes [27]. However, it has recently been suggested that the larger microvesicles may express these proteins as well [28]. To determine whether the EVs detected by $\mathrm{CD}_{3}{ }^{+} \mathrm{CD}_{1} 1^{+}$flow cytometry were truly exosomes, we first determined their size by comparing the flow cytometry signal in non-filtered media with the signal in media passed through a $0.22 \mu \mathrm{m}$ filter. Signal recovery after filtration was complete for both control and CSE-induced EVs (Figure $2 \mathrm{~A}$ ), suggesting that the vast majority of EVs detected using bead-coupled flow cytometry was smaller than 220 $\mathrm{nm}$. We also determined the size distribution of EVs in unfiltered conditioned media using TRPS. The mode size was about $100 \mathrm{~nm}$ for both, control EVs and CSE EVs, with the majority of particles being smaller than $200 \mathrm{~nm}$ (Figure ${ }_{1 C} \mathrm{C}$ ). One of the most commonly applied isolation protocols for small EVs is $0.22 \mu \mathrm{m}$ filtration of conditioned cell culture medium followed by ultracentrifugation at high speed (e.g. 120,000 $\mathrm{x}$ ). Using this protocol, a large fraction of $\mathrm{CD} 63^{+} \mathrm{CD}_{1}{ }^{+} \mathrm{EVs}$ measured in the conditioned medium could be recovered both for control EVs (63.4 \%, IQR 33.4-80.9 \%) and CSE-induced EVs (39.3\%, IQR 17.7-105.4 \%) (Figure 2C). Western blotting confirmed the presence of $\mathrm{CD}_{3} 3$ in the ultracentrifugation isolate from both exposure conditions, whereas the endoplasmic reticulum-derived contamination marker grp94 was undetectable (Figure 2D). Finally, cryo-TEM of isolated control EVs and CSE EVs revealed membrane surrounded spheres ranging from 30 to $170 \mathrm{~nm}$ in diameter (Figure $2 \mathrm{E}, \mathrm{F}$ ). Based on the properties described in this paragraph, we will from now on refer to the EVs in this study as exosomes. 

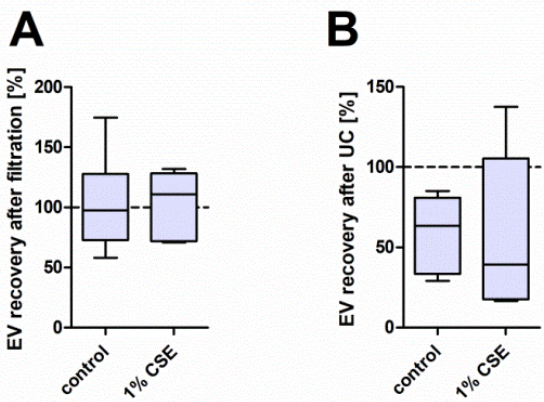

C cells cells EV EV ctrl CSE ctrl CSE

D

control

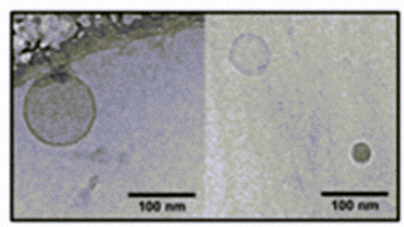

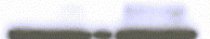

grp94

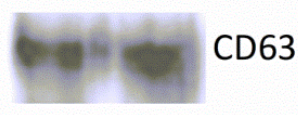

$\mathbf{E}$

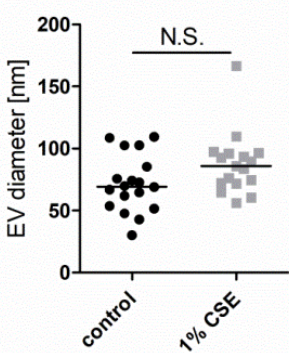

Fig. 2. Characterisation of EVs released by BEAS-2B cells after $24 \mathrm{~h}$ exposure to o or $1 \%$ (v/v) CSE. (A) Quantity of EVs detected using bead-coupled flow cytometry for CD63+CD81+ EVs in conditioned medium before and after $0.22 \mu \mathrm{m}$-filtration; $\mathrm{n}=7$. (B) Recovery of EVs by ultracentrifugation, estimated using bead-coupled flow cytometry for $\mathrm{CD} 63+\mathrm{CD} 81+\mathrm{EVs} ; \mathrm{n}=5$. (C) Western blots of EVs isolated by ultracentrifugation. Blots were stained for endoplasmic reticulum-derived contamination marker grp94 and exosome marker CD63. (D) Cryo-TEM of EVs. The scale bars are $100 \mathrm{~nm}$. (E) EV diameter according to cryo-TEM (horizontal bars indicate the median; $n=18$ for control EVs and $n=17$ for CSE EVs). Statistical differences in EV diameter were analysed using the Mann-Whitney test (N.S. = not significant). Box and whisker plots (A-B) indicate the median (line in box), 25th and 75th percentiles (outer lines of box) and the minimal and maximal values (whiskers).

\section{The exosome induction is mediated by CSE components that react with thiol groups and is prevented by clinically relevant concentrations of thiol-antioxidants}

To confirm that CSE contains oxidative components, CSE was incubated with the thiol group bearing antioxidant GSH. This resulted in a concentration-dependent depletion of free GSH (data not shown). Next, to investigate whether the oxidative components of CSE were causally responsible for the exosome induction, AEC were exposed to CSE in the absence or presence of the antioxidant NAC. NAC completely 
prevented CSE-induced exosome release as determined by $\mathrm{CD}_{3}{ }^{+} \mathrm{CD}_{1} 1^{+}$beadcoupled flow cytometry (Figure $3 \mathrm{~A}$ ) and by TRPS (Figure $3 \mathrm{~B}$ ). It also prevented the decrease in cell viability (Figure ${ }_{3} \mathrm{C}$ ).
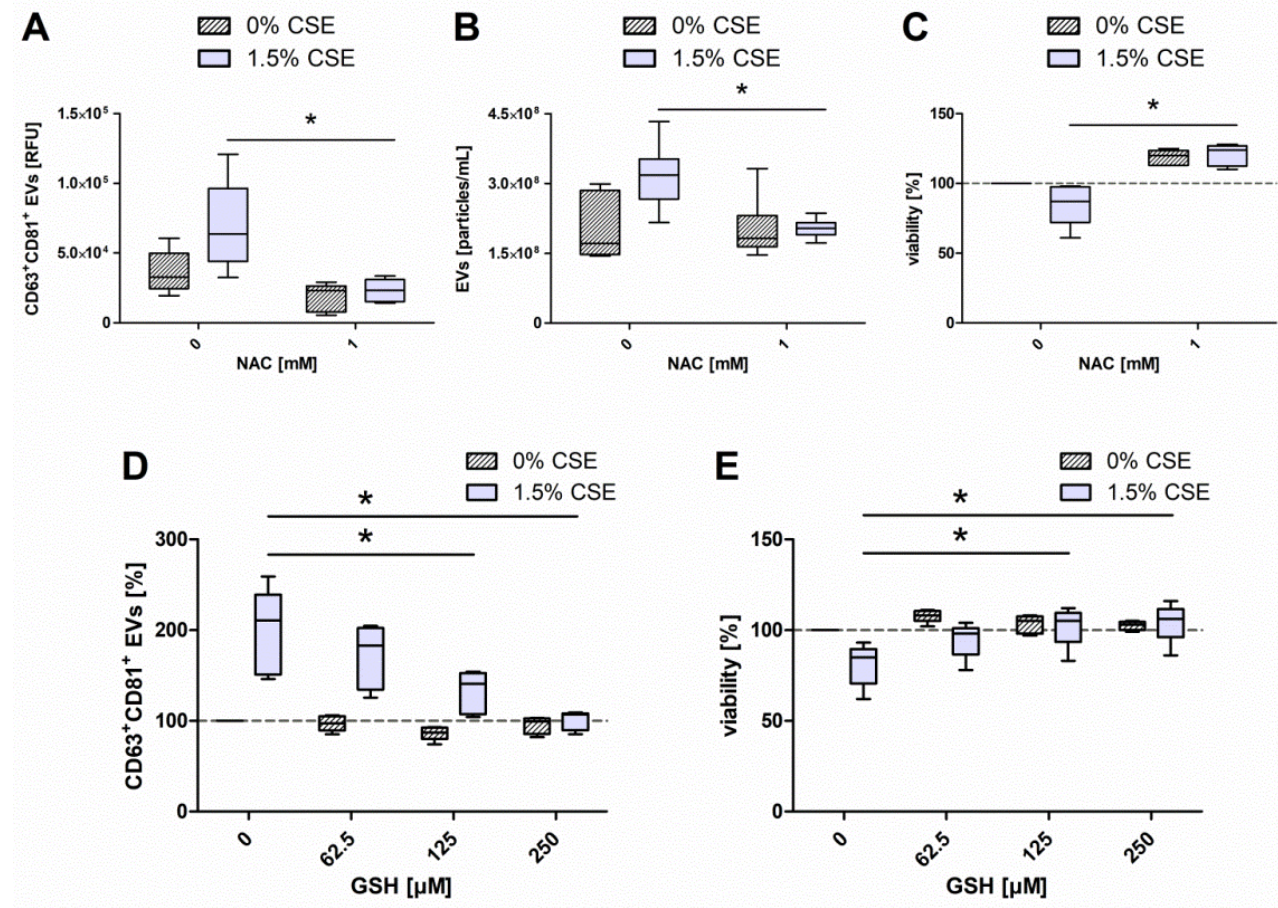

Fig. 3. Contribution of oxidative components to the effects of CSE on EV release and cell viability. BEAS$2 \mathrm{~B}$ cells were exposed to $1.5 \%(\mathrm{v} / \mathrm{v}$ ) PBS (control) or $1.5 \%(\mathrm{v} / \mathrm{v}$ ) CSE for $24 \mathrm{~h}$ in the continuous presence of the thiol-group bearing antioxidant NAC or with several concentrations of the antioxidant GSH. (A) Effect of NAC on CSE-induced EV release (CD63+CD81+ bead-coupled flow cytometry), $n=6$. (B) Effect of NAC on CSE-induced EV release (TRPS), $n=6$. (C) Effect of NAC on cell viability (MTT assay), $n=6$. All graphs show the median $\pm \mathrm{IQR}$. Statistical differences were analysed using Friedmann's test with Dunn's posthoc test $\left({ }^{*} \mathrm{p}<0.05\right)$. Box and whisker plots indicate the median (line in box), 25 th and $75^{\text {th }}$ percentiles (outer lines of box) and the minimal and maximal values (whiskers). (D) Effect of GSH on EV release $($ CD63 $3+\mathrm{CD} 81+$ bead-coupled flow cytometry; $\mathrm{n}=5)$. (E) Effect of GSH on cell viability (MTT assay; $\mathrm{n}=5$ ). The unstimulated control was set to $100 \%$ in both graphs. Box and whisker plots indicate the median (line in box), 25th and 75th percentiles (outer lines of box) and the minimal and maximal values (whiskers). Statistical analysis was performed using Friedmann's test with Dunn's posthoc test ( ${ }^{*} \mathrm{p}<0.05$ compared to $1.5 \%$ (v/v) CSE/o $\mu \mathrm{M}$ GSH). 
Clinically, NAC is used in COPD patients as a mucolytic and antioxidant. While oral NAC treatment hardly increases NAC concentrations in the lung, it has been reported to result in a 1.7-fold increased GSH concentration in the epithelial lining fluid of patients with idiopathic pulmonary fibrosis, from $190 \mu \mathrm{M}$ to $320 \mu \mathrm{M}$ [29]. To determine whether CSE-induced EV release can be inhibited by such clinically relevant GSH concentrations, BEAS-2B cells were exposed to CSE in the continuous presence of different GSH concentrations. GSH concentrationdependently prevented EV induction by CSE (Figure ${ }_{3} \mathrm{D}$ ) and restored cell viability (Figure $3 \mathrm{E}$ ). EV inhibition reached statistical significance at $125 \mu \mathrm{M} \mathrm{GSH}$ and was complete for $250 \mu \mathrm{M}$ GSH.

Among all CSE components, ROS such as $\mathrm{H}_{2} \mathrm{O}_{2}$ and reactive carbonyls such as acrolein can react with the thiol groups of both, GSH and NAC [30]. To determine whether these components contribute to CSE-induced exosome release, we exposed BEAS-2B cells for $24 \mathrm{~h}$ to either $\mathrm{H}_{2} \mathrm{O}_{2}$ or acrolein and measured the same parameters as after CSE exposure. $\mathrm{H}_{2} \mathrm{O}_{2}$ did not affect exosome release (Figure 4A) at concentrations resulting in similar decreases in cell viability to CSE (Figure $4 \mathrm{~B}$ ). In contrast, acrolein augmented exosome release (Figure ${ }_{4} \mathrm{C}$ ) already at concentrations that only mildly affected cell viability (Figure $4 \mathrm{D}$ ). Similar to the CSE-induced exosome release, the exosome induction by acrolein was completely prevented in the continuous presence of NAC (Figure ${ }_{4} \mathrm{E}$ ) and cell viability was restored (Figure ${ }_{4} \mathrm{~F}$ ). This suggests that CSE and acrolein have a different effect on cellular thiols than $\mathrm{H}_{2} \mathrm{O}_{2}$, and that this difference may account for the EV induction.

A
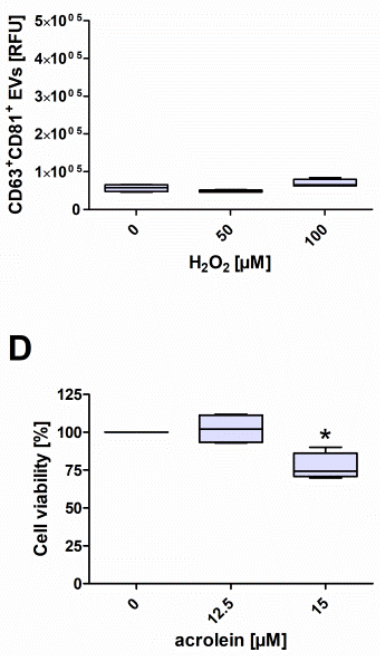

B

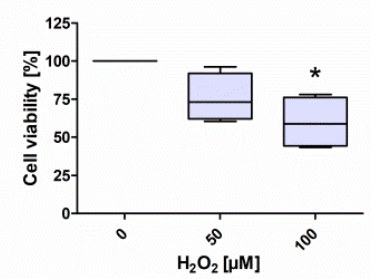

E

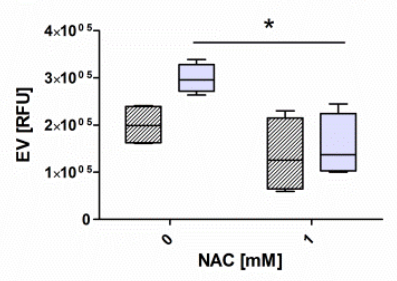

C
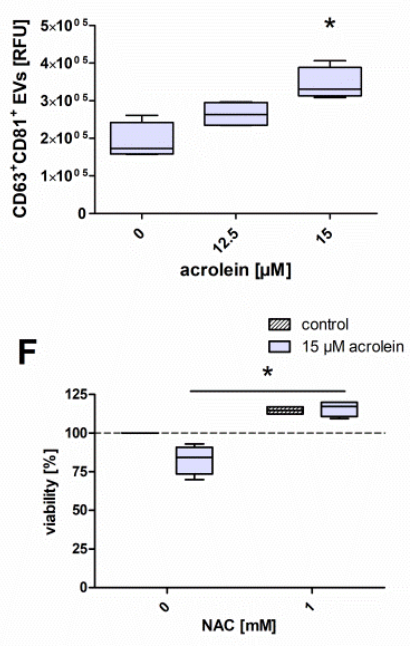
Fig.4. Effect of $\mathrm{H}_{2} \mathrm{O}_{2}$ and acrolein on EV release and cell viability. BEAS-2B cells were exposed for $24 \mathrm{~h}$ to $\mathrm{H}_{2} \mathrm{O}_{2}$ (A-B) or, alternatively, acrolein in the absence or continuous presence of NAC (C-F). EV release was determined using $\mathrm{CD} 63+\mathrm{CD} 81+$ bead-coupled flow cytometry. Cell viability was assessed using MTT assay. (A) Effect of $\mathrm{H}_{2} \mathrm{O}_{2}$ on EV release, $\mathrm{n}=4$. (B) Effect of $\mathrm{H}_{2} \mathrm{O}_{2}$ on cell viability, $\mathrm{n}=4$. (C) Effect of acrolein on $E V$ release, $n=4$. (D) Effect of acrolein on cell viability, $n=4$. (E) Effect of NAC on acrolein-induced EV release $(n=4)$. (F) Effect of NAC on acrolein-induced cytotoxicity $(n=4)$. Box and whisker plots indicate the median (line in box), 25th and 75th percentiles (outer lines of box) and the minimal and maximal values (whiskers). Statistical differences were determined using the Friedmann's test with Dunn's posthoc test ( ${ }^{*} \mathrm{p}<0.05$ compared to unexposed control (B-D) or $\mathrm{p}<0.05$ for $15 \mu \mathrm{M}$ acrolein / $\mathrm{mM}$ NAC compared to $15 \mu \mathrm{M}$ acrolein /o mM NAC (E)).

\section{Reaction with exofacial thiols is sufficient to enhance EV release}

We next aimed to identify changes in cellular thiols that may mediate the exosome induction by CSE and acrolein. First, the intracellular concentrations of reduced GSH and its oxidation product GSSG were measured. While $24 \mathrm{~h}$ exposure to CSE or acrolein caused an increase in both, reduced GSH (Supplementary Figure 1A, B) and its disulphide GSSG (Supplementary Figure $1 \mathrm{D}, \mathrm{E}$ ), the increase in GSH was stronger as illustrated by an increasing GSH/GSSG ratio (Figure ${ }_{5} \mathrm{~A}, \mathrm{~B}$ ). Upon $\mathrm{H}_{2} \mathrm{O}_{2}$ exposure, GSH only increased slightly (Supplementary Figure ${ }_{1} \mathrm{C}$ ), while GSSG (Supplementary Figure ${ }_{1 F}$ ) and the GSH/GSSG ratio (Figure ${ }_{5} \mathrm{C}$ ) remained unchanged. Next, the quantity of free thiol groups on the cell surface was assessed using the membrane impermeable thiol dye AFM. At concentrations of the three stimuli that were rematched for their effect on cell viability, CSE and acrolein both led to a concentration-dependent depletion of exofacial thiol groups (Figure ${ }_{5} \mathrm{D}, \mathrm{E}$ ), while $\mathrm{H}_{2} \mathrm{O}_{2}$ showed no effect (Figure $5 \mathrm{~F}$ ). Thus, the oxidative stress caused by $24 \mathrm{~h}$ exposure to CSE or acrolein was compensated at the intracellular level, as illustrated by the increased GSH/GSSG ratio, but not on the cell surface, as illustrated by the depleted exofacial thiol groups. 
A

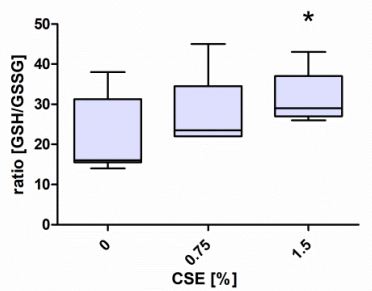

D

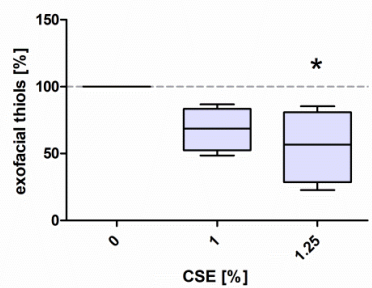

B

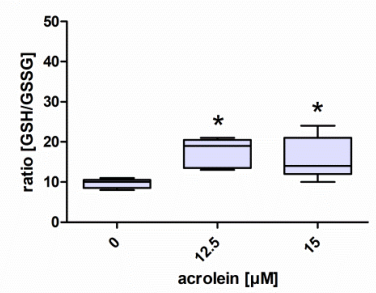

E

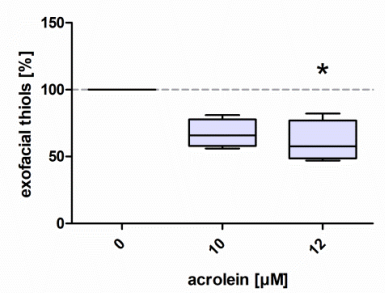

C

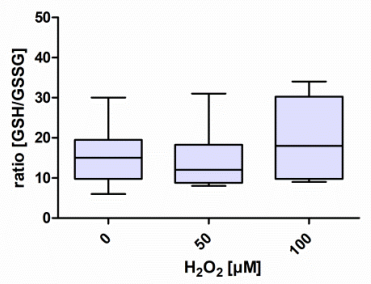

$\mathbf{F}$

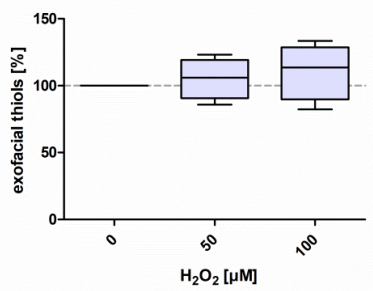

Fig. 5. BEAS-2B cells were exposed to CSE, acrolein or $\mathrm{H}_{2} \mathrm{O}_{2}$ for $24 \mathrm{~h}$. The intracellular GSH/GSSG ratio was determined by means of a GSH reductase cycling assay (A-C) and exofacial free thiol groups were detected using AFM (D-F). (A) The intracellular GSH/GSSG ratio after 24 h exposure to CSE, $n=6$. (B) The intracellular GSH/GSSG ratio after $24 \mathrm{~h}$ exposure to acrolein, $\mathrm{n}=5$. (C) The intracellular GSH/GSSG ratio after $24 \mathrm{~h}$ exposure to $\mathrm{H}_{2} \mathrm{O}_{2}, \mathrm{n}=6$. (D) Exofacial thiols detected by AFM after $24 \mathrm{~h}$ exposure to CSE, $\mathrm{n}=4$. (E) Exofacial thiols detected by AFM after $24 \mathrm{~h}$ exposure to acrolein, $\mathrm{n}=4$. (F) Exofacial thiols detected after $24 \mathrm{~h}$ exposure to $\mathrm{H}_{2} \mathrm{O}_{2}, \mathrm{n}=4$. Box and whisker plots (A-F) indicate the median (line in box), 25th and 75th percentiles (outer lines of box) and the minimal and maximal values (whiskers). Statistical differences were determined using the Friedmann's test with Dunn's posthoc test ( ${ }^{*} \mathrm{p}<0.05$ compared to unexposed control).

Finally, cells were exposed to CSE for $3 \mathrm{~h}$, followed by $24 \mathrm{~h}$ incubation in CSE-free medium, which does not result in increased EV release compared to unexposed cells (Figure ${ }_{1 E}$ ). While GSH (Supplementary Figure $1 \mathrm{G}$ ), GSSG (Supplementary Figure $1 \mathrm{H}$ ), and the GSH/GSSG ratio (Figure 6A) were increased similarly as during $24 \mathrm{~h}$ exposure to CSE, there was no effect on the exofacial thiol groups (Figure 6B). Therefore, the EV induction is more likely mediated by the depletion of exofacial thiols than by the intracellular GSH response.

We next assessed whether depletion of exofacial thiol groups is sufficient to enhance EV release. For this purpose, we exposed the BEAS-2B cells to either DTNB or bacitracin for $24 \mathrm{~h}$. Both compounds have poor membrane permeability and block exofacial thiol groups by forming disulphide bonds [31-34]. Both, DTNB and bacitracin, induced EV release (Figure 6C) without affecting cell viability (Figure 
6D). Bacitracin is known to inhibit the reductase function of protein disulphide isomerase (PDI). However, PDI is not the only target of bacitracin [35]. For this reason, PDI reductase activity was inhibited more specifically using rutin [36] or the monoclonal anti-PDI antibody clone RL9o. However, no effect on EV release was observed for either rutin or the PDI specific antibody at concentrations that have previously been shown to inhibit PDI activity $[36,37$ and that were non-cytotoxic (Figure 6C, D).

A

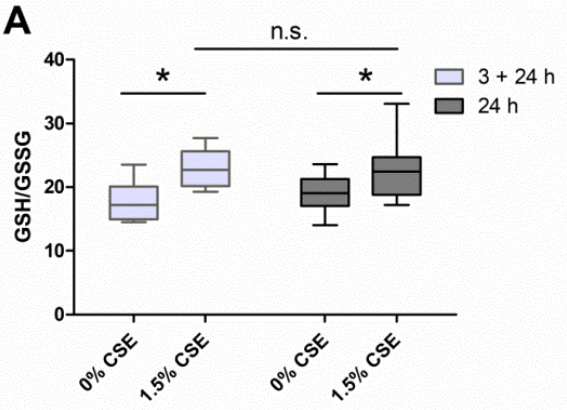

C

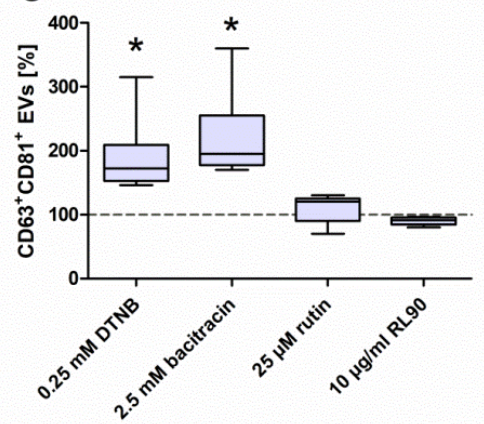

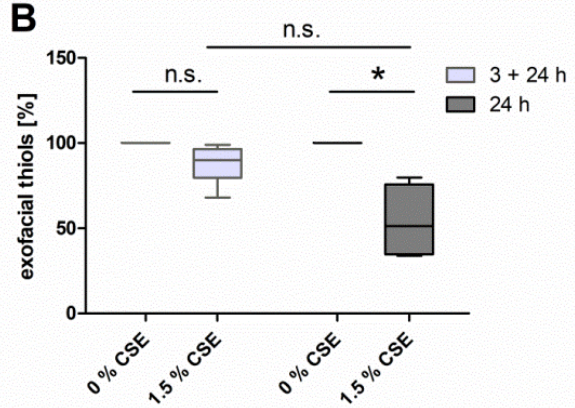

D

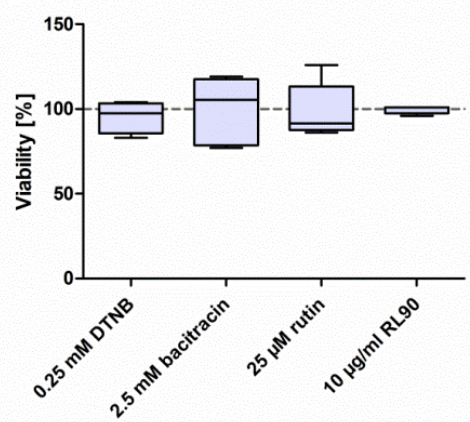

Fig. 6. Effect of exofacial thiol depletion and PDI inhibition on EV release and cell viability. (A-B) Cells were pre-stimulated with CSE for $3 \mathrm{~h}$, followed by $24 \mathrm{~h}$ incubation with CSE-free medium or continuously exposed to CSE for $24 \mathrm{~h}$. (A) Effect on the intracellular GSH/GSSG ratio, $\mathrm{n}=4$. (B) Effect on the exofacial thiols, $n=4$. Statistical differences were assessed using the Friedman test with Dunn's posthoc test. (C-D) BEAS-2B cells were exposed to either $0.25 \mathrm{mM}$ DTNB, $2.5 \mathrm{mM}$ bacitracin, $25 \mu \mathrm{M}$ rutin or $10 \mu \mathrm{M}$ RL9o for $24 \mathrm{~h}$. (C) The percent EV release ( $\mathrm{CD} 63+\mathrm{CD} 81+$ bead-coupled flow cytometry) as compared to the appropriate vehicle control for each stimulus. (D) The cell viability relative to the appropriate vehicle control for each stimulus. ( $\mathrm{n}=6$ for DTNB and bacitracin, $\mathrm{n}=5$ for rutin and RL9o). Statistical differences between the stimuli and their respective vehicle controls were analysed using the Wilcoxon matchedpairs signed rank test ( ${ }^{*} \mathrm{p}<0.05, \mathrm{n}=6$ for DTNB and bacitracin, $\mathrm{n}=5$ for rutin and RL9o). Box and whisker plots indicate the median (line in box), 25th and 75th percentiles (outer lines of box) and the minimal and maximal values (whiskers). 


\section{Discussion}

CS causes serious damage to the airway epithelium [38, 39] and, in long term smokers, it forms an important risk for developing COPD [40]. In vitro, AEC exposed to CSE have been reported to release exosomes which induce myofibroblast differentiation [22] and cytokine secretion [21] in cells that have not been in direct contact with CSE. Therefore, it is conceivable that cigarette smoke-induced exosomes are involved in the pathogenesis of COPD. Understanding the biochemical mechanisms by which cigarette smoke influences exosome release by AEC, and how this can be prevented, could therefore be of clinical relevance.

The first objective of this study was to characterise the EV release after exposure of AEC to CSE in terms of quantity and $\mathrm{EV}$ properties. Using $\mathrm{CD} 63^{+} \mathrm{CD} 81^{+}-$ bead coupled flow cytometry and the label-free TRPS technique, we found that CSE exposure enhances EV release concentration- and time-dependently. Based on their size and marker expression we classified both, control EVs and CSE-induced EVs, as exosomes. Our highly specific methods corroborate and extend a report from Moon et al. who found that CSE exposure of AEC increases the protein content of a 100,00o $x g$ ultracentrifugation pellet [21], which can be seen as a rough estimate for exosome quantity. Notably, we found that the increased exosome release upon CSE-exposure was paralleled by a concentration- and time-dependent decrease in cell viability. Yet, it is unlikely that cell death causes the increase in exosomes irrespective of the stimulus, since exposure to $\mathrm{H}_{2} \mathrm{O}_{2}$-concentrations with a similar impact on cell viability did not enhance exosome release. Additionally, the thiol-blocking compounds DTNB and bacitracin both enhanced EV release without affecting cell viability.

Our second objective was to identify the chemical trigger for CSE-induced exosome release. In line with previous research, we found that CSE is thiol-reactive as it depletes the free thiol groups of GSH in a direct reaction. Moreover, scavenging thiol-reactive compounds in CSE using the thiol-antioxidants NAC or GSH completely prevented the exosome induction. This implies that thiol-reactive compounds within CSE entirely account for the increased exosome release. Components of CSE that can react with thiol groups and thus can be neutralised by thiol-antioxidants comprise $\mathrm{ROS}$ such as $\mathrm{H}_{2} \mathrm{O}_{2}$, which cause disulphide bond formation [41, 42]; and thiol-reactive carbonyls such as acrolein [43], which form adducts [44]. In our study, the cellular effects of CSE could not be mimicked by $\mathrm{H}_{2} \mathrm{O}_{2}$. Although the used $\mathrm{H}_{2} \mathrm{O}_{2}$ concentrations caused a similar decrease in cell viability to CSE, they had no effect on exosome release. This is in contrast to the 
findings of Hedlund et al. who have shown that lymphoma cells release more $\mathrm{CD}_{3}{ }^{+}$ EVs when exposed to $\mathrm{H}_{2} \mathrm{O}_{2}$ for $24 \mathrm{~h}$ [13]. Therefore, it may be cell-type specific whether an oxidative stimulus like $\mathrm{H}_{2} \mathrm{O}_{2}$ induces exosome release or not.

In contrast to $\mathrm{H}_{2} \mathrm{O}_{2}$, acrolein mimicked all cellular effects observed for CSE, including NAC-reversible induction of exosome release. Based on data from Lambert et al. , who quantified acrolein in CSE, we estimate that the CSE concentration in our experiments $(1.5 \%(\mathrm{v} / \mathrm{v}))$ contains between 2.6 and $37.5 \mu \mathrm{M}$ acrolein [45]. This corresponds well with our experimental acrolein concentrations of 12.5 to $15 \mu \mathrm{M}$. Moreover, the fold-change increase in exosome release was similar after exposure to $1.5 \%(\mathrm{v} / \mathrm{v})$ CSE and $15 \mu \mathrm{M}$ acrolein $(2.2 \pm 0.3$ fold vs. $1.9 \pm 0.3$ fold). In addition, NAC could completely restore exosome concentrations to the control level for both, CSE and acrolein exposure. Therefore, it is conceivable that acrolein accounts for the exosome induction upon CSE exposure. Intriguingly, acrolein and other thiolreactive carbonyls are not only present in CSE, but are also formed endogenously during inflammation and oxidative stress $[46,47]$. Thiol-reactive carbonyls have been shown to be increased in COPD patients who have stopped smoking [9], and in other conditions characterised by inflammation and oxidative stress, such as diabetes and neuroinflammatory disorders [9, 48-51]. Hence, they may serve as triggers for exosome release in these chronic inflammatory disorders. This is especially interesting as exosomes have been shown to play a pathological role in both, metabolic and neuroinflammatory diseases [52, 53]. Moreover, NAC, which can prevent thiol-reactive carbonyl-induced exosome release has not only been attributed a protective role in COPD, but also in metabolic and neurological disorders $[54,55]$.

Thirdly, we aimed to identify the cellular target that mediates the EV induction by CSE. Therefore, we first assessed how free thiol concentrations were affected at different subcellular locations. Intracellularly, $24 \mathrm{~h}$ exposure to CSE and acrolein, but not to $\mathrm{H}_{2} \mathrm{O}_{2}$, led to an overall increase in free thiols as indicated by an increased GSH/GSSG ratio. Such an upregulation of the endogenous antioxidant response has previously been reported for cells exposed to reactive carbonyls [5, 56]. In spite of the excess of the oxidant-scavenging GSH inside the cell, free thiol groups on the cell surface were still depleted after $24 \mathrm{~h}$. This suggests the cellular target that mediates the EV induction by CSE may be located on the cell surface. Indeed, blocking exofacial thiols using either of two membrane-impermeable compounds, DTNB or bacitracin, was sufficient to induce exosome release with a similar foldchange to CSE. One target of bacitracin is cell surface-associated PDI [34, 35]. Notably, PDI has previously been implied in EV release [37] and a recent study 
reports that CSE and acrolein, but not $\mathrm{H}_{2} \mathrm{O}_{2}$, inhibit PDI reductase activity [57]. However, in this study neither of two specific PDI reductase inhibitors, i.e. the flavonoid rutin [36] and the monoclonal antibody RL9o [37, 58], elicited an increased exosome release. Thus, blocking thiol-disulphide exchange reactions on the cell surface may be the mechanism by which CSE enhances exosome release, but the precise molecular target remains to be elucidated. It is conceivable that exofacial thiol-depletion causes secondary intracellular changes, which then result in the exosome induction. However, we expect that the depletion of exofacial thiols directly results in the exosome induction as the induction already occurs within 30 minutes of exposure and requires the continuous presence of the stimulus. CSE may trigger the membrane fusion required for exosome release, as thiol-dependent mechanisms have long been known to regulate membrane fusion [59].

As CSE-induced exosomes have been attributed potentially detrimental functions $[21,22]$, the ultimate objective of this study was also to evaluate whether exosome induction could be prevented by antioxidants at clinically relevant concentrations. Recent meta-analyses encourage the use of NAC in COPD patients, as high doses ( $\geq 1200 \mathrm{mg}$ / day orally) were found to be well tolerated and efficient in decreasing exacerbation frequency $[11,60]$ and to improve small airway function [10]. As the bioavailability of the unchanged NAC molecule is low, the beneficial effects are attributed to NAC serving as a precursor for GSH [61]. GSH concentrations are severely decreased in the epithelial lining fluid (ELF) of COPD patients compared to healthy controls [61]. While it is not known if GSH in ELF of COPD patients can be restored by NAC treatment, patients with idiopathic pulmonary fibrosis have similarly decreased GSH concentrations (190 $\mu \mathrm{M}$ vs. $380 \mu \mathrm{M}$ in the control group) and these are restored to the normal level $(310 \mu \mathrm{M})$ by high dose NAC (180o mg/day orally)[29]. Here, we found that GSH prevents CSE-induced EV release at 125-250 $\mu \mathrm{M}$, which matches the concentration range observed in the IPF study. Thus, future studies should aim to explore whether inhibition of exosome release contributes to the protective outcome of oral NAC treatment in COPD patients.

A limitation of this study is that exposure to CSE in vitro is acute, whereas it is chronic cigarette smoking that forms the major risk factor for developing COPD. Additionally, it is currently impossible to match the in vitro CSE exposure to the in vivo CS exposure of the epithelium of smokers. However, it has been argued that acute CSE exposure in vitro is suitable to model changes in the naïve lung during the earliest phase of COPD development [62]. Nevertheless, to translate the in vitro findings of our study, it would be revealing to investigate exosome concentrations in bronchoalveolar lavage fluid or plasma of smokers and COPD patients compared 
with non-smoking control subjects. Although we did not address functional properties of CSE-induced exosomes, there is evidence from earlier studies that CSEinduced airway epithelial-derived exosomes are involved in the pathogenesis of COPD by inducing of pro-inflammatory cytokines and profibrotic changes [21, 22] Therefore, it should also be studied whether exosomes from patients' body fluids contribute to the pathogenesis of COPD.

\section{Conclusion}

Our study reveals that CSE exposure enhances the exosome release by AEC. This is mediated by thiol-reactive compounds like the carbonyl acrolein, which may act by depleting extracellular free thiols. Thiol-antioxidants like NAC and GSH inhibit exosome release induced by CSE or acrolein, which may contribute to the therapeutic benefits of NAC in COPD. These findings pave the way for future research investigating the role of cigarette smoke- and reactive carbonyl-induced exosomes in the pathogenesis of COPD and other chronic inflammatory diseases.

\section{Acknowledgements}

The authors would like to thank Hans Duimel for performing the cryo-transmission electron microscopy recordings and Marie-José Drittij for performing the glutathione reductase cycling assay. They would also like to thank Gert Grauls for her general support in the lab and Mayk Lucchesi for designing the graphical abstract.

\section{Declaration of interest}

The authors declare no conflict of interest.

\section{Funding}

This project was funded by the Netherlands Organization for Scientific Research (NWO) grant number 022.003.011 with the title "NUTRIM NWO Graduate Program: Metabolism and chronic disease". The funding source was not involved in the study design; in the collection, analysis and interpretation of data; in the writing of the report; and in the decision to submit the article for publication. 


\section{References}

1. Hallstrand, T.S., et al., Airway epithelial regulation of pulmonary immune homeostasis and inflammation. Clin Immunol, 2014. 151(1): p. 1-15.

2. Stampfli, M.R. and G.P. Anderson, How cigarette smoke skews immune responses to promote infection, lung disease and cancer. Nat Rev Immunol, 2009. 9(5): p. 377-84.

3. Valavanidis, A., T. Vlachogianni, and K. Fiotakis, Tobacco smoke: involvement of reactive oxygen species and stable free radicals in mechanisms of oxidative damage, carcinogenesis and synergistic effects with other respirable particles. Int J Environ Res Public Health, 2009. 6(2): p. 445-62.

4. Pryor, W.A. and K. Stone, Oxidants in cigarette smoke. Radicals, hydrogen peroxide, peroxynitrate, and peroxynitrite. Ann N Y Acad Sci, 1993. 686: p. 12-27; discussion 27-8.

5. Sthijns, M.M., et al., Adaptation to acrolein through upregulating the protection by glutathione in human bronchial epithelial cells: the materialization of the hormesis concept. Biochem Biophys Res Commun, 2014. 446(4): p. 1029-34.

6. Haenen, G.R., et al., Activation of the microsomal glutathione-S-transferase and reduction of the glutathione dependent protection against lipid peroxidation by acrolein. Biochem Pharmacol, 1988. 37(10): p. 1933-8.

7. Zuo, L., et al., Interrelated role of cigarette smoking, oxidative stress, and immune response in COPD and corresponding treatments. Am J Physiol Lung Cell Mol Physiol, 2014. 307(3): p. L20518.

8. Kirkham, P.A. and P.J. Barnes, Oxidative stress in COPD. Chest, 2013. 144(1): p. 266-73.

9. Deshmukh, H.S., et al., Acrolein-activated matrix metalloproteinase 9 contributes to persistent mucin production. Am J Respir Cell Mol Biol, 2008. 38(4): p. 446-54.

10. Tse, H.N. and C.Z. Tseng, Update on the pathological processes, molecular biology, and clinical utility of N-acetylcysteine in chronic obstructive pulmonary disease. Int J Chron Obstruct Pulmon Dis, 2014. 9: p. 825-36.

11. Cazzola, M., et al., Influence of $N$-acetylcysteine on chronic bronchitis or COPD exacerbations: $a$ meta-analysis. Eur Respir Rev, 2015. 24(137): p. 451-61.

12. Eldh, M., et al., Exosomes communicate protective messages during oxidative stress; possible role of exosomal shuttle RNA. PLoS One, 2010. 5(12): p. e15353.

13. Hedlund, M., et al., Thermal- and oxidative stress causes enhanced release of $N_{K} G_{2} D$ ligandbearing immunosuppressive exosomes in leukemia/lymphoma T and B cells. PLoS One, 2011. 6(2): p. e16899.

14. Szabo-Taylor, K., et al., Oxidative and other posttranslational modifications in extracellular vesicle biology. Semin Cell Dev Biol, 2015. 4o: p. 8-16.

15. Johnstone, R.M., et al., Vesicle formation during reticulocyte maturation. Association of plasma membrane activities with released vesicles (exosomes). J Biol Chem, 1987. 262(19): p. 9412-20.

16. Safaei, R., et al., Abnormal lysosomal trafficking and enhanced exosomal export of cisplatin in drug-resistant human ovarian carcinoma cells. Mol Cancer Ther, 2005. 4(10): p. 1595-604.

17. Robbins, P.D. and A.E. Morelli, Regulation of immune responses by extracellular vesicles. Nat Rev Immunol, 2014. 14(3): p. 195-208.

18. Gould, S.J. and G. Raposo, As we wait: coping with an imperfect nomenclature for extracellular vesicles. J Extracell Vesicles, 2013. 2.

19. Gordon, C., et al., Circulating endothelial microparticles as a measure of early lung destruction in cigarette smokers. Am J Respir Crit Care Med, 2011. 184(2): p. 224-32.

20. Takahashi, T., et al., Increased circulating endothelial microparticles in COPD patients: a potential biomarker for COPD exacerbation susceptibility. Thorax, 2012. 67(12): p. 1067-74.

21. Moon, H.G., et al., CCNi secretion and cleavage regulate the lung epithelial cell functions after cigarette smoke. Am J Physiol Lung Cell Mol Physiol, 2014. 307(4): p. L326-37.

22. Fujita, Y., et al., Suppression of autophagy by extracellular vesicles promotes myofibroblast differentiation in COPD pathogenesis. J Extracell Vesicles, 2015. 4: p. 28388. 
23. Rahman, I., A. Kode, and S.K. Biswas, Assay for quantitative determination of glutathione and glutathione disulfide levels using enzymatic recycling method. Nat Protoc, 2006. 1(6): p. 3159-65.

24. Ostrowski, M., et al., Rab27a and Rab27b control different steps of the exosome secretion pathway. Nat Cell Biol, 2010. 12(1): p. 19-30; sup pp 1-13.

25. Kapustin, A.N., et al., Vascular smooth muscle cell calcification is mediated by regulated exosome secretion. Circ Res, 2015. 116(8): p. 1312-23.

26. Cvjetkovic, A., J. Lotvall, and C. Lasser, The influence of rotor type and centrifugation time on the yield and purity of extracellular vesicles. J Extracell Vesicles, 2014. 3.

27. Thery, C., M. Ostrowski, and E. Segura, Membrane vesicles as conveyors of immune responses. Nat Rev Immunol, 2009. 9(8): p. 581-93.

28. Witwer, K.W., et al., Standardization of sample collection, isolation and analysis methods in extracellular vesicle research. J Extracell Vesicles, 2013. 2.

29. Meyer, A., R. Buhl, and H. Magnussen, The effect of oral N-acetylcysteine on lung glutathione levels in idiopathic pulmonary fibrosis. Eur Respir J, 1994. 7(3): p. 431-6.

30. Wooten, J.B., Chouchane, S., and McGrath, T. E., Tobacco Smoke Constituents Affecting Oxidative Stress., in Cigarette Smoke and Oxidative Stress, B.a.P. Halliwell, H., Eds., Editor. 2006, Springer, Heidelberg. p. pp 5-46.

31. Ellman, G.L., Tissue sulfhydryl groups. Arch Biochem Biophys, 1959. 82(1): p. 70-7.

32. Reglinski, J., et al., Cellular response to oxidative stress at sulfhydryl group receptor sites on the erythrocyte membrane. J Biol Chem, 1988. 263(25): p. 1236o-6.

33. Mandel, R., et al., Inhibition of a reductive function of the plasma membrane by bacitracin and antibodies against protein disulfide-isomerase. Proc Natl Acad Sci U S A, 1993. 9o(9): p. 4112-6.

34. Dickerhof, N., et al., Bacitracin inhibits the reductive activity of protein disulfide isomerase by disulfide bond formation with free cysteines in the substrate-binding domain. FEBS J, 2011. 278(12): p. 2034-43.

35. Karala, A.R. and L.W. Ruddock, Bacitracin is not a specific inhibitor of protein disulfide isomerase. FEBS J, 2010. 277(11): p. 2454-62.

36. Jasuja, R., et al., Protein disulfide isomerase inhibitors constitute a new class of antithrombotic agents. J Clin Invest, 2012. 122(6): p. 2104-13.

37. Furlan-Freguia, C., et al., $\mathrm{P}_{2} \mathrm{X}_{7}$ receptor signaling contributes to tissue factor-dependent thrombosis in mice. J Clin Invest, 2011. 121(7): p. 2932-44.

38. Thorley, A.J. and T.D. Tetley, Pulmonary epithelium, cigarette smoke, and chronic obstructive pulmonary disease. Int J Chron Obstruct Pulmon Dis, 2007. 2(4): p. 409-28.

39. Nyunoya, T., et al., Molecular processes that drive cigarette smoke-induced epithelial cell fate of the lung. Am J Respir Cell Mol Biol, 2014. 5o(3): p. 471-82.

40. Salvi, S., Tobacco smoking and environmental risk factors for chronic obstructive pulmonary disease. Clin Chest Med, 2014. 35(1): p. 17-27.

41. Winterbourn, C.C. and D. Metodiewa, Reactivity of biologically important thiol compounds with superoxide and hydrogen peroxide. Free Radic Biol Med, 1999. 27(3-4): p. 322-8.

42. Droge, W., Free radicals in the physiological control of cell function. Physiol Rev, 2002. 82(1): p. 47-95.

43. Halliwell, B. and H.E. Poulsen, Cigarette smoke and oxidative stress. 2006: Springer.

44. van der Toorn, M., et al., Cigarette smoke irreversibly modifies glutathione in airway epithelial cells. Am J Physiol Lung Cell Mol Physiol, 2007. 293(5): p. L1156-62.

45. Lambert, C., et al., Acrolein in cigarette smoke inhibits T-cell responses. J Allergy Clin Immunol, 2005. 116(4): p. 916-22.

46. Bein, K. and G.D. Leikauf, Acrolein - a pulmonary hazard. Mol Nutr Food Res, 2011. 55(9): p. 1342-6o.

47. Mano, J., Reactive carbonyl species: their production from lipid peroxides, action in environmental stress, and the detoxification mechanism. Plant Physiol Biochem, 2012. 59: p. 90-7.

48. Hopps, E. and G. Caimi, Protein oxidation in metabolic syndrome. Clin Invest Med, 2013. 36(1): p. E1-8. 
49. Karasu, C., Glycoxidative stress and cardiovascular complications in experimentally-induced diabetes: effects of antioxidant treatment. Open Cardiovasc Med J, 2010. 4: p. 240-56.

50. $\quad$ Arai, M., et al., Carbonyl stress and schizophrenia. Psychiatry Clin Neurosci, 2014. 68(9): p. 65565.

51. Adibhatla, R.M. and J.F. Hatcher, Lipid oxidation and peroxidation in CNS health and disease: from molecular mechanisms to therapeutic opportunities. Antioxid Redox Signal, 2010. 12(1): p. 125-69.

52. Lakhter, A.J. and E.K. Sims, Minireview: Emerging Roles for Extracellular Vesicles in Diabetes and Related Metabolic Disorders. Mol Endocrinol, 2015. 29(11): p. 1535-48.

53. Gupta, A. and L. Pulliam, Exosomes as mediators of neuroinflammation. J Neuroinflammation, 2014. 11: p. 68.

54. Lasram, M.M., et al., A review on the possible molecular mechanism of action of $N$-acetylcysteine against insulin resistance and type-2 diabetes development. Clin Biochem, 2015. 48(16-17): p. 1200-8.

55. Deepmala, et al., Clinical trials of $N$-acetylcysteine in psychiatry and neurology: A systematic review. Neurosci Biobehav Rev, 2015. 55: p. 294-321.

56. Tirumalai, R., et al., Acrolein causes transcriptional induction of phase II genes by activation of Nrf2 in human lung type II epithelial (A549) cells. Toxicol Lett, 2002. 132(1): p. 27-36.

57. Kenche, H., et al., Adverse Outcomes Associated with Cigarette Smoke Radicals Related to Damage to Protein-disulfide Isomerase. J Biol Chem, 2016. 291(9): p. 4763-78.

58. Jurk, K., et al., Extracellular protein disulfide isomerase regulates feedback activation of platelet thrombin generation via modulation of coagulation factor binding. J Thromb Haemost, 2011. 9(11): p. 2278-9o.

59. $\quad$ Sanders, D.A., Sulfhydryl involvement in fusion mechanisms. Subcell Biochem, 200o. 34: p. 483514 .

6o. Shen, Y., et al., Effect of high/low dose N-acetylcysteine on chronic obstructive pulmonary disease: a systematic review and meta-analysis. COPD, 2014. 11(3): p. 351-8.

61. Gould, N.S. and B.J. Day, Targeting maladaptive glutathione responses in lung disease. Biochem Pharmacol, 2011. 81(2): p. 187-93.

62. van der Vaart, H., et al., Acute effects of cigarette smoke on inflammation and oxidative stress: a review. Thorax, 2004. 59(8): p. 713-21. 

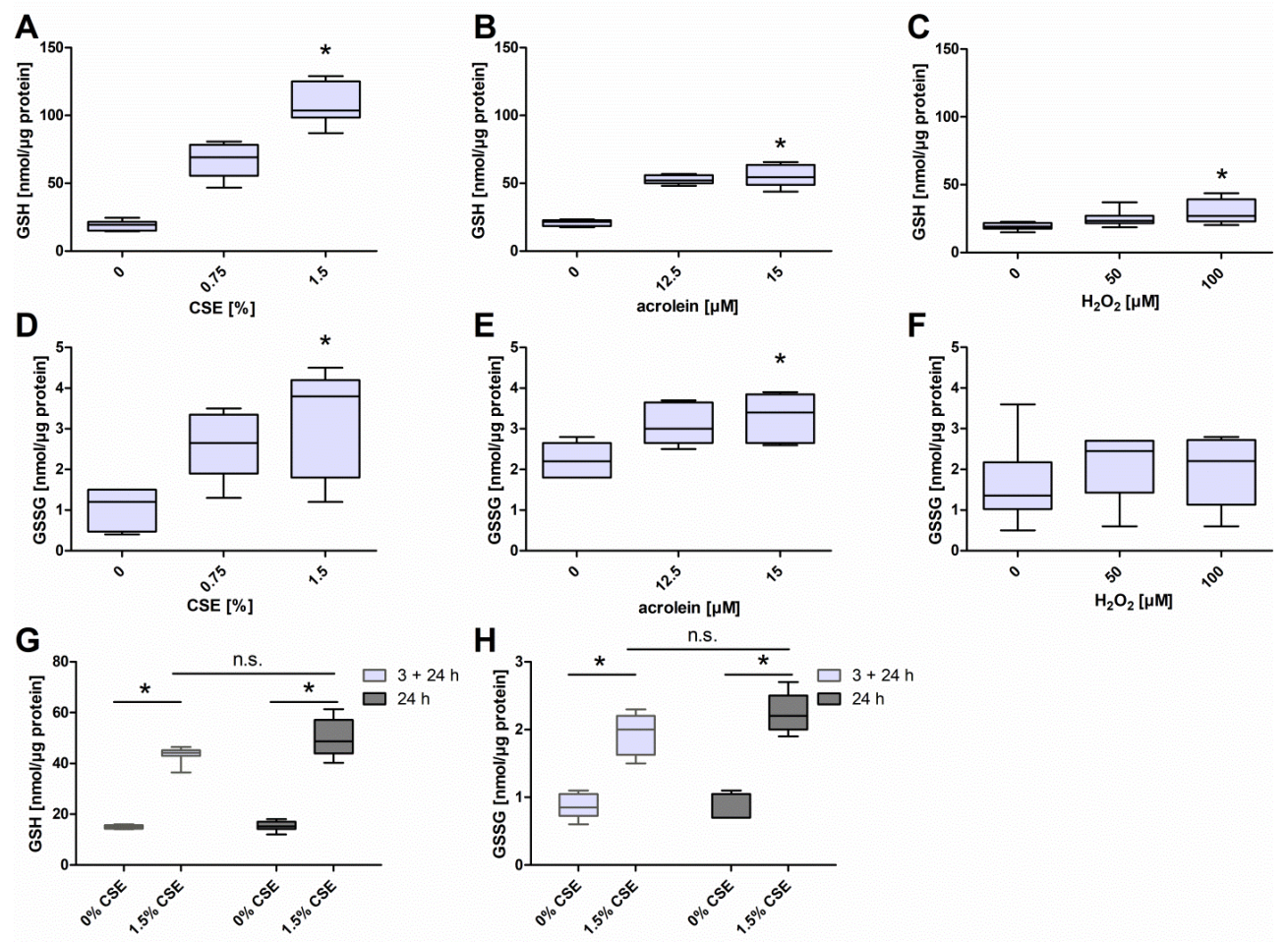

Supplementary Fig. 1: Effect of CSE, acrolein or $\mathrm{H}_{2} \mathrm{O}_{2}$ on intracellular GSH and GSSG. (A-C) Intracellular GSH was assessed after $24 \mathrm{~h}$ exposure of BEAS-2B cells to (A) CSE, (B) acrolein or (C) $\mathrm{H}_{2} \mathrm{O}_{2}$. (D-E) Intracellular GSSG after $24 \mathrm{~h}$ exposure of BEAS-2B cells to (D) CSE, (E) acrolein or (F) $\mathrm{H}_{2} \mathrm{O}_{2}$. (G,H) Intracellular GSH (G) and GSSG (H) was assessed after exposure to CSE for $3 \mathrm{~h}$ followed by $24 \mathrm{~h}$ incubation with CSE-free medium, compared to $24 \mathrm{~h}$ continuous stimulation with CSE. Box and whisker plots indicate the median (line in box), $25^{\text {th }}$ and $75^{\text {th }}$ percentiles (outer lines of box) and the minimal and maximal values (whiskers). Statistical differences were determined using the Friedmann's test with Dunn's post hoc test $\left({ }^{*} \mathrm{p}<0.05\right.$ compared to unexposed control; $\mathrm{n}=6$ for $\mathrm{A}, \mathrm{C}, \mathrm{D}$ and $\mathrm{F} ; \mathrm{n}=5$ for $\mathrm{B}, \mathrm{E} ; \mathrm{n}=4$ for G,H). 



\section{Chapter 8}

\section{Exposure to various respiratory toxicants modulates the release of extracellular vesicles by different pulmonary cell types}

Birke J. Benedikter, Pascalle H. van Eijck, Emiel F.M. Wouters, Paul H.M. Savelkoul, Gernot G.U. Rohde, Jacco J. Briedé, Niki L. Reynaert, Theo. M. de Kok, Frank R.M. Stassen 


\section{Abstract}

Chronic exposure to respiratory stressors increases the risk for pulmonary and cardiovascular diseases. Previously, we have shown that cigarette smoke extract (CSE) triggers the release of $\mathrm{CD} 63^{+} \mathrm{CD}_{1}{ }^{+}$ and tissue factor $(\mathrm{TF})^{+}$procoagulant extracellular vesicles (EVs) by bronchial epithelial cells (BEC) via depletion of cell surface thiols. Here, we hypothesised that this represents a universal response for different pulmonary cell types and respiratory exposures. Using beadbased flow cytometry, we found that BEC and pulmonary fibroblasts, but not pulmonary microvascular endothelial cells or macrophages release $\mathrm{CD}_{3}{ }^{+} \mathrm{CD}_{1}{ }^{+}$and $\mathrm{TF}^{+}$EVs in response to CSE. Cell surface thiols decreased in all cell types upon CSE exposure, but targeted depletion of cell surface thiols using bacitracin only triggered EV release by BEC and fibroblasts. The thiol-antioxidant NAC prevented the EV induction by CSE in BEC and fibroblasts. Exposure of BEC to occupational silica nanoparticles and particulate matter (PM) from outdoor air pollution also enhanced EV release. Cell surface thiols were mildly decreased and NAC partly prevented the EV induction for $\mathrm{PM}_{10}$, but not for silica and $\mathrm{PM}_{2.5}$. Taken together, induction of procoagulant EVs is a cell type specific response to CSE. Moreover, induction of $\mathrm{CD}_{3}{ }^{+} \mathrm{CD}_{1} 1^{+}$and $\mathrm{TF}^{+} \mathrm{EVs}$ in BEC appears to be a universal response to various respiratory stressors. $\mathrm{TF}^{+} \mathrm{EVs}$ may serve as biomarkers of exposure and/or risk in response to respiratory exposures. Inhibiting their induction could be a novel strategy to prevent respiratory exposure-associated morbidity. 


\section{Introduction}

The human lungs are covered with a vast epithelial surface, which makes them very efficient for gas exchange, but also highly vulnerable to inhaled exposures [1]. Such exposures include cigarette smoke, but also gases, volatile compounds and particulates from outdoor and indoor sources of air pollution. Traffic emissions are major contributors to outdoor air pollution [2] whereas exposure to indoor air pollution is often occupational. For instance, workers of many industrial sectors are exposed to crystalline silica nanoparticles at their workplace [3]. Exposure to respiratory toxicants is associated with several health consequences. Many respiratory exposures contribute to the development or aggravation of pulmonary diseases, such as chronic obstructive pulmonary disease (COPD) [4], (occupational) asthma $[5,6]$, or pneumoconiosis [7]. Moreover, respiratory exposures are associated with increased risks of lung cancer [8-10] and cardiovascular diseases (CVD) [11-13]. While the cellular and molecular mechanisms underlying the development of respiratory exposure-associated diseases are still incompletely understood, inflammation is known to play an important role.

Epithelial cells form a major cellular target for respiratory exposures as they cover the entire surface of the airways and alveoli [14]. Due to their respective locations in the lung lumen or directly underneath the epithelial layer, alveolar macrophages, pulmonary fibroblasts and pulmonary capillary endothelial cells are additional targets for inhaled substances. When cells come into contact with environmental stressors, their behaviour is profoundly affected, including the release of extracellular vesicles (EVs) $[15,16]$. These EVs are small secreted membrane vesicles that carry a complex molecular cargo and exert versatile functions in cell-tocell communication and in the extracellular space [17]. They are thought to be actively involved in the pathogenesis of several chronic inflammatory diseases, including CVD [18, 19]. There are two EV subtypes, exosomes and microvesicles. Exosomes $(50-150 \mathrm{~nm})$ are smaller than microvesicles $(150-1000 \mathrm{~nm})$ and express characteristic exosome marker proteins, including the tetraspanins CD63, CD81 and CD9. We have previously shown that cigarette smoke extract (CSE) increases the amount of exosomes released by bronchial epithelial cells (BEC) [15]. These CSEinduced exosomes were enriched in tissue factor (TF) compared to exosomes secreted by unexposed cells [Chapter 5, under review]. Thus, they likely reflect epithelial activation and damage. Moreover, they exert a TF-dependent procoagulant activity and may thereby contribute to the elevated cardiovascular risk in smokers [Chapter 5, under review]. We further demonstrated that the exosome induction by CSE depended on oxidative depletion of cellular thiols and could be prevented by 
antioxidants, such as N-acetyl-L-cysteine (NAC) [15]. In the current study, we aimed to determine whether thiol-dependent exosome induction is a universal response to respiratory exposures in different cell types and for different respiratory toxicants. We first investigated the effect of CSE on the exosome release by BEC, pulmonary fibroblasts, macrophages and pulmonary microvascular endothelial cells. Secondly, we investigated whether respiratory exposures other than CSE also affect exosome release by BEC. For this purpose, BEC were stimulated with either particulate matter (PM) from outdoor sources of air pollution or with crystalline silica particles. Total $\left(\mathrm{CD}_{3}{ }^{+} \mathrm{CD}_{1}{ }^{+}\right)$and procoagulant $\left(\mathrm{TF}^{+}\right)$exosomes were detected using bead-based flow cytometry, a method that we and others have shown to be suitable for semiquantitative EV measurements [20-22].

\section{Materials and Methods}

\section{Cell Culture}

The bronchial epithelial cell line BEAS-2B (ATCC CRL-9609), the pulmonary fibroblast cell lines MRC-5 (ATCC CCL-171) and HEL-299 (ATCC CCL-137), the monocytic cell line THP-1 and the pulmonary microvascular endothelial cell line HPMEC-ST1.6R (a kind gift from Dr. C.J. Kirkpatrick, Institute for Pathology, University of Mainz, Germany) were maintained at $5 \% \mathrm{CO}_{2}$ and $37^{\circ} \mathrm{C}$. BEAS-2B cells were cultured as described previously [15]. MRC-5 and HEL-299 cells were cultured in Minimal Essential Medium (MEM; Gibco) supplemented with $1 \%$ (v/v) $100 \mathrm{x}$ NonEssential Amino Acids (Sigma Aldrich), 2 mM L-glutamine and 10\% (v/v) foetal calf serum (FCS; Lonza). They were passaged once per week with a 1:2 split ratio and used for experiments between passages 20 and 30. THP-1 cells were cultured in RPMI-1640 (Gibco) supplemented with $50 \mu \mathrm{M} \beta$-mercaptoethanol (Sigma Aldrich), 1 $\mathrm{mM}$ sodium pyruvate (Sigma Aldrich), $12.5 \mathrm{mM}$ glucose and 10\% (v/v) FCS. They were passaged once or twice per week with a split ratio of 1:5 to 1:20. HPMEC-ST1.6R cells were cultured as described previously in MCDB1 (Gibco) supplemented with 1 $\mu \mathrm{g} / \mathrm{ml}$ hydrocortisone (Sigma Aldrich), $10 \mathrm{ng} / \mathrm{ml}$ human recombinant epidermal growth factor (Sigma Aldrich), 10\% (v/v) FCS and $1 \%(\mathrm{v} / \mathrm{v})$ 10ox penicillin and streptomycin (Gibco) [23]. They were subcultured twice per week with a split ratio of 1:4 to 1:8. Cell culture dishes were pre-coated with $2 \%(\mathrm{v} / \mathrm{v})$ gelatin (Sigma Aldrich) in MilliQ before HPMEC-ST1.6R cells were seeded.

For experiments, cells were seeded on 12- or 24-well plates. BEAS-2B and HPMEC-ST1.6R were seeded at $5 \times 10^{4}$ cells $/ \mathrm{cm}^{2}$ and allowed to attach overnight. MRC-5 and HEL-299 cells were seeded at $0.4 \times 10^{4}$ cells/well and grown until 
confluence (usually $72 \mathrm{~h}$ ). THP-1 cells were seeded at $0.5 \times 10^{4}$ cells/well in growth medium which was additionally supplemented with $200 \mathrm{nM}$ Phorbol 12-myristate 13acetate (PMA; Sigma Aldrich) to induce monocyte-to-macrophage differentiation. After $72 \mathrm{~h}$, the PMA-medium was replaced by normal growth medium, followed by incubation for another $72 \mathrm{~h}$.

For $2 \mathrm{~h}$ prior to exposure, cells were kept in reduction medium. Reduction medium was DMEM-F12 without phenol-red (Gibco) supplemented with varying percentages of EV-depleted FCS depending on the cell line. For BEAS-2B and HPMEC-ST1.6R cells, reduction medium was supplemented with $0.1 \%(\mathrm{v} / \mathrm{v})$ EVdepleted FCS. For MRC- 5 and HEL-299 cells, it was supplemented with $2 \%(v / v)$ EVdepleted FCS and for THP-1 cells with $2 \%$ (v/v) EV-depleted FCS and $0.5 \mathrm{mM}$ sodium pyruvate. EV-depleted FCS was prepared as described previously [15].

\section{Cell exposures}

CSE, bacitracin and NAC solutions, as well as silica suspensions were prepared as described previously $[15,24]$. Particulate matter with an aerodynamic diameter $\leq 10$ $\mu \mathrm{m}\left(\mathrm{PM}_{10}\right)$ and $\leq 2.5 \mu \mathrm{m}\left(\mathrm{PM}_{2.5}\right)$ was sampled at three primary schools in Maastricht, The Netherlands, as described previously [25]. For extraction of PM, filters were cut into pieces of approximately $1 \mathrm{~cm}^{2}$ and incubated in $250 \mathrm{ml}$ of dichloromethane overnight at room temperature on a shaker. Dichloromethane was then evaporated using a Rotavap rotational evaporator. Remaining dry material was resuspended in 5 $\mathrm{ml}$ methanol and transferred into a centrifuge tube. After 5 minutes centrifugation at $300 \times g$, the supernatant was transferred into a fresh recipient and evaporated using a Rotavap rotational evaporator. The remaining dry material was resuspended in methanol so that particulate matter from $200 \mathrm{~m}^{3}$ of air was suspended per $\mathrm{ml}$. To obtain a suitable vehicle control, the extraction protocol was also applied to an unused $\mathrm{PM}_{10}$ filter. The resulting dry material was weight-matched to the $\mathrm{PM}_{10}$ extract and also suspended in methanol.

Prior to exposure, cells were washed twice with PBS followed by addition of 1 $\mathrm{ml}$ of reduction medium. Different concentrations of CSE, NAC, bacitracin (Sigma Aldrich), Silica, $\mathrm{PM}_{10}$, and $\mathrm{PM}_{2.5}$ or the respective vehicle/solvent controls were then added, followed by $24 \mathrm{~h}$ incubation at $37{ }^{\circ} \mathrm{C}$ and $5 \% \mathrm{CO}_{2}$. CSE concentrations are given in $\%\left(\mathrm{v} / \mathrm{v}\right.$ ). Silica concentrations are given in $\mu \mathrm{m}^{2} / \mathrm{cm}^{2}$ (surface area of the silica particles/cell culture surface area). PM concentrations are given in $\mathrm{m}^{3} / \mathrm{ml}$ (cubic meters of air filtered to obtain the $\mathrm{PM} / \mathrm{ml}$ of cell culture medium). The PM vehicle control was volume-matched to $\mathrm{PM}_{10}$. 


\section{Determination of cell metabolic activity, EV release and exofacial thiols}

Cell viability was assessed by MTT assay as described previously [15]. Quantification of $\mathrm{CD}_{3}{ }^{+} \mathrm{CD}_{1}{ }^{+}$EVs by bead-based flow cytometry of conditioned media was also done as described previously [15], except that $200 \mu \mathrm{l}$ of conditioned media were used instead of $400 \mu \mathrm{l}$. For detection of $\mathrm{CD} 63 / \mathrm{CD} 81 / \mathrm{CD}_{9}{ }^{+} \mathrm{TF}^{+} \mathrm{EVs}$, the protocol was slightly adapted. In brief, $3.5 \times 10^{8}$ beads $/ \mathrm{ml}(4 \mu \mathrm{m}$ aldehyde/sulphate latex beads $5 \%$ (w/v); Molecular Probes Life Technologies, Waltham, MA, USA) were coated with a mixture of $42 \mu \mathrm{g} / \mathrm{ml}$ mouse anti-human CD81 antibody (Clone JS-81; BD Biosciences), $42 \mu \mathrm{g} / \mathrm{ml}$ mouse anti-human $\mathrm{CD}_{3}$ antibody (Clone $\mathrm{H}_{5} \mathrm{C} 6$, BD Biosciences) and $42 \mu \mathrm{g} / \mathrm{ml}$ mouse anti-human $\mathrm{CD}_{9}$ antibody (clone M-L13, BD Biosciences) by overnight incubation in MES buffer. Conditioned media (200 $\mu$ l) were incubated overnight with the beads, followed by staining with $0.01 \mathrm{mg} / \mathrm{ml}$ phycoerythrin (PE)-labelled mouse anti-human TF/CD142 antibody (Clone HTF-1; BD Biosciences). Quantification of exofacial thiols was also performed as previously described [15] except that a different protocol was used for the detachment of adherent cells before staining. EDTA was added directly to the exposure medium to a final concentration of $10 \mathrm{mM}$. After incubating for $10 \mathrm{~min}$ at $37^{\circ} \mathrm{C}$, cells were gently detached using the pipette tip and transferred to $1.5 \mathrm{ml}$ centrifuge tubes.

\section{Electron spin resonance}

Electron spin resonance (ESR) spectroscopy was used to determine generation of reactive oxygen species (ROS) as described previously [26]. In brief, $\mathrm{PM}_{2.5}$ or $\mathrm{PM}_{10}$ filter pieces of $0.5 \mathrm{~cm} \times 2 \mathrm{~cm}$ were placed in a tissue cell (ER 162 TC-Q, Bruker BioSpin $\mathrm{GmbH}$, Rheinstetten, Germany) and saturated with a solution of $70 \mu \mathrm{L}$ of 40 $\mathrm{mM}$ Tris- $\mathrm{HCl}$ buffer supplemented with $100 \mathrm{mM}$ of the spin trap 5,5-Dimethyl-1pyrroline N-oxide (DMPO) and $13 \mu \mathrm{M}$ ascorbate. After sealing, the tissue cell with filter material was immediately placed in the resonator of the ESR spectrometer. ESR spectra were recorded at room temperature on a Bruker EMX 1273 spectrometer equipped with an ER $4119 \mathrm{HS}$ high-sensitivity resonator and 12-kW power supply operating at $\mathrm{X}$ band frequencies. The modulation frequency of the spectrometer was $100 \mathrm{kHz}$. Instrumental conditions were as follows: centre of magnetic field, $3490 \mathrm{G}$; scan range, 6o G; modulation amplitude, $1 \mathrm{G}$; receiver gain, $1 \times 10^{4}$; microwave frequency, $9.85 \mathrm{GHz}$; power, $50 \mathrm{~mW}$; time constant, $40.96 \mathrm{~ms}$; scan time, $20.97 \mathrm{~s}$; number of scans, 10o. Spectra were quantified (in arbitrary units) through peak surface measurements using the WIN-EPR spectrum manipulation program. 


\section{Data analysis}

All values are expressed as percentages of the untreated control condition. Data was analysed using Graphpad Prism V5.03. All datasets were tested for normal distribution using the Kolmogorov-Smirnov test. For those datasets that passed the Kolmogorov-Smirnov test, a one sample t-test was used to test whether the mean of each measurement significantly differed from the control (100\%). For those datasets that were not normally distributed, the Wilcoxon signed rank test was used. To test whether NAC significantly modified the effect of each exposure, a t-test was applied to compare the effect of treatment only to the treatment plus NAC. P-values $<0.05$ were considered statistically significant. All EV measurements are displayed on a Logio scale, whereas cell metabolic activity cell surface thiols and ESR measurements are displayed on a linear scale.

\section{Results}

\section{Effect of CSE on the EV release by different cell types}

The first aim of this study was to investigate the effect of CSE on the EV release by different pulmonary cell types. BEC (BEAS-2B), pulmonary fibroblasts (HEL-299, MRC-5), monocyte-derived macrophages (THP-1) and pulmonary microvascular endothelial cells (HPMEC-ST1.6R, short HPMEC) were exposed to CSE for $24 \mathrm{~h}$. According to MTT assay, the used CSE concentrations decreased cell metabolic activity by no more than $25 \%$ (Figure $1 \mathrm{~A}$ ). We then assessed the effect of these CSE concentrations on cell surface thiols and on the release of $\mathrm{CD}_{3}{ }^{+} \mathrm{CD} 81^{+}$EVs. Despite a significant CSE-induced decrease in cell surface thiols for all cell types (Figure $1 \mathrm{~B}$ ), a concentration dependent increase in EV release was only observed in BEAS-2B, HEL-299 and MRC-5 cells, but not in THP-1 cells or HPMEC (Figure $1 \mathrm{C}$ ). Likewise, the membrane impermeable thiol-blocking agent bacitracin was able to induce EV release by BEAS-2B, HEL-299 and MRC-5 cells, whereas no significant increase in EV release was observed for bacitracin-stimulated THP-1 and HPMEC cells (Figure 1D). Moreover, the thiol-antioxidant NAC inhibited the CSE-dependent EV induction in BEAS-2B, HEL-299 and MRC-5 cells, while it did not influence EV release by THP-1 and HPMEC cells (Figure $2 \mathrm{~A}$ ). Finally, we measured the quantity of the procoagulant protein $\mathrm{TF}$ on EVs released by the different cell types in response to CSE-exposure in the presence or absence of NAC. EVs from BEAS-2B, HEL-299 and MRC-5 cells, but not THP-1 cells and HPMEC showed an increased expression of TF when exposed to CSE, and this was preventable by NAC (Figure $2 \mathrm{~B}$ ). NAC was able to restore the cell metabolic activity during CSE exposure to approximately $100 \%$ for all cell types 
(Figure 2C).
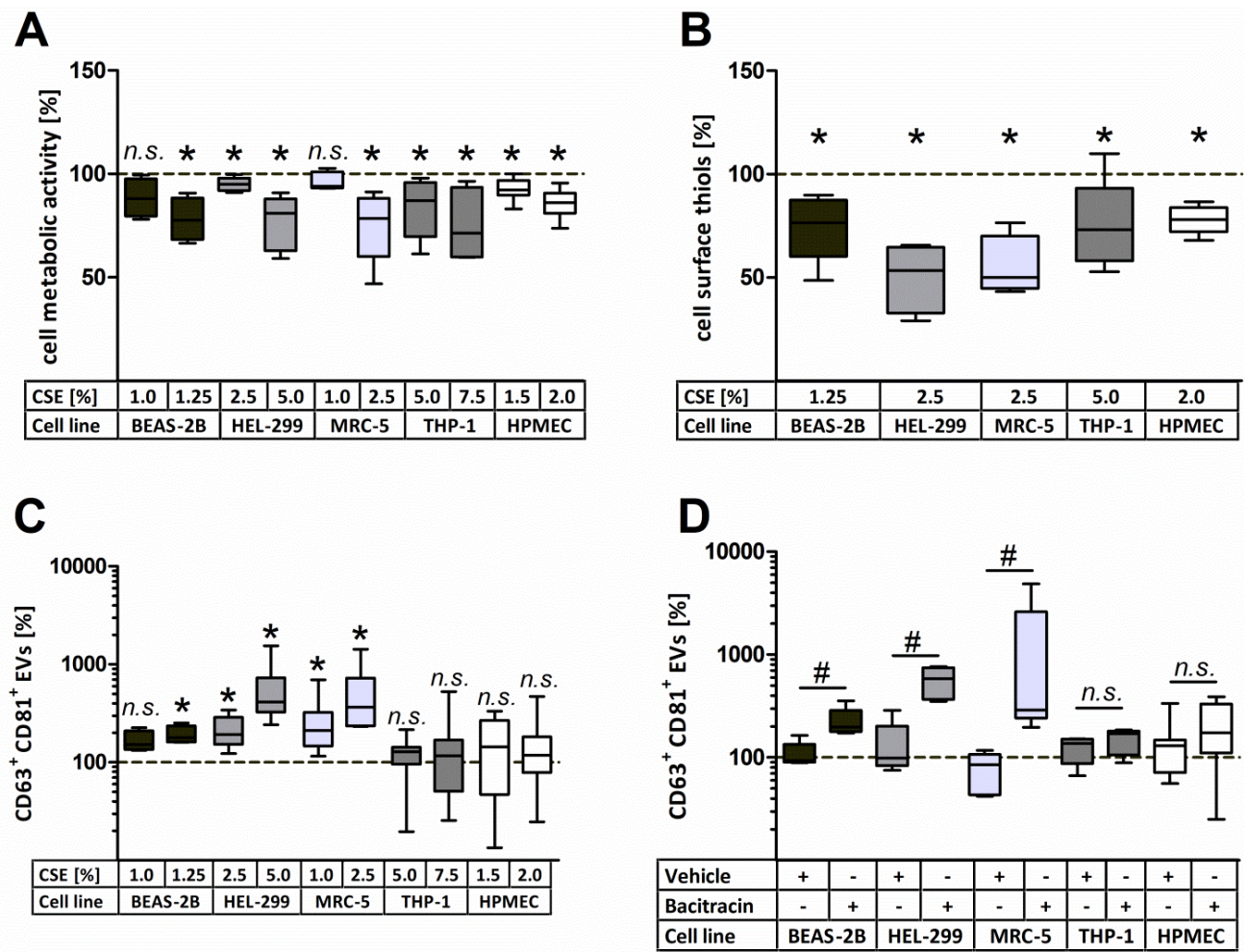

Figure 1 - Effect of CSE and the thiol scavenger bacitracin on different pulmonary cell types. (A-C) effect of CSE-exposure on (A) cell metabolic activity as determined by MTT assay, n=5-11; (B) cell surface thiols, $\mathrm{n}=4-6$; (C) release of $\mathrm{CD} 63^{+} \mathrm{CD} 81^{+}$EVs determined by bead-based flow cytometry, $\mathrm{n}=6-13$; (D) Effect of 2.5 $\mathrm{mM}$ bacitracin on the release of $\mathrm{CD}_{3}{ }^{+} \mathrm{CD}_{1}{ }^{+} \mathrm{EVs}, \mathrm{n}=5-9$. The box and whisker plots show the median (line in box), 25th and 75th percentiles (outer lines of box) and minimal and maximal values (whiskers). ${ }^{*} \mathrm{p}<0.05$ compared to the untreated control $(100 \%), \# \mathrm{p}<0.05$ for bacitracin compared to the vehicle control

Taken together, CSE enhanced the release of $\mathrm{CD}_{3}{ }^{+} \mathrm{CD}_{1} 1^{+} \mathrm{EVs}$ and $\mathrm{TF}^{+} \mathrm{EVs}$ in BEC and pulmonary fibroblasts, which was associated with a decrease in cell surface exposed thiols. In these cells, the membrane impermeable thiol-blocking agent bacitracin also increased the EV release. Moreover, the CSE-induced release of $\mathrm{CD}_{3}{ }^{+} \mathrm{CD} 81^{+}$and $\mathrm{TF}^{+}$EVs was preventable by the thiol-antioxidant NAC. In contrast, despite a significant depletion of cell surface thiols upon treatment with CSE, HPMEC and THP-1 cells did not show an enhanced EV release. In these cells, EV release could neither be triggered by bacitracin and was not decreased by NAC. 

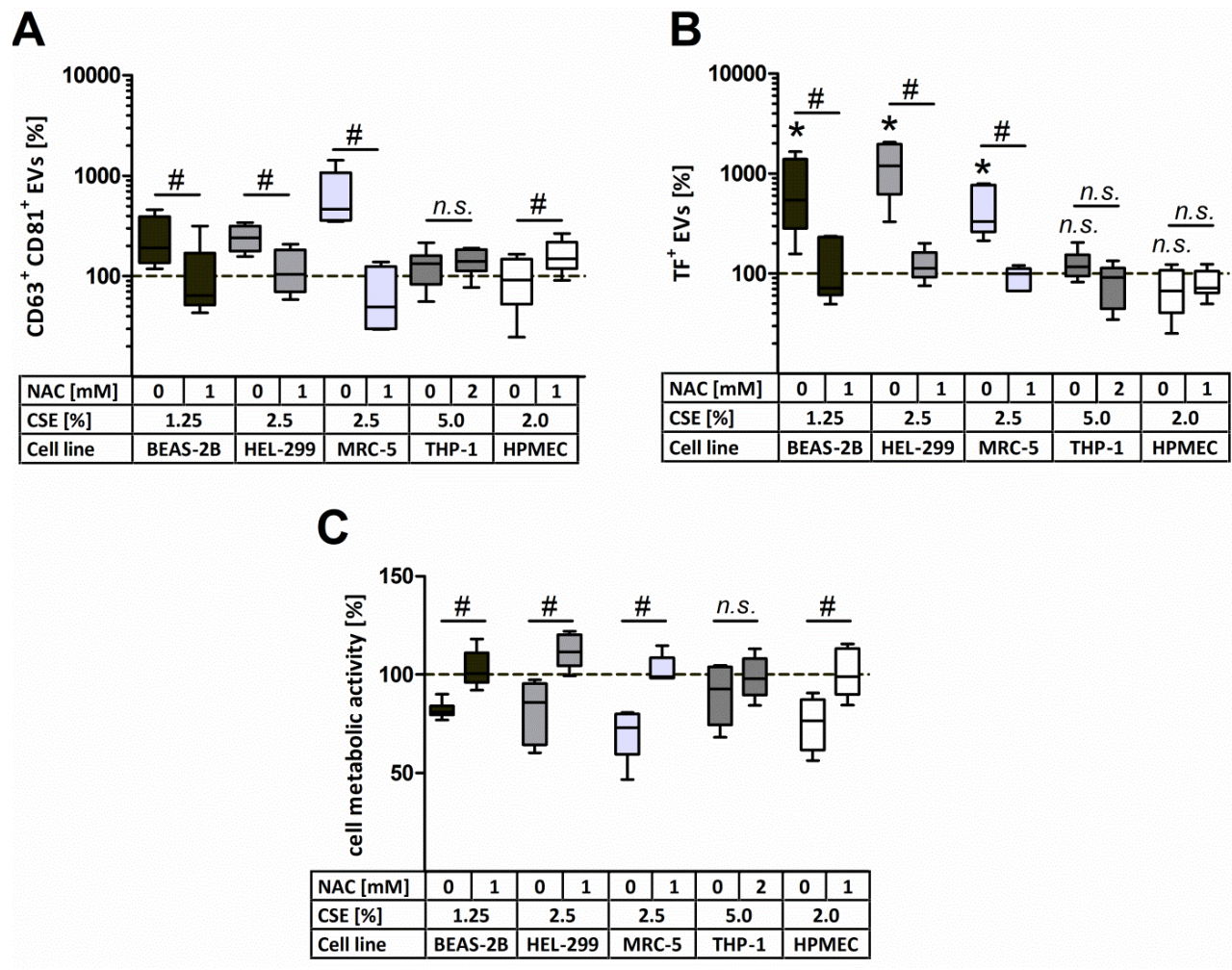

Figure 2 - Effect of NAC on the EV release and cell metabolic activity during CSE exposure. Cells were exposed to CSE in the presence or absence of the thiol antioxidant NAC and different readouts were performed. Concentration of (A) $\mathrm{CD}_{3}{ }^{+} \mathrm{CD}_{1}{ }^{+} \mathrm{EVs}(\mathrm{n}=5-9)$ and (B) $\mathrm{CD} 63 / \mathrm{CD} 81 / \mathrm{CD}_{9}{ }^{+} \mathrm{TF}^{+}$EVs $(\mathrm{n}=5-6)$ as determined by bead-based flow cytometry. (C) Cell metabolic activity as determined by MTT assay ( $n=5^{-}$ 11). The box and whisker plots show the median (line in box), 25th and 75th percentiles (outer lines of box) and minimal and maximal values (whiskers). ${ }^{*} \mathrm{p}<0.05$ compared to the unexposed control (100\%); \#p<0.05 for CSE alone compared to CSE with NAC

\section{Effect of different respiratory exposures on the EV release by BEC}

The second aim of this study was to investigate whether respiratory exposures such as crystalline silica particles or PM from air pollution affect the EV release by BEAS2B BEC similarly to CSE. Firstly, two concentrations of silica as well as $\mathrm{PM}_{2.5}$ and $\mathrm{PM}_{10}$ were determined that decreased cell metabolic activity by at most $25 \%$ (Figure $3 \mathrm{~A}$ ). The concentration of cell surface thiols was not affected by silica or $\mathrm{PM}_{2.5}$, but was significantly decreased upon exposure to $\mathrm{PM}_{10}$ (Figure ${ }_{3} \mathrm{~B}$ ). To test whether the 
difference between $\mathrm{PM}_{2.5}$ and $\mathrm{PM}_{10}$ could be attributed to differences in their ROS forming capacity, ROS generation for both PM types was assessed using ESR. PM samples were derived from three different sampling locations, and for each location, $\mathrm{PM}_{10}$ had a higher ROS-generating capacity than $\mathrm{PM}_{2.5}$ (Figure ${ }_{3} \mathrm{C}$ ). All three exposure types (silica, $\mathrm{PM}_{2.5}$ and $\mathrm{PM}_{10}$ ), but not the vehicle control for $\mathrm{PM}$, triggered an increase in $\mathrm{CD}_{3}{ }^{+} \mathrm{CD}_{1} 1^{+} \mathrm{EVs}$ (Figure $3 \mathrm{D}$ ). NAC did not decrease the quantity of $\mathrm{CD}_{3}{ }^{+} \mathrm{CD} 81^{+}$EVs induced by silica or $\mathrm{PM}_{2.5}$, but a trend for a decrease was observed for $\mathrm{PM}_{10}(\mathrm{p}=0.09$; Figure $4 \mathrm{~A})$. Importantly, $\mathrm{TF}^{+} \mathrm{EVs}$ were also induced by all three stimuli (Figure $4 \mathrm{~B}$ ). Yet, NAC did not significantly decrease $\mathrm{TF}^{+} \mathrm{EVs}$ for any of the exposures (Figure $4 \mathrm{C}$ ). NAC treatment neither led to a significant recovery of the cell metabolic activity (Figure ${ }_{3} \mathrm{~F}$ ).

A
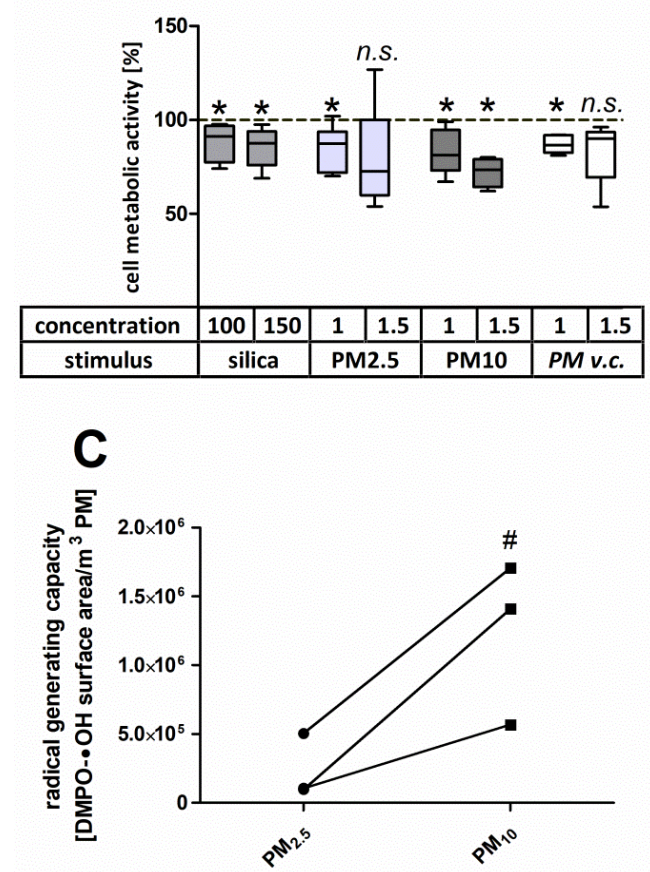

B

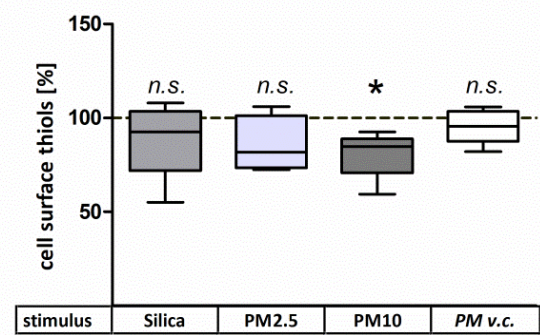

D

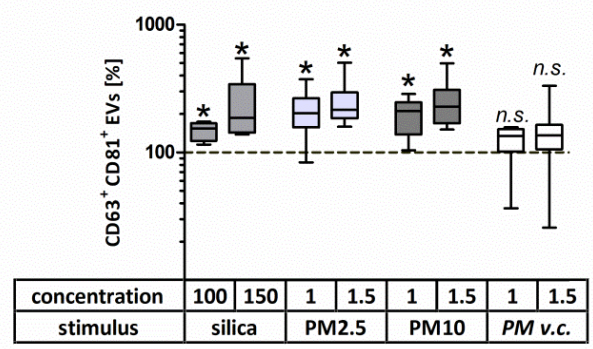

Figure 3 - Effect of silica particles, $\mathrm{PM}_{2.5}, \mathrm{PM}_{10}$ and the $\mathrm{PM}$ vehicle control (v.c.) on BEC. Cells were exposed for 24 h to different concentrations of the 4 stimuli. Silica concentrations are given in $\mu \mathrm{m}^{2} / \mathrm{cm}^{2}$ and PM concentrations in $\mathrm{m}_{3} / \mathrm{ml}$. (A) Cell metabolic activity determined by MTT assay, n=5-8; (B) Cell surface thiols after $24 \mathrm{~h}$ exposure to $100 \mathrm{~m}^{2} / \mathrm{cm}^{2}$ silica or $1.5 \mathrm{~m}^{3} / \mathrm{ml} \mathrm{PM,n=5.} \mathrm{(C)} \mathrm{ROS} \mathrm{generating} \mathrm{capacity}$ of $\mathrm{PM}_{2.5}$ and $\mathrm{PM}_{10}$ as determined by ESR. Paired $\mathrm{PM}_{2.5}$ and $\mathrm{PM}_{10}$ samples from the same sampling location are connected by a line. (D) Release of $\mathrm{CD}_{3}{ }^{+} \mathrm{CD} 1^{+} \mathrm{EVs}$ determined by bead-based flow cytometry, $\mathrm{n}=6-9$. ${ }^{*} \mathrm{p}<0.05$ compared to the unexposed control (100\%); \#p<0.05 for $\mathrm{PM}_{10}$ compared to $\mathrm{PM}_{2.5}$. 

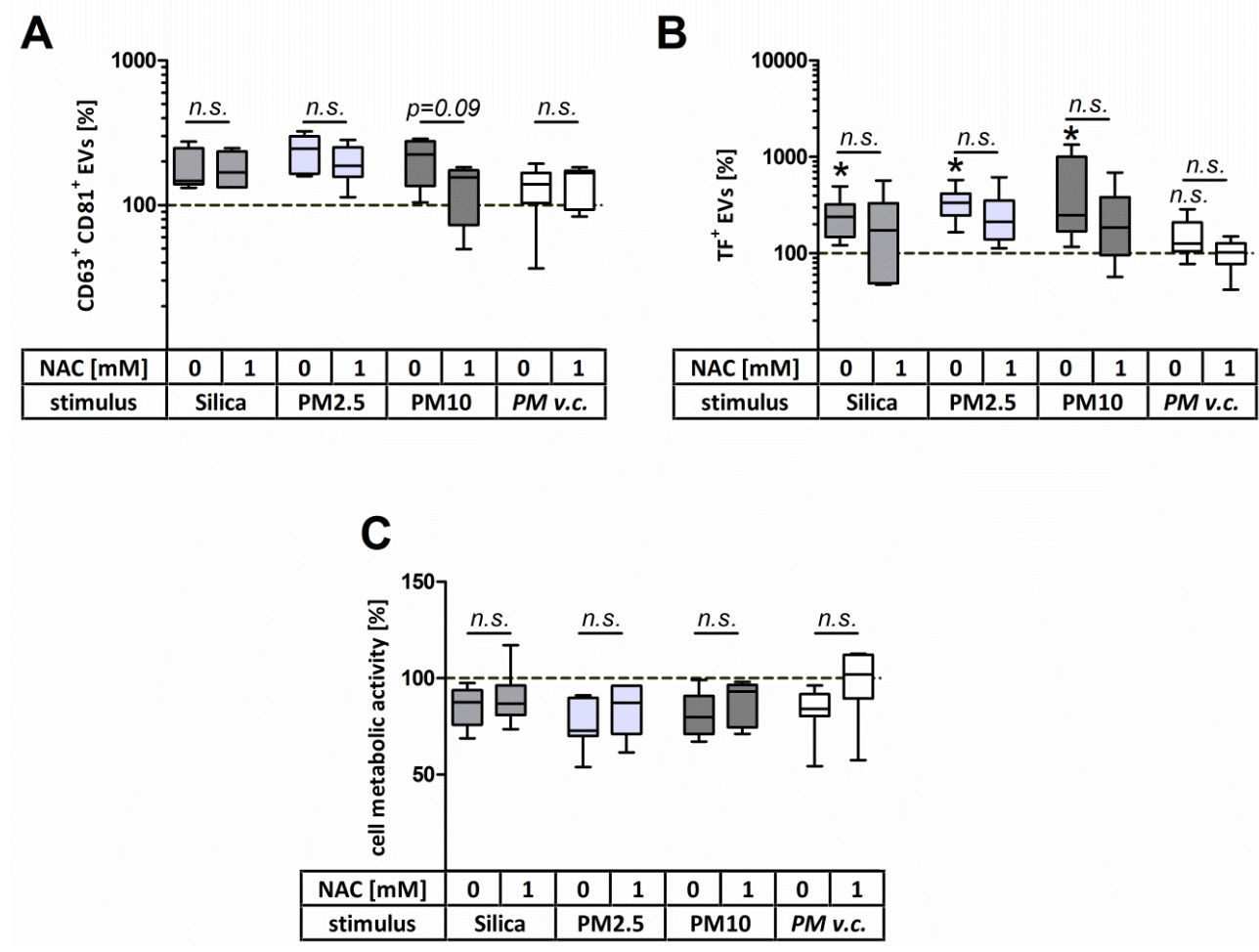

Figure 4 - Effect of $1 \mathrm{mM} \mathrm{NAC} \mathrm{on} \mathrm{EV} \mathrm{release} \mathrm{and} \mathrm{cell} \mathrm{metabolic} \mathrm{activity} \mathrm{during} \mathrm{exposure} \mathrm{to} \mathrm{silica} \mathrm{(100}$ $\left.\mu \mathrm{m}^{2} / \mathrm{cm}^{2}\right)$ or PM $\left(1.5 \mathrm{~m}^{3} / \mathrm{ml}\right)$. Release of (A) $\mathrm{CD}_{3}{ }^{+} \mathrm{CD}_{1}{ }^{+} \mathrm{EVs}, \mathrm{n}=5-9$ and (B) $\mathrm{CD} 63 / \mathrm{CD} 81 / \mathrm{CD}^{+} \mathrm{TF}^{+} \mathrm{EVs}$, $\mathrm{n}=6-7$. (C) Cell metabolic activity as determined by MTT assay, $n=5-8$. The box and whisker plots show the median (line in box), 25th and 75th percentiles (outer lines of box) and minimal and maximal values (whiskers). ${ }^{*} \mathrm{p}<0.05$ compared to the unexposed control (100\%).

To summarise, all tested respiratory stressors, namely CSE (Figure 1 and 2), silica particles, $\mathrm{PM}_{2.5}$ and $\mathrm{PM}_{10}$, triggered total and $\mathrm{TF}^{+} \mathrm{EV}$ release by BEC. The EV induction could be entirely attributed to depletion of cell surface thiols for CSE exposure and partly for the $\mathrm{PM}_{10}$ exposure, whereas another mechanism appears to regulate the EV induction by $\mathrm{PM}_{2.5}$ and silica particles.

\section{Discussion}

$\mathrm{TF}^{+}$procoagulant EVs have been implicated as active contributors to thrombosis [27, 28] as well as pulmonary inflammation [29-32]. We have previously shown that exposure of BEC to CSE causes an increase in total EV release and in TF-dependent procoagulant activity of these EVs [Chapter 5, under review]. Here, we extend these 
findings by showing that pulmonary fibroblasts also respond to CSE by releasing increased concentrations of EVs that express the exosome markers CD63 and CD81 as well as TF. Yet, no increased EV release was observed for monocyte-derived macrophages or pulmonary microvascular endothelial cells when stimulated with CSE. Thus, in our hands, only tissue-resident but not vascular or immune cells responded to acute CSE-exposure by releasing (procoagulant) EVs. Moreover, the quantity of $\mathrm{TF}^{+}$EVs released by unexposed cells was lower for endothelial cells and macrophages than for BEC and lung fibroblasts (data not shown). This suggests that tissue resident cells may be the major source of $\mathrm{TF}^{+} \mathrm{EVs}$ in vivo. Yet, others have reported that monocytes, macrophages and endothelial cells respond to either CSE or PM exposure by releasing an increased quantity of $\mathrm{TF}^{+} \mathrm{EVs}[16,33,34]$. These divergent results may arise from the use different cells (e.g. human umbilical vein endothelial cells [16] instead of pulmonary microvascular endothelial cells) and/or cell culture conditions. Another likely explanation is the use of different methods for EV detection. While we detected $\mathrm{TF}^{+}$EVs that were enriched in exosome markers (CD63/CD81/CD9), the other studies based their findings on techniques that favour detection of microvesicles. Thus, BEC and fibroblasts may secrete TF in exosomes in response to CSE whereas macrophages and endothelial cells may secrete it in microvesicles. Side-by-side comparisons of exosome and microvesicle release by each cell type are required to investigate whether this is the case. Moreover, to address whether smoking increases the concentrations of total and $\mathrm{TF}^{+} \mathrm{EVs}$ in the lungs and/or in the blood circulation, translational studies would be of value.

In the second part of this study, we investigated the effect of silica nanoparticles as well as small $\left(\mathrm{PM}_{2.5}\right)$ and larger $\left(\mathrm{PM}_{10}\right)$ particulates from outdoor sources of air pollution on the release of EVs by BEC. All three respiratory stressors triggered the release of $\mathrm{CD}_{3}{ }^{+} \mathrm{CD}_{1}{ }^{+}$and $\mathrm{TF}^{+} \mathrm{EVs}$ by BEC. Yet, they did not (silica, PM2.5) or only mildly (PM10) deplete cell surface thiols. Moreover, their effect on EV induction was not preventable by the antioxidant NAC (silica, $\mathrm{PM}_{2.5}$ ) or the prevention did not reach statistical significance $\left(\mathrm{PM}_{10}, \mathrm{p}=0.09\right)$. This suggests that the EV induction by silica nanoparticles and $\mathrm{PM}_{2.5}$ may not be mediated by oxidative thiol depletion and the EV induction by $\mathrm{PM}_{10}$ at most partly. A stronger contribution of oxidative mechanisms for $\mathrm{PM}_{10}$ is supported by the observation that our $\mathrm{PM}_{10}$ samples all had more radical generating capacity than the paired $\mathrm{PM}_{2.5}$ samples.

Although PM has previously been shown to induce the release of $\mathrm{TF}^{+}$ microvesicles by endothelial cells in vitro [16], this is to our knowledge the first study reporting PM-induced EV release by epithelial cells. It is also the first study to report $\mathrm{PM}$-induced release of TF on EVs that express exosome marker proteins and the first 
study to report that silica nanoparticles stimulate EV release. The finding that environmental as well as occupational air pollutants trigger the release of $\mathrm{TF}^{+} \mathrm{EVs}$ is important as both types of exposures are associated with an increased risk for pulmonary [4-7] and cardiovascular disease [11-13] and exposure often cannot be avoided by at-risk individuals. Additional research should be performed to elucidate the cellular mechanisms that mediate the increased EV release in response to particulates, as this could allow identifying strategies for modulating particulateinduced changes in EV signaling.

In conclusion, we show that some, but not all pulmonary cell types respond to CSE by releasing $\mathrm{CD}_{3}{ }^{+} \mathrm{CD}_{1} 1^{+}$and $\mathrm{TF}^{+} \mathrm{EVs}$, in particular BEC and fibroblasts. Moreover, $\left(\mathrm{TF}^{+}\right) \mathrm{EV}$ induction in BEC appears to be a universal response to various respiratory toxicants. It may contribute to the elevated risk for cardiovascular and pulmonary disease development in response to respiratory exposures. Therefore, inhibiting the induction of procoagulant EVs might be a novel strategy to prevent respiratory exposure-associated morbidity. Moreover, it should be evaluated whether $\mathrm{TF}^{+}$EVs can serve as biomarkers of exposure and/or risk in individuals exposed to respiratory toxicants.

\section{Acknowledgements}

The authors would like to thank Ingrid Dijkgraaf (Department of Biochemistry, Maastricht University) for her enthusiastic support with the Rotavap. 


\section{References}

1. Weibel, E.R., What makes a good lung? Swiss Med Wkly, 2009. 139(27-28): p. 375-86.

2. Colvile, R.N., et al., The transport sector as a source of air pollution. Atmospheric Environment, 2001. 35(9): p. 1537-1565.

3. Leung, C.C., I.T. Yu, and W. Chen, Silicosis. Lancet, 2012. 379(9830): p. 2008-18.

4. Salvi, S., Tobacco smoking and environmental risk factors for chronic obstructive pulmonary disease. Clin Chest Med, 2014. 35(1): p. 17-27.

5. Guarnieri, M. and J.R. Balmes, Outdoor air pollution and asthma. Lancet, 2014. 383(9928): p. 1581-92.

6. Friedman-Jimenez, G., D. Harrison, and H. Luo, Occupational asthma and work-exacerbated asthma. Semin Respir Crit Care Med, 2015. 36(3): p. 388-407.

7. $\quad$ Cullinan, P. and P. Reid, Pneumoconiosis. Prim Care Respir J, 2013. 22(2): p. 249-52.

8. Steenland, K. and E. Ward, Silica: a lung carcinogen. CA Cancer J Clin, 2014. 64(1): p. 63-9.

9. Raaschou-Nielsen, O., et al., Air pollution and lung cancer incidence in 17 European cohorts: prospective analyses from the European Study of Cohorts for Air Pollution Effects (ESCAPE). Lancet Oncol, 2013. 14(9): p. 813-22.

10. Warren, G.W. and K.M. Cummings, Tobacco and lung cancer: risks, trends, and outcomes in patients with cancer. Am Soc Clin Oncol Educ Book, 2013: p. 359-64.

11. Rigotti, N.A. and C. Clair, Managing tobacco use: the neglected cardiovascular disease risk factor. Eur Heart J, 2013. 34(42): p. 3259-67.

12. Franklin, B.A., R. Brook, and C. Arden Pope, 3rd, Air pollution and cardiovascular disease. Curr Probl Cardiol, 2015. 40(5): p. 207-38.

13. Bourdrel, T., et al., Cardiovascular effects of air pollution. Arch Cardiovasc Dis, 2017.

14. Whitsett, J.A. and T. Alenghat, Respiratory epithelial cells orchestrate pulmonary innate immunity. Nat Immunol, 2015. 16(1): p. 27-35.

15. Benedikter, B.J., et al., Cigarette smoke extract induced exosome release is mediated by depletion of exofacial thiols and can be inhibited by thiol-antioxidants. Free Radic Biol Med, 2017.

16. Neri, T., et al., Particulate matter induces prothrombotic microparticle shedding by human mononuclear and endothelial cells. Toxicol In Vitro, 2016. 32: p. 333-8.

17. Yanez-Mo, M., et al., Biological properties of extracellular vesicles and their physiological functions. J Extracell Vesicles, 2015. 4: p. 27066.

18. Buzas, E.I., et al., Emerging role of extracellular vesicles in inflammatory diseases. Nat Rev Rheumatol, 2014. 10(6): p. 356-64.

19. Loyer, X., et al., Microvesicles as cell-cell messengers in cardiovascular diseases. Circ Res, 2014. 114(2): p. 345-53.

20. Volgers, C., et al., Bead-based flow-cytometry for semi-quantitative analysis of complex membrane vesicle populations released by bacteria and host cells. Microbiol Res, 2017. 20o: p. 2532.

21. Benedikter, B.J., et al., Ultrafiltration combined with size exclusion chromatography efficiently isolates extracellular vesicles from cell culture media for compositional and functional studies. Sci Rep, 2017. 7(1): p. 15297.

22. Suarez, H., et al., A bead-assisted flow cytometry method for the semi-quantitative analysis of Extracellular Vesicles. Sci Rep, 2017. 7(1): p. 11271.

23. Willems, C.H., et al., Alveolocapillary model system to study alveolar re-epithelialization. Exp Cell Res, 2013. 319(1): p. 64-74.

24. Peeters, P.M., et al., Silica induces $\mathrm{NLRP}_{3}$ inflammasome activation in human lung epithelial cells. Part Fibre Toxicol, 2013. 10: p. 3.

25. Hogervorst, J.G., et al., Relationship between radical generation by urban ambient particulate matter and pulmonary function of school children. J Toxicol Environ Health A, 2006. 69(3-4): p. $245-62$. 
26. Briede, J.J., et al., Development and application of an electron spin resonance spectrometry method for the determination of oxygen free radical formation by particulate matter. Environ Sci Technol, 2005. 39(21): p. 8420-6.

27. van Es, N., et al., Clinical Significance of Tissue Factor-Exposing Microparticles in Arterial and Venous Thrombosis. Semin Thromb Hemost, 2015. 41(7): p. 718-27.

28. Owens, A.P., 3rd and N. Mackman, Microparticles in hemostasis and thrombosis. Circ Res, 2011. 108(10): p. 1284-97.

29. Bastarache, J.A., et al., Procoagulant alveolar microparticles in the lungs of patients with acute respiratory distress syndrome. Am J Physiol Lung Cell Mol Physiol, 2009. 297(6): p. L1035-41.

30. Novelli, F., et al., Procoagulant, tissue factor-bearing microparticles in bronchoalveolar lavage of interstitial lung disease patients: an observational study. PLoS One, 2014. 9(4): p. e95013.

31. Park, J.A., et al., Tissue factor-bearing exosome secretion from human mechanically stimulated bronchial epithelial cells in vitro and in vivo. J Allergy Clin Immunol, 2012. 130(6): p. 1375-83.

32. van der Poll, T., Tissue factor as an initiator of coagulation and inflammation in the lung. Crit Care, 2008. 12 Suppl 6: p. S3.

33. Li, M., et al., Tobacco smoke induces the generation of procoagulant microvesicles from human monocytes/macrophages. Arterioscler Thromb Vasc Biol, 2010. 30(9): p. 1818-24.

34. Cordazzo, C., et al., Rapid shedding of proinflammatory microparticles by human mononuclear cells exposed to cigarette smoke is dependent on Ca2+ mobilization. Inflamm Res, 2014. 63(7): p. 539-47. 



\section{Chapter 9}

\section{Redox-dependent thiol modifications: Implications for the release of extracellular vesicles}

Birke J. Benedikter, Antje R. Weseler, Emiel F.M. Wouters, Paul H.M. Savelkoul, Gernot G.U. Rohde, Frank R.M. Stassen

Cellular and Molecular Life Sciences. 2018 Mar 28.

doi: 10.1007/s00018-018-2806-z. [Epub ahead of print] 


\section{Abstract}

Extracellular vesicles (EVs), including microvesicles and exosomes, are emerging as important regulators of homeostasis and pathophysiology. During pro-inflammatory and pro-oxidant conditions, EV release is induced. As EVs released under such conditions often exert pro-inflammatory and procoagulant effects, they may actively promote the pathogenesis of chronic diseases. There is evidence that thiol-group containing antioxidants can prevent EV induction by pro-inflammatory and oxidative stimuli, likely by protecting protein thiols of the EV-secreting cells from oxidation. As the redox state of protein thiols greatly impacts threedimensional protein structure and, consequently, function, redox modifications of protein thiols may directly modulate EV release in response to changes in the cell's redox environment. In this review article, we discuss targets of redox-dependent thiol modifications that are known or expected to be involved in the regulation of EV release, namely redox-sensitive calcium channels, $\mathrm{N}$-ethylmaleimide sensitive factor (NSF), protein disulfide isomerase (PDI), phospholipid flippases, actin filaments, calpains and cell surface-exposed thiols. Thiol protection is proposed as a strategy for preventing detrimental changes in EV signaling in response to inflammation and oxidative stress. Identification of the thiol-containing proteins that modulate EV release in pro-oxidant environments could provide a rationale for broad application of thiol group-containing antioxidants in chronic inflammatory diseases. 


\section{Extracellular vesicles}

Extracellular vesicles (EVs) are small membrane-surrounded vesicles that are secreted by virtually all cell types and that have been detected in various body fluids including plasma [1], urine [2] and bronchoalveolar lavage fluid [3]. These EVs carry a complex cargo composed of proteins, nucleotides and lipids, among others [4]. They can exert multiple biological effects, either by interacting with or being taken up by target cells, or in the extracellular space [5]. As EVs are released under physiological and stress conditions, they have been attributed various functions in homeostasis as well as pathology [5].

\subsection{EV biogenesis and uptake}

In recent years, it has become clear that EVs are a heterogeneous population of membrane-delimited structures that emerge from distinct biogenetic pathways, and that have diverse biophysical and biochemical properties [6,7]. This review focuses on two major EV types, exosomes and microvesicles, whose properties are summarized in Table 1. Several recent review articles provide a detailed overview of the current knowledge on EV biogenesis [8-10] and uptake [11,12]. Therefore, these processes will be described only briefly and non-comprehensively, to provide the necessary context for later sections of this article. Exosome biogenesis takes place in late endosomes, which transform into multivesicular bodies (MVBs) by inward budding of their membrane to form small intraluminal vesicles (ILVs). These MVBs can then fuse with the plasma membrane and release their ILVs to the extracellular space as exosomes. In contrast to exosomes, microvesicles are released from the cell by outward budding of the plasma membrane followed by membrane fission. The membrane rearrangements that occur during exosome and microvesicle biogenesis are regulated by energy-dependent enzymes, including Rab GTPases and the endosomal sorting complex required for transport (ESCRT). EV uptake by target cells appears to occur most commonly by endocytosis or phagocytosis followed by membrane fusion within the endocytic compartment. An alternative pathway is direct membrane fusion at the cell surface. 
Table 3 - Summary of the differential properties of exosomes and microvesicles. ESCRT, endosomal sorting complex required for transport; MVB, multivesicular body

\begin{tabular}{|c|c|c|}
\hline & exosomes & microvesicles \\
\hline alternative names & extracellular vesicles & $\begin{array}{l}\text { extracellular vesicles, } \\
\text { microparticles, } \\
\text { shedding vesicles, ectosomes }\end{array}$ \\
\hline size & $50-150 \mathrm{~nm}$ & $100-1000 \mathrm{~nm}$ \\
\hline biogenesis & $\begin{array}{l}\text { as ILVs in MVBs, followed by } \\
\text { extracellular release by fusion of } \\
\text { the MVBs with the plasma } \\
\text { membrane }\end{array}$ & $\begin{array}{l}\text { direct shedding from the plasma } \\
\text { membrane }\end{array}$ \\
\hline $\begin{array}{l}\text { characteristic } \\
\text { proteins }\end{array}$ & $\begin{array}{l}\text { tetraspanins (e.g. CD63, CD81, } \\
\text { CD9), ESCRT components (ALIX, } \\
\text { TSG101) }\end{array}$ & integrins, selectins \\
\hline
\end{tabular}

\subsection{Pathophysiological relevance of redox-mediated EV signaling}

EVs are actively involved in the pathophysiology of conditions that are associated with local or systemic inflammation and oxidative stress, such as unhealthy aging (also termed 'inflammaging'), cancer, cardiovascular disease (CVD) and chronic lung diseases [13-16]. Several in vitro studies have shown that exposure of EV-secreting cells to pro-inflammatory or pro-oxidant conditions causes pathological changes in EV signaling $[17,18]$. Moreover, chronic inflammatory diseases are associated with oxidative stress as well as elevated EV concentrations and altered EV composition, both of which can contribute to adverse biological effects of EVs [19,15,20]. Pharmacological modulation of $\mathrm{EV}$ formation may therefore be a promising treatment strategy for multiple chronic inflammatory conditions. However, most known targets for inhibiting EV release, including neutral sphingomyelinase 2 and the GTPase Rab27a [21,22], are required for vital cellular processes such as lipid biosynthesis and intracellular membrane trafficking [23,24]. Therefore, currently known strategies for EV inhibition are likely associated with off-target effects, hampering their application for the therapeutic modulation of EV signaling in vivo. An improved understanding of the mechanisms that modulate EV release under conditions of chronic inflammation and oxidative stress could allow identifying pharmacological compounds that only prevent pathological changes in EV signaling but do not interfere with the physiological functions of EVs. Protein thiols can undergo reversible redox modifications. Thereby, they can act as switches in cellular redox signaling, and determine the cell's response to changes in its redox 
environment $[\mathbf{2 5}, \mathbf{2 6}]$. In this review article, we discuss how thiol modifications may be involved in EV formation and propose thiol protection as a novel strategy for preventing pathological changes in EV signaling.

\section{Redox regulation of protein thiols}

This section provides general background information on how redox modifications of protein thiols affect protein function and, consequently, cellular functions. It aims to familiarize the reader with important principles and terminology in the field of redox-dependent thiol modifications before we discuss the relevance of such modifications for the modulation of EV release in section 3.

Thiol groups in proteins are contributed by the amino acid cysteine. Most commonly, protein thiols exist either in a free, reduced form (Cys-SH), or oxidized to a disulfide with another thiol group of the same or another protein (Cys-S-S-Cys) [27]. During protein biosynthesis, disulfide bonds are introduced in a highly regulated manner. They are essential for correct three-dimensional protein structure and, consequently, for protein function. To assure correct protein folding, the position of cysteine residues within proteins is highly conserved [28]. Reduced thiols are nucleophilic and susceptible to electrophilic attacks because of their electronrich sulfur atom [25]. Certain protein microenvironments polarize the S-H bond and thereby lower the acid dissociation constant $\left(\mathrm{pK}_{\mathrm{a}}\right)$ of thiol groups. This favors their deprotonation (i.e. the dissociation of $\mathrm{H}^{+}$), resulting in the formation of even more reactive thiolate anions (Cys-S ${ }^{-}$[27]. This often occurs at active site cysteines, making them especially susceptible for redox modifications [29].

Electrophilic compounds that are prone to react with thiolates or thiols include reactive oxygen species (ROS), which can lead to the formation of ectopic disulfide bonds, reactive nitrogen species (RNS) which lead to S-nitrosylation or Snitration (Cys-S-NO) and reactive carbonyl species (RCS) which result in adduct formation (Cys-S-R) [26] (illustrated in Figure 1). ROS, RNS and RCS are present in environmental exposures, including cigarette smoke and vehicle emissions [30-32] and are also formed endogenously, for instance during inflammation and lipid peroxidation [33-35]. Reaction of such oxidative stimuli with protein thiols can strongly affect protein conformation and functionality and cysteine-rich proteins often underlie redox regulation, especially those containing unpaired cysteines with free thiol groups [27]. The cell has a powerful antioxidant system at its disposal, which consists of glutathione and various antioxidant enzymes [36]. Up to moderate oxidant levels, this system is able to control and reverse thiol modifications by ROS 
and RCS, thereby allowing oxidative thiol modifications to act as transient and specific cell signaling events [36,37]. Studies that investigate the regulation of protein function by redox sensitive thiols often apply electrophiles that covalently modify thiols, trapping them either transiently or irreversibly in an oxidized state [29]. Here, we will refer to these chemicals as thiol scavengers.

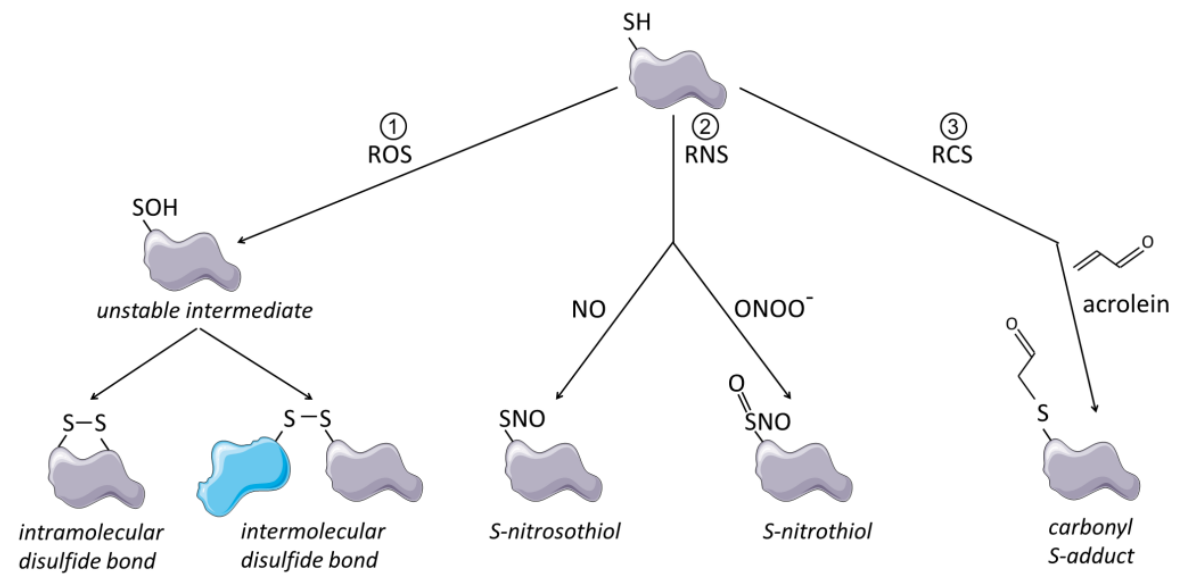

Fig. 1 Schematic representation of thiol modifications by ROS, RNS and RCS. (1) Thiol oxidation by ROS leads to formation of an unstable cysteine sulfenic acid intermediate. This unstable intermediate can react with other thiol groups within the same or another molecule, which leads to formation of intramolecular or intermolecular disulfide bonds. (2) Thiol modification by RNS such as nitric oxide (NO) or peroxynitrite $\left(\mathrm{ONOO}^{-}\right)$leads to S-nitrosylation or S-nitration. (3) Thiol modification by RCS causes formation of relatively large and bulky carbonyl S-adducts as illustrated here for acrolein. This figure was created using Servier Medical Art.

In the following sections, we discuss how thiol modifications may be involved in EV formation and how thiol protection may be used to prevent pathological changes in EV signaling.

\section{Modulation of EV signaling by thiol modifications}

\subsection{Modulation of EV release}

Intriguingly, it was reported as early as 1961 that treatment of various cells with thiolreactive compounds induces blebbing of the plasma membrane [38]. In 1979, Scott and Maercklein found that these blebs were released into the cell culture media as $100 \mathrm{~nm}$ - to $10 \mu \mathrm{m}$-sized vesicles and could be isolated by centrifugation at 30,000 x $\mathrm{g}$ [39]. The phenomenon was universal for cultured cells from different species and 
tissues, including fibroblasts, monocytes and macrophages and could be induced by a wide panel of RCS, including formaldehyde, N-ethyl-maleimide (NEM) and acrolein [39]. More recently, we and others have confirmed that treatment of various cell types with RCS or ROS enhances the release of EVs (for details, see table 2) [4043]. A number of studies have shown that both ROS-dependent and RCS-dependent EV induction are preventable by thiol-based antioxidants such as NAC [42,43,41], suggesting that thiol-reactivity is causally linked to EV induction. Yet, while Vatsyayan et al. proposed that RCS-induced EV release is mediated by secondary ROS generation, we found that only RCS, but not the ROS hydrogen peroxide, elicit increased EV release $[40,41]$. Vatsyayan et al. and the studies that showed ROSinduced EV release detected EVs by direct flow cytometry for microvesicles (detection limit $300 \mathrm{~nm}$ ) [40,42,43], whereas we used a combination of tunable resistive pulse sensing and bead-based flow cytometry to detect small EVs $(85-250$ $\mathrm{nm}$ ) expressing exosome marker proteins [41]. Therefore, thiol modifications by RCS and ROS may differentially affect the release of microvesicles and exosomes. Moreover, it may depend on the cell type and its repertoire of proteins with redox sensitive thiols whether a certain stimulus does or does not trigger EV release. For instance, in the study by Vatsyayan et al., cell exposure to the RCS 4-hydroxy-2nonenal enhanced the release of EVs by endothelial cells and fibroblasts, but not by monocytes [40].

In some studies, ROS or RCS-induced microvesicle production was associated with a considerable amount of apoptotic cell death [23, 48], suggesting that microvesicle shedding in the response to thiol-reactive compounds may be due to cytotoxicity rather than being directly mediated by thiol modifications. However, we have found that the thiol scavengers 5,5-dithio-bis-(2-nitrobenzoic acid) DTNB and bacitracin induce EVs without affecting cell viability [29] and other mechanisms have been implied in ROS and RCS-dependent EV induction, as will be discussed later. While the effect of RNS on EV release is less well studied than that of ROS and RCS, there is evidence that nitric oxide (NO) negatively regulates EV release [44,45]. Table 2 gives an overview of the experimental evidence for modulation of EV release by thiol-reactive compounds. 
Table 2 - Experimental evidence for the involvement of protein thiols in the regulation of EV release. AnxV, Annexin V; ATP, adenosine triphosphate; CSE, cigarette smoke extract; DTNB, 5,5-dithio-bis-(2-nitrobenzoic acid); EV, extracellular vesicle; HCAEC, human coronary artery endothelial cells; GSH, glutathione; HNE, 4-Hydroxy-2-nonenal; LPS, lipopolysaccharide; NAC, N-acetyl-L-cysteine; NACA, N-acetyl-L-cysteine amide; NEM, N-ethylmaleimide; MPG, N-(2Mercaptopropionyl)glycine; PS, phosphatidylserine; RCS, reactive carbonyl species; RPE, retinal pigment epithelial cells; TEM, transmission electron microscopy; TNF- $\alpha$, tumor necrosis factor $\alpha$; TF, tissue factor; TRPS, tunable resistive pulse sensing

\begin{tabular}{|c|c|c|c|c|c|c|c|c|}
\hline study & cell type & $\begin{array}{l}\text { Exogenous thiol- } \\
\text { reactive } \\
\text { compounds }\end{array}$ & $\begin{array}{l}\text { Expo- } \\
\text { sure } \\
\text { time }\end{array}$ & $\begin{array}{l}\text { Endogenous } \\
\text { thiol-reactive } \\
\text { compounds }\end{array}$ & $\begin{array}{c}\text { Thiol } \\
\text { antioxidants }\end{array}$ & $\begin{array}{l}\text { EV nomen- } \\
\text { clature }\end{array}$ & $\begin{array}{l}\text { Effect of the } \\
\text { thiol-reactive } \\
\text { compounds on } \\
\text { EV release }\end{array}$ & Summary of major findings \\
\hline $\begin{array}{l}\text { Belkin and } \\
\text { Hardy, } \\
1961[38]\end{array}$ & $\begin{array}{l}\text { ascites cells, } \\
\text { malignant cells, } \\
\text { non-malignant } \\
\text { cells }\end{array}$ & $\begin{array}{l}\text { RCS (NEM; } \\
\text { iodoacetamide) } \\
\text { ROS }\left(\mathrm{H}_{2} \mathrm{O}_{2}\right) \\
\text { Others (mercurial } \\
\quad \text { diuretics) }\end{array}$ & $\begin{array}{l}\leq 60 \\
\min \end{array}$ & n.d. & none & $\begin{array}{l}\text { plasma } \\
\text { membrane } \\
\text { blebs }\end{array}$ & $\uparrow$ & $\begin{array}{l}\text { All tested cell types respond to treatment with } \\
\text { various extrinsic thiol-reactive compounds by } \\
\text { plasma membrane blebbing. }\end{array}$ \\
\hline $\begin{array}{c}\text { Scott et } \\
\text { al., } 1979 \\
{[39]}\end{array}$ & $\begin{array}{l}\text { fibroblasts, } \\
\text { monocytes, } \\
\text { myoblasts etc. }\end{array}$ & $\begin{array}{l}\text { RCS (e.g. } \\
\text { formaldehyde, } \\
\text { acrolein, NEM, } \\
\text { iodoacetate) }\end{array}$ & $30 \mathrm{~min}$ & n.d. & none & $\begin{array}{l}\text { plasma } \\
\text { membrane } \\
\text { blebs/ } \\
\text { vesicles }\end{array}$ & $\uparrow$ & $\begin{array}{l}\text { All tested RCS, but not control compounds that do } \\
\text { not react with thiols (e.g. succinimide), induce } \\
\text { plasma membrane blebbing. }\end{array}$ \\
\hline $\begin{array}{l}\text { Dachary- } \\
\text { Prigent et } \\
\text { al., } 1993 \\
{[97]}\end{array}$ & human platelets & RCS (NEM, diamide) & $10 \mathrm{~min}$ & n.d. & none & $\begin{array}{c}\text { Micro- } \\
\text { particles }\end{array}$ & $(\downarrow)$ & $\begin{array}{l}\text { Platelet preincubation with RCS inhibits ionophore- } \\
\text { induced calpain activity, PS externalization and EV } \\
\text { release. }\end{array}$ \\
\hline $\begin{array}{l}\text { Furlan- } \\
\text { Freguia et } \\
\text { al., 2011 } \\
\quad[52]\end{array}$ & $\begin{array}{l}\text { murine } \\
\text { macrophages } \\
\text { and smooth } \\
\text { muscle cells }\end{array}$ & $\begin{array}{l}\text { Thiol scavenger } \\
\text { (DTNB) }\end{array}$ & $30 \mathrm{~min}$ & ROS & NAC & $\begin{array}{l}\text { Micro- } \\
\text { particles }\end{array}$ & $\uparrow$ & $\begin{array}{l}\text { ATP stimulation results in endogenous ROS } \\
\text { formation and release of procoagulant EVs. Blocking } \\
\text { cell surface thiols with DTNB and ROS scavenging } \\
\text { both prevent ATP-induced EV release. }\end{array}$ \\
\hline $\begin{array}{l}\text { Vatsyayan } \\
\text { et al., } \\
2013[40]\end{array}$ & $\begin{array}{l}\text { human } \\
\text { macrophages, } \\
\text { coronary artery } \\
\text { endothelial } \\
\text { cells, fibroblasts }\end{array}$ & RCS (HNE, acrolein) & $\begin{array}{l}15 \mathrm{~min} \\
\text { to } 4 \mathrm{~h}\end{array}$ & ROS & $\begin{array}{l}\text { NAC, } \\
\text { MPG }\end{array}$ & $\begin{array}{c}\text { Micro- } \\
\text { particles }\end{array}$ & $\uparrow$ & $\begin{array}{l}\text { In endothelial cells and fibroblasts, but not } \\
\text { monocytes, extrinsic RCS induce procoagulant EVs. } \\
\text { Intrinsic ROS generation and PS externalization are } \\
\text { increased in all cell types and preventable by thiol } \\
\text { protection. }\end{array}$ \\
\hline
\end{tabular}




\begin{tabular}{|c|c|c|c|c|c|c|c|c|}
\hline study & cell type & $\begin{array}{l}\text { Exogenous thiol- } \\
\text { reactive } \\
\text { compounds }\end{array}$ & $\begin{array}{l}\text { Expo- } \\
\text { sure } \\
\text { time }\end{array}$ & $\begin{array}{l}\text { Endogenous } \\
\text { thiol-reactive } \\
\text { compounds }\end{array}$ & $\begin{array}{c}\text { Thiol } \\
\text { antioxidants }\end{array}$ & $\begin{array}{l}\text { EV nomen- } \\
\text { clature }\end{array}$ & $\begin{array}{l}\text { Effect of the } \\
\text { thiol-reactive } \\
\text { compounds on } \\
\text { EV release }\end{array}$ & Summary of major findings \\
\hline $\begin{array}{l}\text { Novelli et } \\
\text { al., } 2014 \\
{[42]}\end{array}$ & $\begin{array}{l}\text { Human alveolar } \\
\text { and bronchial } \\
\text { epithelial cells }\end{array}$ & $\operatorname{ROS}\left(\mathrm{H}_{2} \mathrm{O}_{2}\right)$ & $20 \mathrm{~h}$ & n.d. & NAC & $\begin{array}{c}\text { Micro- } \\
\text { particles }\end{array}$ & $\uparrow$ & $\begin{array}{l}\text { Extrinsic ROS induce the release of procoagulant } \\
\text { EVs by alveolar and bronchial epithelial cells, which } \\
\text { is prevented by thiol protection. }\end{array}$ \\
\hline $\begin{array}{l}\text { Carver et } \\
\text { al., } 2016 \\
{[43]}\end{array}$ & $\begin{array}{l}\text { human retinal } \\
\text { pigment } \\
\text { epithelial cells }\end{array}$ & $\operatorname{ROS}\left(\mathrm{H}_{2} \mathrm{O}_{2}\right)$ & $\begin{array}{c}2 \text { to } 24 \\
h\end{array}$ & n.d. & NACA & $\begin{array}{l}\text { Micro- } \\
\text { particles }\end{array}$ & $\uparrow$ & $\begin{array}{c}\text { Extrinsic ROS induce EV release. The EV release } \\
\text { correlates with cellular apoptosis and is preventable } \\
\text { by thiol protection. }\end{array}$ \\
\hline $\begin{array}{l}\text { Szabó- } \\
\text { Taylor et } \\
\text { al., 2017 } \\
\text { [47] }\end{array}$ & $\begin{array}{l}\text { human } \\
\text { monocytes }\end{array}$ & none & $90 \min$ & n.d. & none & EVs & not determined & $\begin{array}{c}\text { Monocytes from pro-inflammatory conditions have } \\
\text { increased exofacial thiols, but release EVs with } \\
\text { decreased exofacial thiols. These EVs carry } \\
\text { overoxidized proteins. }\end{array}$ \\
\hline $\begin{array}{l}\text { Thom et } \\
\text { al., } 2017 \\
{[67]}\end{array}$ & $\begin{array}{l}\text { human and } \\
\text { murine } \\
\text { neutrophils and } \\
\text { monocytes }\end{array}$ & none & $2 \mathrm{~h}$ & $\begin{array}{l}\text { ROS } \\
\text { RNS }\end{array}$ & none & $\begin{array}{c}\text { Micro- } \\
\text { particles }\end{array}$ & $\uparrow$ & $\begin{array}{c}\text { Treatment of neutrophils with } \mathrm{CO}_{2} \text { activates } \\
\text { mitochondrial ROS generation and subsequent } \\
\text { thiol-dependent activation of IP3 receptors. This } \\
\text { causes calcium flux from the ER to the cytoplasm, } \\
\text { and S-nitrosylation of actin, resulting in increased } \\
\text { EV release. }\end{array}$ \\
\hline $\begin{array}{l}\text { Benedik- } \\
\text { ter et al., } \\
2017[41]\end{array}$ & $\begin{array}{l}\text { human } \\
\text { bronchial } \\
\text { epithelial cells }\end{array}$ & $\begin{array}{l}\text { RCS (acrolein) } \\
\text { ROS }\left(\mathrm{H}_{2} \mathrm{O}_{2}\right) \\
\text { Thiol scavengers } \\
\text { (DTNB, bacitracin) }\end{array}$ & $\begin{array}{l}30 \mathrm{~min} \\
-24 \mathrm{~h}\end{array}$ & n.d. & NAC, GSH & exosomes & $\begin{array}{c}\uparrow(\mathrm{RCS}) / \rightarrow \\
\quad(\mathrm{ROS})\end{array}$ & $\begin{array}{l}\text { RCS and thiol scavengers, but not ROS deplete } \\
\text { exofacial thiols and induce EV release. The EV } \\
\text { induction by RCS can be prevented by thiol- } \\
\text { protection. }\end{array}$ \\
\hline
\end{tabular}




\subsection{Modulation of EV cargo and functions}

Functional implications of EVs released under oxidative stress conditions have been described in detail elsewhere $[46,18]$. Therefore, we will only discuss those studies that explicitly investigated EV functions related to oxidative thiol modifications. Szabó-Taylor et al. have exposed monocytes to pro-inflammatory conditions associated with oxidative stress and assessed the expression of the thiol-dependent redox enzyme peroxiredoxin 1 on the cells and their EVs [47]. While exofacial peroxiredoxin 1 was readily detectable on both, secreting cells and EVs, the overoxidized and enzymatically inactive form was exclusively enriched on the EVs [47]. This suggests that cells may release membrane proteins with oxidized thiol groups on EVs to maintain a reduced membrane status in oxidative environments. Similarly, the thiol groups of the cytosolic enzyme glyceraldehyde 3-phosphate dehydrogenase (GAPDH) become oxidized during red blood cell storage and the oxidized form of GAPDH is then released in an EV-associated manner [48]. This implies that intraluminal proteins with oxidized thiols may also be released in EVs as a protective mechanism.

However, the release of EVs under thiol-depleting conditions may not only confer cellular protection, as EV-associated oxidized proteins and phospholipids can serve as danger-associated molecular patterns and trigger inflammation [49]. Oxidative thiol modifications also appear to promote coagulation in an EVdependent manner. A variety of thiol-depleting oxidative and pro-inflammatory conditions have been found to result in accumulation of prothrombotic EVs in vitro and in vivo [40,42,50-53]. The prothrombotic effect of these EVs has been ascribed to the phospholipid phosphatidylserine (PS) [42,50,53] and to EV-associated tissue factor (TF) $[40,42,50,52]$. PS-rich membranes provide a negatively charged surface for the assembly of coagulation factors and thereby promote coagulation [54]. Since PS is considered a universal constituent of the outer leaflet of EV membranes [55], an increase in the number of secreted EVs should be sufficient to enhance PSdependent coagulation. TF is the initiator of the extrinsic coagulation cascade [56]. Expression and activity of TF are both increased in EVs secreted by cells stimulated with thiol-reactive compounds $[40,42,50,52]$. Intriguingly, the activity of TF increases when its free thiol groups are oxidized to form a disulfide bond [57], suggesting that redox modifications are important regulators of both, quantity and activity of EVassociated TF. 


\subsection{Summary}

Cell exposure to thiol-reactive compounds, particularly RCS and ROS, results in plasma membrane blebbing and increased release of EVs. EVs released in response to thiol-modifications protect the secreting cell from oxidative damage, but also promote potentially harmful processes such as inflammation and coagulation.

\section{Molecular targets of thiol modifications that regulate EV release or EV uptake}

Although thiol modifications modulate the release and biological functions of EVs, relatively little is known about the thiol-bearing proteins that mediate these changes. In this section, various thiol-dependent mechanisms are presented that regulate either membrane fusion or blebbing and that are known or hypothesized to modulate EV release. These mechanisms are summarized in Table 3 and visualized in Figure 2. Additionally, three recent publications are discussed in detail, which specifically imply modifications of cell surface-exposed thiols in EV release [52,47,41]. 
Table 3 - Molecular targets with redox-sensitive thiol groups that regulate EV biology. AFF-1, anchor cell fusion failure 1; EFF-1, epithelial fusion failure 1; EV, extracellular vesicle; ER, endoplasmic reticulum; IP3, inositol-1,3,5-triphosphate receptors; MVE, multivesicular endosome; NSF, N-ethylmaleimide-sensitive factor; PDI, protein disulfide isomerase; PE, phosphatidylethanolamine; PS, phosphatidylserine; RyR, ryanodine receptor; SERCA, sarco/endoplasmic reticulum Caz+ATPase; SNARE, soluble NSF-attachment protein receptor; TRPA1, transient receptor potential A1

\begin{tabular}{|c|c|c|c|c|c|c|}
\hline molecular target & $\begin{array}{l}\text { Subcellular } \\
\text { location }\end{array}$ & mechanism of action & active form & $\begin{array}{c}\text { (expected) effect of } \\
\text { oxidation/thiol blockage }\end{array}$ & Mechanism of EV release & References \\
\hline $\begin{array}{l}\text { Calcium channels } \\
\text { (TRPAl, RyR, L- } \\
\text { type channels, } \\
\text { SERCA, IP3 } \\
\text { receptors) }\end{array}$ & transmembrane & $\begin{array}{l}\text { calcium influx into the cytoplasm } \\
\text { inhibits flippases, } \\
\text { activates SNARE-dependent } \\
\text { membrane fusion and }\end{array}$ & $\begin{array}{l}\text { oxidized/adducted/ } \\
\text { nitrosylated }\end{array}$ & increased EV release & $\begin{array}{l}\text { plasma membrane } \\
\text { blebbing, fusion of MVE }\end{array}$ & {$[6 o, 61,67]$} \\
\hline $\begin{array}{l}\text { Calcium channels } \\
\text { (SERCA, L-type } \\
\text { channels, T-type } \\
\text { channels) }\end{array}$ & & $\begin{array}{c}\text { promotes calpain-and caspase- } \\
\text { dependent cytoskeletal } \\
\text { reorganization }\end{array}$ & reduced & $\begin{array}{l}\text { decreased EV induction by } \\
\text { activators of these channels }\end{array}$ & with plasma membrane & {$[6 o]$} \\
\hline NSF & intracellular & $\begin{array}{l}\text { recovers SNAREs for repeated } \\
\text { rounds of membrane fusion }\end{array}$ & reduced & decreased EV release & $\begin{array}{l}\text { Fusion of MVE with } \\
\text { plasma membrane }\end{array}$ & {$[72-74,69]$} \\
\hline $\begin{array}{l}\text { PDI family } \\
\text { members }\end{array}$ & ER, cell surface & $\begin{array}{l}\text { unknown, may catalyze thiol- } \\
\text { dependent conformational } \\
\text { changes in fusion proteins }\end{array}$ & $\begin{array}{l}\text { reduced (reductase) } \\
\text { oxidized (oxidase) }\end{array}$ & $\begin{array}{l}\text { decreased (thiol blockage, } \\
\text { DTNB)/increased (oxidation, } \\
\text { ROS) EV release observed }\end{array}$ & $\begin{array}{l}\text { unknown, EVs can have } \\
\text { microvesicle- or } \\
\text { exosome-like properties }\end{array}$ & {$[52,81,83]$} \\
\hline $\begin{array}{l}\text { thiol-rich fusion } \\
\text { proteins (syncytin- } \\
\text { 1,-2, EFF-1, AFF-1) }\end{array}$ & transmembrane & mediate membrane fusion & reduced & decreased EV-uptake & $\begin{array}{l}\text { Involved in EV uptake } \\
\text { (syncytin-1,-2), unknown } \\
\text { (EFF-1, AFF-1) }\end{array}$ & {$[109,87]$} \\
\hline $\begin{array}{l}\text { phospholipid } \\
\text { flippases }\end{array}$ & transmembrane & $\begin{array}{l}\text { maintain conical phospholipids } \\
\text { (PS, PE) in inner membrane leaflet }\end{array}$ & reduced & increased EV release & $\begin{array}{l}\text { plasma membrane } \\
\text { blebbing }\end{array}$ & {$[89]$} \\
\hline actin cytoskeleton & intracellular & retraction of membrane blebs & reduced & increased EV release & $\begin{array}{l}\text { plasma membrane } \\
\text { blebbing }\end{array}$ & {$[95,67]$} \\
\hline calpains & $\begin{array}{l}\text { intracellular, can } \\
\text { be membrane- } \\
\text { associated }\end{array}$ & $\begin{array}{l}\text { degrade actin cytoskeleton and } \\
\text { thereby prevent retraction of } \\
\text { membrane blebs }\end{array}$ & reduced & decreased EV release & $\begin{array}{l}\text { plasma membrane } \\
\text { blebbing }\end{array}$ & [97] \\
\hline cell surface thiols & Cell surface & unknown & $\begin{array}{l}\text { Reduced/oxidized } \\
\text { (conflicting data) }\end{array}$ & increased EV release? & $\begin{array}{l}\text { Unknown, EVs can have } \\
\text { microvesicles or } \\
\text { exosome-like properties }\end{array}$ & {$[41,52,47]$} \\
\hline
\end{tabular}


A

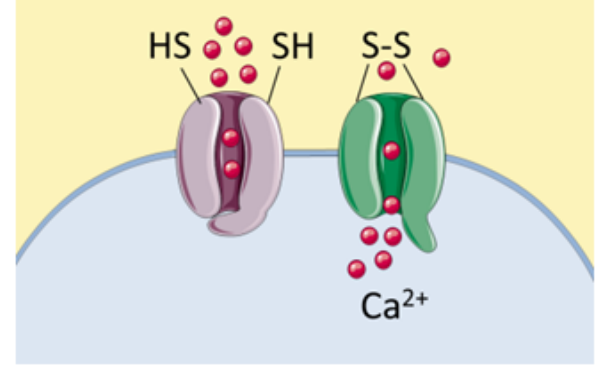

C
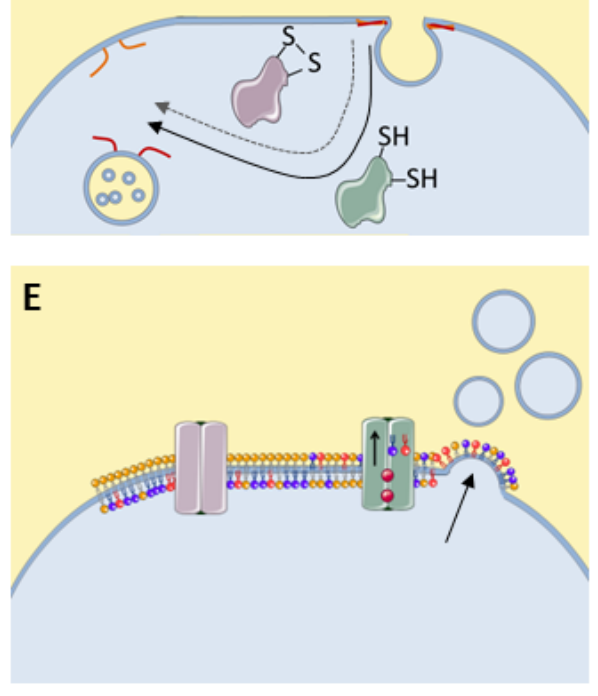

B

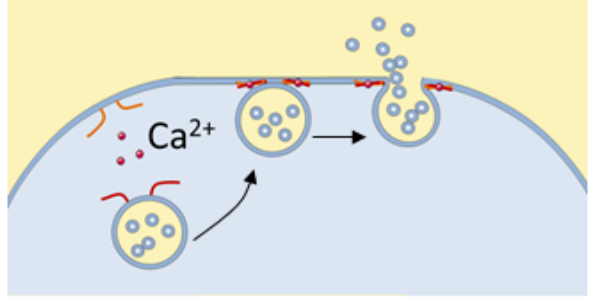

D
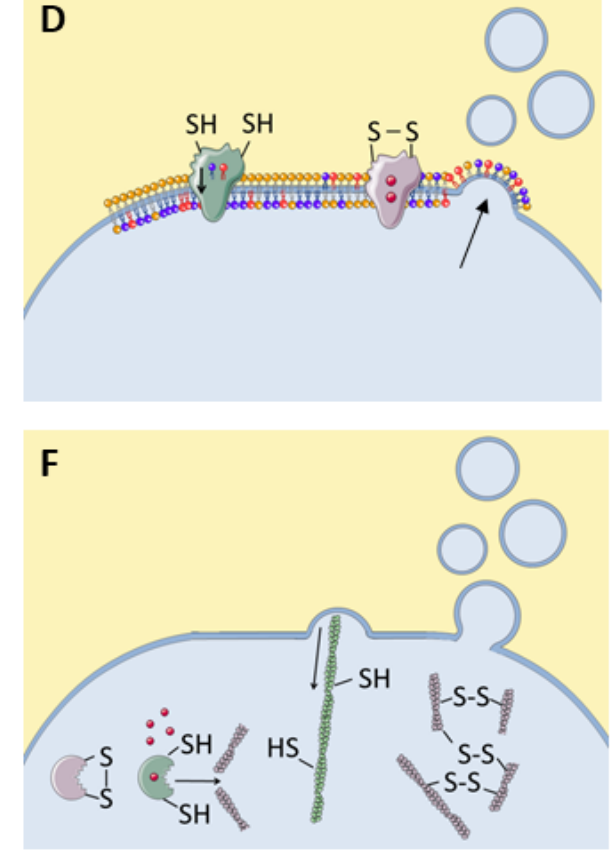

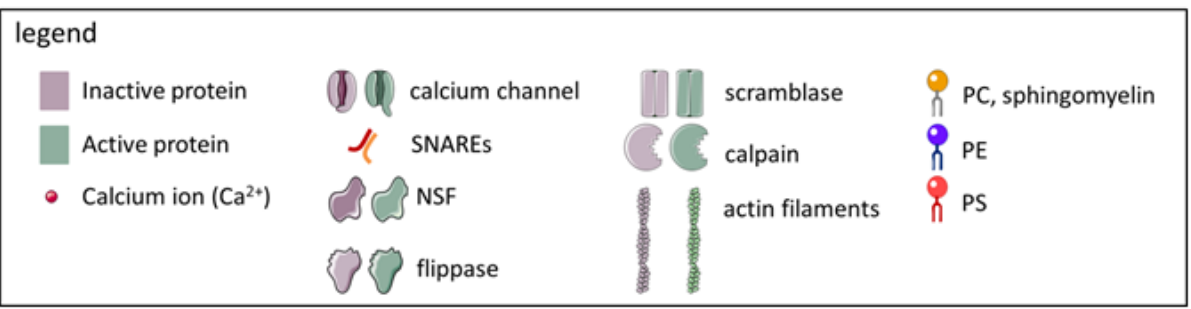

Fig. 2 Known modulators of EV release that are directly or indirectly regulated by redox-sensitive thiols. Active proteins are represented in green and inactive proteins in purple. Disulfide bonds (-S-S-) in this figure are used representatively for all oxidative thiol modifications. (A) Several calcium channels become activated upon thiol oxidation, resulting in calcium influx and increased cytoplasmic calcium 
concentration. (B) Upon the thiol-dependent calcium influx, SNAREs mediate calcium-dependent fusion of MVBs with the plasma membrane, resulting in exosome release. (C) Reduced, but not oxidize NSF catalyzes the separation of v-SNAREs and t-SNAREs, allowing their recovery for repeated membrane fusion events. (D) Flippases ensure localization of PE and PS in the inner membrane leaflet. Upon thiol oxidation or upon thiol-dependent calcium influx, the enzymatic activity of flippase is inhibited, resulting in accumulation of PE and PS in the outer membrane leaflet and consequently, in membrane blebbing. (E) Upon thiol-dependent calcium influx, scramblase becomes activated, allowing PE and PS to diffuse to the outer membrane leaflet, enhancing membrane blebbing. (F) The actin cytoskeleton depends on reduced thiols for retracting membrane blebs. Oxidation of actin thiols causes depolymerization of actin filaments and impairs their functionality. Moreover, actin filaments can be degraded by calpains, cysteine proteases which are activated by cytoplasmic calcium but inactivated by thiol oxidation. NSF, Nethylmaleimide sensitive factor; PC, phosphatidylcholine; PE, phosphatidylethanolamine; PS, phosphatidylserine SNARE, soluble NSF attachment protein receptor; t-SNARE, target membraneassociated SNARE; v-SNARE, vesicle-associated SNARE. This figure was created using Servier Medical Art

\subsection{Redox sensitive calcium channels}

Cytoplasmic calcium influx is a major inducer of both, microvesicle and exosome release, as it promotes membrane blebbing as well as fusion of MVBs with the plasma membrane $[58,59]$. Intriguingly, several calcium channels bear redoxsensitive thiol groups and become activated upon their oxidation [6o-64] (Figure 2A; for details of the different calcium channels see Table 3 ). The nociceptor transient receptor potential ankyrin subtype 1 (TRPA1) is among the best-studied calcium channels whose activity is modulated by thiol modifications [65]. Expressed by sensory neurons and other sensory cells, including epithelial cells [65], TRPA1 becomes activated upon covalent thiol oxidation by RCS or ROS [61,66]. While a causal link between TRPA1 activation and induction of EV release has to our knowledge not been investigated, oxidative stimuli such as cigarette smoke and acrolein cause TRPA1 activation [63] and also enhance EV release [41]. Direct evidence that thiol-dependent calcium flux to the cytoplasm is associated with increased EV release stems from a study by Thom et al. The authors have shown that, ROS-dependent thiol oxidation of inositol-1,3,5-triphosphate ( $\mathrm{IP}_{3}$ ) receptors triggers calcium flux from the endoplasmic reticulum to the cytoplasm and, consequently, EV release [67]. However, it should be noted that some calcium channels are inhibited, rather than activated by oxidative modification of their thiols [6o]. Therefore it may depend on the types of calcium channels expressed by a cell whether cytoplasmic calcium influx and, consequently, EV release is promoted or inhibited by cell exposure to thiol-reactive species. 
Additionally to the direct effects of thiol modifications on EV release, the coming sections will also address how cytoplasmic calcium concentrations influence EV release.

\subsection{SNARES and NSF}

Soluble N-ethylmaleimide sensitive factor attachment protein receptors (SNAREs) mediate various intracellular membrane fusion events and are also involved in EV release [68-70]. In the presence of cytoplasmic calcium, e.g. upon activation of thiolregulated calcium channels, vesicle-associated (v)-SNAREs and target membrane associated ( $\mathrm{t}$ )-SNAREs form a highly stable complex that can force two membranes together, resulting in membrane fusion (Figure $2 \mathrm{~B}$ ) [71]. After SNARE-mediated fusion, the ATPase N-ethylmaleimide-sensitive factor (NSF) can translate the energy from ATP hydrolysis into a large conformational change that mechanically separates v-SNAREs and t-SNAREs, making them available for further membrane fusion events [71] (Figure $2 \mathrm{C}$ ). Importantly, activity of NSF depends on reduced thiols and can be inhibited by the thiol-reactive carbonyl N-ethyl-maleimide (NEM) [72]. SNAREs as well as NSF have been implicated in the fusion of MVBs with the plasma membrane, resulting in exosome release $[69,73,74]$. Taken together, under oxidative conditions, thiol-dependent calcium influx is expected to cause SNARE-dependent exosome release. Yet, oxidation of the free thiol group of NSF may prevent recovery of the SNARE proteins for subsequent membrane fusion events.

\subsection{The protein disulfide isomerase family and thiol-rich fusion proteins}

The protein disulfide isomerase (PDI) family is a family of proteins with thioldependent oxidoreductase activity. The prototype family member PDI is expressed abundantly in most tissues and has two thioredoxin-like active sites (-Cys-XX-Cys-) [75]. Both active sites contain two cysteine residues, which catalyze various redox reactions, such as reduction of disulfide bonds, isomerization of disulfide bonds and oxidation of free thiols, by forming intermolecular disulfides with a substrate protein [76]. The redox state of PDI, and thus whether it is prone to catalyze oxidations or reductions, is controlled by other redox enzymes and by glutathione [75]. While most PDI is sorted to the endoplasmic reticulum (ER), significant amounts of PDI have also been detected associated with the plasma membrane, with the redox sites exposed on the cell surface [77], and secreted in an EV-associated form [78,79,52]. Importantly, PDI activity has been shown to be crucially involved in ATP-induced EV release by murine myeloid cells [52]. 
Several studies have implicated PDI family members as regulators of membrane fusion, making it conceivable that EV release and/or uptake can be mediated by PDI-dependent membrane rearrangements. For instance, sperm-egg fusion can be prevented by thiol scavengers and depends on expression of the PDI family member Erp57 on the sperm cell membrane and of the tetraspanins CD81 and CD9 on the egg cell membrane [80-82]. Notably, exosomal membranes are commonly associated with both tetraspanins and PDI, making it tempting to speculate that PDI may be involved in the fusion of tetraspanin-enriched membranes during EV biogenesis or uptake. Next to gamete fusion, the PDI family is also involved in the cell entry of several enveloped viruses, including retroviruses, whose biogenesis and cellular uptake bear striking resemblances to those of exosomes $[83,84]$. PDI-catalyzed reduction of disulfide bonds in viral fusion proteins induces conformational changes which mediate fusion of the viral envelope with the host cell membrane $[85,86]$. PDI may similarly regulate EV uptake by catalyzing thiol-disulfide exchange reactions in EV-borne fusion proteins. For instance, the fusion proteins syncytin-1 and syncytin-2 have been identified on EVs and proposed to mediate EV uptake by target cells [87]. The fusogenic activity of syncytins depends on several highly conserved cysteine residues [88], supporting the notion that they may be subject to thiol oxidoreductase regulation.

\subsection{Phospholipid flippases and scramblase}

Phospholipid flippases and scramblase are enzymes that regulate the proportions of various phospholipids in the inner and outer leaflet of the cell membrane. Each membrane lipid has a characteristic shape due to the form of its head and the composition of its acyl tail. Therefore, the phospholipid composition of the inner and outer membrane leaflets determines membrane curvature. Under physiological conditions, phospholipid flippases assure the localization of the negatively charged phosphatidylserine (PS) and the conical phophatidylethanolamine (PE) in the inner membrane leaflet. Importantly, flippase function depends on free thiol groups and is inhibited by thiol scavengers $[89,90]$. This results in accumulation of PE and PS in the outer membrane leaflet and, consequently, in curving of the plasma membrane into blebs (Figure 2D). Calcium influx, for instance triggered by oxidation of thiolbearing calcium channels, also inhibits flippase function [91]. Furthermore, it stimulates the activity of scramblase, an enzyme that allows phospholipids to move along their concentration gradient from one membrane leaflet to the other (Figure 2E)[91]. Together, calcium-dependent flippase inhibition and scramblase activation result in rapid accumulation of PS and PE in the outer leaflet and in bleb formation. 
Loss of membrane asymmetry is of direct relevance for microvesicle formation. In $C$. elegans, deletion of the PE-flippase TAT5 resulted in PE accumulation in the outer membrane leaflet and in large scale shedding of 100 to $200 \mathrm{~nm}$ sized microvesicles from the plasma membrane [92]. Additionally, a number of studies report that ROS or RCS-induced microvesicle production is associated with cellular PS externalization, which may be caused by flippase inactivation and/or scramblase activation [40].

\subsection{Retractive actin filaments and calpains}

Under physiological conditions, membrane blebbing is counteracted by the retractive force of cytoskeletal actin filaments, whose activity depends on reduced thiols [93,94] (Figure 2E). Cytoskeletal inhibition by membrane permeable thiol scavengers results in rapid and abundant shedding of plasma membrane-derived microvesicles (reviewed in [95]). The EVs induced by this treatment are very large (5-15 $\mu \mathrm{m}$ in diameter) and are thought to reflect the cytosolic and plasma membrane composition of their cells of origin [95,39]. However, such large EVs rarely occur under physiological conditions. Thus, it remains to be elucidated whether blocking of cytoskeletal free thiols contributes to normal EV biogenesis. Thom et al. reported that exposure of neutrophils to $\mathrm{CO}_{2}$ results in increased activity of inducible nitric oxide synthase (iNOS) and, consequently, in S-nitrosylation of actin. Abrogation of actin S-nitrosylation by UV-light prevented the EV induction, suggesting that the Snitrosylation was required for $\mathrm{CO}_{2}$-induced $\mathrm{EV}$ release. Intriguingly, the authors found that S-nitrosylated actin was associated with phospholipid flippase and PDI, which may further contribute to thiol-dependent regulation of EV release as discussed above.

Retraction of membrane blebs is additionally regulated by calpains, cysteine proteases that degrade actin filaments. Calcium-dependent activation of calpains prevents retraction of membrane blebs and promotes microvesicle formation [91,96]. However, while calpains are activated by calcium, they become inactivated when their free thiols are oxidized. Therefore, calpain-dependent microvesicle release may be enhanced by membrane impermeable thiol-reactive compounds that activate calcium influx channels at the cell surface, but inactivated by thiol-reactive compounds that enter the cell and oxidize the active site thiols of calpains. Congruently, Dachary-Prigent et al. have shown that the membrane-permeable RCS $\mathrm{N}$-ethylmaleimide and diamide inhibit calpain function and thereby prevent the release of platelet EVs in response to the calcium ionophore A23187 [97]. 


\subsection{Cell surface-exposed thiols}

A number of recent studies have proposed that the redox state of cell surfaceexposed thiols is involved in the regulation of EV release [52,47,41]. Firstly, FurlanFreguia et al have shown that stimulation of murine macrophages with the danger associated molecular pattern (DAMP) ATP results in $\mathrm{P}_{2} \mathrm{X}_{7}$ receptor-dependent upregulation of free thiols at the cell surface and in ROS-dependent release of thiolrich microvesicles [52]. Cell pre-treatment with the membrane impermeable thiolscavenger DTNB, as well as inhibition of PDI reductase activity (using the anti-PDI clone RL9o) prevented the microvesicle induction in response to ATP [52]. In contrast, inhibition of PDI oxidase activity (using the anti-PDI clone 34) directly induced increased cell surface thiols and thiol-rich microvesicle release [52]. A possible interpretation of these findings is that PDI may maintain thiols in an oxidized state under control conditions, thereby preventing microvesicle formation. Upon ATP exposure, PDI activity may then shift from oxidase to reductase activity, resulting in the appearance of free cell surface thiols and subsequent ROSdependent induction of thiol-rich microvesicles. Similarly to Furlan-Freguia et al., Szabó-Taylor et al. have found that stimulation of human monocytes with proinflammatory stimuli, namely lipopolysaccharide (LPS) or tumor necrosis factor (TNF)- $\alpha$, caused an upregulation of cell-surface exposed thiols [47]. However, the EVs that these cells secreted were poor in exofacial thiols [47], in contrast to the thiol-rich EVs observed by Furlan-Freguia et al. While Szabó-Taylor et al. did not assess whether there was a quantitative change in $\mathrm{EV}$ release when monocytes were stimulated with LPS or TNF- $\alpha$, they did hypothesize that the shedding of thiol-poor EVs may be a protective mechanism to maintain the cell surface in a reduced state [47].

Data from our group further corroborates that the redox state of exofacial thiols regulates EV release [41], although part of our results appear to disagree with findings of the two other groups. We found that treatment of airway epithelial cells with the RCS acrolein but not with the $\mathrm{ROS}_{2} \mathrm{O}_{2}$ causes depletion of cell surface thiols. Acrolein as well as the membrane impermeable thiol scavengers DTNB and bacitracin triggered increased release of small EVs expressing the exosome markers CD63 and CD81, whereas $\mathrm{H}_{2} \mathrm{O}_{2}$ had no measurable effect on EV release. The EV induction appeared to be directly caused by the depletion of cell surface thiols rather than being associated with the cell's adaptive antioxidant response because EV induction required continuous presence of the RCS, whereas a transient RCSstimulation was sufficient to induce upregulation of the cellular antioxidant glutathione [41]. In our study, neither the anti-PDI clone RL9o nor the PDI-inhibitor 
rutin affected basal or RCS-induced EV release. Although we were unable to identify a specific exofacial target protein of thiol modifications, we could conclude that depletion of cell surface thiols is sufficient to elicit an increased EV release in airway epithelial cells.

Although all 3 studies provide evidence that cell surface thiols may be crucially involved in the regulation of EV release, a number of discrepancies remain. While Furlan-Freguia et al. argue that an increase in the number of cell-surface thiols is required for EV induction [52], we found that depletion of exofacial thiols enhances EV release [41]. Another discrepancy is that EVs released by cells with increased cell-surface thiols were rich in exofacial thiols in the study of FurlanFreguia et al. [52], while they were poor in exofacial thiols in the study of SzabóTaylor et al [47]. Additional research is required to reveal whether the differences between studies are due to the stimuli, the cell types, the EV subpopulations or the exposure times that were investigated. It has to be noted that oxidative processes were involved in the cell surface thiol-dependent EV release in all three studies. Thus, initial upregulation of reduced cell surface thiols may be a prerequisite for subsequent oxidant-dependent thiol modifications and EV induction. It should be investigated whether the amount of cell surface thiols regulates EV release via one or more specific thiol-bearing proteins, or whether a more general mechanism is involved, such as disulfide cross-linking of exofacial thiol-bearing proteins by ROS or formation of bulky adducts by RCS, both of which may influence membrane curvature.

\section{Thiol protection to prevent EV modifications - therapeutic implications}

As thiol modifications appear to modulate the formation and functions of EVs upon cell exposure to pro-oxidant conditions, thiol protection may be a promising strategy to prevent detrimental changes in EV signaling under such conditions. Indeed, several thiol-bearing small molecules, such as NAC; NACA and glutathione are able to prevent EV induction by a variety of ROS, RCS and pro-inflammatory stimuli, likely by scavenging thiol-reactive compounds and preventing them from reacting with cellular thiols [41-43,52,53,98-10o]. NAC also inhibits EV-associated release of TF and PS by cells exposed to oxidant conditions and consequently decreases the pro-coagulant potential of EVs $[42,52,53]$. It may also prevent EV-dependent secretion of pro-inflammatory molecules [98], although this has been less well studied. Importantly, NAC treatment appears to restore EV secretion, composition and functions to the level observed for unexposed cells, rather than completely 
inhibiting EV signaling. Thus, NAC may specifically prevent oxidant-induced detrimental changes in EV signaling without interfering with the physiological functions of EVs.

In lung disease, particularly chronic obstructive pulmonary disease (COPD), NAC is currently used as a mucolytic. According to recent meta-analyses, NAC is associated with improved small airway function and decreased exacerbation frequency in this target group when administered orally at $\geq 1200 \mathrm{mg} /$ day [101-103]. Importantly, it has been proposed that these clinical benefits can at least partly be attributed to antioxidant and anti-inflammatory properties of NAC or its thiolbearing metabolites rather than to the mucolytic activity alone [102,104]. Additional research could reveal whether prevention of cellular thiol modifications and subsequent changes in EV signaling contribute to this alternative mechanism of action. Importantly, NAC has recently been proposed to be of clinical benefit in other conditions that are also hallmarked by inflammation and oxidative stress, such as insulin resistance and possibly neurological disorders $[105,106]$. There is even early stage evidence suggesting an anti-thrombotic effect of NAC treatment [107,108,104]. This is in line with the observation that NAC prevents the release of procoagulant EVs in the response to oxidative thiol modifications $[52,42,53]$. Translational studies are required to elucidate whether inhibition of thiol-dependent EV modifications contributes to the clinical benefit of NAC in COPD patients and to determine whether additional target groups may benefit from NAC treatment due to this mechanism of action.

\section{Conclusion}

Taken together, protein thiols play a crucial role in the modulation of membrane fusion and membrane blebbing. Thereby, they regulate EV release and, possibly, uptake. EV release under thiol-depleting conditions may have evolved as a beneficial adaptive response to cellular oxidative stress. However, these EVs may also exert detrimental pro-inflammatory and prothrombotic effects. Additional research is required to establish the importance of thiols in EV biology and to identify the molecular mechanisms that mediate the thiol-dependent regulation of EV-related membrane rearrangements. Many known inhibitors of EV signaling interfere with vital cellular processes, making them unsuitable for the therapeutic modulation of EV signaling. Thiol-containing antioxidants such as NAC counteract the induction of EVs by pro-oxidant stimuli in vitro. Clinical studies are required to investigate whether inhibiting the release of pro-inflammatory and pro-coagulant EVs contributes to the therapeutic benefit of NAC in conditions of chronic inflammation 
and oxidative stress. Additionally, future research should focus on identifying the specific thiol-dependent mechanisms that are involved in the regulation of EV release and uptake, as these may be promising targets for specific pharmacological modulation of EV signaling.

\section{Disclosure of interest}

The authors declare no conflict of interest.

\section{Funding}

This work was supported by the Netherlands Organization for Scientific Research (NWO) grant \# 022.003.011 with the title "NUTRIM NWO Graduate Program: Metabolism and chronic disease" awarded to BJB. 


\section{References}

1. Wolf P (1967) The nature and significance of platelet products in human plasma. British journal of haematology 13 (3):269-288

2. Pisitkun T, Shen RF, Knepper MA (2004) Identification and proteomic profiling of exosomes in human urine. Proceedings of the National Academy of Sciences of the United States of America 101 (36):13368-13373. doi:10.1073/pnas.0403453101

3. Admyre C, Grunewald J, Thyberg J, Gripenback S, Tornling G, Eklund A, Scheynius A, Gabrielsson S (2003) Exosomes with major histocompatibility complex class II and co-stimulatory molecules are present in human BAL fluid. The European respiratory journal 22 (4):578-583

4. Choi DS, Kim DK, Kim YK, Gho YS (2013) Proteomics, transcriptomics and lipidomics of exosomes and ectosomes. Proteomics 13 (10-11):1554-1571. doi:10.1002/pmic.201200329

5. Yanez-Mo M, Siljander PR, Andreu Z, Zavec AB, Borras FE, Buzas EI, Buzas K, Casal E, Cappello F, Carvalho J, Colas E, Cordeiro-da Silva A, Fais S, Falcon-Perez JM, Ghobrial IM, Giebel B, Gimona M, Graner M, Gursel I, Gursel M, Heegaard NH, Hendrix A, Kierulf P, Kokubun K, Kosanovic M, Kralj-Iglic V, Kramer-Albers EM, Laitinen S, Lasser C, Lener T, Ligeti E, Line A, Lipps G, Llorente A, Lotvall J, Mancek-Keber M, Marcilla A, Mittelbrunn M, Nazarenko I, Nolte-'t Hoen EN, Nyman TA, O'Driscoll L, Olivan M, Oliveira C, Pallinger E, Del Portillo HA, Reventos J, Rigau M, Rohde E, Sammar M, Sanchez-Madrid F, Santarem N, Schallmoser K, Ostenfeld MS, Stoorvogel W, Stukelj R, Van der Grein SG, Vasconcelos MH, Wauben MH, De Wever O (2015) Biological properties of extracellular vesicles and their physiological functions. Journal of extracellular vesicles 4:27066. doi:10.3402/jev.v4.27066

6. Raposo G, Stoorvogel W (2013) Extracellular vesicles: exosomes, microvesicles, and friends. The Journal of cell biology 200 (4):373-383. doi:10.1083/jcb.201211138

7. Kowal J, Arras G, Colombo M, Jouve M, Morath JP, Primdal-Bengtson B, Dingli F, Loew D, Tkach M, Thery C (2016) Proteomic comparison defines novel markers to characterize heterogeneous populations of extracellular vesicle subtypes. Proceedings of the National Academy of Sciences of the United States of America 113 (8):E968-977. doi:10.1073/pnas.1521230113

8. Abels ER, Breakefield XO (2016) Introduction to Extracellular Vesicles: Biogenesis, RNA Cargo Selection, Content, Release, and Uptake. Cellular and molecular neurobiology 36 (3):301-312. doi:10.1007/s10571-016-0366-z

9. Dreyer F, Baur A (2016) Biogenesis and Functions of Exosomes and Extracellular Vesicles. Methods in molecular biology 1448:201-216. doi:10.1007/978-1-4939-3753-0_15

10. Hessvik NP, Llorente A (2018) Current knowledge on exosome biogenesis and release. Cellular and molecular life sciences : CMLS 75 (2):193-208. doi:10.1007/s00018-017-2595-9

11. Mulcahy LA, Pink RC, Carter DR (2014) Routes and mechanisms of extracellular vesicle uptake. Journal of extracellular vesicles 3. doi:10.3402/jev.v3.24641

12. Prada I, Meldolesi J (2016) Binding and Fusion of Extracellular Vesicles to the Plasma Membrane of Their Cell Targets. International journal of molecular sciences 17 (8). doi:10.3390/ijms17081296

13. Robbins PD (2017) Extracellular vesicles and aging. Stem cell investigation 4:98. doi:10.21037/sci.2017.12.03

14. Minciacchi VR, Freeman MR, Di Vizio D (2015) Extracellular vesicles in cancer: exosomes, microvesicles and the emerging role of large oncosomes. Seminars in cell \& developmental biology 40:41-51. doi:10.1016/j.semcdb.2015.02.010

15. Loyer X, Vion AC, Tedgui A, Boulanger CM (2014) Microvesicles as cell-cell messengers in cardiovascular diseases. Circulation research 114 (2):345-353. doi:10.1161/CIRCRESAHA.113.300858

16. Fujita Y, Kosaka N, Araya J, Kuwano K, Ochiya T (2015) Extracellular vesicles in lung microenvironment and pathogenesis. Trends in molecular medicine 21 (9):533-542. doi:10.1016/j.molmed.2015.07.004

17. Ayers L, Nieuwland R, Kohler M, Kraenkel N, Ferry B, Leeson P (2015) Dynamic microvesicle release and clearance within the cardiovascular system: triggers and mechanisms. Clinical science 129 (11):915-931. doi:10.1042/CS20140623

18. Larson MC, Hillery CA, Hogg N (2014) Circulating membrane-derived microvesicles in redox biology. Free radical biology \& medicine 73:214-228. doi:10.1016/j.freeradbiomed.2014.04.017

19. Strulovici-Barel Y, Staudt MR, Krause A, Gordon C, Tilley AE, Harvey BG, Kaner RJ, Hollmann C, Mezey JG, Bitter H, Pillai SG, Hilton H, Wolff G, Stevenson CS, Visvanathan S, Fine JS, Crystal RG (2016) Persistence of circulating endothelial microparticles in COPD despite smoking cessation. Thorax 71 (12):1137-1144. doi:10.1136/thoraxjnl-2015-208274 
20. Lakhter AJ, Sims EK (2015) Minireview: Emerging Roles for Extracellular Vesicles in Diabetes and $\begin{array}{llll}\text { Related Metabolic Disorders. Molecular endocrinology } 29 & \text { (11):1535-1548. }\end{array}$ doi:10.1210/me.2015-1206

21. Ostrowski M, Carmo NB, Krumeich S, Fanget I, Raposo G, Savina A, Moita CF, Schauer K, Hume AN, Freitas RP, Goud B, Benaroch P, Hacohen N, Fukuda M, Desnos C, Seabra MC, Darchen F, Amigorena S, Moita LF, Thery C (2010) Rab27a and Rab27b control different steps of the exosome secretion pathway. Nature cell biology 12 (1):19-30; sup pp 11-13. doi: $10.1038 /$ ncb2000

22. Trajkovic K, Hsu C, Chiantia S, Rajendran L, Wenzel D, Wieland F, Schwille P, Brugger B, Simons M (2008) Ceramide triggers budding of exosome vesicles into multivesicular endosomes. Science 319 (5867):1244-1247. doi:10.1126/science.1153124

23. Kimura T, Niki I (2011) Rab27a in pancreatic beta-cells, a busy protein in membrane trafficking. $\begin{array}{llllll}\text { Progress in biophysics and molecular biology } 107 & \text { (2):223. }\end{array}$ doi:10.1016/j.pbiomolbio.2011.06.016

24. Shamseddine AA, Airola MV, Hannun YA (2015) Roles and regulation of neutral sphingomyelinase-2 in cellular and pathological processes. Advances in biological regulation 57:24-41. doi:10.1016/j.jbior.2014.10.002

25. Winterbourn CC, Hampton MB (2008) Thiol chemistry and specificity in redox signaling. Free radical biology \& medicine 45 (5):549-561. doi:10.1016/j.freeradbiomed.2008.05.004

26. Antelmann H, Helmann JD (2011) Thiol-based redox switches and gene regulation. Antioxidants \& redox signaling 14 (6):1049-1063. doi:10.1089/ars.2010.3400

27. Poole LB (2015) The basics of thiols and cysteines in redox biology and chemistry. Free radical biology \& medicine 80:148-157. doi:10.1016/j.freeradbiomed.2014.11.013

28. Marino SM, Gladyshev VN (2010) Cysteine function governs its conservation and degeneration and restricts its utilization on protein surfaces. Journal of molecular biology 404 (5):902-916. doi:10.1016/j.jmb.2010.09.027

29. Sanders DA (2000) Sulfhydryl involvement in fusion mechanisms. Sub-cellular biochemistry 34:483-514

30. Horinouchi T, Higashi T, Mazaki Y, Miwa S (2016) Carbonyl Compounds in the Gas Phase of Cigarette Mainstream Smoke and Their Pharmacological Properties. Biological \& pharmaceutical bulletin 39 (6):909-914. doi:10.1248/bpb.b16-00025

31. Valavanidis A, Vlachogianni T, Fiotakis K (2009) Tobacco smoke: involvement of reactive oxygen species and stable free radicals in mechanisms of oxidative damage, carcinogenesis and synergistic effects with other respirable particles. International journal of environmental research and public health 6 (2):445-462. doi:10.3390/ijerph6020445

32. Jakober CA, Robert MA, Riddle SG, Destaillats H, Charles MJ, Green PG, Kleeman MJ (2008) Carbonyl emissions from gasoline and diesel motor vehicles. Environmental science \& technology 42 (13):4697-4703

33. Wen X, Wu J, Wang F, Liu B, Huang C, Wei Y (2013) Deconvoluting the role of reactive oxygen species and autophagy in human diseases. Free radical biology \& medicine 65:402-410. doi:10.1016/j.freeradbiomed.2013.07.013

34. Bein K, Leikauf GD (2011) Acrolein - a pulmonary hazard. Molecular nutrition \& food research 55 (9):1342-1360. doi:10.1002/mnfr.201100279

35. Mano J (2012) Reactive carbonyl species: their production from lipid peroxides, action in environmental stress, and the detoxification mechanism. Plant physiology and biochemistry : PPB / Societe francaise de physiologie vegetale 59:90-97. doi:10.1016/j.plaphy.2012.03.010

36. Couto N, Wood J, Barber J (2016) The role of glutathione reductase and related enzymes on cellular redox homoeostasis network. Free radical biology \& medicine 95:27-42. doi:10.1016/j.freeradbiomed.2016.02.028

37. Randall MJ, Hristova M, van der Vliet A (2013) Protein alkylation by the alpha,beta-unsaturated aldehyde acrolein. A reversible mechanism of electrophile signaling? FEBS letters 587 (23):38083814. doi:10.1016/j.febslet.2013.10.006

38. Belkin M, Hardy WG (1961) Relation between Water Permeability and Integrity of Sulfhydryl Groups in Malignant and Normal Cells. The Journal of biophysical and biochemical cytology 9 (4):733-745

39. Scott RE, Perkins RG, Zschunke MA, Hoerl BJ, Maercklein PB (1979) Plasma membrane vesiculation in 3T3 and SV3T3 cells. I. Morphological and biochemical characterization. Journal of cell science 35:229-243

40. Vatsyayan R, Kothari H, Pendurthi UR, Rao LV (2013) 4-Hydroxy-2-nonenal enhances tissue factor activity in human monocytic cells via p38 mitogen-activated protein kinase activation-dependent 
phosphatidylserine exposure. Arteriosclerosis, thrombosis, and vascular biology 33 (7):16011611. doi:10.1161/ATVBAHA.113.300972

41. Benedikter BJ, Volgers C, van Eijck PH, Wouters EF, Savelkoul PH, Reynaert NL, Haenen GR, Rohde GG, Weseler AR, Stassen FR (2017) Cigarette smoke extract induced exosome release is mediated by depletion of exofacial thiols and can be inhibited by thiol-antioxidants. Free radical biology \& medicine. doi:10.1016/j.freeradbiomed.2017.03.026

42. Novelli F, Neri T, Tavanti L, Armani C, Noce C, Falaschi F, Bartoli ML, Martino F, Palla A, Celi A, Paggiaro P (2014) Procoagulant, tissue factor-bearing microparticles in bronchoalveolar lavage of interstitial lung disease patients: an observational study. PloS one 9 (4):e95013. doi:10.1371/journal.pone.0095013

43. Carver KA, Yang D (2016) N-Acetylcysteine Amide Protects Against Oxidative Stress-Induced Microparticle Release From Human Retinal Pigment Epithelial Cells. Investigative ophthalmology \& visual science 57 (2):360-371. doi:10.1167/iovs.15-17117

44. Nolan S, Dixon R, Norman K, Hellewell P, Ridger V (2008) Nitric oxide regulates neutrophil migration through microparticle formation. The American journal of pathology 172 (1):265-273. doi:10.2353/ajpath.2008.070069

45. Ju R, Zhuang ZW, Zhang J, Lanahan AA, Kyriakides T, Sessa WC, Simons M (2014) Angiopoietin-2 secretion by endothelial cell exosomes: regulation by the phosphatidylinositol 3-kinase (PI3K)/Akt/endothelial nitric oxide synthase (eNOS) and syndecan-4/syntenin pathways. The Journal of biological chemistry 289 (1):510-519. doi:10.1074/jbc.M113.506899

46. Szabo-Taylor K, Ryan B, Osteikoetxea X, Szabo TG, Sodar B, Holub M, Nemeth A, Paloczi K, Pallinger E, Winyard P, Buzas EI (2015) Oxidative and other posttranslational modifications in extracellular vesicle biology. Seminars in cell \& developmental biology 40:8-16. doi:10.1016/j.semcdb.2015.02.012

47. Szabo-Taylor KE, Toth EA, Balogh AM, Sodar BW, Kadar L, Paloczi K, Fekete N, Nemeth A, Osteikoetxea X, Vukman KV, Holub M, Pallinger E, Nagy G, Winyard PG, Buzas EI (2017) Monocyte activation drives preservation of membrane thiols by promoting release of oxidised membrane moieties via extracellular vesicles. Free radical biology \& medicine 108:56-65. doi:10.1016/j.freeradbiomed.2017.03.016

48. Reisz JA, Wither MJ, Dzieciatkowska M, Nemkov T, Issaian A, Yoshida T, Dunham AJ, Hill RC, Hansen KC, D'Alessandro A (2016) Oxidative modifications of glyceraldehyde 3-phosphate dehydrogenase regulate metabolic reprogramming of stored red blood cells. Blood 128 (12):e32-42. doi:10.1182/blood-2016-05-714816

49. Binder CJ, Papac-Milicevic N, Witztum JL (2016) Innate sensing of oxidation-specific epitopes in health and disease. Nature reviews Immunology 16 (8):485-497. doi:10.1038/nri.2016.63

50. Li M, Yu D, Williams KJ, Liu ML (2010) Tobacco smoke induces the generation of procoagulant microvesicles from human monocytes/macrophages. Arteriosclerosis, thrombosis, and vascular biology 30 (9):1818-1824. doi:10.1161/ATVBAHA.110.209577

51. Woei AJFJ, De Kruif MD, Garcia Rodriguez P, Osanto S, Bertina RM (2012) Microparticles expressing tissue factor are concurrently released with markers of inflammation and coagulation during human endotoxemia. Journal of thrombosis and haemostasis : JTH 10 (6):1185-1188. doi:10.1111/j.1538-7836.2012.04733.x

52. Furlan-Freguia C, Marchese P, Gruber A, Ruggeri ZM, Ruf W (2011) P2X7 receptor signaling contributes to tissue factor-dependent thrombosis in mice. The Journal of clinical investigation 121 (7):29322944. doi:10.1172/JCI46129

53. Lim KM, Kim S, Noh JY, Kim K, Jang WH, Bae ON, Chung SM, Chung JH (2010) Low-level mercury can enhance procoagulant activity of erythrocytes: a new contributing factor for mercury-related thrombotic disease. Environmental health perspectives 118 (7):928-935. doi:10.1289/ehp.0901473

54. Owens AP, 3rd, Mackman N (2011) Microparticles in hemostasis and thrombosis. Circulation research 108 (10):1284-1297. doi:10.1161/CIRCRESAHA.110.233056

55. Kastelowitz N, Yin H (2014) Exosomes and microvesicles: identification and targeting by particle size and lipid chemical probes. Chembiochem : a European journal of chemical biology 15 (7):923928. doi:10.1002/cbic.201400043

56. Kleinjan A, Boing AN, Sturk A, Nieuwland R (2012) Microparticles in vascular disorders: how tissue factor-exposing vesicles contribute to pathology and physiology. Thrombosis research 130 Suppl 1:S71-73. doi:10.1016/j.thromres.2012.08.281 
57. Ahamed J, Versteeg HH, Kerver M, Chen VM, Mueller BM, Hogg PJ, Ruf W (2006) Disulfide isomerization switches tissue factor from coagulation to cell signaling. Proceedings of the National Academy of Sciences of the United States of America 103 (38):13932-13937. doi:10.1073/pnas.0606411103

58. Bucki R, Bachelot-Loza C, Zachowski A, Giraud F, Sulpice JC (1998) Calcium induces phospholipid redistribution and microvesicle release in human erythrocyte membranes by independent pathways. Biochemistry 37 (44):15383-15391. doi:10.1021/bi9805238

59. Savina A, Furlan M, Vidal M, Colombo MI (2003) Exosome release is regulated by a calcium-dependent mechanism in K562 cells. The Journal of biological chemistry 278 (22):20083-20090. doi:10.1074/jbc.M301642200

60. Zima AV, Blatter LA (2006) Redox regulation of cardiac calcium channels and transporters. Cardiovascular research 71 (2):310-321. doi:10.1016/j.cardiores.2006.02.019

61. Mori Y, Takahashi N, Polat OK, Kurokawa T, Takeda N, Inoue M (2016) Redox-sensitive transient receptor potential channels in oxygen sensing and adaptation. Pflugers Archiv : European journal of physiology 468 (1):85-97. doi:10.1007/s00424-015-1716-2

62. Muralidharan P, Cserne Szappanos H, Ingley E, Hool L (2016) Evidence for redox sensing by a human cardiac calcium channel. Scientific reports 6:19067. doi:10.1038/srep19067

63. Kichko TI, Kobal G, Reeh PW (2015) Cigarette smoke has sensory effects through nicotinic and TRPA1 but not TRPV1 receptors on the isolated mouse trachea and larynx. American journal of $\begin{array}{llll}\text { physiology Lung cellular and molecular physiology } 309 & \text { (8):L812-820. }\end{array}$ doi:10.1152/ajplung.00164.2015

64. Todorovic SM, Jevtovic-Todorovic V (2014) Redox regulation of neuronal voltage-gated calcium channels. Antioxidants \& redox signaling 21 (6):880-891. doi:10.1089/ars.2013.5610

65. Zygmunt PM, Hogestatt ED (2014) Trpa1. Handbook of experimental pharmacology 222:583-630. doi:10.1007/978-3-642-54215-2_23

66. Hinman A, Chuang HH, Bautista DM, Julius D (2006) TRP channel activation by reversible covalent modification. Proceedings of the National Academy of Sciences of the United States of America 103 (51):19564-19568. doi:10.1073/pnas.0609598103

67. Thom SR, Bhopale VM, Hu J, Yang M (2017) Increased carbon dioxide levels stimulate neutrophils to produce microparticles and activate the nucleotide-binding domain-like receptor 3 inflammasome. Free radical biology \& medicine 106:406-416. doi:10.1016/j.freeradbiomed.2017.03.005

68. Beckers CJ, Block MR, Glick BS, Rothman JE, Balch WE (1989) Vesicular transport between the endoplasmic reticulum and the Golgi stack requires the NEM-sensitive fusion protein. Nature 339 (6223):397-398. doi:10.1038/339397a0

69. Fader CM, Sanchez DG, Mestre MB, Colombo MI (2009) TI-VAMP/VAMP7 and VAMP3/cellubrevin: two $\mathrm{v}$-SNARE proteins involved in specific steps of the autophagy/multivesicular body pathways. Biochimica et biophysica acta 1793 (12):1901-1916. doi:10.1016/j.bbamcr.2009.09.011

70. Robinson LJ, Aniento F, Gruenberg J (1997) NSF is required for transport from early to late endosomes. Journal of cell science 110 ( Pt 17):2079-2087

71. Bombardier JP, Munson M (2015) Three steps forward, two steps back: mechanistic insights into the assembly and disassembly of the SNARE complex. Current opinion in chemical biology 29:66-71. doi:10.1016/j.cbpa.2015.10.003

72. Zhao M, Brunger AT (2016) Recent Advances in Deciphering the Structure and Molecular Mechanism of the AAA+ ATPase N-Ethylmaleimide-Sensitive Factor (NSF). Journal of molecular biology 428 (9 Pt B):1912-1926. doi:10.1016/j.jmb.2015.10.026

73. Hyenne V, Apaydin A, Rodriguez D, Spiegelhalter C, Hoff-Yoessle S, Diem M, Tak S, Lefebvre O, Schwab Y, Goetz JG, Labouesse M (2015) RAL-1 controls multivesicular body biogenesis and exosome secretion. The Journal of cell biology 211 (1):27-37. doi:10.1083/jcb.201504136

74. Gross JC, Chaudhary V, Bartscherer K, Boutros M (2012) Active Wnt proteins are secreted on exosomes. Nature cell biology 14 (10):1036-1045. doi:10.1038/ncb2574

75. Parakh S, Atkin JD (2015) Novel roles for protein disulphide isomerase in disease states: a double edged sword? Frontiers in cell and developmental biology 3:30. doi:10.3389/fcell.2015.00030

76. Benham AM (2012) The protein disulfide isomerase family: key players in health and disease. Antioxidants \& redox signaling 16 (8):781-789. doi:10.1089/ars.2011.4439

77. Donoghue N, Yam PT, Jiang XM, Hogg PJ (2000) Presence of closely spaced protein thiols on the surface of mammalian cells. Protein science : a publication of the Protein Society 9 (12):2436-2445. doi: $10.1110 /$ ps.9.12.2436 
78. Booth C, Koch GL (1989) Perturbation of cellular calcium induces secretion of luminal ER proteins. Cell $59(4): 729-737$

79. Raturi A, Miersch S, Hudson JW, Mutus B (2008) Platelet microparticle-associated protein disulfide isomerase promotes platelet aggregation and inactivates insulin. Biochimica et biophysica acta 1778 (12):2790-2796. doi:10.1016/j.bbamem.2008.07.003

80. Mammoto A, Masumoto N, Tahara M, Yoneda M, Nishizaki T, Tasaka K, Miyake A (1997) Involvement of a sperm protein sensitive to sulfhydryl-depleting reagents in mouse sperm-egg fusion. The Journal of experimental zoology 278 (3):178-188

81. Ellerman DA, Myles DG, Primakoff P (2006) A role for sperm surface protein disulfide isomerase activity in gamete fusion: evidence for the participation of ERp57. Developmental cell 10 (6):831-837. doi:10.1016/j.devcel.2006.03.011

82. Anifandis G, Messini C, Dafopoulos K, Sotiriou S, Messinis I (2014) Molecular and cellular mechanisms of sperm-oocyte interactions opinions relative to in vitro fertilization (IVF). International journal of molecular sciences 15 (7):12972-12997. doi:10.3390/ijms150712972

83. Diwaker D, Mishra KP, Ganju L (2013) Potential roles of protein disulphide isomerase in viral infections. Acta virologica 57 (3):293-304

84. Izquierdo-Useros N, Puertas MC, Borras FE, Blanco J, Martinez-Picado J (2011) Exosomes and retroviruses: the chicken or the egg? Cellular microbiology 13 (1):10-17. doi:10.1111/j.14625822.2010.01542.x

85. Barbouche R, Miquelis R, Jones IM, Fenouillet E (2003) Protein-disulfide isomerase-mediated reduction of two disulfide bonds of HIV envelope glycoprotein 120 occurs post-CXCR4 binding and is required for fusion. The Journal of biological chemistry 278 (5):3131-3136. doi:10.1074/jbc.M205467200

86. Markovic I, Stantchev TS, Fields KH, Tiffany LJ, Tomic M, Weiss CD, Broder CC, Strebel K, Clouse KA (2004) Thiol/disulfide exchange is a prerequisite for CXCR4-tropic HIV-1 envelope-mediated Tcell fusion during viral entry. Blood 103 (5):1586-1594. doi:10.1182/blood-2003-05-1390

87. Vargas A, Zhou S, Ethier-Chiasson M, Flipo D, Lafond J, Gilbert C, Barbeau B (2014) Syncytin proteins incorporated in placenta exosomes are important for cell uptake and show variation in abundance in serum exosomes from patients with preeclampsia. FASEB journal : official publication of the Federation of American Societies for Experimental Biology 28 (8):3703-3719. doi:10.1096/fj.13-239053

88. Cheynet V, Ruggieri A, Oriol G, Blond JL, Boson B, Vachot L, Verrier B, Cosset FL, Mallet F (2005) Synthesis, assembly, and processing of the Env ERVWE1/syncytin human endogenous retroviral envelope. Journal of virology 79 (9):5585-5593. doi:10.1128/JVI.79.9.5585-5593.2005

89. Chang QL, Gummadi SN, Menon AK (2004) Chemical modification identifies two populations of glycerophospholipid flippase in rat liver ER. Biochemistry 43 (33):10710-10718. doi:10.1021/bi049063a

90. Moriyama Y, Nelson N (1988) Purification and properties of a vanadate- and N-ethylmaleimide-sensitive ATPase from chromaffin granule membranes. The Journal of biological chemistry 263 (17):85218527

91. Morel O, Jesel L, Freyssinet JM, Toti F (2011) Cellular mechanisms underlying the formation of circulating microparticles. Arteriosclerosis, thrombosis, and vascular biology 31 (1):15-26. doi:10.1161/ATVBAHA.109.200956

92. Wehman AM, Poggioli C, Schweinsberg P, Grant BD, Nance J (2011) The P4-ATPase TAT-5 inhibits the budding of extracellular vesicles in C. elegans embryos. Current biology : CB 21 (23):1951-1959. doi:10.1016/j.cub.2011.10.040

93. Charras GT, Hu CK, Coughlin M, Mitchison TJ (2006) Reassembly of contractile actin cortex in cell blebs. The Journal of cell biology 175 (3):477-490. doi:10.1083/jcb.200602085

94. Dalle-Donne I, Rossi R, Milzani A, Di Simplicio P, Colombo R (2001) The actin cytoskeleton response to oxidants: from small heat shock protein phosphorylation to changes in the redox state of actin itself. Free radical biology \& medicine 31 (12):1624-1632

95. Ingato D, Lee JU, Sim SJ, Kwon YJ (2016) Good things come in small packages: Overcoming challenges to harness extracellular vesicles for therapeutic delivery. Journal of controlled release : official journal of the Controlled Release Society 241:174-185. doi:10.1016/j.jconrel.2016.09.016

96. Pasquet JM, Dachary-Prigent J, Nurden AT (1996) Calcium influx is a determining factor of calpain activation and microparticle formation in platelets. European journal of biochemistry 239 (3):647-654 
97. Dachary-Prigent J, Freyssinet JM, Pasquet JM, Carron JC, Nurden AT (1993) Annexin V as a probe of aminophospholipid exposure and platelet membrane vesiculation: a flow cytometry study showing a role for free sulfhydryl groups. Blood 81 (10):2554-2565

98. Cho YE, Im EJ, Moon PG, Mezey E, Song BJ, Baek MC (2017) Increased liver-specific proteins in circulating extracellular vesicles as potential biomarkers for drug- and alcohol-induced liver injury. PloS one 12 (2):e0172463. doi:10.1371/journal.pone.0172463

99. Shiau JY, Chang YQ, Nakagawa-Goto K, Lee KH, Shyur LF (2017) Phytoagent Deoxyelephantopin and Its Derivative Inhibit Triple Negative Breast Cancer Cell Activity through ROS-Mediated Exosomal Activity and Protein Functions. Frontiers in pharmacology 8:398. doi:10.3389/fphar.2017.00398

100. Volgers C, Benedikter BJ, Grauls GE, Hellebrand PHM, Savelkoul PHM, Stassen FRM (2017) Effects of Nacetyl-L-cysteine on the membrane vesicle release and growth of respiratory pathogens. FEMS microbiology letters 364 (9). doi:10.1093/femsle/fnx087

101. Cazzola M, Calzetta L, Page C, Jardim J, Chuchalin AG, Rogliani P, Matera MG (2015) Influence of Nacetylcysteine on chronic bronchitis or COPD exacerbations: a meta-analysis. European respiratory review : an official journal of the European Respiratory Society 24 (137):451-461. doi:10.1183/16000617.00002215

102. Tse HN, Tseng CZS (2014) Update on the pathological processes, molecular biology, and clinical utility of $\mathrm{N}$-acetylcysteine in chronic obstructive pulmonary disease. International journal of chronic obstructive pulmonary disease 9:825-836. doi:10.2147/Copd.S51057

103. Shen YF, Cai WR, Lei S, Zhang ZH (2014) Effect of High/Low Dose N-Acetylcysteine on Chronic Obstructive Pulmonary Disease: A Systematic Review and Meta-analysis. Copd-Journal of Chronic Obstructive Pulmonary Disease 11 (3):351-358. doi:10.3109/15412555.2013.858315

104. Rushworth GF, Megson IL (2014) Existing and potential therapeutic uses for N-acetylcysteine: the need for conversion to intracellular glutathione for antioxidant benefits. Pharmacology \& therapeutics 141 (2):150-159. doi:10.1016/j.pharmthera.2013.09.006

105. Lasram MM, Dhouib IB, Annabi A, El Fazaa S, Gharbi N (2015) A review on the possible molecular mechanism of action of $\mathrm{N}$-acetylcysteine against insulin resistance and type-2 diabetes $\begin{array}{lllll}\text { development. } & \text { Clinical } & \text { biochemistry } & 48 & \text { (16-17):1200-1208. }\end{array}$ doi:10.1016/j.clinbiochem.2015.04.017

106. Deepmala, Slattery J, Kumar N, Delhey L, Berk M, Dean O, Spielholz C, Frye R (2015) Clinical trials of Nacetylcysteine in psychiatry and neurology: A systematic review. Neuroscience and biobehavioral reviews 55:294-321. doi:10.1016/j.neubiorev.2015.04.015

107. Pawlak R, Chabielska E, Matys T, Kucharewicz I, Rolkowski R, Buczko W (2000) Thiol repletion prevents venous thrombosis in rats by nitric oxide/prostacyclin-dependent mechanism: relation to the antithrombotic action of captopril. Journal of cardiovascular pharmacology 36 (4):503-509

108. Lopez-Pedrera C, Barbarroja N, Jimenez-Gomez Y, Collantes-Estevez E, Aguirre MA, Cuadrado MJ (2016) Oxidative stress in the pathogenesis of atherothrombosis associated with antiphospholipid syndrome and systemic lupus erythematosus: new therapeutic approaches. Rheumatology 55 (12):2096-2108. doi:10.1093/rheumatology/kew054

109. Sapir A, Avinoam 0, Podbilewicz B, Chernomordik LV (2008) Viral and developmental cell fusion mechanisms: conservation and divergence. Developmental cell 14 (1):11-21. doi:10.1016/j.devcel.2007.12.008 

Chapter 10

General discussion and future perspectives 


\section{Scientific context of the dissertation}

Tobacco smoking is the major preventable cause of morbidity and mortality worldwide, accounting for an immense economic loss and approximately $10 \%$ of all deaths $[1,2]$. In spite of various smoking control policies that have been implemented over the past decades, smoking remains highly prevalent and will continue to contribute to the public health burden in the coming decades [3]. The most important contributors to the smoking-associated disease burden are cancer, cardiovascular diseases (CVD) and chronic lung diseases [4]. Extracellular vesicles (EVs) are well accepted to be involved in the pathogeneses of cancer and CVD and have also been proposed to contribute to the development of chronic lung disease [5-7]. To date, it has not been thoroughly investigated how environmental risk factors for these diseases, particularly tobacco smoke, influence EV secretion, composition and function. This thesis explored how EVs are affected by exposure to tobacco smoke and related respiratory exposures, and whether they may contribute to the pathogenesis of smoking-associated diseases.

In chapter 2 we systematically reviewed the literature on how respiratory exposures affect the release, composition and biological functions of EVs. We found that respiratory exposure-induced EVs have been implicated in the modulation of biological processes such as inflammation, hypercoagulability, endothelial dysfunction, tissue remodelling and angiogenesis. By influencing these processes, respiratory exposure-induced EVs may contribute to the development of CVD and COPD, as well as lung cancer and allergic asthma. However, it has to be noted that EV research is a relatively novel and rapidly developing field. Therefore, methodologies for EV isolation and characterization need to be constantly evaluated and improved. Many of the published studies on EVs released in the response to respiratory exposures used outdated isolation techniques that provide EVs with suboptimal purity, such as ultracentrifugation without further purification or even polymer-based precipitation. Moreover, EVs obtained using these techniques were often characterised only by a single method, whereas the current consensus in the EV field is that several complementary techniques should be used when defining EVs and their functions [8]. Therefore, an important aspect of the work presented in this dissertation was to establish up-to-date specific and reliable methods for EV detection and isolation.

\section{EV detection}

One major challenge of EV research has been to develop fast, sensitive and specific 
assays that allow high throughput screening for the quantity of EVs released under different experimental conditions. While classical, light scatter-triggered flow cytometry can be applied for the quantitation of the relatively large microvesicles, this method is not suitable for exosomes which are virtually all smaller than the detection limit of this technique (300 $\mathrm{nm}$ ) [9]. Therefore, nanoparticle tracking analysis (NTA) and tuneable resistive pulse sensing (TRPS) have recently emerged for the quantification of small EVs down to ca. $50 \mathrm{~nm}$ in diameter [10, 11]. However, these techniques do not allow distinguishing between EVs and non-vesicular nanoparticles. Hence, they should only be applied to purified EVs or in combination with other characterisation methods to verify the vesicular nature of the analysed nanoparticles. The currently most specific method for the detection of individual EVs and their quantitation is fluorescence-triggered flow cytometry [12-15]. However, this technique requires laborious sample pre-treatment including EV isolation and staining with a generic EV dye, as well as expert operators. Another technique that can be used for semi-quantitative EV measurements is bead-based flow cytometry. This method was first used by Ostrowski et al. to screen for the effect of an shRNA library on the EV release by cultured cells [16]. In brief, Ostrowski et al. captured EVs from small volumes of cell culture media on beads coated with an antibody against the exosome marker protein CD63. They then stained the bead-bound EVs with either fluorescently labelled annexin V for the phospholipid phosphatidylserine (PS) or fluorescently labelled antibodies against one of the membrane proteins CD81 or MHCII, followed by flow cytometric detection. In chapter 3, we confirmed that bead-based flow cytometry using anti-CD63 beads and anti-CD81 detection allows semi-quantitative measurements of human cell-derived EVs [17]. We also demonstrated that, using appropriate antibodies, the technique can be applied for the detection of membrane vesicles secreted by different bacterial species. Thus, bead-based flow cytometry is currently one of the only options for studying the relative contributions of host cell-derived EVs and bacterial-derived membrane vesicles to the total vesicle population during infection. Throughout the different chapters of this thesis, several adaptations of the bead-based flow cytometry have been applied using various combinations of capture and detection antibodies. For instance, in chapter 4, we applied the technique to determine the EV recovery of different EV isolation protocols. Moreover, in chapter 5, bead-based flow cytometry allowed us to confirm the presence tissue factor (TF) and PS on EVs expressing either one of the exosome marker proteins CD63, CD81 and CD9, and their upregulation when the EV secreting cells were exposed to cigarette smoke. Finally, in chapters 7 and 8, bead-based flow cytometry was applied to screen for the effect 
of several stimuli and inhibitors on the release of $\mathrm{CD}_{3}{ }^{+} \mathrm{CD} 81^{+} \mathrm{EVs}$ by bronchial epithelial cells and other cell types of the lungs. Advantages of the technique include that it is simple to perform, fast, sensitive and scalable as an experienced operator can process up to 150 samples per day. Recently, it has been confirmed by Suarez et al. that bead-based flow cytometry is a suitable method for semi-quantitative EV detection [18]. However, while bead-based flow cytometry provides a very sensitive and specific signal when applied to cell culture media, it is less suitable for detecting EVs in human plasma or isolated from plasma (chapter 6). Incubation of plasma with generic capture beads coated with annexin $\mathrm{V}$ or with antibodies against a combination of EV marker proteins (CD63/CD81/CD9) caused irreversible bead agglutination. Moreover, using annexin $\mathrm{V}$ or the anti-CD63/CD81/CD9 combination for detection resulted in a high unspecific signal. We were able to identify certain combinations of capture beads and detection antibodies that provided a specific signal even for plasma (CD81/CD81, CD81/TF and CD81/EpCAM). Yet, these combinations only detect subsets of EVs and do not provide a comprehensive representation of the total EV population. Therefore, other methods like fluorescence-triggered flow cytometry $[12,14]$ may be more suitable for EV detection in plasma.

\section{EV isolation}

Concerning EV isolation, at the start of this $\mathrm{PhD}$ project in 2013, ultracentrifugation was considered the gold standard. However, in the past years, it has become clear that ultracentrifugation is associated with several disadvantages, including a relatively low yield, formation of EV aggregates due to the high gravitational forces and co-isolation of non-vesicular macromolecular complexes [15, 19, 20]. Technically neat studies therefore further purify ultracentrifugation-isolated EVs by density gradient centrifugations. Yet, gradient centrifugations are time-consuming, labourintensive and subject to inter-operator variations. Moreover, the highly osmolar sucrose gradients have been found to decrease EV functionality [21]. Finally, many functional effects of EVs overlap with those reported for free secreted molecules. Due to a relative lack of side-by-side comparisons, it is currently unclear to what extent the overlapping functions of EVs and free secreted molecules are complementary, redundant or maybe even experimental artefacts. Ultracentrifugation concentrates EVs but leaves the free secreted molecules dilute, making the technique unsuitable for side-by-side comparisons of EVs and the EVfree secretome. In this thesis, we aimed to develop an easy and robust protocol that provides well-matched concentrates of EVs and free secreted molecules from the 
same starting material. A requirement was that the quality of EV isolates should be at least equivalent to that of isolates obtained by ultracentrifugation. In 2014, size exclusion chromatography was proposed as a fast, easy and robust technique for EV isolation from plasma [21]. As most of the research in this thesis was performed using cultured cells rather than plasma, chapter 4 describes how we adapted the SEC protocol for EV isolation from conditioned cell culture media. Because culture media are commonly less concentrated in EVs than plasma, we added a concentration step prior to SEC. We applied ultrafiltration with a $10 \mathrm{kDa}$ molecular weight cut-off to equally concentrate EVs and most free secreted molecules. It has now been shown by Vergauwen et al. that the $10 \mathrm{kDa}$ filters that we used (Amicon Ultracel Centrifugal Filter units from Merck Millipore, made from regenerated cellulose) provide the best EV recovery compared to a range of ultrafiltration devices with different molecular weight cut-off values and membrane materials [22]. Vergauwen et al. and we have both shown that the EV recovery is approximately ${ }_{100} \%$ using these Amicon filters. After the $10 \mathrm{kDa}$ concentration, we separated the EVs from free secreted protein using a sepharose $\mathrm{CL}-4 \mathrm{~B}$ SEC matrix. We then analysed the proteomic composition and functional effects of both, EVs and free protein fractions. We showed that EVs and free protein show a differential enrichment for biological pathways and distinct biological effects. Moreover, the EV fractions showed presence of several EV marker proteins that were absent in the protein fractions. We also performed a side-by-side comparison of ultrafiltration-SEC with the classical ultracentrifugation protocol. In line with two studies by other groups, we show that ultrafiltration-SEC provides EVs with a similar to superior yield and purity as compared to ultracentrifugation $[15,23]$. However, it remains important to note that there was a significant overlap between the proteins identified in either ultracentrifugation-isolated EVs or ultrafiltrationSEC EV fractions and the ultrafiltration-SEC protein fractions, suggesting an imperfect separation of EVs from free secreted molecules for both isolation techniques. Additionally, bovine albumin was the most abundant protein in both ultracentrifugation and ultrafiltration-SEC isolated EVs. This implies that both methods only enrich but do not completely purify EVs. Thus, ultrafiltration-SEC is unlikely to replace density gradient centrifugations as the method of choice for high purity EV isolation. Nevertheless, proteomic characterisation of ultrafiltration-SECisolated EVs can be a useful tool to predict EV functions, provided that appropriate experimental controls are performed to validate that functionally active molecules are indeed EV-associated, rather than co-isolated. This can for instance be done by bead-based flow cytometry using beads coated with a capture antibody against an EV marker protein and a detection antibody against the protein of interest. 


\section{Functional characterisation of cigarette smoke- induced EVs}

In chapter 5, we aimed to predict functions of cigarette smoke-induced EVs by characterizing their proteomic composition. Ultrafiltration-SEC was used to isolate EVs from conditioned media of bronchial epithelial cells that were either unexposed or exposed to a mildly cytotoxic concentration of cigarette smoke extract (CSE). EVassociated proteins were precipitated, followed by labelling with isobaric mass tags and nanoscale liquid chromatography coupled with tandem mass spectrometry (nano LC-MS/MS). The isobaric mass tags allowed us to determine differences in protein expression between control-EVs and CSE-induced EVs. Subsequent functional enrichment analysis of the differentially expressed proteins revealed that several biological pathways were significantly enriched in CSE-induced EVs, most prominently "hemostasis". In total, 29 proteins that contribute to hemostasis were upregulated in the CSE-induced EVs, among which TF, the trigger for the extrinsic pathway of coagulation. Using bead-based flow cytometry, we confirmed that TF in cell culture media as well as in ultrafiltration-SEC isolates was associated with tetraspanin-expressing EVs. Moreover, we confirmed a significant increase in EVbound TF for CSE-induced EVs. CSE-EVs triggered more thrombin generation when added to normal human plasma than control EVs, and this effect was partly TFdependent as it could be inhibited by the TF inhibitor active site inhibited factor VIIa (ASIS). Additionally, we have shown that CSE exposure results in increased PS exposure on the EV surface and PS-dependent thrombin generation. Other groups have previously shown that cigarette smoke and particulate matter from air pollution can induce the release of TF- and PS-enriched EVs by monocytes and endothelial cells [24-26]. Thus, it seems likely that tobacco smoking induces release of pro-coagulant EVs by several cell types of the lung and of the blood vessels. When these CSE-induced pro-coagulant EVs enter the blood circulation, they may contribute to the increased risk for atherothrombotic events in smokers. However, Badrnya et al. only detected a small and non-significant increase in $\mathrm{TF}^{+}$microvesicles in the plasma of young healthy smokers compared to non-smokers by direct flow cytometry [27]. Yet, there may have been a more marked increase in small $\mathrm{TF}^{+} \mathrm{EVs}$ (exosomes) in their study population, which would have been missed by the direct flow cytometry approach. Future research should aim to reproduce the findings of Badrnya et al. and to extend the measurement of $\mathrm{TF}^{+} \mathrm{EVs}$ to the smaller exosomes.

We attempted to address the latter by applying bead-based flow cytometry to assess the circulating EV profile of young healthy smokers 1) before and after 
smoking ( $\mathrm{n}=6)$ and 2) compared to non-smoking controls(n=14 per group, Chapter 6). As discussed above, only the following capture/detection combinations provided a specific signal for human plasma: $C D 81 / C D 81$ for detecting 'total exosome population', CD81/TF for the detecting 'procoagulant exosomes' and CD81/EpCAM for detecting 'epithelial-derived exosomes'. Using these combinations, no significant differences were found in smokers before and after smoking. However, the number of cigarettes smoked per day tended to be positively associated with increased $\mathrm{CD}_{1}{ }^{+} \mathrm{TF}^{+}$EVs. Moreover, $\mathrm{CD}_{1}{ }^{+} \mathrm{EpCAM}^{+} \mathrm{EVs}$ were significantly decreased in male smokers compared to male non-smokers. As CS causes epithelial-to-mesenchymal transition [28], the decrease in $\mathrm{CD}_{1}{ }^{+} \mathrm{EpCAM}^{+}$EVs might reflect an early smokinginduced decrease of epithelial marker expression by lung epithelial cells and, consequently, their EVs. To investigate this, EpCAM expression in lung epithelial cells and lung epithelial-derived EVs should be assessed in response to in vitro exposure to CSE. We also found that $\mathrm{CD}_{1}{ }^{+} \mathrm{EpCAM}^{+} \mathrm{EVs}$ showed a moderate negative correlation with the time required for thrombin generation in our study participants, implying faster thrombin generation for higher $\mathrm{CD}^{+}{ }^{+} \mathrm{EpCAM}^{+} \mathrm{EVs}$. This finding was surprising, considering that $\mathrm{CD} 8{ }^{+}{ }^{+} \mathrm{ECAM}^{+} \mathrm{EVs}$ were decreased in male smokers whereas smoking is known to activate the coagulation cascade [29]. Larger studies with a more thorough profiling of circulating EVs are required to validate this observation and to place it into context. Translational studies in older and more severe smokers may reveal more pronounced effects of smoking on $\mathrm{TF}^{+}$ EVs, especially when using more comprehensive methods for EV detection.

Another possible explanation why neither we nor Badrnya et al. detected significant increases in circulating $\mathrm{TF}^{+} \mathrm{EVs}$ in smokers may be that the majority of smoking-induced $\mathrm{TF}^{+}$EVs remain within the lungs, particularly in young healthy individuals with an intact epithelial-endothelial barrier. We are not aware of any studies that investigated whether smokers have elevated concentrations of $\mathrm{TF}^{+} \mathrm{EVs}$ in their lungs. Yet, for patients with asthma, interstitial lung diseases or acute respiratory distress syndrome, such elevated concentrations have been reported in sputum, bronchoalveolar lavage fluid (BALF) or pulmonary oedema fluid [30-32]. $\mathrm{TF}^{+}$ EVs may contribute to airway remodelling and inflammation by promoting subepithelial angiogenesis, fibrin deposition in alveoli and protease activated receptor (PAR)-dependent pro-inflammatory signalling [31, 33, 34]. These TFmediated processes are of potential relevance to smoking-associated chronic obstructive pulmonary disease (COPD). Therefore, future studies are warranted to examine whether $\mathrm{TF}^{+} \mathrm{EVs}$ are elevated in the lungs of smokers and COPD patients, and whether they actively contribute to the pathogenesis of COPD. 


\section{Mechanisms of EV induction by respiratory exposures and therapeutic modulation}

As we and others have found that CSE-induced airway epithelial-derived EVs exert potentially detrimental biological effects $([35,36]$, chapter 5$)$, it is of relevance to investigate the mechanisms by which CSE influences the release of EVs and whether this can be prevented. In chapter 7 , we have shown that CSE causes a concentration-dependent increase in EV release by BEAS-2B airway epithelial cells which is associated with oxidative stress and oxidation of cell surface-exposed thiols. These effects could be mimicked by the CSE component acrolein, but not by hydrogen peroxide. Moreover, we have shown that depletion of cell surface thiols with membrane impermeable thiol-blocking compounds is sufficient to induce EV release. Intriguingly, other groups have also provided evidence that thiol modifications influence the release and cargo of EVs [37-39]. Finally, and most importantly, thiol-based antioxidants such as the glutathione (GSH) precursor Nacetyl-L-cysteine (NAC) and GSH itself were able to inhibit CSE-induced EV release (chapter 7) at concentrations that can be reached after oral administration of NAC [40]. In chapter 8, we extended these findings by showing that also the CSEdependent induction of $\mathrm{TF}^{+}$-EVs can be prevented by NAC. Moreover, others have shown that NAC and structurally related antioxidants can prevent $\left(\mathrm{TF}^{+}\right) \mathrm{EV}$ induction by other oxidative stimuli as we highlighted in chapter 9 [30, 37, 41].

Airway epithelial cells are not the only cells within the lungs to come in contact with inhaled cigarette smoke. Moreover, even individuals who do not smoke are exposed to respiratory irritants from occupational or environmental sources, such as silica particles or particulate matter (PM) from air pollution. In chapter 8, we therefore investigated whether EV induction is a universal response to respiratory exposures, for different cell types and different respiratory irritants. We showed that airway epithelial cells and lung fibroblasts, but not monocyte-derived macrophages or pulmonary microvascular endothelial cells respond to CSE by releasing $\mathrm{CD}_{3}{ }^{+} \mathrm{CD}^{+} 1^{+}$and $\mathrm{TF}^{+} \mathrm{EVs}$, whereas cell surface thiols are decreased in all cell types. This implies that the EV induction by thiol-depletion is likely a cell type-specific mechanism. We also found that both silica particles and particulate matter (PM) from air pollution induce $\mathrm{CD}_{3}{ }^{+} \mathrm{CD}_{1}{ }^{+}$and $\mathrm{TF}^{+} \mathrm{EV}$ release by BEAS-2B bronchial epithelial cells. Yet, only relatively larger PM $\left(\mathrm{PM}_{10}\right)$, but not fine PM $\left(\mathrm{PM}_{2.5}\right)$ or silica nanoparticles resulted in cell surface thiol depletion. In line with this NAC tended to decrease EV induction by $\mathrm{PM}_{10}(\mathrm{p}=0.09)$, whereas it did not influence EV induction by $\mathrm{PM}_{2.5}$ or silica. Thus, while induction of pro-coagulant EVs appears to be a 
universal response to respiratory exposures, this is not necessarily triggered by depletion of cell surface thiols. Other factors, such as mechanical stimulation by nanoparticles, may also be involved.

Finally, in chapter 9, we reviewed a number of proteins with redox sensitive protein thiols that regulate membrane rearrangements. These include redox-regulated calcium channels, N-ethylmaleimide sensitive factor (NSF), oxidoreductases of the protein disulphide isomerase (PDI) family, fusion proteins, phospholipid flippases, and cytoskeletal actin filaments. We propose that such proteins may be crucially involved in the regulation of $\mathrm{EV}$ formation and uptake and give an overview over the literature supporting this hypothesis. Numerous studies have shown that thiolreactive compounds including reactive oxygen and carbonyl species trigger increased EV release by various cell types. There is experimental evidence that this is mediated by mechanisms such thiol-dependent inactivation of flippase and actin filaments, resulting in membrane blebbing, and by modifications of cell surface-exposed thiols that may be mediated by PDI. Importantly, these thiol modifications appear to regulate EV formation upon cell exposure not only to thiol-reactive compounds, but also to pro-inflammatory stimuli that do not directly react with thiols. Moreover, thiol group-bearing small molecules such as NAC, that scavenge thiol-reactive compounds, can prevent EV modifications by pro-oxidant as well as proinflammatory conditions. The prevention of EV modifications by NAC and its biologically active metabolite GSH is particularly relevant because NAC is currently used as a mucolytic in COPD patients. Recent meta-analyses have demonstrated that oral administration of NAC at a dose of $1200 \mathrm{mg} /$ day is safe. Moreover, it is efficient in reducing exacerbation frequency and improving small airway function in this target group [42-44]. Intriguingly, there is also early stage evidence that oral administration of NAC exerts anti-thrombotic effects in individuals with an elevated cardiovascular risk, by decreasing platelet activation and improving endothelial function (reviewed in [45]). Future studies should investigate whether inhibition of CSE-dependent EV induction mechanistically contributes to the therapeutic benefit of NAC in COPD patients, and to potential benefits in smokers and individuals at high cardiovascular risk. Protection of cellular thiols using NAC may be a promising strategy for preventing pathological changes in EV signalling not only upon respiratory exposure to cigarette smoke or air pollution but also in various diseases that are hallmarked by inflammation and oxidative stress. 


\section{Conclusions}

In this thesis we investigated the effect of cigarette smoke and related respiratory exposures on the release of EVs by pulmonary cells. We first focused on optimizing methods for the quantification, isolation and characterisation of EVs from cultured cells. For instance, we established bead-based flow cytometry as a simple, fast and high throughput method for semi-quantitative EV detection and for confirming the EV association of molecules with biological functions. Moreover, we have established UF-SEC as a robust, efficient and easy-to-use method for EV isolation that also provides well-matched free secreted factors for comparative compositional and functional studies. We then applied these methods to demonstrate an enrichment of CSE-induced EVs from airway epithelial cells in pro-coagulant factors, including TF. As we found that CSE-EVs exert a strong and potentially harmful procoagulant activity, we further investigated the mechanism by which CSE modulates EV release in order to develop a strategy for preventing CSE-dependent EV modifications. We demonstrated that the EV induction by CSE depends on oxidative thiol modifications at the cellular level and that antioxidants, such as NAC and GSH, protect against the EV induction by CSE. Oral or respiratory administration of NAC may prevent the induction of EVs by cigarette smoke in vivo, which may contribute to the beneficial effects that NAC exerts in COPD patients and that have also been suggested for CVD. Finally, we have shown that lung fibroblasts, but not monocytederived macrophages or endothelial cells also respond to CSE-exposure by secreting $\mathrm{TF}^{+}$EVs and that respiratory exposures other than CSE, namely silica particles and PM, have similar effects. If CSE-induced pro-coagulant EVs from the lungs enter the blood circulation, they may contribute to the increased cardiovascular risk in smokers. Additionally, $\mathrm{TF}^{+}$EVs may contribute to the pathogenesis of pulmonary diseases, by promoting intrapulmonary fibrin deposition, inflammation and profibrotic changes. Translational studies are required to elucidate the importance of CSE-induced EVs in these processes.

\section{Future perspectives}

The studies in this dissertation were almost entirely based on in vitro experiments performed with undifferentiated cell monocultures. Therefore, the physiological relevance of our findings needs to be validated in more complex experimental systems and translational studies.

Airway epithelial cells cultured in monolayers do not reflect the true complexity of the pseudostratified airway epithelium with its polarity and specialised 
cellular subtypes. Primary human bronchial epithelial cells (PBECs) could be differentiated in a transwell system and experiments performed at the air-liquid interface. One advantage of this system is that cells could be exposed to gaseous cigarette smoke rather than CSE, which resembles the human exposure more closely. Moreover, differentiated cells can be maintained over longer periods of time, which allows testing the effect of repetitive and chronic rather than acute exposure as was done in this thesis. Finally, epithelial and endothelial cells could be co-cultured in transwell systems to test whether procoagulant EVs are increased on the 'vascular side' of the epithelial-endothelial barrier upon exposure to CS.

Another possibility to investigate whether cigarette smoke or PM-induced EVs contribute to the development of pulmonary and cardiovascular diseases could be the use of animal models. Cigarette smoke exposure of mice that are genetically susceptible for the development of atherosclerosis have been used as a combined model for the smoking-induced pathogenesis of COPD and atherosclerosis [46, 47]. These include apolipoprotein $\mathrm{E}$ deficient $\left(\mathrm{ApoE}^{-/}\right)$and low density lipoprotein receptor deficient $\left(\operatorname{LDLR}^{-/}\right)$mice. Such genetically susceptible mice could be intratracheally instilled with isolated EVs from CSE-exposed cells or control cells. Lung function could be monitored over time and lungs harvested at several time points for assessment of emphysema formation and tissue remodelling. Moreover, systemic and pulmonary inflammation, as well as formation of atherosclerotic lesions could be assessed.

Another important focus for future research is translating our in vitro findings to human cohorts. Concentrations of total and $\mathrm{TF}^{+}$-EVs could be studied in BALF and plasma of smokers and non-smokers as well as in COPD patients with and without cardiovascular comorbidity compared to non-COPD controls. Before doing so, efforts should be made to improve detection methods for small $(<250 \mathrm{~nm})$ and low abundant EVs in the complex and highly concentrated plasma EV pool. It could be attempted to enhance the sensitivity and specificity of the bead-based flow cytometry for plasma samples. Alternatively, small EVs could be detected by fluorescence-triggered flow cytometry. With the appropriate choice of dyes, this technique should allow detecting the total plasma EV population as well as subsets expressing specific marker proteins or molecules with known biological functions such (e.g. TF and PS). Platelet-derived EVs are the most abundant EVs in plasma [48] and may obscure the detection of EVs from other cellular sources simply by outnumbering them. (Immuno-) affinity based methods could be developed for the depletion of platelet-derived EVs from plasma. Such a negative selection of 
confounding EVs is anticipated to improve the detection of less abundant EVs by bead-based as well as fluorescence-triggered flow cytometry.

Finally, it remains to be noted that the most efficient strategy to fight smoking-associated disease morbidity and mortality should and likely will be the continued implementation of novel smoking control policies. While smoking incidence and the smoking-associated disease burden should therefore decrease on the long term, other respiratory exposures, particularly outdoor air pollution, are of increasing concern [49] and their health implications need to be thoroughly investigated. While cigarette smoking is an active lifestyle decision, exposure to outdoor pollution is passive and vulnerable groups, such as pregnant women, children and patients with asthma or diabetes cannot avoid being exposed. Therefore, future research should also focus on extending the finding of this dissertation that $\mathrm{PM}$ induces the release of $\mathrm{TF}^{+} \mathrm{EV}$ s from bronchial epithelial cells. The functions of PM-induced EVs should be studied in vitro and, possibly in animal models as suggested for CSE-induced EVs above. Moreover, it should be assessed whether at-risk populations show elevated concentrations of circulating $\mathrm{TF}^{+}$-EVs at times of high air pollution. Identifying strategies for preventing PM-induced EV modifications could be a first step towards preventing detrimental effects of PM exposure.

Taken together, we have shown that lung cells respond to respiratory exposures by releasing increased concentrations of EVs, which likely exert functions in cell communication, immunity and, most evidently, hemostasis. NAC can prevent the EV induction by CSE. Our results should enable new developments in the understanding and therapy of respiratory exposure-associated diseases. 


\section{References}

1. Mol, E.A., et al., Higher functionality of extracellular vesicles isolated using size-exclusion chromatography compared to ultracentrifugation. Nanomedicine, 2017. 13(6): p. 2061-2065.

2. Goodchild, M., N. Nargis, and E. Tursan d'Espaignet, Global economic cost of smokingattributable diseases. Tob Control, 2017.

3. Organization, W.H., WHO report on the global tobacco epidemic 2011. 2011, Geneva: World Health Organization.

4. GBD 2015 Tobacco Collaborators. Smoking prevalence and attributable disease burden in 195 countries and territories, 1990-2015: a systematic analysis from the Global Burden of Disease Study 2015. Lancet, 2017. 389(10082): p. 1885-1906.

5. Minciacchi, V.R., M.R. Freeman, and D. Di Vizio, Extracellular vesicles in cancer: exosomes, microvesicles and the emerging role of large oncosomes. Semin Cell Dev Biol, 2015. 4o: p. 41-51.

6. Loyer, X., et al., Microvesicles as cell-cell messengers in cardiovascular diseases. Circ Res, 2014. 114(2): p. 345-53.

7. Fujita, Y., et al., Extracellular vesicles in lung microenvironment and pathogenesis. Trends Mol Med, 2015. 21(9): p. 533-42.

8. Lotvall, J., et al., Minimal experimental requirements for definition of extracellular vesicles and their functions: a position statement from the International Society for Extracellular Vesicles. J Extracell Vesicles, 2014. 3: p. 26913.

9. van der Pol, E., et al., Optical and non-optical methods for detection and characterization of microparticles and exosomes. J Thromb Haemost, 2010. 8(12): p. 2596-6o7.

10. Gardiner, C., et al., Extracellular vesicle sizing and enumeration by nanoparticle tracking analysis. J Extracell Vesicles, 2013. 2.

11. Coumans, F.A., et al., Reproducible extracellular vesicle size and concentration determination with tunable resistive pulse sensing. J Extracell Vesicles, 2014. 3: p. 25922.

12. van der Vlist, E.J., et al., Fluorescent labeling of nano-sized vesicles released by cells and subsequent quantitative and qualitative analysis by high-resolution flow cytometry. Nat Protoc, 2012. 7(7): p. 1311-26.

13. Nolte-'t Hoen, E.N., et al., Quantitative and qualitative flow cytometric analysis of nanosized cell-derived membrane vesicles. Nanomedicine, 2012. 8(5): p. 712-20.

14. Arraud, N., et al., Fluorescence triggering: A general strategy for enumerating and phenotyping extracellular vesicles by flow cytometry. Cytometry A, 2016. 89(2): p. 184-95.

15. Nordin, J.Z., et al., Ultrafiltration with size-exclusion liquid chromatography for high yield isolation of extracellular vesicles preserving intact biophysical and functional properties. Nanomedicine, 2015. 11(4): p. 879-83.

16. Ostrowski, M., et al., Rab27a and Rab27b control different steps of the exosome secretion pathway. Nat Cell Biol, 2010. 12(1): p. 19-30; sup pp 1-13.

17. Volgers, C., et al., Bead-based flow-cytometry for semi-quantitative analysis of complex membrane vesicle populations released by bacteria and host cells. Microbiol Res, 2017. 200: p. 2532.

18. Suarez, H., et al., A bead-assisted flow cytometry method for the semi-quantitative analysis of Extracellular Vesicles. Sci Rep, 2017. 7(1): p. 11271.

19. Webber, J. and A. Clayton, How pure are your vesicles? J Extracell Vesicles, 2013. 2.

20. Linares, R., et al., High-speed centrifugation induces aggregation of extracellular vesicles. J Extracell Vesicles, 2015. 4: p. 29509.

21. Boing, A.N., et al., Single-step isolation of extracellular vesicles by size-exclusion chromatography. J Extracell Vesicles, 2014. 3.

22. Vergauwen, G., et al., Confounding factors of ultrafiltration and protein analysis in extracellular vesicle research. Sci Rep, 2017. 7(1): p. 2704.

23. Mol, E.A., et al., Higher functionality of extracellular vesicles isolated using size-exclusion chromatography compared to ultracentrifugation. Nanomedicine, 2017. 
24. Li, M., et al., Tobacco smoke induces the generation of procoagulant microvesicles from human monocytes/macrophages. Arterioscler Thromb Vasc Biol, 2010. 3o(9): p. 1818-24.

25. Cordazzo, C., et al., Rapid shedding of proinflammatory microparticles by human mononuclear cells exposed to cigarette smoke is dependent on Ca2+ mobilization. Inflamm Res, 2014. 63(7): p. 539-47.

26. Neri, T., et al., Particulate matter induces prothrombotic microparticle shedding by human mononuclear and endothelial cells. Toxicol In Vitro, 2016. 32: p. 333-8.

27. Badrnya, S., R. Baumgartner, and A. Assinger, Smoking alters circulating plasma microvesicle pattern and microRNA signatures. Thromb Haemost, 2014. 112(1): p. 128-36.

28. Eurlings, I.M., et al., Cigarette smoke extract induces a phenotypic shift in epithelial cells; involvement of HIFialpha in mesenchymal transition. PLoS One, 2014. 9(10): p. e107757.

29. Csordas, A. and D. Bernhard, The biology behind the atherothrombotic effects of cigarette smoke. Nat Rev Cardiol, 2013. 10(4): p. 219-30.

30. Novelli, F., et al., Procoagulant, tissue factor-bearing microparticles in bronchoalveolar lavage of interstitial lung disease patients: an observational study. PLoS One, 2014. 9(4): p. e95013.

31. Park, J.A., et al., Tissue factor-bearing exosome secretion from human mechanically stimulated bronchial epithelial cells in vitro and in vivo. J Allergy Clin Immunol, 2012. 130(6): p. 1375-83.

32. Bastarache, J.A., et al., Procoagulant alveolar microparticles in the lungs of patients with acute respiratory distress syndrome. Am J Physiol Lung Cell Mol Physiol, 2009. 297(6): p. L1035-41.

33. van der Poll, T., Tissue factor as an initiator of coagulation and inflammation in the lung. Crit Care, 2008. 12 Suppl 6: p. S3.

34. Jose, R.J., A.E. Williams, and R.C. Chambers, Proteinase-activated receptors in fibroproliferative lung disease. Thorax, 2014. 69(2): p. 190-2.

35. Moon, H.G., et al., CCNi secretion and cleavage regulate the lung epithelial cell functions after cigarette smoke. Am J Physiol Lung Cell Mol Physiol, 2014. 307(4): p. L326-37.

36. Fujita, Y., et al., Suppression of autophagy by extracellular vesicles promotes myofibroblast differentiation in COPD pathogenesis. J Extracell Vesicles, 2015. 4: p. 28388.

37. Furlan-Freguia, C., et al., $\mathrm{P}_{2} X_{7}$ receptor signaling contributes to tissue factor-dependent thrombosis in mice. J Clin Invest, 2011. 121(7): p. 2932-44.

38. Szabo-Taylor, K.E., et al., Monocyte activation drives preservation of membrane thiols by promoting release of oxidised membrane moieties via extracellular vesicles. Free Radic Biol Med, 2017. 108: p. 56-65.

39. Thom, S.R., et al., Increased carbon dioxide levels stimulate neutrophils to produce microparticles and activate the nucleotide-binding domain-like receptor 3 inflammasome. Free Radic Biol Med, 2017. 106: p. 406-416.

40. Meyer, A., R. Buhl, and H. Magnussen, The effect of oral N-acetylcysteine on lung glutathione levels in idiopathic pulmonary fibrosis. Eur Respir J, 1994. 7(3): p. 431-6.

41. Carver, K.A. and D. Yang, N-Acetylcysteine Amide Protects Against Oxidative Stress-Induced Microparticle Release From Human Retinal Pigment Epithelial Cells. Invest Ophthalmol Vis Sci, 2016. 57(2): p. 360-71.

42. Cazzola, M., et al., Influence of N-acetylcysteine on chronic bronchitis or COPD exacerbations: a meta-analysis. Eur Respir Rev, 2015. 24(137): p. 451-61.

43. Tse, H.N. and C.Z. Tseng, Update on the pathological processes, molecular biology, and clinical utility of $\mathrm{N}$-acetylcysteine in chronic obstructive pulmonary disease. Int J Chron Obstruct Pulmon Dis, 2014. 9: p. 825-36.

44. Shen, Y., et al., Effect of high/low dose $N$-acetylcysteine on chronic obstructive pulmonary disease: a systematic review and meta-analysis. COPD, 2014. 11(3): p. 351-8.

45. Rushworth, G.F. and I.L. Megson, Existing and potential therapeutic uses for N-acetylcysteine: the need for conversion to intracellular glutathione for antioxidant benefits. Pharmacol Ther, 2014. 141(2): p. 150-9.

46. Lo Sasso, G., et al., The Apoe(-/-) mouse model: a suitable model to study cardiovascular and respiratory diseases in the context of cigarette smoke exposure and harm reduction. J Transl Med, 2016. 14(1): p. 146. 
47. Khedoe, P.P., et al., Murine models of cardiovascular comorbidity in chronic obstructive pulmonary disease. Am J Physiol Lung Cell Mol Physiol, 2016. 310(11): p. L1o11-27.

48. Berckmans, R.J., et al., Cell-derived microparticles circulate in healthy humans and support low grade thrombin generation. Thromb Haemost, 2001. 85(4): p. 639-46.

49. de Koning A and Nieuwenhuis M. Bijna 17o longartsen slaan alarm: mensen ziek door vuile lucht. 2017 [cited 2017 12/14/2017]; Available from: https://www.ad.nl/binnenland/bijna-170longartsen-slaan-alarm-mensen-ziek-door-vuile-lucht a afeerfe/. 

Addendum 


\section{I - Abbreviations}

ABB

ADAM

AEC

$\mathrm{AF}_{4} 88$

AFF-1

AFM

AMD

AnxV

ARDS

ASIS

ATP

AU

$\mathrm{B}(\mathrm{a}) \mathrm{P}$

BALF

BCA

BEC

BSA

CAT

CD

CFU

CI

$\mathrm{CO}$

$\mathrm{CO}_{2}$

COPD

cryo-TEM

CS

CSE

CVD

Cys

DAMP

DMSO

DNA

DTNB

DTT

EDTA

EFF-1

ELISA

EM annexin binding buffer

a disintegrin and metalloproteinase

airway epithelial cells

alexa fluor 488 dye

anchor cell fusion failure 1

alexa fluor 488-labelled maleimide

age-related macular degeneration

annexin $\mathrm{V}$

acute respiratory distress syndrome

active site inhibited factor VII

adenosine triphosphate

arbitrary units

benzo(a)pyrene

bronchoalveolar lavage fluid

bicichoninic acid

bronchial epithelial cells

bovine serum albumin

calibrated automated thrombogram

cluster of differentiation

colony forming units

confidence interval

carbon monoxide

carbon dioxide

chronic obstructive pulmonary disease

cryo transmission electron microscopy

cigarette smoke

cigarette smoke extract

cardiovascular disease

Cysteine

danger associated molecular pattern

dimethylsulfoxide

desoxyribonucleic acid

5,5'-dithiobis-(2-nitrobenzoic acid

1,4-dithiothreitol

ethylenediaminetetraacetic acid

epithelial fusion failure 1

enzyme-linked immunosorbent assay

electron microscopy mass spectrometry 


\begin{tabular}{|c|c|}
\hline EpCAM & epithelial cell adhesion molecule \\
\hline ER & endoplasmic reticulum \\
\hline Erp57 & Protein disulphide-isomerase $\mathrm{A}_{3}$ \\
\hline ESCRT & endosomal complex required for transport \\
\hline ESR & electron spin resonance \\
\hline ETP & endogenous thrombin potential \\
\hline EV & extracellular vesicles \\
\hline FC & flow cytometry \\
\hline FCS & foetal calf serum \\
\hline GAPDH & glyceraldehyde 3-phosphate dehydrogenase \\
\hline GO & gene ontology \\
\hline grp94 & glucose regulated protein 94/heat shock protein 9okDa beta member 1 \\
\hline GSH & glutathione \\
\hline GSSG & glutathione disulphide \\
\hline $\mathrm{H}_{2} \mathrm{O}_{2}$ & hydrogen peroxide \\
\hline HCAEC & human coronary artery endothelial cells \\
\hline HDL & high density lipoprotein \\
\hline HEPES & 4-(2-hydroxyethyl)-1-piperazineethanesulfonic acid \\
\hline HMGB1 & high mobility group box 1 \\
\hline HNE & 4-hydroxy-2-nonenal \\
\hline HPLC & high performance liquid chromatography \\
\hline HPMEC & human pulmonary microvascular endothelial cells \\
\hline HRP & horseradish peroxidase \\
\hline $\mathrm{HSP}_{70}$ & 70 kilo Dalton heat shock protein \\
\hline HUVEC & human umbilical vein endothelial cells \\
\hline ICAM-1 & intercellular adhesion molecule 1 \\
\hline IL & interleukin \\
\hline ILV & intraluminal vesicles \\
\hline iNOS & inducible nitric oxide synthase \\
\hline $\mathrm{IP}_{3}$ & inositol-1,3,5-triphosphate \\
\hline IQR & interquartile range \\
\hline LPS & lipopolysaccharide \\
\hline $\mathrm{MCP} 1$ & monocyte chemotactic protein 1 \\
\hline MES & 2-(N-morpholino)ethanesulfonic acid \\
\hline MFGE8 & milk fat globule-EGF factor 8 protein/lactadherin \\
\hline MFI & median fluorescence intensity \\
\hline MION & magnetic iron oxide nanoparticles \\
\hline MMP & matrix metalloproteinase \\
\hline MPG & N-(2-Mercaptopropionyl)glycine \\
\hline Mrc & Moraxella catarrhalis \\
\hline
\end{tabular}


MS

MTT

MV

MVB

MVE

MWCO

NAC

NACA

$\mathrm{NaCl}$

nano LC-MS/MS

NLF

NNK

NO

$\mathrm{NP}-40$

NS

NSF

NTA

OVA

PAR

PBS

PC

PDCD6IP

PDI

PE

PE

PI

PM

PM10

PM2.5

PPP

PRDXI

PS

Psa

PSM

RCS

RFU

RNA

RNS

ROS

RPE mass spectrometry

thiazolyl blue tetrazolium bromide

membrane vesicles

multivesicular body

multivesicular endosome

molecular weight cut-off

$\mathrm{N}$-acetyl-L-cysteine

$\mathrm{N}$-acetyl-L-cysteine amide

sodium chloride

nanoscale liquid chromatography followed by tandem mass spectrometry

nasal lavage fluid

Nitrosamine 4-(Methylnitrosamino)-1-(3-pyridyl)-1- butanone

nitric oxide

nonyl phenoxypolyethoxylethanol

non-smokers

$\mathrm{N}$-ethylmaleimide sensitive factor

nanoparticle tracking analysis

ovalbumin

protease activated receptor

phosphate buffered saline

phosphatidylcholine

programmed cell death 6-interacting protein

protein disulphide isomerase

phycoerythrin

phophatidylethanolamine

propidium iodide

particulate matter

particulate matter with an aerodynamic diameter smaller than $10 \mu \mathrm{m}$

particulate matter with an aerodynamic diameter smaller than $2.5 \mu \mathrm{m}$

platelet poor plasma

peroxiredoxin 1

phosphatidylserine

Pseudomonas aeruginosa

peptide spectral matches

reactive carbonyl species

relative fluorescent units

ribonucleic acid

reactive nitrogen species

reactive oxygen species

retinal pigment epithelium 


\begin{tabular}{|c|c|}
\hline RPMI medium & Rosewell Park Memorial Institute medium \\
\hline RyR & ryanodine receptor \\
\hline S & smokers \\
\hline SDS-PAGE & sodium dodecyl sulphate polyacrylamide gel electrophoresis \\
\hline SEC & size exclusion chromatography \\
\hline SEM & standard error of the mean \\
\hline SERCA & Sarco-/endoplasmic reticulum $\mathrm{Ca}^{2+}$-ATPase \\
\hline SNAP & soluble NSF attachment protein \\
\hline SNARE & soluble NSF attachment protein receptor \\
\hline SOCS & suppressor of cytokine signalling \\
\hline t1 & time point 1 , baseline \\
\hline t2 & time point 2 , post-exposure \\
\hline TBS & Tris buffered saline \\
\hline TCA & trichloroacetic acid \\
\hline TCEP & tris(2-carboxyethyl)phosphine \\
\hline TEAB & triethylammonium bicarbonate \\
\hline TEM & transmission electron microscopy \\
\hline $\mathrm{TF}$ & tissue factor \\
\hline TMT & tandem mass tag \\
\hline $\mathrm{TNF}-\alpha$ & tumour necrosis factor $\alpha$ \\
\hline TRPA1 & transient receptor potential A 1 \\
\hline TRPS & tuneable resistive pulse sensing \\
\hline TSG101 & tumour suppressor gene 101 \\
\hline t-SNARE & target membrane-associated SNARE \\
\hline ttPeak & time to peak \\
\hline UC & ultracentrifugation \\
\hline UCM & unconditioned cell culture medium \\
\hline UC-wash & ultracentrifugation including a PBS wash step \\
\hline UF & ultrafiltration \\
\hline UF-SEC & ultrafiltration followed by size exclusion chromatography \\
\hline UV & ultraviolet \\
\hline $\mathrm{VAMP}_{7}$ & vesicle-associated membrane protein 7 \\
\hline VEGF & vascular endothelial growth factor \\
\hline v-SNARE & vesicle-associated SNARE \\
\hline WCL & whole cell lysate \\
\hline
\end{tabular}




\section{II - Summary}

Tobacco smoking is highly prevalent and predisposes to developing various chronic diseases, including cardiovascular disease (CVD), chronic obstructive pulmonary disease (COPD) and cancer. It thereby accounts for $10 \%$ of all deaths worldwide. Other respiratory exposures such as occupational and environmental air pollutants also predispose to chronic disease and may act via the same biological processes as tobacco smoke. When tobacco smoke or air pollutants are inhaled, they interact with several cell types of the lung, most prominently the epithelial cells that cover the surface of the lungs. Exposure of lung cells to respiratory toxicants results in cell stress and pro-inflammatory activation. It is well established that cell stress influences the release of extracellular vesicles (EVs). These EVs are secreted membrane vesicles that carry various proteins and RNA derived from their secreting cell. Via this complex cargo, they act as mediators of cell-to-cell signalling and exert functions in the extracellular space. It is thought that EVs are involved in the pathogenesis of both, CVD and COPD. However, it is poorly investigated whether EVs could constitute a mechanistic link between environmental exposures and the elevated risk for chronic disease. In this thesis, we explored how EV release and composition are influenced by exposure to cigarette smoke and related respiratory exposures, and whether EVs may contribute to the pathogenesis of smokingassociated diseases.

In chapter 2 an overview is given of the literature on how respiratory exposures affect the release, composition and biological functions of EVs. The PubMed and Google Scholar search engines were used to systematically search for publications in which effects of tobacco smoke, particulate matter or other air pollutants on EVs were assessed. Fifty original research articles were identified, most of which investigated the effect of respiratory exposures on EV release in vitro or on circulating EVs in human plasma. Respiratory exposure-induced EVs were found to modulate biological processes such as inflammation, hypercoagulability, endothelial dysfunction, tissue remodelling and angiogenesis. By influencing these processes, respiratory-exposure induced EVs may contribute to the development of CVD and COPD, as well as lung cancer and allergic asthma. However, many of the identified studies based their main observations on relatively unspecific and partly outdated methods for EV detection, isolation and characterisation.

Therefore, an important aspect of the work presented in this dissertation was to establish up-to-date, specific and reliable methods for EV detection and isolation. In chapter 3, we provided a protocol for bead-based flow cytometry that 
allows semi-quantitative detection of bacterial as well as human cell derived EVs. This method is easy to perform and allows rapidly comparing the quantity of EVs in a relatively large number of samples. In chapter 4, we then compared two protocols for EV isolation from cell culture media; the classical ultracentrifugation and the more recently described combination of ultrafiltration with size exclusion chromatography (UF-SEC). We showed that UF-SEC isolates EVs with a similar to superior yield and purity compared to ultracentrifugation. Importantly, we also demonstrated that UF-SEC provides well-matched EVs and free secreted molecules from the same starting material for comparative compositional and functional studies.

In the following chapters of this dissertation, we applied the methods described in chapters 3 and 4 to study how cigarette smoke and related respiratory exposures influence the quantity, composition and functions of EVs released by bronchial epithelial cells and other lung cells. In chapter 5, we used UF-SEC to isolate EVs from bronchial epithelial cells that were either unexposed or stimulated with cigarette smoke extract (CSE). We compared the proteomic composition of control EVs and CSE-induced EVs by Mass Spectrometry. Bioinformatics analysis of the identified EV proteome revealed that CSE-induced EVs are enriched in proteins of the biological pathway hemostasis compared to control EVs. This included tissue factor (TF), the initiator of the extrinsic pathway of coagulation. Several in vitro assays were performed to assess the pro-coagulant effects of the CSE-induced EVs. Using these assays, we confirmed that CSE-induced EVs are more procoagulant than control EVs. We established that this was attributable to increased EV-associated TF and phosphatidylserine. Based on these findings, we propose that smoking-induced EVs may contribute to the increased cardiovascular risk in smokers by promoting intravascular coagulation and consequent thrombus formation. Additionally, procoagulant EVs may contribute to pulmonary inflammation and remodelling.

In chapter 6, we aimed to translate the findings of chapter 5 to the human situation. We first validated bead-based flow cytometry for EV detection in human plasma. Only some combinations of capture beads and detection antibodies provided a specific signal, namely CD81/CD81, CD81/TF and CD81/EpCAM. No significant differences in these EV subtypes were found in healthy smokers before and after smoking. Yet, in baseline samples, $\mathrm{CD}^{+}{ }^{+} \mathrm{TF}^{+} \mathrm{EVs}$ tended to be positively associated with the number of cigarettes smoked per day. However, the concentration of these EVs was not correlated to thrombin generation. We suggest that more clear-cut effects of smoking on circulating EVs and EV-dependent thrombin generation may be observed in translational studies with older and more 
severe smokers, especially when using more comprehensive methods for EV detection.

After showing that CSE-induced EVs are potentially detrimental, we next studied the biochemical mechanism by which CSE modulates EV release. It was also tested whether the effects of CSE can be counteracted by antioxidants (chapter 7). The quantity of EVs released by CSE-stimulated bronchial epithelial cells increased in a time and concentration-dependent manner. Moreover, the EV induction by CSE was associated with a decrease of cell surface thiols and that could be prevented by the thiol-based antioxidants glutathione and N-acetyl-L-cysteine (NAC). Finally, the thiol-reactive CSE component acrolein and two membrane impermeable thiol blockers, but not the reactive oxygen species hydrogen peroxide, were able to induce EV release. We conclude that thiol-reactive compounds likely mediate the EV induction by CSE via depletion of cell surface exposed thiol groups. We also suggest that inhibition of EV induction may mechanistically contribute to the clinical benefit of NAC in COPD patients.

In chapter 8 we investigated whether modulation of EV release is a common effect of respiratory exposures in different pulmonary cell types and for different types of respiratory toxicants. We demonstrated that pulmonary fibroblasts respond to CSE by releasing more EVs and more EV-associated TF. Furthermore, EV induction in pulmonary fibroblasts was associated with a decrease in cell surface thiols and reversible by NAC, similar to the observations reported for bronchial epithelial cells in earlier chapters. In contrast, CSE had no clear effect on EV release and EV-associated TF in monocyte-derived macrophages or pulmonary microvascular endothelial cells. In summary, only some cell types responded to CSE by releasing procoagulant EVs. We also tested the effect of silica nanoparticles and particulate matter from outdoor air pollution on EV release by bronchial epithelial cells. Both, silica and particulate matter enhanced the release of total and TFexpressing EVs. Only for larger particulate matter $\left(\mathrm{PM}_{10}\right)$, but not for small particulate matter $\left(\mathrm{PM}_{2.5}\right)$ or silica, the induction was associated with depletion of cell surface thiols and tended to be reversible by addition of NAC. This implies that a thiol-dependent biochemical mechanism underlies EV induction by CSE and $\mathrm{PM}_{10}$, and that $\mathrm{PM}_{2.5}$ and silica particles induce EVs via a different mechanism.

Thiols are present on the side chain of the amino acid cysteine and act as crucial regulators of three-dimensional protein structure as well as protein function, as they can exist either in a free form (-SH), or link protein domains via disulphide bonds (-S-S-). Free thiols are highly susceptible to electrophilic attacks by reactive oxygen, nitrogen and carbonyl species and their oxidation alters protein function. In 
chapter 9, we discussed several proteins that are regulated by redox sensitive thiols and that in turn regulate membrane fusion and membrane blebbing, including calcium channels, phospholipid flippases, retractive actin filaments, Nethylmaleimide sensitive factor and protein disulphide isomerase. These molecules may be targeted by thiol-reactive components of CSE and mechanistically explain why depletion of cell surface thiols results in increased EV release. Literature is discussed showing that other thiol-reactive stimuli besides CSE induce EV release by various cell types and that EV induction by some non-oxidative stimuli is mediated by secondary thiol modifications.

Taken together, this thesis provides protocols for the detection and isolation of cell culture-derived EVs. It demonstrates that CSE and other respiratory toxicants enhance the quantity and alter the composition of EVs released by bronchial epithelial cells and pulmonary fibroblasts, resulting in a procoagulant EV phenotype. The CSE-dependent EV modifications are dependent on thiol-reactive CSE components and can be prevented by the thiol antioxidant NAC. Translational studies are now warranted to determine whether these in vitro findings are involved in the aetiology of respiratory exposure-associated diseases in vivo. 


\section{III - Samenvatting}

Het roken van tabak verhoogt het risico voor een groot aantal chronische ziekten, waaronder hart- en vaatziekten (CVD), chronisch obstructieve longziekte (COPD) en kanker. Hierdoor veroorzaakt roken meer dan $10 \%$ van alle sterfgevallen wereldwijd. Ondanks een steeds strenger rookbeleid blijven veel mensen roken, en zal roken in de komende decennia blijven bijdragen aan de totale ziektelast en ziektekosten. Naast roken verhogen ook andere respiratoire blootstellingen het risico voor chronische ziekten, bijvoorbeeld werk- en omgevings-gerelateerde luchtvervuiling. Wanneer sigarettenrook of andere schadelijke stoffen ingeademd worden, komen zij in contact met verschillende longcellen, waaronder de longepitheelcellen, die de gehele oppervlakte van de long bedekken. Wanneer longcellen aan schadelijke stoffen blootgesteld worden, leidt dit tot cellulaire stress en ontstekings-gerelateerde activatie van de cellen. Blootstelling aan stimuli die celstress veroorzaken beïnvloedt de uitscheiding van zogenaamde "extracellulaire vesikels” (EV's). Deze EV's zijn membraanblaasjes, die verschillende eiwitten en RNA-moleculen bevatten, die van hun moedercel afkomstig zijn. Door hun veelzijdige lading fungeren EV's als mediatoren van intercellulaire communicatie en oefenen ze ook functies in de tussencelruimte uit. EV's zijn waarschijnlijk betrokken bij de pathogenese van zowel CVD als ook COPD. Tot op heden is echter niet bekend of EV's een mechanistische verbinding vormen tussen respiratoire blootstellingen en het verhoogde risico voor chronische ziekten. In dit proefschrift werd onderzocht hoe EV's beïnvloedt worden door sigarettenrook en vergelijkbare blootstellingen, en of zij mogelijk bijdragen aan het ontstaan van ziekten die met roken geassocieerd zijn.

Hoofdstuk 2 is een overzichtsartikel over hoe respiratoire blootstellingen de uitscheiding, samenstelling en biologische functies van EV's beïnvloeden. Er is gebruik gemaakt van de Pubmed en Google Scholar zoekmachines om systematisch naar artikelen te zoeken waarin het effect van sigarettenrook, fijnstof of andere luchtvervuilers op EV's is onderzocht. De meeste van de vijftig geïdentificeerde artikelen onderzochten het effect van respiratoire blootstellingen op de productie van EV's in vitro, of op circulerende EV's in humaan plasma. EV's, die als reactie op respiratoire blootstellingen uitgescheiden worden, beïnvloeden biologische processen zoals ontsteking, trombofilie, endotheel dysfunctie, weefselveranderingen en angiogenese. Hierdoor zouden de EV's kunnen bijdragen aan het ontstaan van CVD, COPD, en mogelijk ook longkanker en astma. Echter verkregen vele van de 
onderzochte studies hun bevindingen met behulp van relatief aspecifieke en gedeeltelijk verouderde methodes voor de detectie, isolatie en karakterisering van EV's.

Daarom was een belangrijk onderdeel van het werk in dit proefschrift het opzetten van actuele, specifieke en betrouwbare methodes voor de detectie en isolatie van EV's. In hoofdstuk 3 is een protocol beschreven voor een beadgebaseerde flow cytometrie methode voor de detectie van bacteriële en humane EV's. Deze methode is makkelijk uit te voeren en maakt het mogelijk om snel de hoeveelheid EV's in een groot aantal monsters te vergelijken. Hoofdstuk 4 bevat een vergelijking van twee protocollen voor de opzuivering van EV's uit geconditioneerde celkweekmedia, namelijk de klassieke ultracentrifugatie en de recenter beschreven ultrafiltratie met size exclusionchromatografie (UF-SEC). In dit hoofdstuk toonden we aan dat EV's met behulp van UF-SEC met een vergelijkbare tot betere opbrengst en zuiverheid geïsoleerd kunnen worden dan met behulp van ultracentrifugatie. Tevens lieten we zien dat we door middel van UF-SEC gepaarde concentraten van EV's en het EV-vrije secretoom kunnen verkrijgen, om hun samenstelling en functies met elkaar te vergelijken.

In hoofdstuk $\mathbf{5}$ werd UF-SEC toegepast om EV's van bronchiale epitheelcellen te isoleren, die onder controle-omstandigheden gekweekt werden of blootgesteld werden aan sigarettenrookextract (CSE). De eiwit-samenstelling van controle-EV's en CSE-EV's werd vervolgens met behulp van massaspectrometrie vergeleken. Bioinformatische analyse van het EV-proteoom liet zien dat CSE-EV's verrijkt zijn met eiwitten uit de biologische pathway 'hemostase'. Een van deze eiwitten is tissue factor (TF), de initiator van het extrinsieke bloedstollingsketen. Verschillende in vitro methodes werden gebruikt om te laten zien dat CSE-EV's sterker procoagulant zijn dan controle-EVs, en dat dit toe te schrijven is aan EVgebonden TF en phosphatidylserine. Gebaseerd op deze bevindingen kan worden gesteld dat EV's mogelijk bijdragen aan het verhoogde cardiovasculaire risico in rokers door intravasculaire bloedstolling te bevorderen. Tevens dragen procoagulante EV's mogelijk bij aan ontsteking en weefselverandering in de long.

In hoofdstuk 6 werd gepoogd, de bevindingen van hoofdstuk 5 naar de mens te vertalen. In eerste instantie werd de bead-gebaseerde flow cytometrie voor detectie van EV's in humaan plasma gevalideerd. Alleen bepaalde combinaties van capture beads en detectie-antilichamen gaven een specifiek signaal, namelijk CD81/CD81, CD81/TF en CD81/EpCAM. Met deze detectiemethodes waren er geen significante verschillen in rokers voor en na het roken, maar was er wel een positief verband tussen het aantal sigaretten per dag en de concentratie van $\mathrm{CD}_{1}{ }^{+} \mathrm{TF}^{+}$EV's 
in baseline monsters $(\mathrm{p}=0.07)$. Geen verband werd er echter gevonden tussen $\mathrm{CD}_{1}{ }^{+} \mathrm{TF}^{+} \mathrm{EV}^{\prime}$ s en trombine vorming. Het dient nader onderzocht te worden of in oudere en hevigere rokers duidelijkere effecten op circulerende EV's te zien zijn, vooral in verband met een uitgebreidere karakterisering van EV's.

Aangezien rook-geïnduceerde EV's mogelijk schadelijke biologische functies kunnen uitoefenen, bestudeerden we in hoofdstuk $\mathbf{7}$ het biochemisch mechanisme waardoor CSE de uitscheiding van EV's door longepitheelcellen beïnvloedt. Hiervoor bepaalden we met behulp van bead-gebaseerde flow cytometrie het effect van verschillende cel-behandelingen op de hoeveelheid EV's in de celkweekmedia. We toonden aan dat blootstelling van longepitheelcellen aan CSE leidt tot een tijd- en concentratieafhankelijke verhoging van de EV-uitscheiding. Tevens was de EVinductie geassocieerd met een afname van thiol-groepen aan het celoppervlak, en kon worden voorkomen door de thiol-gebaseerde antioxidant N-acetyl-L-cysteine (NAC). We lieten zien dat zowel acroleïne, een thiol-reactief bestanddeel van CSE, alsook twee membraan-impermeabele thiol-blokkers EV uitscheiding kunnen induceren. De reactieve zuurstofverbinding waterstofperoxide daarentegen had geen effect op de vrijstelling van EV's. Deze bevindingen suggereren dat thiol-reactieve stoffen de EV inductie door CSE veroorzaken door thiol-groepen aan het celoppervlak uit te putten. Het werd gehypothetiseerd dat de klinische werking van NAC in COPD patiënten mogelijk gedeeltelijk berust op het remmen van de EV inductie.

In hoofdstuk 8 onderzochten we of modulatie van de EV-uitscheiding een algemeen effect van respiratoire blootstellingen is. Hiervoor werden verschillende longceltypes blootgesteld aan diverse stoffen, die de luchtwegen irriteren. Longfibroblasten reageerden op CSE door meer EV's en meer EV-gebonden TF vrij te zetten, zoals in eerdere hoofdstukken voor longepitheelcellen beschreven. Verder was de EV-inductie in longfibroblasten geassocieerd is met een afname van thiolgroepen aan het celoppervlak en kon worden voorkomen door NAC. Daarentegen had CSE geen duidelijk effect op de uitscheiding van EV's en EV-gebonden TF door macrofagen en microvasculaire endotheelcellen uit de long. Samengevat reageerden alleen bepaalde celtypes door uitscheiding van procoagulante EV's op CSE. We testten ook het effect van silica-deeltjes en fijnstof op de uitscheiding van EV's door longepitheelcellen. Zowel silica alsook fijnstof veroorzaakten een toename in de uitscheiding van totale en TF-positieve EV's. Alleen voor het grove fijnstof $\left(\mathrm{PM}_{10}\right)$, maar niet voor het fijne fijnstof $\left(\mathrm{PM}_{2.5}\right)$ of silica-deeltjes was de EV-inductie geassocieerd met een gedeeltelijke afname van thiol-groepen aan het celoppervlak en gedeeltelijk te voorkomen door toevoeging van NAC. Dit suggereert dat een thiol- 
afhankelijk mechanisme verantwoordelijk is voor de EV-inductie door CSE en gedeeltelijk verantwoordelijk voor de EV-inductie door $\mathrm{PM}_{10}$. $\mathrm{PM}_{2.5}$ en silica-deeltjes daarentegen lijken EV's via een ander mechanisme te induceren.

Thiol-groepen zijn aanwezig op de zijketen van het aminozuur cysteine. Zij fungeren als belangrijke regelaars van de driedimensionale eiwitstructuur en eiwitfunctie, doordat zij in een vrije vorm (-SH) of als disulfide bruggen (-S-S-) voorkomen. Vrije thiol-groepen zijn zeer vatbaar voor electrofiele aanvallen door reactieve zuurstof-, stikstof- of carbonylverbindingen. Hoofdstuk 9 geeft een overzicht over verschillende eiwitten, die gereguleerd worden door redox-gevoelige thiol-groepen, onder andere calcium kanalen, phospholipid flippases, actine vezels, $\mathrm{N}$-ethylmaleimide sensitive factor en protein disulfide isomerase. Deze moleculen kunnen doelwit zijn van veranderingen door thiol-reactieve stoffen in CSE en dus als mechanistische verbinding fungeren tussen de depletie van thiol-groepen en de inductie van EV's. Tevens wordt de literatuur besproken, die laat zien dat naast CSE ook andere thiol-reactieve stimuli de EV-uitscheiding door verschillende celtypes verhogen. Ook lijkt de EV-inductie door sommige niet-oxidatieve stimuli afhankelijk van secundaire thiol-veranderingen.

Samenvattend bevat dit proefschrift een aantal protocollen voor de detectie en isolatie van celkweek-afkomstige EV's. Tevens werd aangetoond dat CSE en andere respiratoire blootstellingen leiden tot een toename in de hoeveelheid EV's en een verandering in de samenstelling van EV's die afkomstig zijn van longepitheelcellen en longfibroblasten. Dit leidt tot een procoagulant EV fenotype. De door CSE veroorzaakte veranderingen kunnen worden voorkomen door NAC. Als volgende stap zijn translationele studies nodig om te bepalen of onze in vitro bevindingen een rol spelen in de pathogenese van chronische ziekten die geassocieerd zijn met respiratoire blootstellingen. 


\section{IV - Valorisation}

"The important thing is not to stop questioning. Curiosity has its own reason for existing. One cannot help but be in awe when he contemplates the mysteries of eternity, of life, of the marvelous structure of reality. It is enough if one tries merely to comprehend a little of this mystery every day."

Albert Einstein

Knowledge utilisation is the process of making knowledge valuable by making it suitable for social or economic use and for translation into competitive products, services, processes and new commercial activities (definition based on the National Valorisation Committee 2011). Over the past decades, such practical applicability of research has increasingly become a prerequisite for obtaining government funding in the Netherlands and elsewhere. Yet, when asked why they spend their unpaid evenings and weekends performing experiments, analysing data and writing papers, few fundamental researchers will reply: "Because I am trying to save the world." or "Because my research will give a real boost to the Dutch economy." I, for one, might reply: "Because cells produce extracellular vesicles, and I really want to understand why."

I believe that the intrinsic curiosity that drives many fundamental researchers is what allowed mankind to develop into the modern society that we are. An example of a purely curiosity-driven finding is the discovery of the hyperthermophilic bacterium Thermus aquaticus that lives in hot springs in the Yellowstone National Park [1]. While this beautiful finding showed that life is possible under circumstances (i.e. at temperatures) that were previously thought incompatible with life, no one at the time would have anticipated that the thermoresistant DNA polymerase of Thermus aquaticus would form the basis for one of the most important biotechnological inventions of the late $20^{\text {th }}$ century, the polymerase chain reaction (PCR). PCR is now one of the most used laboratory techniques in molecular biology research and has substantially improved and accelerated the diagnostic process for several diseases, including viral and bacterial infections.

Obviously, it is unlikely that the research presented in this dissertation, or most other fundamental studies, will have a similar impact on science, healthcare and society as the discovery of Thermus aquaticus. However, to quote Thomas Levenson of the Massachusetts Institute of Technology, "Science is a set of ways of 
thinking and acting through which, sometimes, results emerge. Failure, "wasted" time, is intrinsic to that process. It's impossible to do science without a tolerance for uncertainty over the years or decades it can take to reveal what many discoveries actually mean." [2] Moreover, "Science as a body of knowledge is powerful, valuable, essential to human well-being. Science as a human process is wasteful, necessarily and even more, usefully — so." [2] The major and, in my opinion, most relevant societal gain of the studies in this dissertation is that they make a contribution to the body of human knowledge (however little it may be).

\section{Societal and economic relevance}

On a less philosophical and more practical note, this thesis describes a number of fundamental studies investigating extracellular vesicles (EVs) as a novel mechanistic link between exposure to respiratory toxicants such as cigarette smoke and the development of respiratory exposure-associated chronic diseases. Despite extensive efforts to control smoking prevalence, smoking currently causes $10 \%$ of all deaths worldwide $[3,4]$. It is projected to continue making an important contribution to the public health burden in the coming decades, in terms of productivity losses, health expenditures and mortality [3, 5]. Additionally, respiratory exposure to air pollutants, especially in urbanised areas, is also an important public health concern [6]. Smoking and exposure to high levels of air pollution are both associated with increased risks for developing cardiovascular disease, chronic lung disease and cancer $[4,6]$. Improved understanding of how respiratory exposures cause these diseases is highly relevant, as it forms the first step for developing novel preventive and therapeutic strategies. In this thesis, we have found that cultured lung cells exposed to cigarette smoke release procoagulant EVs which may contribute to the increased cardiovascular risk in smokers, and which may even be involved in lung pathogenesis. While we did not find any significant changes in circulating procoagulant EVs between young healthy smokers and non-smokers, only a subgroup of smokers may respond to respiratory exposures with elevated concentrations of circulating procoagulant EVs. In that case, these EVs could be used as a noninvasive biomarker of risk to identify those individuals that are susceptible to developing chronic disease in response to respiratory toxicants. We have also shown that the clinically tested antioxidant NAC and its active metabolic product glutathione can prevent the release of procoagulant EVs in cells exposed to smoke. Although these are very early stage in vitro findings, they provide a rationale for testing the efficacy of NAC to prevent cardiovascular adverse events in individuals with a history of exposure to respiratory toxicants, such as COPD patients. 


\section{Target groups}

At the current stage, the findings of this research project are mainly relevant to the scientific community, which may use them as the basis for additional fundamental and clinical studies. As suggested in the general discussion of this dissertation (chapter 9) and in the previous section, future research could focus on determining whether circulating EVs can serve as biomarkers of exposure to respiratory toxicants and/or for the risk of developing disease. For this purpose, sensitive, specific and fast methods for the detection of procoagulant EVs in plasma should be developed. Moreover, it could be tested whether NAC can benefit additional target groups besides the subgroup of COPD patients who currently receive NAC for its mucolytic activity. These intermediate steps are required before the findings described in this thesis can be used by the pharmaceutical industry as a basis to develop novel EV based screening tests or before NAC may be implemented in additional target groups in the clinic.

\section{Products and innovation}

An important aspect of the work presented in this dissertation was the development of two techniques; one for reliable detection of EVs and EV subtypes in cell culture media, and one for isolation of EVs from cell culture media. While we are not the first ones to use these techniques, and no commercial benefit arises from publishing our protocols, making the protocols publicly available is a valuable contribution to the scientific community. While EVs attract increasing attention and interest from the biomedical research community, only relatively few large and specialised research groups have the expertise, funding and equipment to perform EV isolation and characterisation at the highest quality level. Unfortunately, applying these highest quality techniques as a standard for daily use in smaller or less specialised laboratories seems almost impossible. To prevent a large number of low quality studies being performed with suboptimal EV isolation techniques, such as commercial precipitation kits, techniques need to be developed that are costeffective, easy and fast to perform. These techniques should also be reliable in terms of specificity for EV detection and in terms of yield and purity for EV isolation. We think that these prerequisites are met by the bead-based flow cytometry that we describe for $\mathrm{EV}$ detection and the ultrafiltration with size exclusion chromatography that we describe for EV isolation. Therefore, the publication of these protocols should be a valuable contribution to the $\mathrm{EV}$ research community. 


\section{Personal development of the candidate and contributions to the scientific community}

This $\mathrm{PhD}$ project has been the result of a proposal written by the $\mathrm{PhD}$ candidate. During the proposal writing, as well as during the $\mathrm{PhD}$ project itself, the candidate learned a lot about planning, performing and writing about scientific research. Furthermore, the candidate has attended several specialised courses and gained teaching experience as a tutor for Bachelor and Master students. The research was performed with a supervision team from two departments at Maastricht University, Medical Microbiology and Respiratory Medicine. Moreover, a lot of the work was done in close collaboration with researchers from the departments of Toxicology and Pharmacology, Toxicogenomics, Human Biology, and Biochemistry. Thereby, this project has brought together experts from different fields of biomedical research and has resulted in an intensive exchange of knowledge and in shared use of specialised equipment. This group effort was largely initiated by the $\mathrm{PhD}$ candidate and has resulted in two original research papers in international peer-reviewed journals with the $\mathrm{PhD}$ candidate as first author, as well as four publications with the $\mathrm{PhD}$ candidate as second author. Two review articles have also been published with the $\mathrm{PhD}$ candidate as first author, providing other researchers with an overview of the candidate's field of expertise. Moreover, several additional manuscripts are currently submitted or in preparation for publication, in order to make the findings originating from this $\mathrm{PhD}$ project broadly available to the scientific community. Parts of the work presented in this thesis have also been presented as posters and oral presentations at several conferences, including the annual meetings of the International Society for Extracellular Vesicles and of the European Respiratory Society.

\section{Conclusion}

The major value of the work presented in this dissertation is its contribution to the scientific body of knowledge. We have initiated novel collaborations between researchers from different departments and different fields of expertise. Moreover, we have published protocols that may be of value to the EV research community and have provided evidence that respiratory exposures induce the release of procoagulant EVs, which may contribute to chronic disease risk. These findings may form the basis for additional fundamental and clinical research and may eventually lead to the development of novel screening tests and/or strategies for disease prevention and management. 


\section{References}

1. Brock, T.D. and H. Freeze, Thermus aquaticus gen. n. and sp. n., a nonsporulating extreme thermophile. J Bacteriol, 1969. 98(1): p. 289-97.

2. Levenson, T. Let's waste more money on science. 2016 accessed on 16 november 2017]; Available from: $\quad$ http://www.bostonglobe.com/ideas/2016/12/11/let-waste-more-moneyscience/afvbusk8G5T5IcrgldkmJJ/story.html?s_campaign=bostonglobe\%3Asocialflow\% ${ }_{3}$ Atwitte r\&utm_content=bufferc78f6\&utm_medium=social\&utm_source=twitter.com\&utm_campaign=b uffer.

3. Organization, W.H., WHO report on the global tobacco epidemic 2011. 2011, Geneva: World Health Organization.

4. GBD 2015 Tobacco Collaborators. Smoking prevalence and attributable disease burden in 195 countries and territories, 1990-2015: a systematic analysis from the Global Burden of Disease Study 2015. Lancet, 2017. 389(10082): p. 1885-1906.

5. Goodchild, M., N. Nargis, and E. Tursan d'Espaignet, Global economic cost of smokingattributable diseases. Tob Control, 2017.

6. Kelly, F.J. and J.C. Fussell, Air pollution and public health: emerging hazards and improved understanding of risk. Environ Geochem Health, 2015. 37(4): p. 631-49. 


\section{V - Acknowledgements}

This dissertation would not have been possible without the people who have supported and encouraged me throughout the past four and half years, who have supervised and directed me, who have been productive collaborators and who made my time in Maastricht worthwhile and very memorable.

First of all, I would like to thank my co-supervisor Frank Stassen. Frank, I still remember when I first sat in your office applying for a senior internship. After more than half an hour of discussing the project that you had in mind, you asked that one fateful question: "Or is there anything else you are interested in?" Thank you for providing an inspiring environment and for giving me the opportunity then and later to bring in my ideas and shape my personal research interests. Without your openness and support, especially for the NUTRIM grant application, this project would never have happened or turned out the way it did. To my second cosupervisor, Gernot Rohde, thank you for your enthusiasm and support throughout the years.

To my two supervisors Prof. Miel Wouters and Prof. Paul Savelkoul, thank you for your support, particularly during the final phase of my PhD project. I would especially like to thank you for giving me extra time to complete the unfinished ends of my $\mathrm{PhD}$ project and for supporting my ambition to follow a career in academic research after the PhD. I hope we have a fruitful collaboration ahead of us.

To my paranymphs: Carla, you are not only a great friend but you've also been an unofficial mentor to me concerning all aspects of PhD life: experimental design, lab work, data analysis, writing and all the practical and administrative things. I've always appreciated your input and opinion. Gert, thank you for being a great teacher and a wonderful colleague. Working with you was a pleasure and many things (like aliquoting and analysing 360 plasma samples within less than a week) would not have been possible without you. Most of all, thank you for your moral support whenever I felt stressed or discouraged.

To my colleagues over the years and the MMB lunch party: Fahad, Erik, Gert, Christel, Marie-Louise, John, Petra, Amita, Fleur, Anne, Danyta, Charlotte, Carla, Chris, Mayk, Kevin, Gianluca, Brian, Liene, Niels, Melissa, Pascalle, Laura, Nader, Abdullah, Casper and all others - thank you for the positive work environment and for the good time during work, the breaks, the vrijdagmiddagborrels and during shared projects like the Sinterklaas surprises, AIO 
onderwijs, filming of PhD movies and so on. In particular, Charlotte, my EV buddy, thank you for the good time we had setting up methods and travelling around the Netherlands, Europe and the world for EV courses and conferences! And, of course, for all the fun we had with Gesiele and Carla. Pascalle, you have been a tremendous help during the last year of my PhD. Thanks to you, I have been able to complete many more experiments with much less stress and I am very grateful for that. Without you, my thesis would have been at least one chapter shorter. I am sure you and Nader will keep the lab running! My roomie Kevin, thank you for listening to me complain whenever I got stressed out and for (almost) always being able to cheer me up. I hope I was able to return the favour every once in a while. Mayk, it was a lot of fun being ortho(?)nymphs. Thank you for your support with all the little lab stuff, and of course with all kinds of graphical designs. Gianluca, thanks for the entertainment, the good food, a beautiful heatmap and for always being happy to help. John, Brian and you were great data analysis advisors.

The ladies from the secretary's office - Angèle, Manon, Fia and Anja thank you for the administrative support and for patiently answering all questions. Wil and Nancy, thank you for your support with the orders and other financial matters. Ans and Radouan, thank you for helping around the lab always with some friendly words and with a smile.

To those who were directly involved in my research: Jos and Miriam, thank you for guiding my first baby steps in the lab, and in research more generally. Antje, thank you for the nice collaboration, many productive discussions, and the fun at various EV meetings. I would also like to thank Marie-José and Guido for the GSH and GSSG measurements and redox-related input. Edwin and Freek, thank you for your help with the Mass Spectrometry, especially Freek for always being available and for working in such a highly efficient manner. Tanja, Alexandra and Rory, I'm glad we found each other via labhelp. Working with you was fun and very productive. Thanks to Niki, Frits, Miriam and the rest of the ICE-age study team for making your samples and database available to me and for supporting me with the data analysis, even though the ICE-age data unfortunately didn't make it into my thesis. Mieke, thank you for sharing the PBECs and COSMO samples for pilot experiments. Theo and Jacco, thank you for your support with the particulate matter experiments. I would also like to thank Carmen and Hans for helping with the electron microscopy and Henri, Rene, Diane and Stefanie for a productive collaboration on the coagulation experiments. Gesiele, thank you for filling our lab with sunshine, positive energy and a perfect dose of Brazilian craziness! 
I would also like to thank all the participants of the smoker study for sharing their blood with me.

Irene and Shirley Longshore, thank you for last minute language advice.

Cori, without you I would never have considered going into sciences. Thank you for opening my eyes to that direction! I would also like to thank my other 'old' friends who were happy to see me whenever I suddenly showed up after months of silence, especially Isa, Dani, Sarah, Simon and Sonja.

Monika, Nicola, Núria, Joe, Dennie, Grace, Tim, Wendy, Ivo, Núria, Kostas, Renata, Xin and Harry: To the scientists among you, thank you for many inspiring conversations that have kept me involved in research outside of my own niche. To all of you, thank you for making Maastricht my second home and for filling the place with wonderful memories. Monika, I want to thank you especially, because you were there for me from my first week in Maastricht until the last day of the PhD. Núria Wasabi, your untiring motivation and enthusiasm have been and will continue to be a great inspiration to me, both personally and professionally.

Meiner Familie - Opa und Else, Margit, Bene, Niels und Mathis möchte ich danken für die Unterstützung in allen Phasen meiner persönlichen und beruflichen Entwicklung. Thank you for raising me in an environment where science - from sterile cooking techniques to homemade fireworks - was part of everyday life and where every discussion had to be won with carefully chosen arguments. Looking back, I realise that I probably owe a large part of my scientific thinking and argumentation skills, as well as my assertiveness, to you.

Frannie, Loes, Ton and Truus, thank you for welcoming me into your family.

Thijs, thank you for being there for me all the way. Thank you for your patience whenever work seemed more important than spending time with you and for your encouragement when I could no longer see how to work it all out. Most of all, thank you for making me take my mind off of work and have fun even during the busiest times. 


\section{VI - Curriculum Vitae}

Birke Benedikter was born on June 29th, 1989 in Springe, Germany. In 2008, she obtained her secondary school degree (Abitur) at the Remstal-Gymnasium Weinstadt in Germany. She then performed her Bachelor studies as a binational codiplomation at the Universities of Luxembourg (Luxembourg) and Liège (Belgium). In 2011, she obtained the Bachelor of Science in Biological Sciences from both universities with a specialisation in Biochemistry and Molecular Cell Biology. She then continued her studies at Maastricht University (The Netherlands), following a two years research-oriented Master program in Biomedical Sciences and specialised in Clinical Molecular Science. During this Master program, she performed two traineeships at Maastricht University, one at the department of Molecular Cell Biology and one at the departments of Medical Microbiology and Respiratory Medicine. During the latter internship, she first started working with extracellular vesicles. After completing her Master's degree cum laude, Birke received a personal NUTRIM NWO graduate programme grant for which she was selected based on a written research proposal and a proposal defence. With this grant, she continued as a PhD student at the departments of Medical Microbiology and Respiratory Medicine. From September 2013 to December 2017 she worked in this function and performed the studies presented in this dissertation. Since February 2018, Birke works for the BBF Sterilisationsservice GmbH in Kernen, Germany, a company that is specialised in packaging, sterilisation and (micro-) biological safety testing of medical products. At the company's microbiology department, she performs tasks such as biological safety assessments for medical devices and establishment of novel test systems. 


\section{VII - List of publications}

Ultrafiltration combined with size exclusion chromatography efficiently isolates extracellular vesicles from cell culture media for compositional and functional studies

Benedikter BJ, Bouwman FG, Vajen T, Grauls G, Mariman EC, Wouters EFM, Savelkoul PHM, Lopez-Iglesias C, Koenen RR, Rohde GGU, Stassen FRM

Sci Rep. 2017 Nov 10;7(1):15297. doi: 10.1038/s41598-017-15717-7.

Cigarette smoke extract induced exosome release is mediated by depletion of exofacial thiols and can be inhibited by thiol-antioxidants

Benedikter BJ, Volgers C, van Eijck PH, Wouters EFM, Savelkoul PHM, Reynaert NL, Haenen GRMM, Rohde GGU, Weseler AR, Stassen FRM.

Free Radic Biol Med. 2017 Jul;108:334-344. doi: 10.1016/j.freeradbiomed.2017.03.026. Epub 2017 Mar 28.

Redox-dependent thiol modifications: implications for the release of extracellular vesicles Benedikter BJ, Weseler AR, Wouters EFM, Savelkoul PHM, Rohde GGU, Stassen FRM Cell Mol Life Sci. 2018 Mar 28. doi: 10.1007/sooo18-018-2806-z. [Epub ahead of print].

Extracellular vesicles released in the response to respiratory exposures: implications for chronic disease

Benedikter BJ, Wouters EFM, Savelkoul PHM, Rohde GGU, Stassen FRM

J Toxicol Environ Health B Crit Rev. 2018 May 1. doi: 10.1080/10937404.2018.1466380 [Epub ahead of print].

Platelet extracellular vesicles induce a pro-inflammatory smooth muscle cell phenotype Vajen T, Benedikter BJ, Heinzmann ACA, Vasina EM, Henskens Y, Parsons M, Maguire PB, Stassen FR, Heemskerk JWM, Schurgers LJ, Koenen RR.

J Extracell Vesicles. 2017 May 16;6(1):1322454. doi: 10.108o/20013078.2017.1322454.

Bead-based flow-cytometry for semi-quantitative analysis of complex membrane vesicle populations released by bacteria and host cells

Volgers C, Benedikter BJ, Grauls GE, Savelkoul PHM, Stassen FRM.

Microbiol Res. 2017 Jul;200:25-32. doi: 10.1016/j.micres.2017.04.003. Epub 2017 Apr 2.

Effects of $\mathrm{N}$-acetyl-L-cysteine on the membrane vesicle release and growth of respiratory pathogens

Volgers C, Benedikter BJ, Grauls GE, Hellebrand PHM, Savelkoul PHM, Stassen FRM.

FEMS Microbiol Lett. 2017 May 1;364(9). doi: 10.1093/femsle/fnxo87.

Immunomodulatory role for membrane vesicles released by THP-1 macrophages and respiratory pathogens during macrophage infection

Volgers C, Benedikter BJ, Grauls GE, Hellebrand PHM, Savelkoul PHM, Stassen FRM. BMC Microbiol. 2017 Nov 13;17(1):216. doi: 10.1186/s12866-017-1122-3. 